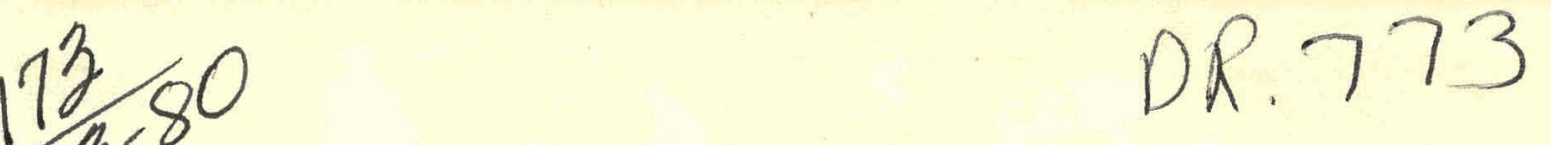

\title{
GA-A15501
}

UC-77

\section{MW(t) HTGR - GAS TURBINE NON-INTERCOOLED TECHNICAL EVALUATION REPORT}

\author{
Prepared under \\ Contract No. DE-AT03-76SF70046 \\ for the San Francisco Operations Office \\ Department of Energy
}

DATE PUBLISHED: DECEMBER 1979

\section{GENERAL ATOMIC COMPANY}




\section{DISCLAIMER}

This report was prepared as an account of work sponsored by an agency of the United States Government. Neither the United States Government nor any agency Thereof, nor any of their employees, makes any warranty, express or implied, or assumes any legal liability or responsibility for the accuracy, completeness, or usefulness of any information, apparatus, product, or process disclosed, or represents that its use would not infringe privately owned rights. Reference herein to any specific commercial product, process, or service by trade name, trademark, manufacturer, or otherwise does not necessarily constitute or imply its endorsement, recommendation, or favoring by the United States Government or any agency thereof. The views and opinions of authors expressed herein do not necessarily state or reflect those of the United States Government or any agency thereof. 


\section{DISCLAIMER}

Portions of this document may be illegible in electronic image products. Images are produced from the best available original document. 


\section{NOTICE}

This report was prepared as an account of work sponsored by the United States Government. Neither the United States nor the Department of Energy, nor any of their employees, nor any of their contractors, subcontractors, or their employees, makes any warranty, express or implied, or assumes any legal liability or responsibility for the accuracy, completeness or usefulness of any information, apparatus, product or process disclosed, or represents that its use would not infringe privately owned rights.

Printed in the United States of America Available from

National Technical Information Service

U.S. Department of Commerce 5285 Port Royal Road

Price: Printed Copy $\$ 11.00 ;$ Microfiche $\$ 3.00$

$(6,2)$ 
GA-A15501

UC-77

\title{
3000 MW(t) HTGR - GAS TURBINE NON-INTERCOOLED TECHNICAL EVALUATION REPORT
}

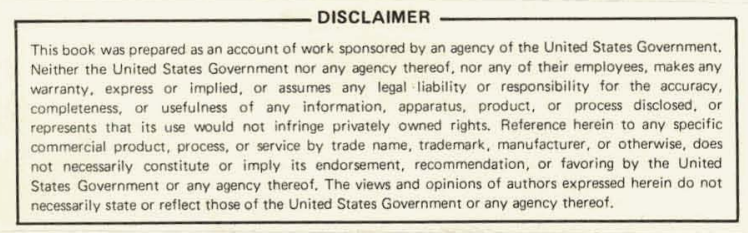

\section{Prepared under}

Contract No. DE-AT03-76SF70046 for the San Francisco Operations Office Department of Energy

\author{
GENERL ATOMIC PROJECT 6800 \\ DATE PUBLISHED: DECEMBER 1979
}

\section{GENERAL ATOMIC COMPANY}


THIS PAGE

\section{WAS INTENTIONALLY LEFT BLANK}




\section{ABSTRACT}

This report summarizes all the technical work performed on the 3000-MW(t) 3-loop High-Temperature Gas-Cooled Reactor Gas Turbine design as of June 1979. Although the plant configuration has changed to a 2000-MW(t) 2-10op plant, most of the technical assessments described in this report are still applicable to the 2000-MW(t) plant.

The report covers the criteria under which the plant was designed, the technical feasibility problems associated with the plant and their potential solutions, and other potential applications and improvements which could make the gas turbine concept more attractive economically. 
THIS PAGE

\section{WAS INTENTIONALLY \\ LEFT BLANK}


CONTENTS

ABSTRACT . . . . . . . . . . . . . . . . . . . . .

1. INTRODUCTION . . . . . . . . . . . . . . . . . . . 1-1

1.1 Foreword . . . . . . . . . . . . . . . 1-1

1.2 HTGR Development . . . . . . . . . . . . 1-3

1.3 HTGR-GT Development . . . . . . . . . . . . 1-7

1.4 International HTR Development Programs . . . . . . 1-10

1.4.1 European HTR Development Programs . . . . . . 1-10

1.4.2 International Cooperation . . . . . . . . . 1-11

1.4.3 Status of Cooperative Agreements . . . . . . 1-11

2. SUMMARY . . . . . . . . . . . . . . . . . .

2.1 HTGR-GT Power Plant Concept ............ . 2-1

2.2 HTGR-GT Plant Performance . . . . . . . . . . 2-1

2.3 Major Power Conversion System Components . . . . . . 2-4

2.3.1 Helium Turbomachine . . . . . . . . . . 2-4

2.3.2 Heat Exchangers .. . . . . . . . . . 2-5

2.3.3 Materials Research and Development....... 2-5

2.4 HTGR-GT Plant Operability . . . . . . . . . . 2-6

2.4.1 Part-Load Operation . . . . . . . . . 2-6

2.4.2 Tlant Availabillly . . . . . . . . . . 2-6

2.4.3 Plant Maintenance ............ . . 2-7

2.4.4 Inservice Inspection (ISI) . . . . . . . . 2-7

2.5 Power Generation Economics . . . . . . . . . 2-8

2.6 HTGR-GT Program Support . . . . . . . . . . . 2-9

3. PLANT/FUEL DESCRIPTION . . . . . . . . . . . . . . . 3-1

3.1 Reactor Turbine System . . . . . . . . . . . 3-1

3.2 General Description of the Plant. . . . . . . . 3-1

3.2.1 Major Parameters .............. 3-1

3.2.2 Plant Performance Definitions ........ . 3-2

3.2.3 Operation and Control .......... 3-2 
3.3 Overall Plant Specifications . . . . . . . . . 3-6

3.3.1 Nuclear Safety . . . . . . . . . . . 3-6

3.3.2 Shielding and Source Strength .......... 3-7

3.3.3 . Expected RTS Performance . . . . . . . . . 3-8

3.3.4 RTS Thermal Performance Requirements . . . . . 3-10

3.3.5 RTS Output Capability . . . . . . . . . 3-10

3.3.6 Transient Performance . . . . . . . . . 3-10

3.3.7 Seismic Requirements ............ 3-11

3.4 RTS Systems . . . . . . . . . . . . . . 3-11

3.4.1 PCRV . . . . . . . . . . . . . . 3-11

3.4.2 Neutron and Region Flow Control ........ 3-13

3.4.3 Fuel Handling . . . . . . . . . . . . 3-18

3.4.4 Fuel Shipping . . . . . . . . . . . 3-20

3.4.5 Reactor Service. Equipment and Storage System . . 3-21

3.4.6 Reactor Internal Components . . . . . . . . 3-21

3.4.7 Reactor Core .............. 3-26

3.4.8 Primary Coolant System - Power Conversion . . . 3-27

3.4.9 Rotating Machinery Service System . . . . . . 3-32

3.4.10. Helium Services System ........... 3-33

3.4.11 Core Auxiliary Cooling System (CACS) . . . . . 3-34

3.4.12 Plant Protection . . . . . . . . . . 3-37

3.4.13 Plant Control ............. . . 3-42

3.4.14 Plant DAP . . . . . . . . . . . . . 3-49

3.5 Balance of Plant . . . . . . . . . . . . . 3-50

3.5.1 General Plant Arrangement . . . . . . . . 3-50

3.5.2 Balance of Plant Systems . . . . . . . . . 3-79

3.5.3 Comparison of HTGR-GT and LWR Plants. . . . . 3-85

3.6 Fuel .. . . . . . . . . . . . . . . 3-86

4. PLANT CAPABILITY .................. . . . . 4-1

4.1 Load Following Capability . . . . . . . . . . . 4-1

4.2 Drop Load Recovery .. . . . . . . . . . . . . 4-5

4.2.1 Early Reload ................ 4 4-6

4.2.2 Late Reload .............. . 4-10 
4.3 Availability . . . . . . . . . . . . . 4-12

4.3.1 Summary ................ . . 4-12

4.3.2 Definitions of Availability and Capacity Factor . 4-14

4.3.3 Avallability Goals . . . . . . . . . . . 4-17

4.3.4 Effect of GT Unique Features on Plant. $4-20$

5. SAFETY AND LICENSING . . . . . . . . . . . . . . . . 5-1

5.1 Inherent and Passive Safety Features . . . . . . . . 5-3

5.2 Engineered Safety Features . . . . . . . . . . . 5-5

6. RESOURCE CONSERVATION .................. . . . 6-1

6.2 Urantum Conservation ............. . . 6-9

6.2.1 Reference Fuel Cycle . . . . . . . . . . 6-11

6.2.2 Fuel Cycle Variations . . . . . . . . . 6-12

7. ENVIRONMENT IMPACT . . . . . . . . . . . . . . . . 7-1

7.1 Radioactive Waste . . . . . . . . . . . . . 7-1

7.1 .1 Liquid Wastes ............... $7-1$

7.1 .2 Gaseous Wastes ............. . 7-6

7.1 .3 Solid Waste ................ 7-7

7.2 Siting Flexibility . . . . . . . . . . . . . 7-9

7.2.1 Site Boundary Dose - Gasous Releases . . . . . 7-9

7.2.2 Liquid Pathway Individual Dose . . . . . . . 7-13

7.3 Proliferation Resistance of HTGR Fuel . . . . . . . 7-15

7.3.1 Introduction .............. 7-15

7.3.2 The HTGR Fuel Cycle . . . . . . . . . . 7-15

7.3.3 Inherent Proliferation Resistance Advantages . . 7-18

8. MAINTENANCE REQUIREMENTS . . . . . . . . . . . . . . 8-1

8.1 Maintenance PhIlosophy . . . . . . . . . . . . 8-1

8.2 Maintenance Plan ................ 8 8-4

8.2.1 Turbomachine Maintenance .. . , . . . . . 8-4

8.2.2 Core-To-Turbine Hot Gas Duct Maintenance . . . 8-8

8.2.3 Heat Exchanger Maintenance . . . . . . . 8-9

8.2.4 Hellum Control Valve Maintenance . . . . . 8-15

8.3 Malntenance Related Studies . . . . . . . . . . 8-18

8.4 GT-HTGR Plant Inservice Inspection (ISI) . . . . . . 8-18 
8.5 References .................. 8-19

9. MAJOR DEVELOPMENT REQUIREMENTS . . . . . . . . . . . 9-1

9.1 High Temperature Material . . . . . . . . . . . 9-1

9.1.1 Adequate High Temperature Strength . . . . . . 9-2

9.1.2 Environmental Compatibility . . . . . . . 9-6

9.1.3 Thermal Aging . . . . . . . . . . . 9-7

9.1.4 High Helium Velocity Effects . . . . . . . . 9-9

9.1.5 Effects of Compatibility Phenomena on Mechanical Properties ................ 9-9

9.1.6 Properties and Design Methodologies for Ceramics Ceramics ............... . 9-10

9.1.7 Joining and Fabrication Feasibility . . . . . . 9-10

9.1.8 Wear Protection ............... . 9-10

9.1.9 Elevated Temperature Irradiation Damage . . . . 9-11

9.1.10 Materials Applications, Codes and Standards . . 9-12

9.1.11 On-Going and Planned Materials R\&D Programs . . . . 9-12

9.2 Graphite . . . . . . . . . . . . . . . 9-12

9.3 HTGR Turbomachine Development Program . . . . . . 9-16

9.3.1 Program Approach . . . . . . . . . . . 9-16

9.3.2 Testing Required .............. 9-16

9.3.3 Helium Testing. . . . . . . . . . . 9-17

9.3.4 Bearing and Seal Testing .......... 9-17

9.3.5 Compressor and Turbine Performance Tests . . . 9-18

9.3.6 Rotor Stress Tests . . . . . . . . . . 9-19

9.3.7 Systems Test ................ 9-20

9.4 Heat Exchanger Development Requirements . . . . . . 9-20

9.4.1 "Feasibility Confirming" Development . . . . . . 9-21

9.4.2 "Envelop Defining" Development ......... 9-23

9.4.3 Fabrication Related Development . . . . . . . 9-23

9.4.4 Confirmatory and Pre-Operational Development . . 9-24

9.5. Hot Duct . . . . . . . . . . . . . . . 9-24

9.5.1 Materials Design Considerations ........ 9-24

9.5.2 Thermal Barrier Components and Assemblies . . . 9-25

9.5.3 Hot Duct and Extension ........... 9-26 
9.6 Gas Turbine By-Pass Valve Development . . . . . . 9-26

9.6.1 Bypass Control Valve Quarter Scale Test . . . . 9-28

9.6.2 Mechanical Load Simulation . . . . . . . 9-28

9.7 Electrical Penetration . . . . . . . . . . . 9-29

9.8 Fuel ..................... . 9-30

9.8.1 Alternate Particles ............. 9-35

9.8.2 Reference Fuel Rod .............. 9-37

9.8.3 Fuel Element Graphite . . . . . . . . . 9-39

10. REJECT HEAT UTILIZATION . . . . . . . . . . . . . . 10-1

10.1 GT-HTGR Thermodynamic Cycle . . . . . . . . . . 10-1

10.2 Dry-Cooling . . . . . . . . . . . . . . 10-4

10.3 Bottoming Rankine Cycle .. . . . . . . . . . 10-7

10.4 District Heating . . . . . . . . . . . . 10-15

10.5 Process Steam Supply . . . . . . . . . . . 10-18

10.6 Water Desalination . . . . . . . . . . . . 10-18

11. IMPROVEMENT POTENTIAL . . . . . . . . . . . . . . . . 11-1

11.1 Higher Turbine Inlet Temperature . . . . . . . . . 11-1

11.2 Intercooled HTGR-GT Plant ............ 11-3

FIGURES

1.2-1 Comparison of commerical experience with
reactor types . . . . . . . . . . . . . . . 1-5

3-1 Representation of load-following cycle . . . . . . . . 3-3

3-2 Gas turbine HTGR cycle diagram . . . . . . . . . . 3-29

3-3 Simplified control valve diagram for GT-HTGR power plant . 3-30

3-4 Plant schematic showing location of major plant $3-43$ parameters . . . . . . . . . . . . . . . 3-43

3-5 Plant control system . . . . . . . . . . . . . 3-45

3-6 Plot plan . . . . . . . . . . . . . . . 3-51

3-7 Fifth \& sixth floor ................ 3-53

3-8 Fourth floor.................. . . 3-55

3-9 Third floor ................. . . . . 3-57

3-10 second floor . . . . . . . . . . . . . . . 3-59 
3-11 First floor . . . . . . . . . . . . . . . 3-61

3-12 Basement floor . . . . . . . . . . . . . 3-63

3-13 Sections . . . . .............. . . 3-65

3-14 Access and Administration Building . . . ........ 3-67

3-15 Containment plans and sections . . . . . . 3-69

3-16 Reactor internal layout ........... . . 3-89

3-17 Reactor internal layout . . . . . . . . . . . . . 3-91

3-18 Reactor internal layout . . . . . . . . . . . 3-93

3-19 HTGR-GT standard fuel element . . . . . . . . . 3-95

3-20 HTGR-GT control fuel element . . . . . . . . . . . 3-96

4.1-1 Part-load efficiency for the various control modes... . 4-2

4.1-2 Part-load efficiency for the valve/temperature control mode ....................... 4-4

4.2-1a Plant loss of load turbine transients, early reload . . . 4-7

4.2-1b Piant loss of load high temperature transient . . . . . 4-8

4.2-1c Plant loss of load low temperature transients . ... . . 4-9

4.2-2 Plant loss of load turbine transients, late reload . . . 4-11

6.1-1 Wet/dry cooling tower system . . . . . . . . . . 6-3

6.1-2 Annual wet/dry bulb temperature histogram for ${ }^{\text {Modesto, California . . . . . . . . . . . . 6-4 }}$

6, 1-3 Percent heat rejection as dry bulb temperature . . . . . 6-5

8-1 Integrated HTGR-GT plant . . . . . . . . . . . 8-2

8-2 Summary of preliminary inservice examination and testing 8

9-1 Approximate 300,000 hours allowable stresses versus temperature for various metallic and ceramic structural materials . . . . . . . . . . . . 9-5

9-2 Comparative carburization behavior of metals in HTGR-GT . 9-8

9.8-2 The development of coated particle fuel in the U.S. . . . 9-29

10-1 Closed cycle gas turbine adaptabillty . . . . . . . 10-2

10-2 Comparison of. steam and gas turbine plant cycles . . . . . 10-3

10-3 Energy balance as a function of compressor inlet temperature .................. 10-5

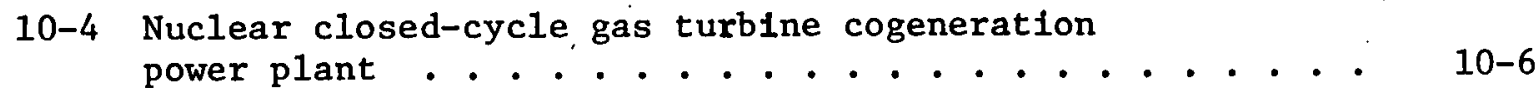

10-5 Amplified comparison of steam cycle and gas turbine
plant skyline profiles . . . . . . . . . . 10-8 
10-6 Loop cycle diagram for dry-cooled HTGR-CT power plant . . 10-9

10-7 Simplified temperature-entropy diagram . . . . . . . . 10-11

10-8 Cycle diagram in nuclear closed cycle gas turbine power plant with ammonia bottoming cycle . . . . 10-12

10-9 Supercritical ammonia bottoming cycle diagram from HTGR-GT plant . . . . . . . . . . . . . . 10-13

10-10 Flow diagram for ammonia bottoming cycle... . . . . . 10-14

10-11 Conceptual design of $460 \mathrm{MW}(\mathrm{e})$ double-flow ammonia turbine ............. 10-16

10-12 Desalination module for coupling to HTGR-GT power plant ................. . . 10-20

11-1 2-loop intercooled HTGR-GT . . . . . . . . . . 11-5

11-2 Cycle selection parameters for intercooled nuclear gas turbine power plant . . . . . . . . . . 11-6

\section{TABLES}

1.1-1 iiajor Plant Parameter Cowparisois - 1-4

1.2-1 Gas-cooled, graphite-moderated reactors . . . . . . . . 1-6

3-1 Design rates of electrtcal load change . . . . . . . . 3-4

3-1 Approximate startup/shutdown times . . . . . . . . . 3-5

3-3 Primary coolant expected system data - summary . . . . . . 3-9

3-4 Representative plant transients . . . . . . . . . 3-12

3-5 Major parameters of the thermal barrier . . . . . . . . 3-14

3-6 Major parameters of the PCRV liner and penetrations . . 3-15

3-7 Major parameters of the neutron and region flow control system .................. 3-19

3-8 Spent and recycle fuel shipping system data . . . . . . 3-22

3-9 Major parameters of the reactor internal components 3-24 system . . . . . . . . . . . . . . . . . .

3-10 Core auxiliary circulator data . . . . . . . . . 3-35

3-11 Core auxiliary heat exchanger module data . . . . . . . 3-36

3-12 Summary of protective function of the plant protective system ................ 3-39

3-13 HTGR-GT basic core parameters . . . . . . . . . 3-88

4.3-1 Assumed breakdown of HTGR-GT availability parameters . . . 4-19

4.3-2 Gas and steam turbine fallure rates . . . . . . . . . 4-26 
4.3-3 Representative heat exchanger failure rates . . . . . 4-29

5-1 Key Inherent and passive safety features of the HTGR . . . . 5-2

6.1-1 Water requirements of HTGR and LWR . . . . . . . . 6-7

6.1-2. Water requirements of HTGR as dry bulb temperature.$\cdots$ 6-7

6.1-3 HTGR-GT normalized cost effects . . . . . . . . . . 6-8

6.1-4 All-dry and wet/dry cooling comparisons of normalized capital and capacity penalty costs . . . . . 6-10

6.2-1 30 year $\mathrm{U}_{3} \mathrm{O}_{8}$ and enrichment requirements . . . . . . . 6-14

7.1-1 Annual radioactive waste generation . . . . . . . . . 7-3

7.2-1 Estimated site dose levels for normal operation, design
basis accidents and the siting event

7.2-2 Estimated site dose levels for normal operations . . . . 7-14

7.3-1 Proliferation-resistant features of thorium cycle in HTGR . 7-17

7.3-2 Generic safeguards advantages of HTGR MEU/Th fuel and fuel cycle . . . . . . . . . . . . . . 7-19

8-1 GT-HTGR Turbomachine maintenance philosophy . . . . . . . 8-6

8-2 Turbomachine maintenance procedures . . . . . . . . 8-7

8-3 GT-HTGR. Turbine inlet duct maintenance philosophy . . . . . 8-10

8-4 Hot duct maintenance procedures . . . . . . . . . . . 8-11

8-5 GT-HTGR Precooler maintenance approach . . . . . . . . 8-13

8-6 GT-HTGR Recuperator maintenance approach . . . . . . . 8-14

8-7 GT-HTGR Valve(s) maintenance philosophy . . . . . . . . . 8-16

8-8 Helium control valve(s) maintenance . . . . . . . . . 8-17

9-1 High temperature material used in HTGR-GT . . . . . . . 9-3

9-2 GT-HTGR: key materials issues ............ . 9-4

9.6-1 Basic bypass valve data . . . . . . . . . . . . 9-27

9.8-1 Reference MEU fuel particle designs . . . . . . . . . 9-34

9.8-2 Fuel rod characterisitics . . . . . . . . . . . 9-38

11-1 GT-HTGR Power plant comparison . . . . . . . . . . . . 11-4

11-2 Cycle selection parameters for integrated nuclear
gas turbine power plant . . . . . . . . . 11-6 


\section{INTRODUCTION}

\subsection{FOREWORD}

In the fall of 1978, the High-Temperature Gas-Cooled Reactor Gas Turbine (HTGR-GT) Program became the lead HTGR development program at the direction of the Department of Energy (DOE) and recommendation of the Gas Cooled Reactor Associates (GCRA). A definitive goal was set for the program which is to establish a strong U.S. HTGR-GT Program through international cooperation with Germany and Switzerland.

The HTGR-GT plant development program is subdivided into four phases:

Phase I - Program Definition (FY 79-80)

To define the U.S. preferred plant features and configuration, establish international cooperation program and select subcontractors for major component development.

Phase II - Conceptual Design and Prelicensing (FY 81-82)

To obtain the approval of Generic Licensing Topical Reports from NRC, select reference fuel design, complete the plant conceptual design package and obtain initial plant owner(s) commitment to the site for the first unit.

Phase III - Detailed Design and Licensing (FY 83-87) To complete the detailed design of the plant, submit PSAR/ER and obtain Limited Work Authorization/Construction Permit, initiate site preparation, and order long lead material.

Phase IV - Construction and Startup (FY 88-95) To complete plant construction, submit FSAR and obtain Operating Permit, complete fuel load/startup and begin commercial operation. 
During Fiscal Year 1979 (FY 79), the program objectives are:

1. Evaluate the Gas Turbine technical concept.

2. Establish the preferred Gas Turbine plant design features as the basis for further development.

3. Establish the short-term (to FY 82) and long-term (to FY 95) program plan,

4. Establish the basis for international cooperation.

5. Establish the development requirements for the program.

Until June of 1979 the major engineering effort related to the HTGR-GT was the 3-1oop non-intercooled 1200 MW(e) Reference Design P1ant. This plant was to be the basis for comparison with alternate design studies which were also being conducted in the same time frame. These studies include:

1. Parameter studies to select major plant parameters i.e. reactor outlet temperature, pressure ratio etc.

2. Intercooled versus non-intercooled cycle studies.

3. Plant major features study i.e. loop number and loop rating.

4. Maintenance and contamination studies as required to determine fuel type and to address the impact of remote maintenance on component designs.

5. Warm versus conventional liner studies as required to address the feasibility of the high temperature reactor with helium turbine (HHT) warm liner concept. 
In June 1979, agreement was reached between General Atomic Company and the GCRA to shift the reference design from the 3-1oop 1200 MW(e) plant to a 2-10op $800 \mathrm{MW}(\mathrm{e})$ plant.

The purpose of this report is to provide sufficient technical detals of the 3-1oop $1200 \mathrm{MW}(\mathrm{e})$ HTGR-GT plant design. Although the plant configuration has changed from 3-1oop $1200 \mathrm{MW}(\mathrm{e})$ to 2-100p $800 \mathrm{MW}(\mathrm{e})$, the major design features remain the same. This report will be used as a base for the 2-10op $800 \mathrm{MW}(\mathrm{e})$ plant technical evaluation and cost trend analysis In FY 80. For reference purpose, the major plant parameters of the 3-10op $1200 \mathrm{MW}(\mathrm{e})$ plant and the 2-loop $800 \mathrm{MW}(\mathrm{e})$ plant are listed in Table 1.1-1, the remaining of the report is derived from the 3-loop $1200 \mathrm{MW}(\mathrm{e})$ configuration.

\subsection{HTGR DEVELOPMENT}

The gas-cooled reactor was the earliest type of nuclear power reactor proposed, both in Europe and in the U.S., where gas-cooled power reactors were suggested in 1942. Farrington Daniels did pioneering studies at Oak Ridge National Laboratory (ORNL) in the mid-1940's on the development of a helium-cooled direct cycle (gas turbine) reactor with ceramic fuel and moderator and a U-235/Th/U-233 fuel cycle. The fist gas-cooled reactor power station at Calder Hall, however, used carbon dioxide $\left(\mathrm{CO}_{2}\right)$ as a coolant and natural uranium as a fuel and went into operation in the United Kingdom in 1956. Calder Hall initiated the first generation of gas-cooled nuclear power systems - the Magnox reactors. Thirty-six Magnox systems with a combined electrical rating of 8200 megawatts are now in operation (see Table 1.2-1). The available operating experience acquired over many years is comprehensive and by the end of 1978 it included nearly 580 reactor years. Figure 1.2-1 compares world wide gas-cooled reactor experience with that of light water reactors. The oldest system has been in operation for more than 20 years and the average availability 
TABLE 1.1-1

IMAJOR PARAMETER COMPARISON OF 2 LOOP 800 MW(e)

AND 3 LOOP 1200 MW(e) HTGR-GT PLANTS

\begin{tabular}{|c|c|c|}
\hline Major Parameter & $\begin{array}{l}3 \mathrm{LoOp} \\
1200 \mathrm{MW}(\mathrm{e})\end{array}$ & $\begin{array}{l}2 \text { Loop } \\
800 \text { MW (e) }\end{array}$ \\
\hline . & & \\
\hline Power conversion loops, aty & 3 & 2 \\
\hline Reactor power, $M W(t)$ & 3000 & 2000 \\
\hline Nominal electrical output (net), MW(e) & 1186 & 800 \\
\hline Helium inventory - total, kg (lbs) & 54,200 & 40,000 (est) \\
\hline $\begin{array}{l}\text { Helium flow rate (through compressors), } \\
\mathrm{kg} / \mathrm{sec}(1 \mathrm{~b} / \mathrm{hr})\end{array}$ & $573(4,547,000)$ & $563(4,471,000)$ \\
\hline $\begin{array}{l}\text { Helium pressure at HP compressor discharge, } \\
\text { MPa (psia) }\end{array}$ & $7,929(1150)$ & $8,412(1220)$ \\
\hline $\begin{array}{l}\text { Total primary circuit pressure loss, } \\
\text { KPa (psi) }\end{array}$ & $373.7(54.2)$ & $419.9(60.9)$ \\
\hline Recuperator high pressure $\triangle P$, Kpa (psi) & $60.7(8.8)$ & $64.1(9.3)$ \\
\hline $\begin{array}{l}\text { Reactor core, core support block and } \\
\text { orifice } \triangle \mathrm{P}, \mathrm{KPa} \text { (psi) }\end{array}$ & $54.5(7.9)$ & $100.0(14.5)$ \\
\hline Turbine $\triangle \mathrm{P}, \mathrm{MPa}$ (psi) & $4.385 .(636)$ & $4.766(691)$ \\
\hline Recuperator low pressure $\triangle P, \mathrm{KPa}$ (ps1) & $44.8(6.5)$ & $72.5(10.5)$ \\
\hline Precooler $\triangle \mathrm{P}, \mathrm{KPa}$ (psi) & $22.8(3.3)$ & $11.0 \cdot(1.6)$ \\
\hline Core inlet gas temperature, ${ }^{\circ} \mathrm{C}\left({ }^{\circ} \mathrm{F}\right)$ & $498(928)$ & $494(922)$ \\
\hline Core outlet gas temperature, ${ }^{\circ} \mathrm{C}\left({ }^{\circ} \mathrm{F}\right)$ & $850.0(1562)$ & $850.0(1562)$ \\
\hline Turbine inlet gas temperature, ${ }^{\circ} \mathrm{C}\left({ }^{\circ} \mathrm{F}\right)$ & $849.0(1560)$ & $849.0(1560)$ \\
\hline Compressor inlet gas temperature, ${ }^{\circ} \mathrm{C}\left({ }^{\circ} \mathrm{F}\right)$ & $26.7(80.1)$ & $26.7(80.1)$ \\
\hline Minimum cycle helium temperature, ${ }^{\circ} \mathrm{C}\left({ }^{\circ} \mathrm{F}\right)$ & $26.1(79.0)$ & $26.1(79.0)$ \\
\hline Recuperator effectiveness & 0.898 & 0.905 \\
\hline Turbine isentropic efficiency, \% & $9 \cdot 1.8$ & 91.8 \\
\hline Compressor isentropic efficiency, \% & 89.8 & 89.8 \\
\hline Disc cooling flow, \% & 3.6 & 2.96 \\
\hline Generator efficiency, \% & 98.8 & 98.8 \\
\hline
\end{tabular}


Table 1:1-1 (continued)

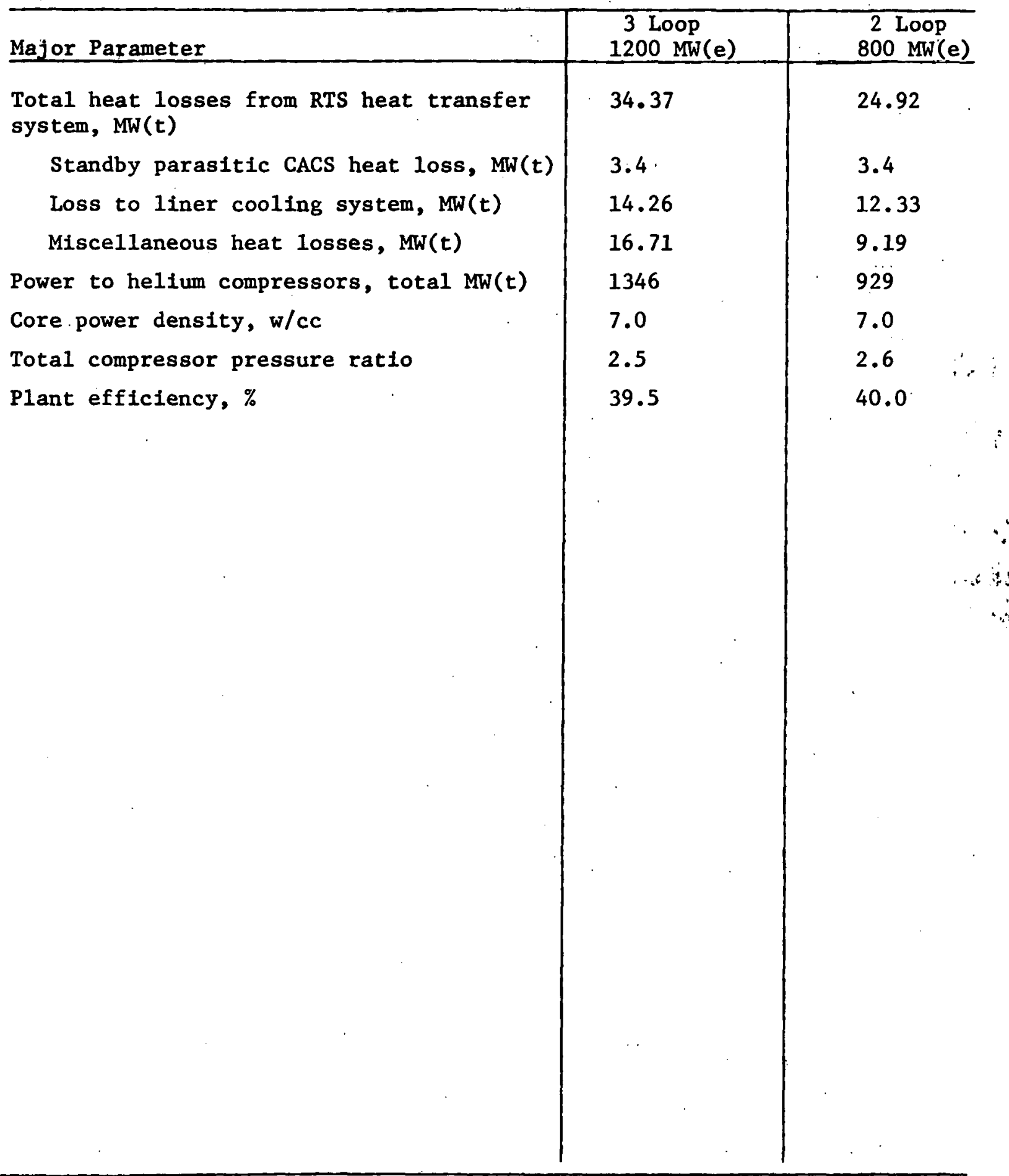


TABLE $1.2-1$

GAS-COOLED, GRAPHITE-MODERATED REACTORS

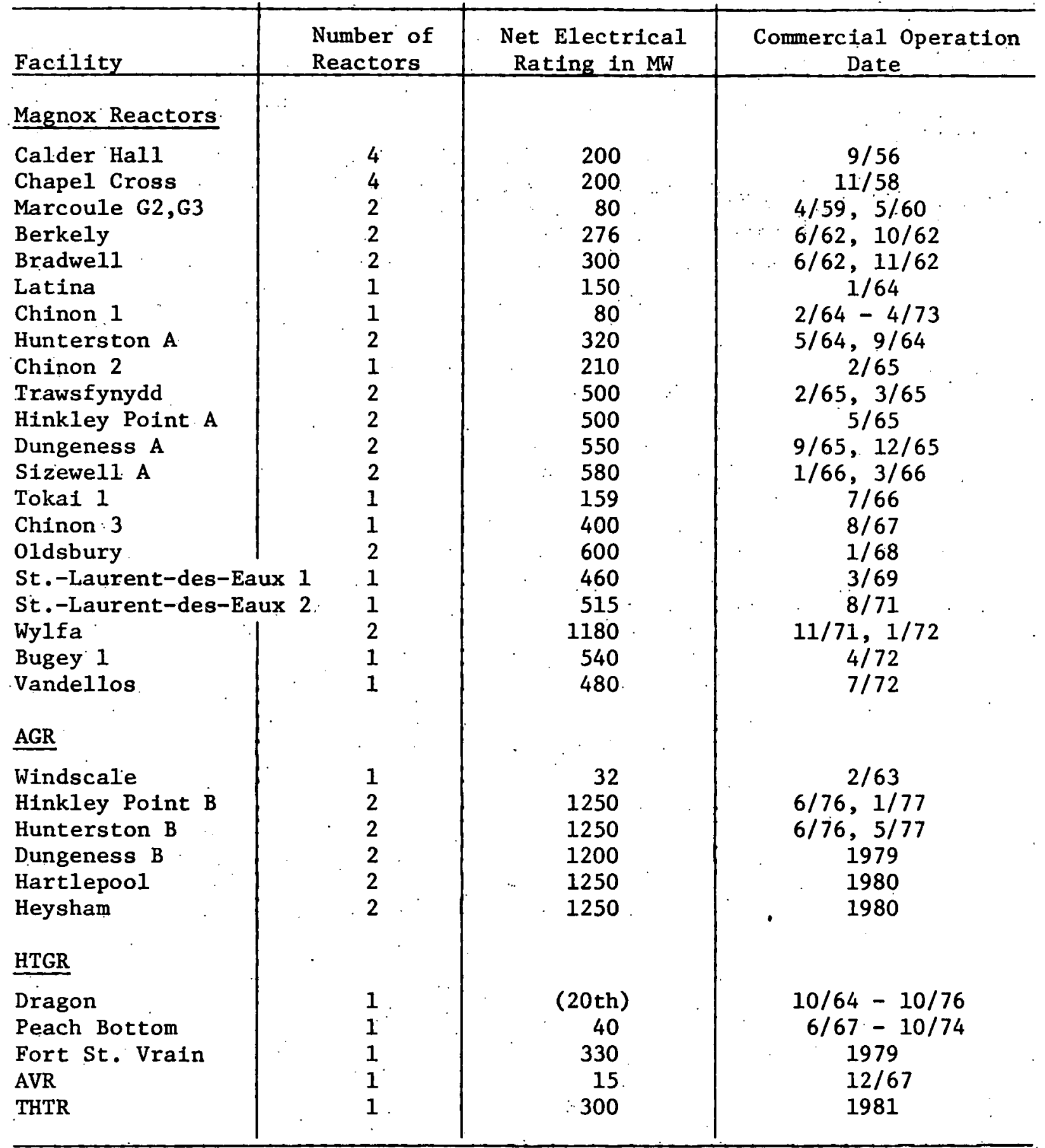




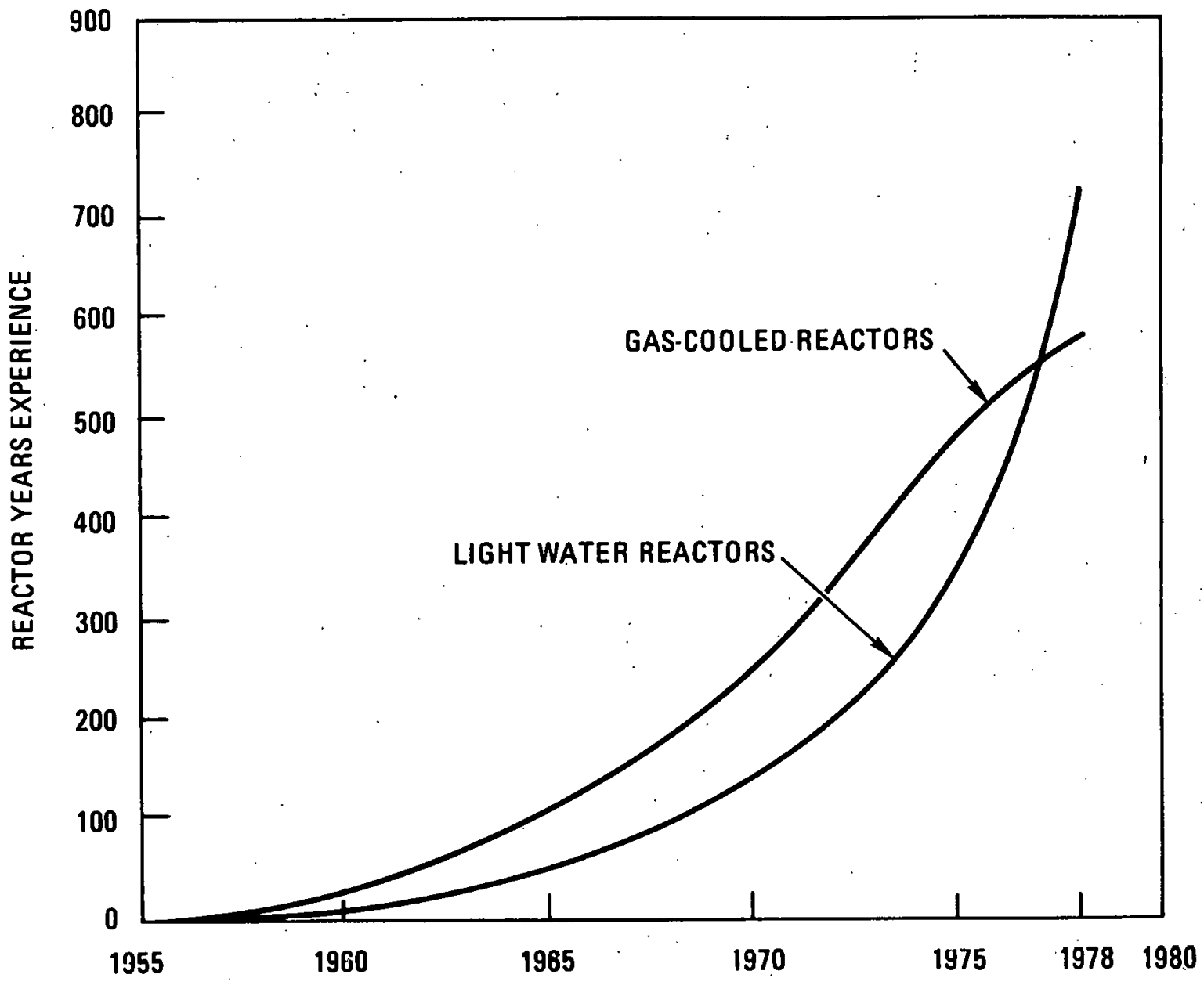

Fig. 1.2-1. Comparison of commercial experience with reactor types 
of all systems from startup until the end of 1975 was approximately $60 \%$, five percentage points better than the comparable light water reactor figure.

The Advanced Gas-Cooled Reactor (AGR) represents a further development of the Magnox reactor accomplished in the United Kingdom. The significant improvement is in the new fuel element which allows higher gas temperatures to create conditions equivalent to those of modern conventional power plants Other characteristics of Magnox reactors such as the graphite moderator, integrated steam generators, prestressed concrete reactor vessel (PCRV). and core loading under power have been retained. At the present time eleven AGR systems with a combined electrical rating of 6,232 megawatts are in operation or under construction.

The HTGR is an advanced development of the Magnox and AGR reactors aimed at further increasing the performance of the gas-cooled, graphite moderated reactor.: This required another modification of the fuel element, the use of coated fuel particles and a change from $\mathrm{CO}_{2}$ to helium as the primary circuit coolant. The resulting concept features high plant efficiency, low fission product release and a relatively clean primary loop.

The $20 \mathrm{MW}(\mathrm{t})$ DRAGON reactor, a joint development of European Organization for Economic Cooperation and Development (OECD) countries, was the first HTGR and was commissioned in 1964. The reactor was a test facility which supplied valuable experience in the field of fuel element development, core design, helium technology and high temperature metallurgy. This reactor. was decomissioned late in 1975 after more than ten years of successful operation.

The first HTGR to produce electricity was the $40 \mathrm{MW}(e)$ Peach Bottom prototype which began commercial operation in June 1967. The Peach Bottom plant was shut down in October 19.74 after a total of 1349 equivalent 
full-power days and production of more than 1.38 billion kilowat hours of electricity for the Philadelphia Electric Company. This reactor served as an invaluable test bed. for the fuel designed for large HTGRs and for reactor physics studies. The average gross plant efficiency over its 7-1/2 year 1ife was 37.2 percent and the nuclear steam system availability was 88 percent. All reactor systems in Peach Bottom performed without major problems. The reactor control system operated exceptionally well, and the steam generator operated throughout its entire life without experiencing failure or plugging of tubes.

\subsection{HTGR-GT DEVELOPMENT}

Design studies and R\&D work on the HTGR-GT plant have been in progress at General Atomic since late 1970 by means of several complementary programs supported by the U.S. Department of Energy, the Gas-Cooled Reactor Associates (GCRA), General Atomic (GA), and participating industrial firms.

These studies included:

1. Thermodynamic cycle options

2. Turbomachinery design

3. Safety/licensing evaluation

4. System dynamics analysis

5. Heat exchanger design

6. Control system design

7. Capital cost incentives and tradenffs

8. Development program requirements

9. Waste heat utilization

Development work and evaluations in the U.S. and Europe have consistently indicated the HTGR-GT to be technically feasible, and to possess high potential for economical power generation, resource conservation, and environmental benefits. In the U.S., work has been accomplished by GA, the Power Systems and Pratt \& Whitney Divisions of United Technologies Corporation, General Electric Gas Turbine Products Division, Combustion 
Engineering, United Engineers and Constructors, and Ralph M. Parsons Company. In Europe, a program based on the same concept has been established as the high-temperature reactor with helium turbine (HHT) project led by Hochtemperatur-Reaktorbau (HRB), a GA affiliate; Kerforschunsanlage (KFA), a German national laboratory; Eidgenossisches Institut fur Reaktorforschung (EIR), a Swiss national laboratory; with major industrial participation and support by the Federal Republic of Germany (FRG) and the Swiss government. Cooperation between the GA and HHT projects was initiated in 1974 and is continuing. The HHT project has attracted substantial interest from European governments and utilities.

The $330 \mathrm{MW}\left(\mathrm{e}^{\circ}\right.$ Fort St. Vrain HTGR was built for the Public Service Company of Colorado under the Power Reactor Demonstration Program of the U.S. Atomic Energy Commission - now the Department of Energy. It contains a number of design features which are new to power reactor systems in the U.S., namely, hexagonal graphite fuel assemblies incorporating pyrocarbon and silicon-carbide coated uranium and thorium dicarbide fuel particles, once-through modular steam generators with integral superheaters and reheaters, steam driven helium circulators, and a PCRV. Criticality was first achieved in January 1974. To date the plant has reached 68 percent of rates capacity in its power ascension phase.

Recent projects in the Federal Republic of Germany (FRG) include the Thorium-Hochtemperatur-Kernkraftwerk (THTR), Oberhausen and Hochtemperatur Helium-Versuchsanlage (HHV). THTR is a $300 \mathrm{MW}(\mathrm{e})$ demonstration plant for the HTGR Steam Cycle system which uses the spherical fuel element concept introduced with Arbeitsgemeinschaft Versuchsreaktor (AVR). Startup is projected for the $1982 / 83$ time frame.

The HTGR systems described above were based on the "Steam Cycle" design, i.e., the helium coolant is used to generate steam to power a turbine generator. The renewed international focus on the HTGR has now brought the "Direct Cycle" gas turbine concept into the forefront of the HTGR design and development effort. 
The gas-turbine industry has already established as state-of-the-art for heavy-duty gas turbines the level of temperatures, unit frame size, and much of the basic technology needed for high-temperature helium turbines suitable for use with the direct-cycle HTGR. The reactor technology has been demonstrated by the Fort St. Vrain Nuclear Generating Station, the Peach Bottom Unit I HTGR, and other prototype HTGRs in Great Britain and Germany.

Four significant assessments of the technology and of the economics of the HTGR-Gas Turbine (HTGR-GT) have been conducted and documented by U.S. organizations other thàn GA beginning in 1975; extending into 1978. The general coverage data and preparer of the assessments are indicated below:

$\begin{array}{ll}\text { Technical } & \text { Economic } \\ \text { Assessment } & \text { Assessment }\end{array}$

A. Nuclear Utility Services (NUS) 1978 GT-HTGR Technology

\section{$\mathrm{X}$}

B. RAMCO 1977

GCR Commercialization

$\mathbf{X}$

$\mathrm{X}$

$\mathrm{X}$

C. A. D. Little 1976

Gas Cooled Reactor Assessment

$\mathrm{X}$

$\mathrm{X}$

$\mathrm{X}$

D. ERDA + United Engineers

ERDA 1091975

$\mathrm{X}$

$\mathrm{X}$

E. GCRA Technical Assessment

Guide 1979

$\mathrm{X} \quad \mathrm{X}$

The NUS assessment in 1978 concluded: "the concept is essentially based on the established technologies of HTGRs and open and closed-cycle gas turbines. No significant technological breakthroughs in power conversion equipment and materials appear to be necessary. However, an extensive program of design, development, and testing is required to achieve the performance and availability necessary for commercial power generation." 
The RAMCO study in 1978 concluded: "...no technical or pragmatic problems have been identified as far as the design has progressed which would lessen the feasibility of designing or operating the HTGR-GT. Various technical areas requiring further work have been identified."

The A. D. Little study in 1976 did not make a clear summarizing statement. However, qualitative judgements of technical, risk associated with major components were developed. Based on this R\&D programs, to deal with the problems and risk were identified and the cost estimated.

The ERDA 109 study has a favorable conclusion on the feasibility of the HTGR-GT, identifies problem areas, and points to the need for a concentrated national R\&D program. to bring the concept to fruition.

\subsection{INTERNATIONAL HTR DEVELOPMENT PROGRAMS}

\subsubsection{European HTR Development Programs}

The Federal Republic of Germany (FRG) funds two projects for the application of HTGR systems: the HHT-600 and PNP-500. The HHT-600 will be a $675 \mathrm{MW}(\mathrm{e})$ single loop HTR Gas Turbine Demonstration Plant. The PNP-500 will be a $500 \mathrm{MW}(t)$ Process Heat Demonstration Plant which will be a prototype for coal gasification. The present schedule calls for HHT construction to start in $1984 / 85$ and be operational by the early 1990s. The Prototypanlage Nukleare Prozebwärme (PNP) plant is planned to start construction in 1988 and be operational by the mid-1990s. The HHT and PNP Projects are supported by the HBK Project for fuel development and fuel recycle. Switzerland participates in the HHT Program by funding the Swiss organizations, both commercial and research, for performing work for the HHT Project. This amounts to 10 to 15 percent of the total HHT Project budget.

The top priority in the FRG HTR Program is the completion and startup of the THTR-300. The THTR-300 is a $300 \mathrm{MW}(\mathrm{e})$ Steam Cycle HTGR incorporating a pebble bed core and is scheduled to start operation in 1982/83. THTR is to be operational before construction begins on the HHT-600. 


\subsubsection{International Cooperation}

A clear incentive exists to maximize international cooperation within the HTGR Program. Through such cooperation the effectiveness of the individual programs is increased resulting in decreased costs and risks. The cooperation involves both exchange of information and joint development efforts outlined below:

1. Base Technology. Base technology elements such as materials data, fuels development, etc. are jointly developed and/or exchanged. The framework for such exchanges exists through the Umbrella Agreement and various Project Work Statements are in place to effect this type of cooperation.

2. Project Design. Design data pertaining to HTGR projects is jointly developed and/or exchanged. General Atomic has been cooperating with the HHT Project since 1974 in the design area.

3. Joint Project Development. Components, systems, or even demonstration plants would be jointly developed. While this mode of international cooperation may be the most cost effective from an international resource point of view, it would require major programmatic and technical compromises. by the respective participants.

The mode and degree of future international cooperation on the development of the HTGR will depend on the compatibility of the programs.

\subsubsection{Status of Cooperative Agreements}

In February 1977, the U.S. ERDA and the Federal Republic of Germany (FRG), : Federal Ministry for Research and Technology (BMFT), signed the IImbrella Agreement for the cooperation between the U.S. and FRG in research and technology in the field of gas-cooled reactors. In mid-1977, the Swiss and French governments also became partners in the Umbrella Agreement. 
An Implementing Agreement has been negotiated by the Thermal Gas Reactor Working Group under the Umbrella Agreement. This Agreement enables industrial agreements covering the exchange of industrial information between countries and companies and assures the confidentiality of proprietary data. This Agreement has been accepted in principle by the U.S. Industrial and FRG participants and is awaiting DOE and BMFT approval.

Cooperation on a utility-to-utility level is being initiated between GCRA and the FRG HHT utility group by means of a draft Memorandum of Understanding. Utility cooperation is aimed at developing common utility functional requịrements. In addition, the utilities will exchange operating experience from HTGR plants and results from: related test factlities, as well as pertinent experience from LWR plants. 


\section{SUMMARY}

\subsection{HTGR-GT POWER PLANT CONCEPT}

A major feature of the integrated HTGR-GT plant is that the power conversion system components are within the PCRV, thus eliminating the need for buildings such as the traditional turbine hall. This particular layout is for a twin plant concept in which the two reactor units share the reactor service building and fuel storage facilities. Separate control buildings and safety-related auxiliaries are provided for each unit.

The simplified isometric diagram of the reactor and primary system shows the core, turbomachinery, heat exchangers, and the entire helium inventory enclosed in the PCRV. This particular plant concept, embodying three power conversion loops, is based on a $3000 \mathrm{MW}(t)$ reactor core, and has a power output of $1200 \mathrm{MW}(\mathrm{e})$. The three-power conversion loops are located symmetrically around the central core cavity. Each loop includes a gas turbine, recuperative gas-to-gas heat exchanger, and a precooler (gas-to-water heat exchanger) for cycle heat rejection to the dry-cooling tower. The components are connected by large internal ducts within the PCRV. The main features of the HTGR-GT plant concept are summarized on Table 2-1.

\subsection{H'I'GR-GT PLANT PERFORMANCE}

Key elements of the performance advantages projected for the CloseCycle Gas Turbine (CCGT) over the more traditional steam Rankine cycle can be best discussed by observing the cycle diagrams. Stress levels and metallurgical considerations in the steam turbine tend to limit temperature growth much above $1050^{\circ} \mathrm{F}$ for the Rankine power conversion system, and higher efficiencies can take advantage of higher temperature, and as Carnot established over a century ago, this has a direct impact on cycle efficiency. 
TABLE 2-1

MAIN FEATURES OF NUCLEAR CLOSED-CYCLE GAS TURBINE PLANT

3000 MW(t). core thermal rating for commercial plant

Power plant life, 40 years

Plant availability, $80 \%$

Efficiency with dry-cooling, $40 \%$

Efficiency with ammonia bottoming cycle, $47 \%$

Reference design based on:

Optimized parameters for minimum power generating cost

Integrated configuration

Reactor outlet temperature, $850^{\circ} \mathrm{C}\left(1562^{\circ} \mathrm{F}\right)$

Multiple gas turbine power conversion loops

Thermodynamic cycle, non-intercooled

High degree of heat recuperation

State-of-the-art technology, materials; and fabrication methods Major components within rail transportation limits 
A very important advantage of the CCGT is that heat rejection occurs over a range of temperatures, rather than at the one temperature of a condensing vapor. The result is that the higher average temperature of heat rejection can greatly ease the practical problem of reject heat dissipation. A higher mean rejection temperature can become valuable as a premium for economical dry cooling, and for use of the waste heat for district heating, and for additional bottoming cycle power production.

The most important parameter influencing plant performance is turbine inlet temperature. In both the U.S. and Europe, nuclear CCGT plant design work is underway based on a turbine inlet temperature of $850^{\circ} \mathrm{C}\left(1562^{\circ} \mathrm{F}\right)$. This temperature is modest compared to that for most industrial gas turbine practice. This value was chosen from the following reasons: 1) it is nearly compatible with current HTGRs, 2) it is below the level where turbine blade cooling is necessary, and 3 ) it facilitates utilization of an existing nickel-base alloy, which is used extensively in industrial gas turbines.

There are enormous efficiency rewards for operating at higher levels of temperature. This point is emphasized to illustrate the potential the CCGT has, and to substantiate the earlier claim that this power conversion system will not suffer from technical obsolescence in coming decades. Other important performance parameters are the compressor pressure ratio and recuperator effectiveness. Based on a non-intercooled cycle, with drycooling a plant efficiency of $40 \%$ is projected for the turbine inlet temperature of $850^{\circ} \mathrm{C}\left(1562^{\circ} \mathrm{F}\right)$. For an intercooled cycle the efficiency level would increase by about 3 percentage points.

The HTGR-GT plant is well suited to operation in a cogeneration mode, although it is recognized that the owner/operator may not want the multiple heat rejection capability shown. Because of a combination of high reject temperature and the sensible mode of heat transfer, the dry towers for a HTGR-GT can be designed for about a tenth of the airflow needed for a Rankine steam cycle. The towers are therefore smaller and the higher exit 
air temperature increases the buoyancy effect. The overall result (in terms of the skyline profile) shows alternative nuclear plants of approximately the same power, drawn to the same scale.

An alternate use of the waste heat involves cogeneration in the form of a combined cycle. With added emphasis in the U.S. on fuel conservation and minimum environment impact, waste heat utilization from the HTGR-GT power plant secondary cycle can increase the combined cycle overall efficiency to around $50 \%$.

A strong point for the CCGT is its ability to operate effectively as a combined electrical power plus heat production plant. The electrical power is rather independent of the amount of heat production. Only for an extremely high demand on heat production is there a reduction of approximately $25 \%$ in electrical power output. The amount of heat production, for district heating, process steam, or desalination, can be simply regulated by controlling the compressor inlet temperature.

\subsection{MAJOR POWER CONVERSION SYSTEM COMPONENTS}

\subsubsection{Helium Turbomachine}

Preliminary design of the turbomachinery for the HTGR-GT plant has been done by the Power Systems Division and Pratt and Whitney Aircraft Division of United Technologies Corporation. A simple and rugged arrangement consisting of a single-shaft, direct-drive turbomachine was chosen for the HTGR-GT. The design and high performance predictions for this machine reflect the influence of technology from demonstrated advanced-technology industrial gas turbines.

The $400 \mathrm{MW}(\mathrm{e})$ helium turbomachine has 18 compressor and 8 turbine stages. The rotor, supported on two journal bearings, is of welded construction. Rotor burst protection is incorporated in the machine design In the form of burst shields around the compressor and turbine rotor-bladed 
sections. Man-access cavities are provided in the PCRV for inspection and limited maintenance work on the journal bearings, which are of the multiple tilting pad, oil lubricated type.

By virtue of the high degree of pressurization the external dimensions of the $400 \mathrm{MW}(\mathrm{e})$ helium gas turbine are similar to those of an air-breathing, advanced, open-cycle industrial gas turbine in the $100 \mathrm{MW}(\mathrm{e})$ range. While helium turbomachines are not well known in the U.S., the helium axial flow turbomachines over an impressive power range have been constructed and operated successfully in Europe.

\subsubsection{Heat Exchangers}

The heat exchanger types selected for the HTGR-GT plant design have a sound technology base, and the metal temperatures, flux-levels and internal pressure differentials are modest compared with modern steam generators, permitting the use of code-approved low alloy steels. The axial counterflow recuperator (embodying straight tubes of small diameter) bears a close resemblance to units that have operated trouble-free for over half a million hours in the European fossil-fired CCGT plants. The multipass cross-counterflow helical bundle approach selected for the precooler has been used extensively for steam generators in gas-cooled reactors. The environment associated with the HTGR-GT plant, namely operation with single phase, non-corrosive working fluids, is conducive to long, troublefree exchanger life. The exchangers are no longer or heavier than units being built for contemporary steam plants, and existing and proven methods of assembly, handling, and transportation are applicable.

\subsubsection{Materials Research and Development}

For the HTGR-GT, the power conversion components are designed for the full operating life of the plant (280,000 hours). Selection of qualified materials for these components is an essential requirement of achieving the goals of minimum maintenance, and high reliability. The long-term 
behaviour of these materials under a representative reactor environment is being characterized and the environmental effects on material properties quantitatively established.

The GA materials screening program represents only a part of an overall effort being carried out by several countries to establish materials data for advanced gas-cooled reactor systems. To date, over 25,000 hours have been accumulated on creep and corrosion tests at elevated temperature in a representative helium environment of the HTGR-GT primary circuit. Particularly encouraging are the results for the baseline candidate turbine blade/vane alloy (IN-100) which show no apparent degradation in properties.

\subsection{HTGR-GT PLANT OPERABILITY}

\subsubsection{Part-Load Operation}

While designed as a base-load plant the HTGR-GT design has the capability for load following to meet utility power profile needs. At present, there are essentially three methods of plant control being considered: 1) by-pass valve, 2) reactor outlet temperature, and 3) helium inventory control. For rapid short-term load changes the by-pass valve mode of control would be in effect. However, extended operation in this mode is not desirable because of the inherent low efficiency.

In a closed-cycle system the power level is a function of pressure level, and the mass flow can be regulated by extracting or adding helium to the system. This inventory control mode of operation permits a high level of efficiency to be maintained at low power levels. In practice, a combination of all three of the aforementloned control modes would in effect give a high plant efficiency down to a plant output of $25 \%$.

\subsubsection{Plant Availability}

An advantage of the multiloop power conversion system approach is that the plant can continue to operate with one loop down. If this occurs 
during a period of peak demand, then the plant can operate at reduced power output until it is convenient to shut down and remedy the problem. In the case of a faulted turbomachine the philosophy proposed to date has been to replace the machine with a spare unit. This spare unit could be owned by a group of utilities, a utility service organization, or the turbomachine company. The point to be made here is simply that the time for machine replacement is known, and hence the impact on plant availability can be determined. With a single-loop large power conversion system, the retention of a spare unit may not be cost-effective, and the down-time for machine repair is dependent on the severity of the fault. A high level of availability is projected for the multiloop HTGR-GT plant concept.

\subsubsection{Plant Maintenance}

For the integrated system it is important that maintenance aspects be considered during the plant conceptual design phase. The primary objective of the HTGR-GT plant maintenance plan is to provide facilities, equipment, and components of reasonable cost that will yield good plant availability. It is therefore a matter of policy to design the reactor and power conversion system installation, as well as the related maintenance facilities, for practical operation for both planned and unplanned maintenance.

Turbomachine change-out is regarded as a planned maintenance activity and the sequence of events, together with the necessary equipment items, for removal and re-installation of the gas turbine represent an important activity in the plant design study. As the HTGR-GT plant design efforts proceed, the maintenance related studies will intensify to ensure compliance with utility requirements.

\subsubsection{Inservice Inspection (ISI)}

Inservice inspection requirements are continually becoming more demanding to satisfy the various code requirements, regulatory guides, and licensing commitments. An important aspect of ISI considerations, considering both regulatory requirements and projected utility owner's needs, is 
the impact on component design, plant layout, and access provisions. It is prudent therefore to consider ISI requirements during the plant conceptual design and to pursue a policy of proving inspectable designs where required.

\subsection{POWER GENERATION ECONOMICS}

The projected competitive power generation economics associated with the HTGR-GT plant stem from both the inherent features of the thermodynamic cycle, and the simplistic nature of the plant design. The economics of dry cooling, which will become an ever increasing economic factor in coming decades, are enhanced by the high grade sensible heat rejection characteristics of HTGR plant. High plant efficiency (above $40 \%$ ) can be realized with dry cooling. Further increase in plant efficiency (to about 50\%) is projected for a plant option with a Rankine bottoming cycle.

A reduction in plant cost (compared with contemporary power plants) has been made possible by the elimination of costly steam-cycle related equipment (i.e., high temperature steam piping, condenser, pumps, turbines, controls, etc.). "The compact nature of the overall power plant is also conducive to minimum land use.

In the time frame when the HTGR-GT is projected to have an impact on power generating capacity in the U.S. (i.e. early decades of the 21 st century) it is likely that the energy situation will demand utilization of the waste heat from power plants. Today in the U.S. the waste heat discharged from power plants is about $10 \%$ of the energy consumed by the U.S. each year. The high grade reject heat from the HTGR-GT power plant can be used to meet the total energy needs of urban and industrial communities, and the economic worth of this energy source for district heating, process steam production, and desalination, will result in even better economics of plant operation. 


\subsection{HTGR-GT PROGRAM SUPPORT}

Work on the HTGR-GT program has been supported by the U.S. Department of Energy, and by a dedicated group of electric utility companies. Work participation by industrial partners, particularly United Technologies Corporation and Combustion Engineering, has played an important role in the design of the HTGR-GT plant. 


\section{PLANT/FUEL DESCRIPTION}

\subsection{REACTOR TURBINE SYSTEM}

This section provides the basic design data, criteria, and description, for the Reference Gas Turbine Plant High-Temperature Gas-Cooled Reactor (HTGR-GT) Reactor Turbine System (RTS). The HTGR-GT Reference Plant described is a three-loop variant based on a non-intercooled cycle.

\subsection{GENERAL DESCRIPTION OF THE PLANT}

\subsubsection{Major Parameters}

$\begin{array}{ll}\text { Access } & \text { Road/rail } \\ \text { Type of cooling } & \text { Dry cooling tower } \\ \text { Life, years } & 40 \\ \text { Power conversion loops, qty } & 3 \\ \text { Nominal net station efficiency, } \% & 39.6 \\ \text { Nominal electric output (net), MW(e) } & 1186 \\ \text { Nominal reactor power, MW(t) } & 3000 \\ \text { Availability factor } & 90 \% \\ \text { Capacity factor } & 80 \% \\ \text { Plant layout } & \text { Single unit } \\ \text { Fuel cycle } & \text { Medium enriched. } \\ \text { Core power density, w/cc } & 7.0 \\ \text { Fuel iffetime, years } & 4 \\ \text { Refueling cycle time, years } & 1\end{array}$




$\begin{array}{ll}\text { Carbon/thorium ratio } & \\ \text { Inttial core } & 350 \\ \text { Reload cores } & 600 \\ \text { Fissile material } & \mathrm{UC}_{2} \\ \text { Fertile material } & \mathrm{ThO}_{2}\end{array}$

\subsubsection{Plant Performance Definitions}

The plant performance and operating conditions are described as follows:

The nominal reactor power for the Gas Turbine Reference Plant is $3000 \mathrm{MW}(\mathrm{t})$.

The design reactor power for the Gas Turbine Reference Plant is $102 \%$ of nominal reactor power $[3060 \mathrm{MW}(\mathrm{t})]$.

The proposed licensed reactor power level for the Gas Turbine Reference Plant has not yet been fixed, but is expected to be $100 \%$ of nominal reactor power $[3000 \mathrm{MW}(t)]$.

The minimum load for the Gas Turbine Reference Plant will be $25 \%$.

\subsubsection{Operation and Contro1}

3.2.3.1. Normal Operation. The plant shall be designed to be capable of continuous operation under automatic control at any point between Design Power and Minimum Load. The plant shall also be designed for load following capability within this operating range at rates of load change up to those shown in Table 3-1. The normal weekly load following cycle to be used as a design basis is shown in Figure 3-1. 


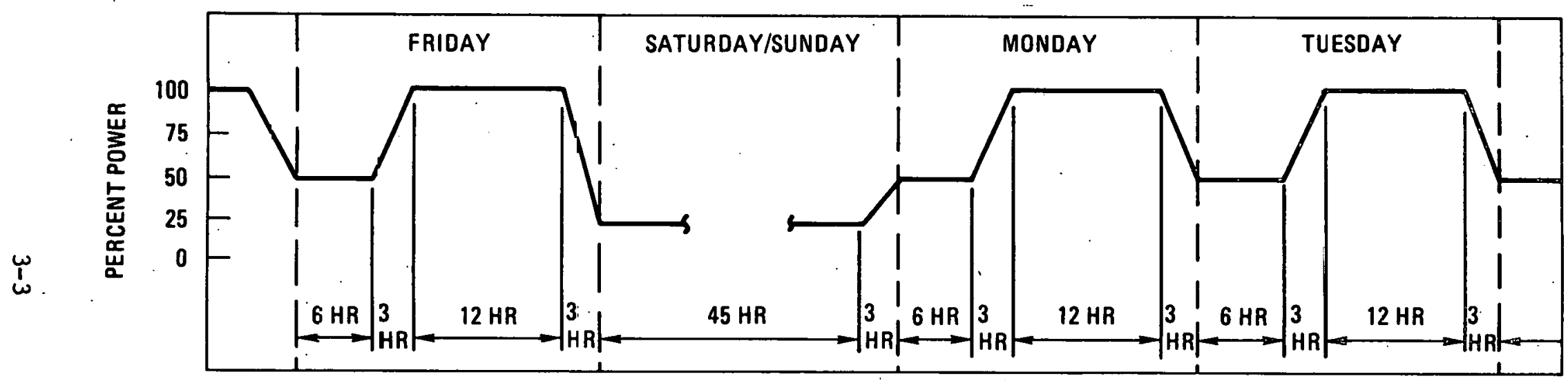

TOTAL LIFETIME SHUTDOWN CYĆLES: 400

Fig. 3-1. Representation of 1oac-following cycle (operator action permitted during load changes and dwells, provided rate of change meets spec) 
3.2.3.2. Abnormal Operation. The plant shall be capable of continued operation at reduced thermal power and electrical load with one main loop or with one control rod drive unit out of service (except for an uncontrolled withdrawal).

The transient deviations in plant parameters associated with the sudden shutdown of a main loop or the fallure of a control rod drive shall be sufficiently limited so that the plant can continue in operation without a shutdown.

TABLE 3-1

DESIGN RATES OF ELECTRICAL LOAD CHANGE

Maximum rate of load change

(for changes $>10 \%$ )

Maximum step load change

(no less than two hours between)
$5 \%$ of rated load per minute between $25 \%$ and $100 \%$ of rated load

$10 \%$ of rated 1 oad

Following a trip of any or all of the generators from any load level, the reactor shall be capable of continued operation at reduced thermal power and flow, pending subsequent resynchronization and load increase over at 1east $90 \%$ of each fuel cycle. The reactor power reduction shall be made with acceptable transient deviations in temperature and pressure levels.

The limiting conditions and allowable durations for such abnormal operations will be prescribed later in appropriate technical specifications or operating criteria.

3.2.3.3. Startup and Shutdown. The Reactor Turbine System shall be capable of accomplishing routine startup and shutdown operations in the approximate times stated in Table 3-2. 
TABLE 3-2

APPROXIMATE STARTUP/SHUTDOWN TIMES

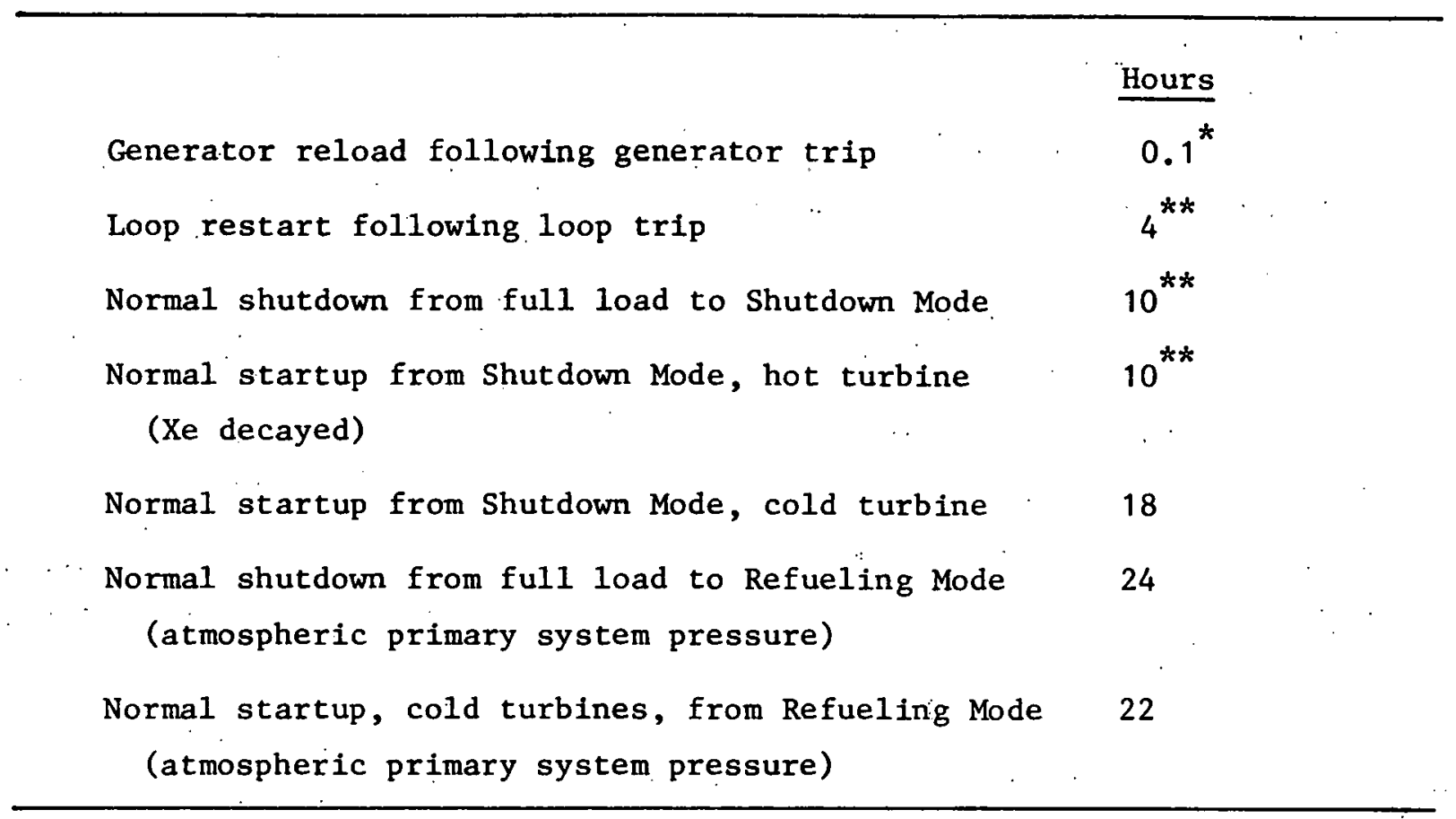

$*$

* Depends on automatic control selection, electrical system and grid characteristics. The time required could be shorter.

${ }^{* *}$ Times required for these modes can be varied according to utility requirements. 


\subsection{OVERALL PLANT SPECIFICATIONS}

\subsubsection{Nuclear Safety}

The nuclear safety specification defines the nuclear safety requirements for the HTGR-GT and includes the following information:

1. A discussion of the safety philosophy on which the HTGR design is based, including single failure criteria, definition of safety classes, loading combinations to be used"for analysis and consequence limits for all plant conditions. The safety philosophy is presented in such a manner so that its correct application to spectfic problems can be achieved consistently by the design or analysis groups.

2. The safety functions to be performed and safety requirements to be met by each safety-related system; includes industry (codes and standards) and regulatory requirements.

3. HTGR-SC (Steam Cycle) Lead Plant position on each NRC Regulatory Guide.

4. A list of abnormal events and accidents to be evaluated.

5. A summary table of the safety classification, quality group and seismic classification of major systems and components.

For design parameters which are site related the plant criteria will be for acceptability on $75 \%$ of U.S. sites, provided $90 \%$ acceptability for an upgraded design is possible. For parameters which are inherent in the RTS design and cannot be adapted on a site-by-site basis the following criteria apply (corresponding to acceptability on $90 \%$ of U.S. sites): 
Atmospheric Diffusion Factors $(\mathrm{X} / \mathrm{Q})$ :

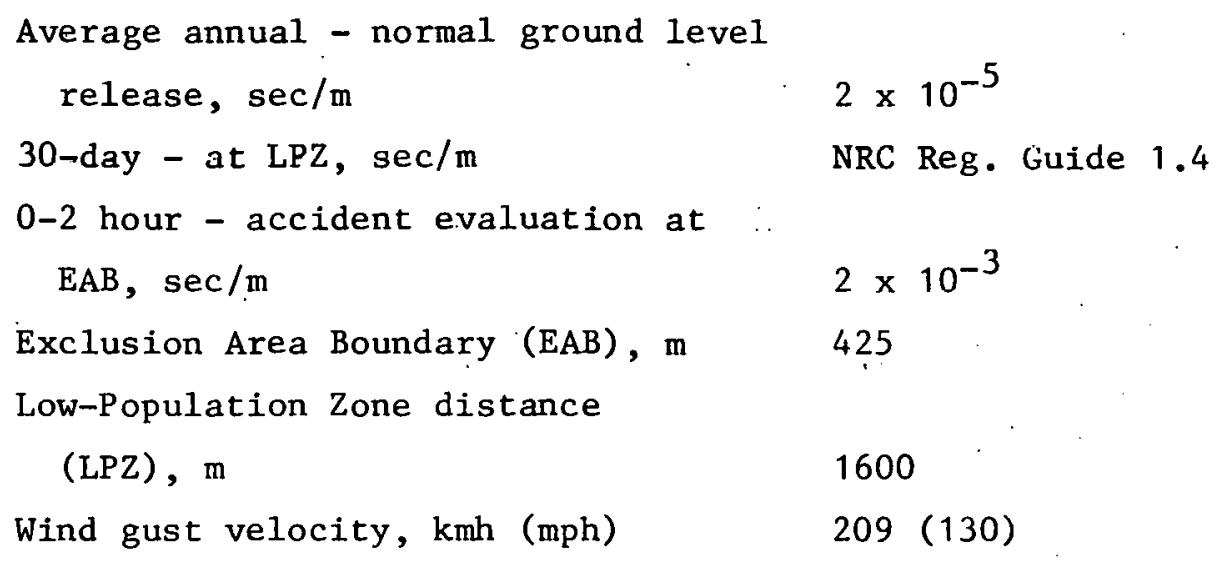

Tornado:

Rotational, kmh (mph)

483 (300)

Translational, kmh (mph)

97 (60)

Pressure change, $\mathrm{KPa} / \mathrm{sec}$ (psi/sec)

$20.7 / 3(3 / 3)$

Safety-Related Cooling Water Requirements:
Maximum wet bulb, ${ }^{\circ} \mathrm{C}\left({ }^{\circ} \mathrm{F}\right)$
$27.8(82)$
Maximum dry bulb, ${ }^{\circ} \mathrm{C}\left({ }^{\circ} \mathrm{F}\right)$
46.1 (115)

\section{3,2. Shielding and Source Strength}

Radiation shielding and component layout for the RTS are designed such that radiation exposures received by plant personnel during normal operation, refueling, and maintenance are as low as reasonably achievable (ALARA) and within the limits set forth in the U.S. Code of Federal Regulations, 10C.FR?ח. 
In the HTGR, primary shielding, that is, shielding against nuclear radiation emanating from the reactor core and internals and the primary coolant circuit, is furnished by the prestressed concrete reactor vessel. The direct dose rate outside the PCRV, except at penetrations, is less than . $1 \mathrm{mrem} / \mathrm{hr}$.

Radiation levels inside the PCRV are such that the maximum NDT shift in the liner is about (TBD) in 40 years; the maximum heating rate in the concrete is about $5 \mathrm{~mW} / \mathrm{cc}$; and the maximum local gamma exposure of the side tendon lubricant is about $10^{10}$ rads in 40 years.

Other physical shielding is provided as necessary around radioactive RTS components outside the PCRV, such as the moisture monitor system, the analytical instrument board, and for the various handling casks (fuel handling machine, fuel transfer cask, auxiliary service cask, thermocouple cask and turbomachine cask).

Refueling shielding and access is arranged such that the total radiation exposure received by working personnel is less than 20 man-rem per refueling operation. No individual worker receives more than 500 mrem per refueling, and the wholebody dose rate is not allowed to exceed $100 \mathrm{mrem} / \mathrm{hr}$. (Maintenance dose criteria; dose rates, and shielding will be provided later.)

Afterheat rates for spent HTGR fuel (HEU fuel), in terms of percent of operating power, are $0.65 \%$ one day after shutdown, $0.38 \%$ ten days aftèr shutdown, and $0.092 \%$ one hundred days after shutdown. These afterheat values are conservative for MEU fuel.

\subsubsection{Expected RTS Performance}

The expected plant performance at $3000 \mathrm{MW}(\mathrm{t})$ reactor power is shown in Table 3-3. 
TABLE 3-3

PRIMARY COOLANT EXPECTED SYSTEM DATA - SUMMARY

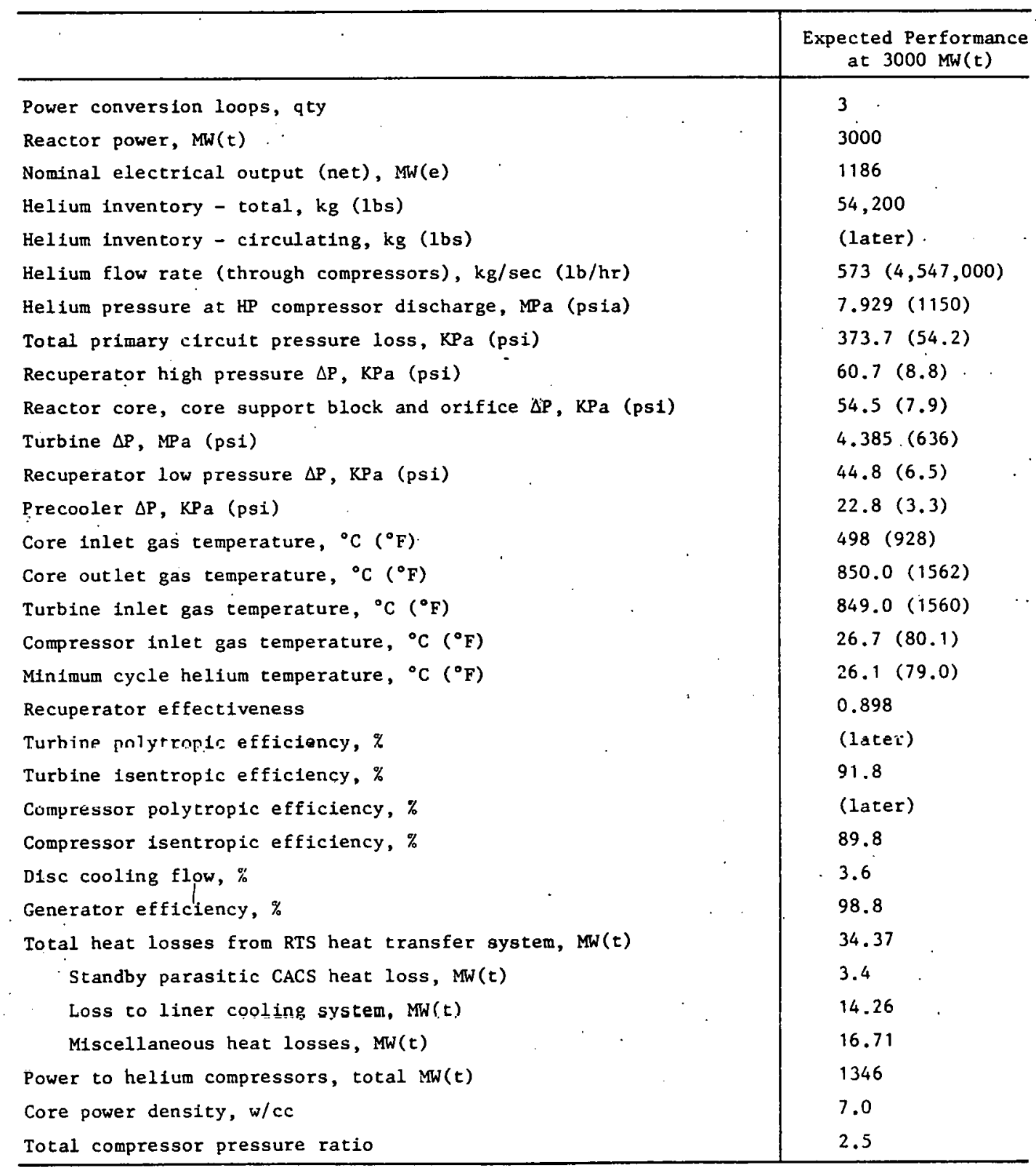




\subsubsection{RTS Thermal Performance Requirements}

Reactor Turbine System (RTS) thermal performance requirements are provided for the design of all systems, subsystems and components which are affected by the primary coolant operating conditions. The stated points include minimum load, expected operating conditions and adverse operating conditions. Each system and/or component shall be capable of operating for the life of the RTS under any of these conditions.

\subsubsection{RTS Output Capability}

The RTS output capability is stated in terms of the RTS power to the generator shafts.

Plant performance and probability of success are predicted using the established system design limits and component design uncertainties. The intent is to establish sufficient control margin such that the plant has a high probability of achieving $100 \%$ reactor power without exceeding a system design limit. The system design limits are limits imposed on system parameters by the limitations of Individual components. Component design uncertainty is the estimated deviation from expected component performance.

\subsubsection{Transient Performance}

Plant transients and the number of cycles for each will be specified and documented, and are used as a basis for the plant design. Also documented are the calculated plant performance in the form of transient plots of major plant parameters. The initial conditions for the transients occurring from full and part load are the steady state "extreme hot helium" conditions which are provided by the thermal performance requirements specified for the RTS. 
A list of representative transients and their design number of occurrences is provided in Table 3-4; the classification of events in the Normal, Upset, Emergency and Faulted transients are currently being revised and are therefore not available in a complete form at this time.

\subsubsection{Seismic Requirements}

The HTGR-GT Reference plant design shall be based on a reference site having the following soil characteristics and plant site parameters:

Seismic level OBE/SSE, g

Soil conditions

Shear wave velocity, $\mathrm{m} / \mathrm{sec}$ (ft/sec)

Soil shear modulus, dyne $/ \mathrm{cm}^{2}$ (psi)
$0.15 / 0.30$ at ground leve1 Competent rock/soft. soil 2438.4 to 121.9 . $(8,000$ to 400$)$

$17.24 \times 10^{8}$ to $24.82 \times 10^{5}$ $\left(2.5 \times 10^{6}\right.$ to $\left.3.6 \times 10^{3}\right)$

\subsection{RTS SYSTEMS}

\subsubsection{PCRV (System 11)}

System 11 consists of the prestressed concrete reactor vessel (PCRV), including lie cavity liners, penetrations, closures, and the thermal barrier. Included within this scope are the embedded portions of the liner cooling water system, PCRV structural instrumentation and data acquisition equipment, and the wire winding machine which is used during construction of the vessel.

The PCRV functions as the primary containment for the reactor core, the primary coolant system, and portions of the secondary coolant system. The PCRV also provides the necessary biological shielding and minimizes heat loss from the primary coolant system. The prestressed concrete portion of the PCRV and those portions of the penetrations unbacked by concrete, in- 


\begin{tabular}{l|l}
\hline & \multicolumn{1}{|c}{$\begin{array}{c}\text { Design Number of } \\
\text { Occurrences for P1ant }\end{array}$} \\
\hline Normal transients (see Fig. 3-1)* & \\
Startup from refueling status & 130 \\
Shutdown to refueling status & 80 \\
Shutdown with full helium inventory & 40 \\
Rapid load increase $(5 \% / \mathrm{min})(25 \%-100 \%)$ & 500 \\
Normal load increase $(0.42 \% / \mathrm{min})(25 \%-100 \%)$ & 2,600 \\
Normal load increase $(0.42 \% / \mathrm{min})(50 \%-100 \%)$ & 10,400 \\
Rapid load decrease $(5 \% / \mathrm{min})(100 \%-25 \%)$ & 500 \\
Normal load decrease $(0.42 \% / \mathrm{min})(100 \%-25 \%)$ & 2,600 \\
Normal load decrease $(0.42 \% / \mathrm{min}) .(100 \%-50 \%)$ & 10,400 \\
Step load increase $(+10 \%)$ & 2,000 \\
Step load decrease $(-10 \%)$ & 2,000 \\
Upset transients & $(1$ ater $)$ \\
Emergency transients & $(1$ ater $)$ \\
Faulted transients & $(1$ ater $)$ \\
\hline
\end{tabular}


cluding their closures, form the primary coolant pressure-resisting boundary. The cavity and penetration liners, including closures, form the continuous gas-tight boundary of the PCRV. Liner and penetration anchors transmit loads from internal equipment support structures to the PCRV concrete. The PCRV in turn transmits these loads to the vessel support structure: During construction, the liners serve as formwork for the concrete.

The thermal barrier minimizes heat loss from the primary coolant system. The PCRV cooling water system and the thermal barrier together function to control temperature levels in the PCRV to protect against structural material degradation and excessive thermal stress in the concrete.

PCRV pressure relief is provided by an internal system utilizing bypass valves (System 21-3) between the high and low pressure zones.

PCRV structural instrumentation is used to obtain data to verify PCRV response to temperature and pressure loads to prove the adequacy of the design and quality of materials and construction.

Tables 3-5 and 3-6 provide the major parameters of the PCRV system.

\subsubsection{Neutron and Region Flow Control (System 12)}

The Neutron and Region Flow Control System consists of two major subsystems: 1) the neutron control subsystem which comprises (a) the normal control and shutdown system of control rod pairs, power rods, and neutron detectors, (b) the Reserve Shutdown System (RSS), and (c) the movable incore flux mapping and startup detector system, and 2) the primary coolant flow control subsystem consisting of variable orifices and outlet temperature thermocouples for 91 core regions.

Appropriate actuation devices together with position and limit of travel sensors, controls and indications are included in each of the above subsystems. The Neutron and Region Flow Control System (System 12) utilizes 
TABLE 3-5

MAJOR PARAMETERS OF THE THERMAL BARRIER

Total thermal barrier area, $\mathrm{m}^{2}\left(\mathrm{ft} \mathrm{t}^{2}\right.$ )

. $71.62(77,063)$

Details of thermal barrier:

$$
\text { Area, } \mathrm{m}^{2}\left(\mathrm{ft}^{2}\right): \begin{aligned}
& \text { Class } \mathrm{A} \\
& \\
& \text { Class } \mathrm{B}_{1} \\
& \\
& \text { Class } \mathrm{B}_{2} \\
& \text { Class } \mathrm{C}
\end{aligned}
$$$$
4333(46,623)
$$$$
2117(22,779)
$$$$
572(6156)
$$$$
140 \text { (1506) }
$$ 


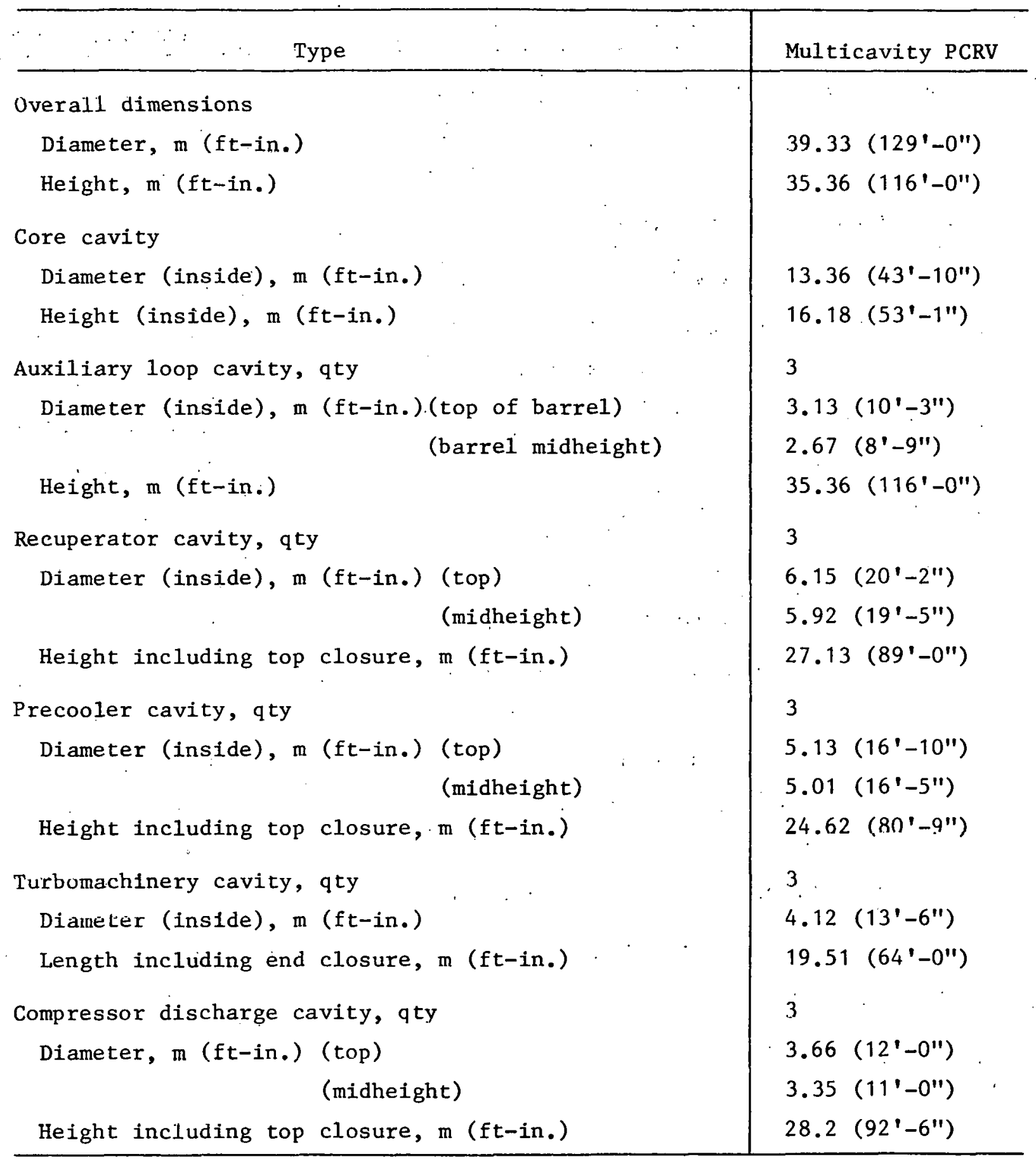


TABLE 3-6 (Continued)

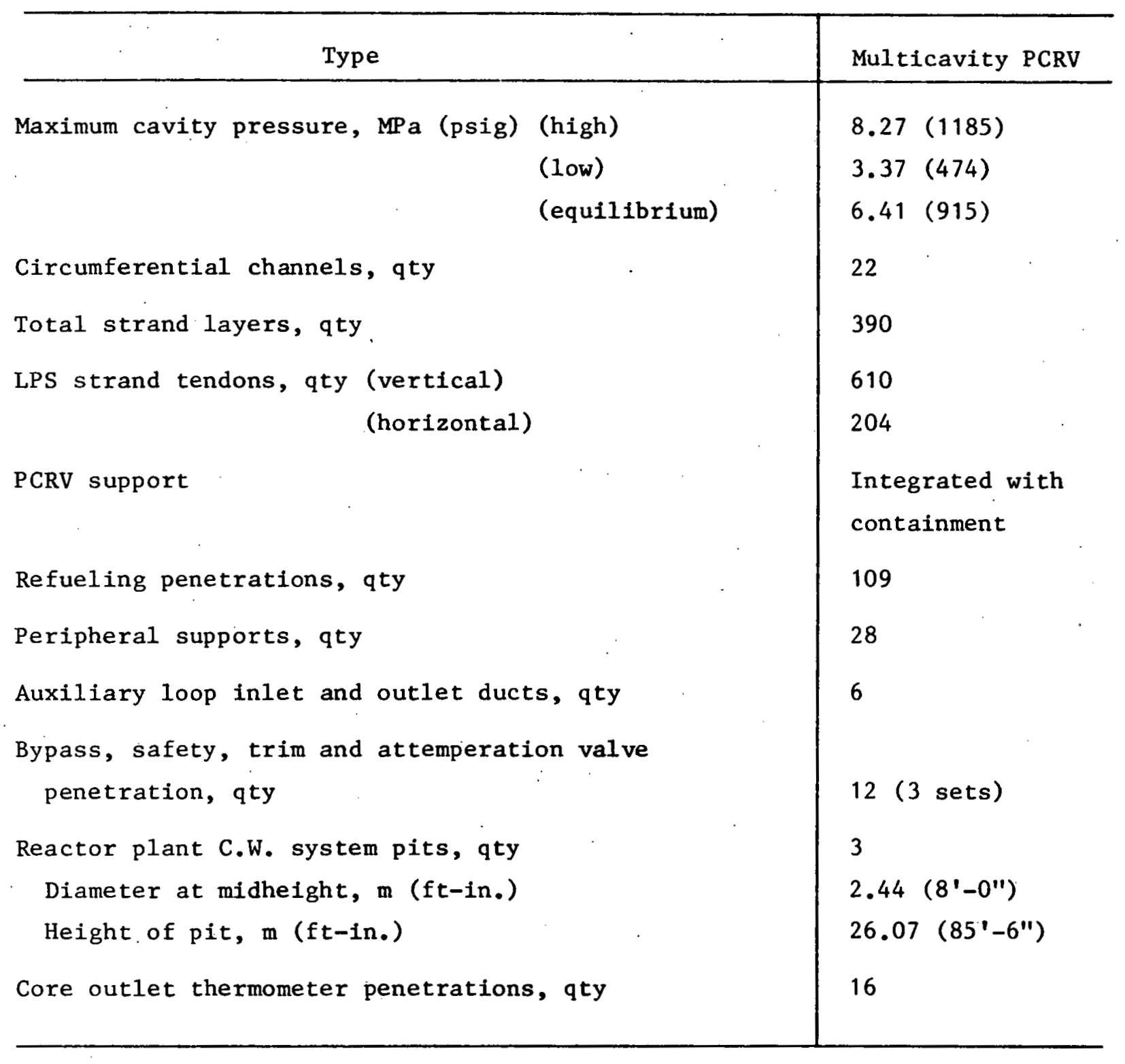




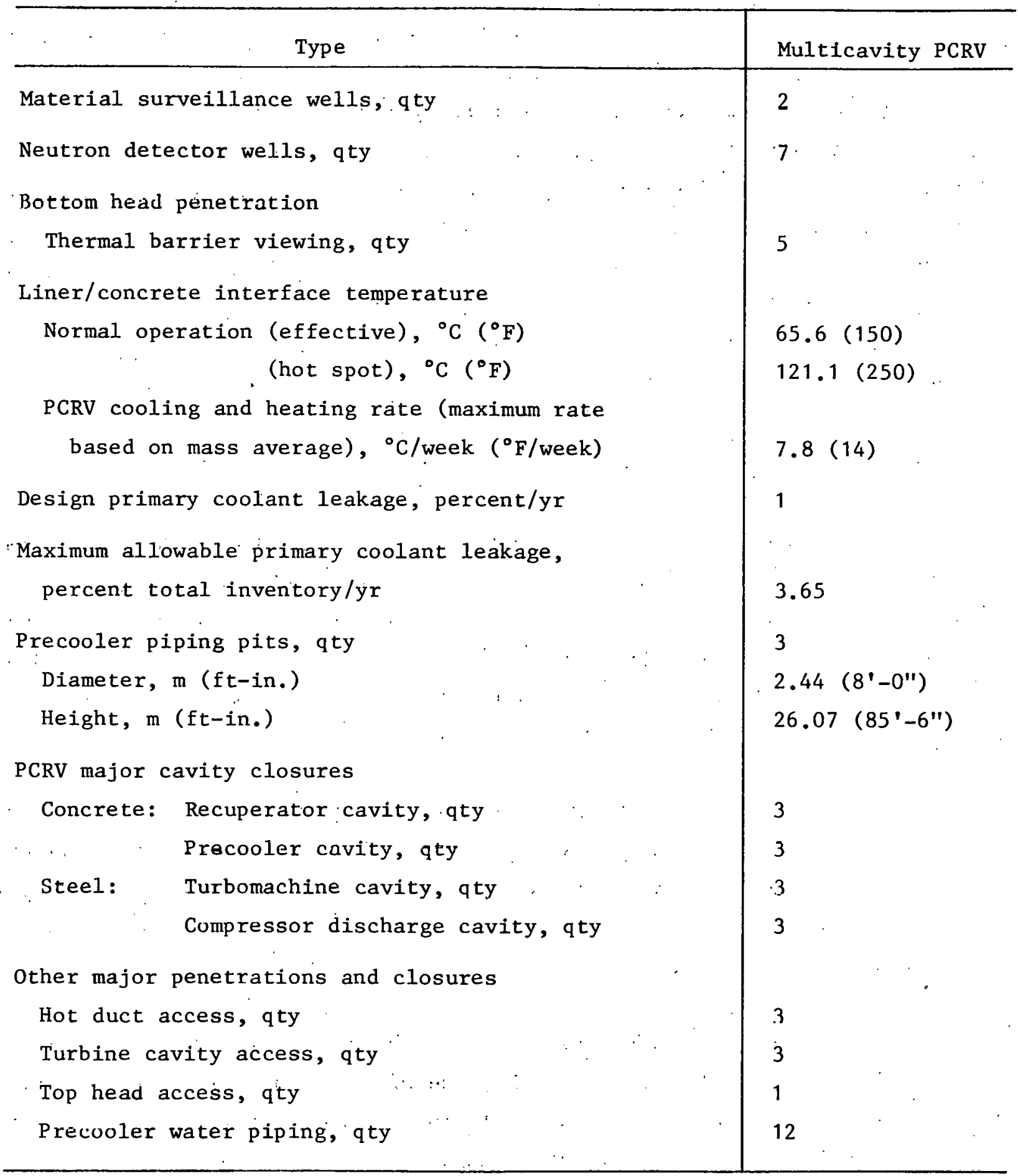


ex-core flux detectors and controllers, together with power rods, control rods and/or the reserve shutdown material to adjust core reactivity as demanded by the Plant Control System (PCS, System 33), the Plant Protection System (PPS, System 32), or the plant operator. System 12 also adjusts the helium flow through regions of the core by incremental manual positioning of each adjustable core region inlet orifice valve as commanded by the plant operator. Reactor in-core flux mapping and startup flux measurements are also performed by System 12 using movable detectors in selected core locations. Temperature indications from the core region outlet thermocouples are utilized by the plant operator to adjust region power with power rods or control rods, or to adjust region flow with the flow control orifices.

Table 3-7 provides the major system parameters.

\subsubsection{Fuel Handling (System 13)}

The fuel handling equipment consists of a fuel handling machine (FHM), fuel transfer casks, an auxiliary service cask, a refueling equipment transfer dolly, reactor isolation valves, floor valves, a control station, and the fuel sealing and inspection facility. This system handles both new and used fuel between its in-core location and delivery to the fuel storage facility. The operations are as follows:

After reactor shutdown and depressurization of the PCRV, a refueling penetration closure plate is removed. A reactor isolation valve (RIV), which serves as a radiation and atmospheric barrier between the reactor cavity (or refueling penetration) and working personnel on the refueling floor, is attached to the refueling penetration.

The auxiliary service cask (ASC), which is designed to handle the control rod drive (CRD) unit, the high-temperature filters and absorbers (HTF/A), then removes the CRD assembly and places it in a CRD storage well within the PCRV if the assembly is reusable, or in the reactor service building (RSB) if the assembly is spent or requires servicing. The fuel handling machine (FHM) is then secured to the refueling penetration and sealed to the preplaced RIV. 
Total number of regions requiring control and/or orificing (C\&O) assemblies, qty

Number of regions requiring control rod drive and mechanism (CRDM) assemblies. (This type of C\&O assembly is equipped with a control rod pair and drive, a power rod and drive, an RSS unit, a flow control orifice and drive, and the capability to install an in-core flux mapping unit (IFMU)), qty

Number of CRDM assemblies which will be equipped with an IFMU, qty

Number of regions requiring control rod drive and instrumentation ( $C R D \&$ Instr.) assemblies. (This type of C\&O assembly is equipped with a control rod pair and drive, a power rod and drive, a flow control orifice and drive, and a startup detector and drive), qty

Number of regions requiring only a shield plug assembly, qty

Number of ex-core neutron detectors providing input to the flux controller (System 33), qty

Length between top and bottom of the poison material Same as active in control rod pairs and power rods core length

Number of ex-core neutron detectors providing input 12 (two per to protection System 32, qty detector well) 
A fuel transfer mechanism within the FHM lowers down through the refueling penetration into the reactor, picks up a fuel or reflector element, and lifts it back into the shielded.portion of the machine, where it is transferred to the fuel transfer cask (FTC). When loaded with spent fuel elements (five maximum), the FTC is transported to the RSB, which is adjacent to the reactor containment building; and positioned to mate with a plug actuator above the fuel sealing facility, from which it is passed on to the storage facility after sealing. Reflector elements are handled in the same manner as fuel elements, with the exception that "spent". reflector elements are stored in a reflector storage well in the RSB and "reusable" elements temporarily placed in a reflector storage well in the PCRV.

When the working refueling region has been emptied, new fuel and reflector elements are brought in the FTC from storage to. the FHM, which transfers the elements into the core. After the region has been refueled and the RIV closed, the FHM is detached and moved to the next refueling penetration: The ASC and RIV are then removed, and connection of service lines and installation of the closure plate complete the process for a refueling region.

The fuel sealing facility, which operates in a helium atmosphere, inserts each fuel element into a storage canister and seals the can before it is transferred to the storage facility.

\subsubsection{Fuel Shipping (System 15)}

The Spent and Recycle Fuel Shipping System consists of rail equipment designed to transport spent fuel elements to the storage facility and/or the recycle plant. This equipment is also designed to ship recycle fuel elements from the recycle plant.

The rail shipping system consists of a rail cask, a rail car and fuel shipping containers. The rail cask has an inner basket that holds 12 fuel shipping containers. Each fuel shipping container holds six spent fuel 
elements or five recycle fuel elements within protective packaging. The cask body and the cask closure is shielded with depleted uranium.

The rail cask is transported on a special purpose, eight axle, drop center rail car in a horizontal position, supported and attachéd by trun" nions." The rail cask is lifted from the rail car and then rotated to a vertical position for loading and unloading.

Table 3-8 provides the major parameters of the fuel shipping system.

\subsubsection{Reactor Service Equipment and Storage System (System 16)}

The Reactor Service Equipment and Storage System consists of a collection of RTS equipment which is used to service selected areas of the HTGR-GT.

Each category of equipment is designed to perform a particular function and has only minimal impact.upon the design of other equipment in the system. The equipment involved are the wire winding machine, the control :rod drive storage turntable, the auxiliary circulator handling equipment, the in-core thermocouple service equipment, core service tools, and service facility tools.

Additional equipment will be required to service the turbomachinery, the hot duct liners, the crim and control valves, etc. The scope of supply and the functional requirements for this equipment will be specified later.

\subsubsection{Reactor Internal Components (System 17)}

The Reactor Internal Components System includes all the graphite components of the core support floor, permanent side reflector and the core peripheral seal; the metal peripheral seal support structure including those items which attach the structure to the PCRV liner and others providing the interface with adjacent thermal barrier; the metal core lateral restraint and side shield assemblies; the metal plenum elements fitting over the top 
TABLE 3-8

SPENT AND - RECYCLE FUEL SHIPPING SYSTEM DATA

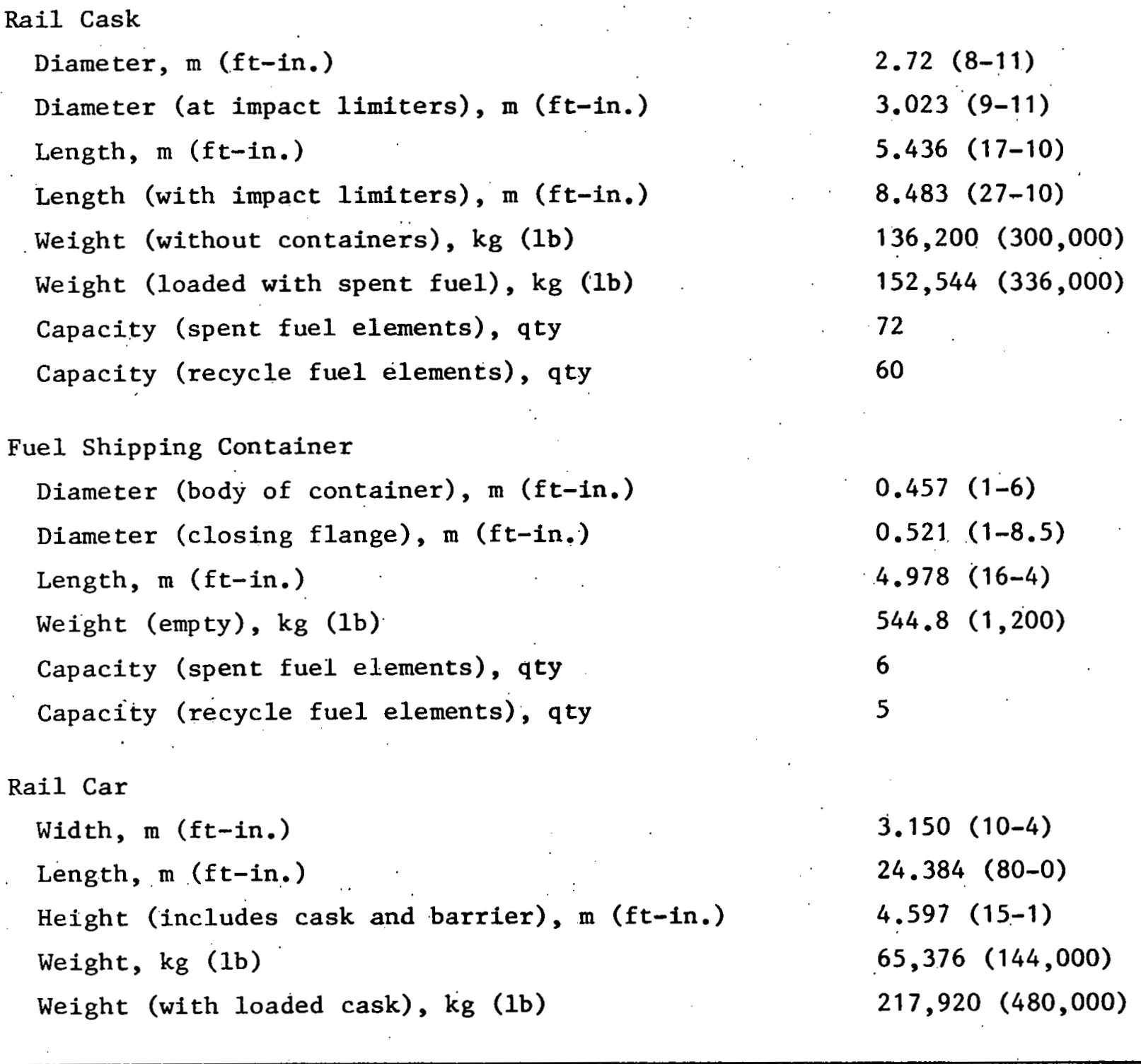


permanent side reflector blocks; and the free-standing sections of the core inlet and outlet ducts. Table 3-9 provides the major parameters for the Reactor Internal Components System.

The following is a brief description of the reactor internal components:

1. Core Support Structure. The basic function of the core support floor (CSF) is to support the reactor core, the graphite reflectors, the plenum elements and variable orifice assemblies which rest atop the core. The CSF provides a lower plenum for the core outlet gas, and allows for relative horizontal movements between the bottom of the core and the PCRV bottom head. Each region core, support block (CSB) includes coolant passages to mix the coolant flows from the various columns and direct the mixed stream over a graphite sleeve which houses the core outlet temperature thermocouples before the gas enters the lower plenum. The peripheral support blocks provide a seat for the core peripheral seal which restricts bypass flow through the annular space between the support floor and the PCRV liner.

2. Core Lateral Restraint. The primary function of the core lateral restraint (CLR) assemblies is to provide lateral support for the reactor core, support floor and reflectors. The CLR locates the core, reflector and support assembly; accommodates relative movements due to thermal expansion and PCRV shrinkage and creep; cushions the core and reflectors during an earthquake to avoid excessive horizontal loads on fuel or reflector elements; prevents excessive displacement of the core during an earthquake, which could damage control elements; and restores the core to its nominal position , after a disturbance. Support for the plates which form the side. shield is also provided by the CLR. The function of the side shield is to reduce the thermal neutron flux reaching the PCRV sidewall liner. 
TABLE 3-9

MAJOR PARAMETERS OF THE REACTOR INTERNAL COMPONENTS SYSTEM

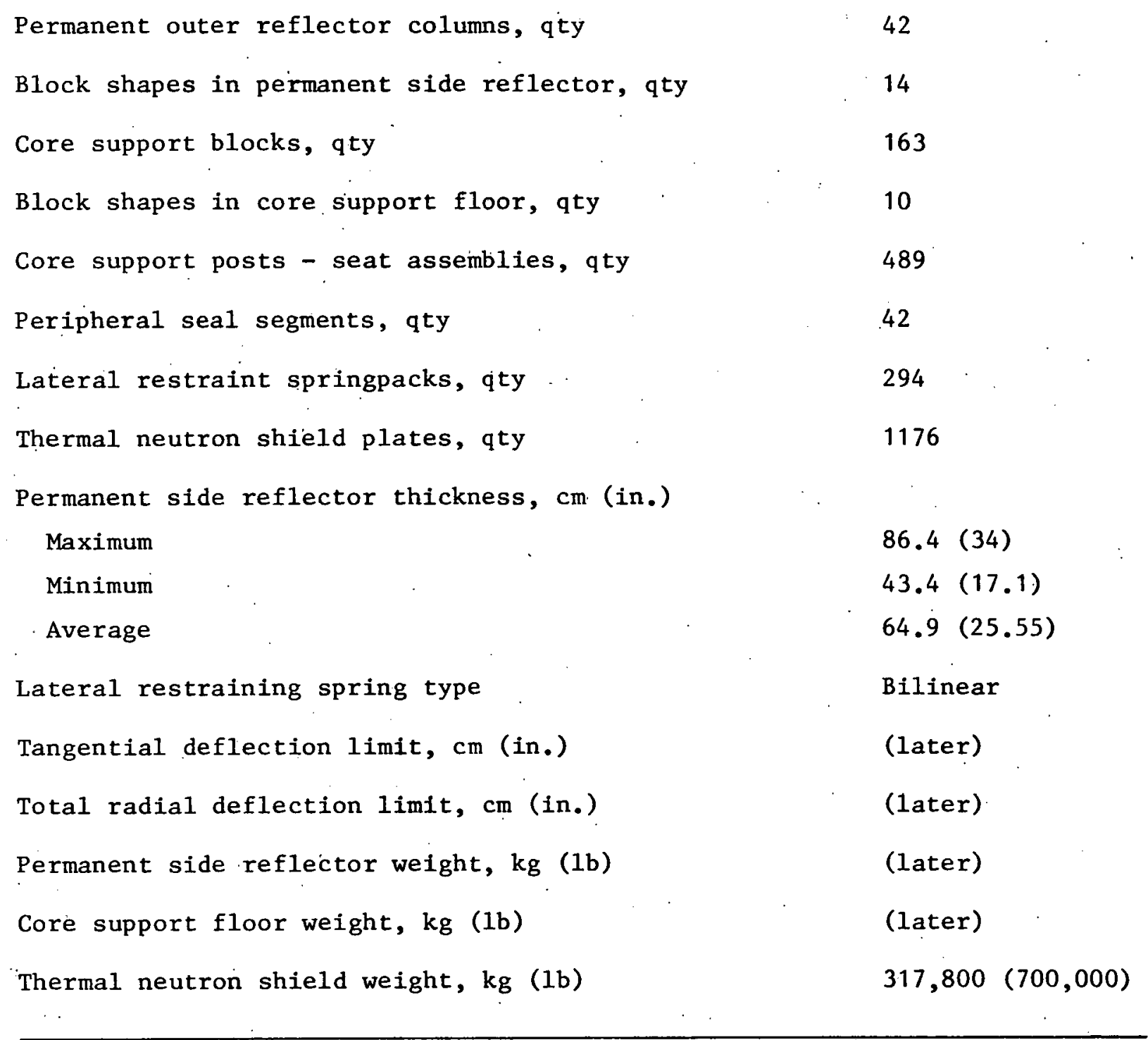


3. Permanent Side Reflector. The primary function of the permanent side reflector (PSR) is to attenuate neutron flux to components surrounding the'core and to reflect neutrons back into the core. The PSR blocks are shaped to make a transition from the irregular outer boundary formed by the hexagonal core and reflector columns to an approximately circular shape concentric'with the PCRV liner. Thus; the PSR also serves. to locate and maintain the shape of the core lateral restraint assemblies. Finally, the PSR, as a closefitting cylindrical assemblage of blocks serves to inhibit the radial inflow of bypass coolant into the core.

4. Peripheral Seal. The function of the core peripheral seal (CPS) assembly is to limit the amount of coolant which bypasses the reactor core by flowing through the annular space between the PSR and PCRV liner. While performing that function, the seal must accommodate relative movements between the CSF and PCRV due to thermal expansion and PCRV shrinkage and creep. Although the seal is not required to limit bypass flow during an earthquake, it must withstand the displacements involved and then reestablish its sealing effectiveness upon termination of the disturbance.

5. Core Inlet and Outlet Ducts. The function of the core inlet duct (CID) is to carry warm gas from the recuperator to the core inlet plenum. The function of the core outlet duct (COD) is to carry hot core oullet gas to the turbine inlet. Both free-standing sections of the ducts are located in the vertical compressor-discharge cavity,'where they are "cooled" externally by compressor discharge flow. The upper horizontal section of the CID is located concentrically in a cross duct which carries this gas from the compressor discharge duct to the recuperator. 


\subsubsection{Reactor Core (System 18)}

This system includes the fuel elements, the hexagonal reflector elements, the top layer/plenum elements, and the startup neutron sources.

The fuel element is a graphite block with the dual function of containing the fuel and acting as a moderator. Each fuel element consists of a hexagonal graphite block containing drilled coolant passages and also parallel fuel channels into which the individual fuel rods are inserted. The individual fuel rods contain the fuel particles distributed in a graphite matrix. The initial core elements and the reload elements, whether containing fresh fuel or recycle fuel, are identical in geometry.

For the reference cycle with medium-enriched fuel (MEU), the fissile kernel is uranium carbide surrounded by a buffer layer of low-density pyrolytic carbon, a thinner layer of high-density pyrolytic carbon, a layer of silicon carbide which improves containment of fission products, and an outer layer of high-density pyrolytic carbon which adds strength to the coating. : This coating system is referred to as a TRISO coating. The fertile kernel is thorium oxide surrounded by the same type of TRISO coatings as the fissile kernels, or be all-pyrocarbon $B 150$ coatings.

For the low enrichment fuel cycle (LEU), the fuel element design would be essentially unchanged except for the fuel rod diameter, which would most likely be reduced to accommodate the typically lower fuel loadings of this cycle. The fuel particle designs would be similar in character to those used in the reference medium enrichment cycle, except that thorium would not be used as a fertile material. Specific LEU fuel designs have not yet been selected.

The fuel elements and hexagonal reflector elements are arranged in columns supported on the core support blocks. Each support block under the major portion of the active core corresponds to one fuel region which has a 
central: control colum and six surrounding fuel columns. The fuel regions are surrounded by two rows of hexagonal reflector colums which are in turn surrounded by the PSR. The elements of the core are as follows:

1. Fuel Elements. Graphite hexagonal right prisms with arrays of fuel and coolant holes and a hole for burnable poison shim. Control rod and reserve shutdown holes are included where required.

2. Refueling Region. A section of the core containing adjacent fuel elements which are normally loaded or reloaded in the same time interval.

3. Reflector Elements. Graphite hexagonal right prisms. Reflector elements may have coolant holes, control rod and reserve shutdown holes, and shielding material as required, but do not contain fuel.

4. Top Layer/Plenum Elements. Alloy steel hexagonal components which provide the flow plenums for distributing the flow from the region flow control valves to the individual columns, lateral restraint during refueling, and the flow control valve/lower guide tube assembly support.

5. Startup Neutron Sources. A material, Cf-252, with a suitable container which is inserted into core fuel elements to provide a source of neutrons of sufficient strength to ensure a safe, controlled approach to reactor criticality.

\subsubsection{Primary Coolant System - Power Conversion (System 21)}

The primary coolant system is comprised of those subsystems and components required for the transfer of energy from the reactor core to the gas turbine and secondary coolant systems. The major system components 
involved in this function are the turbomachine, precooler, recuperator and control valves which constitute the single power conversion loop (PCL) (see Fig. 3-2 and 3-3).

The system uses an inventory of helium to transfer energy from the reactor core to the gas turbine unit, where expansion of the helium drives the compressor and electric generator. After leaving the turbine, low pressure helium passes through the recuperator and gives up heat to the high pressure helium flowing from the compressor discharge. Leaving the recuperator, the cooled low pressure helium flows to the precooler and additional heat is transferred to the secondary coolant loop (circulating water system). The cold low pressure helium then passes to the compressor inlet and is pumped through the recuperator to the reactor core and completes the circuit.

3.4.8.1. Turbomachinery. The $400 \mathrm{MW}(\mathrm{e})$, single shaft, direct drive helium turbomachine has 18 compressor stages (for a pressure ratio of 2.5 with the low molecular weight gas) and eight turbine stages. The rotor is of welded construction. With the $60,800 \mathrm{~kg}$ (67 ton) rotor supported on two journal bearings (with state-of-the-art loading and peripheral speed), the overall - length of the machine is $11.3 \mathrm{~m}$ ( $37 \mathrm{ft}$ ). The overall diameter and machine weight are $3.5 \mathrm{~m}(11.5 \mathrm{ft}$ ) and $277,000 \mathrm{~kg}$ (305 tons), respectively.

Rotor burst protection is incorporated in the machine design in the form of containment rings around the compressor and turbine rotor-bladed sections. Man-access cavities are provided in the PCRV for inspection and limited maintenance work on the journal bearings. The spaces in which the bearings are located are isolated from the main cycle working fluid by shielding (purged gas from the purification system is used to provide an acceptable radiological environment for man access). The drive to the generator is from the compressor end of the turbomachine, and the thrust bearing and $\# 3$ journal'bearing are located external. to the PCRV to facilitate inspection and maintenance. 


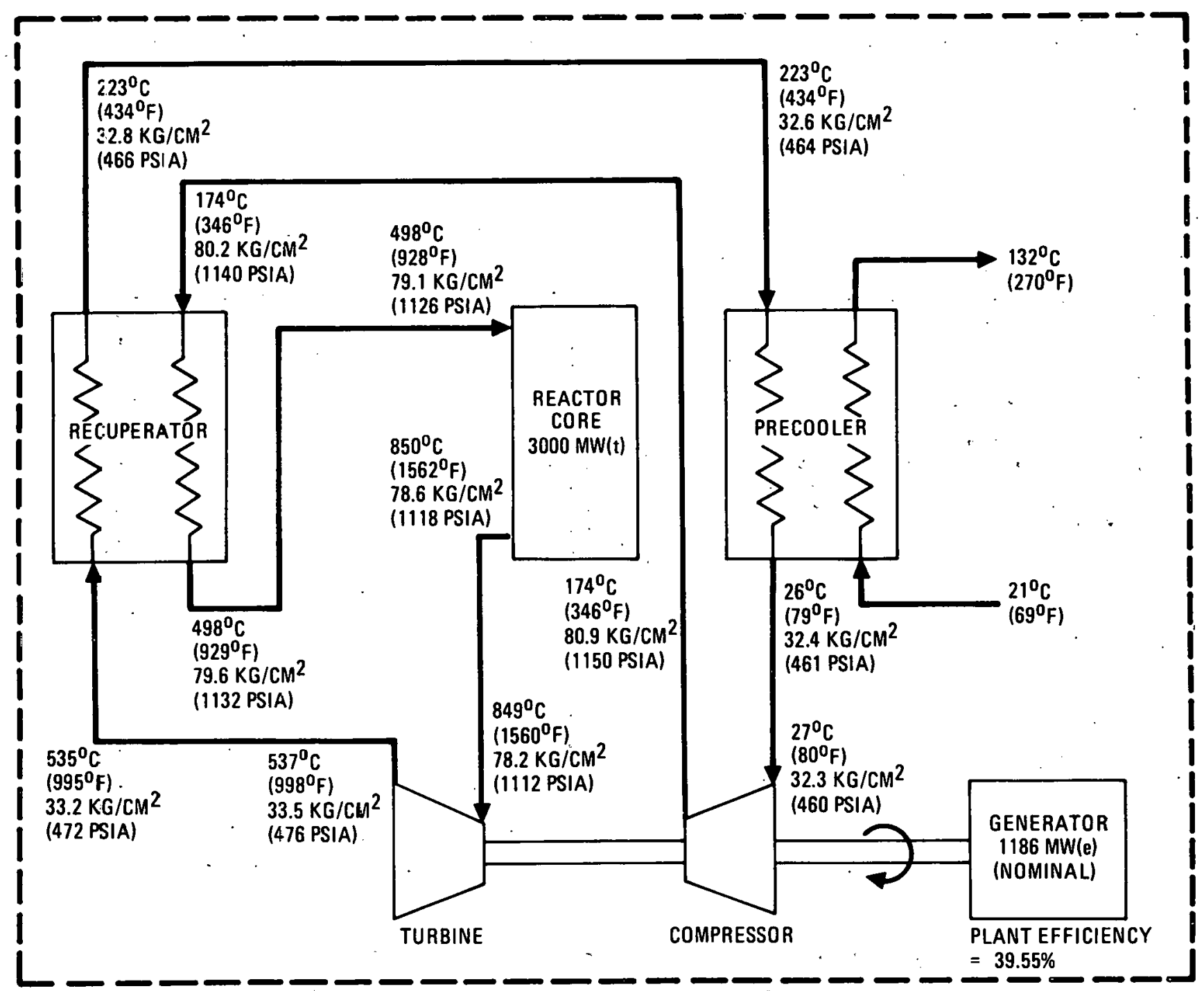

Fig. 3-2. Gas turbine HTGR cycle diagram 
- LP PART OF CIRCUIT APPROXIMATELY $3.2 \mathrm{MPa}$ (470 PSIA)

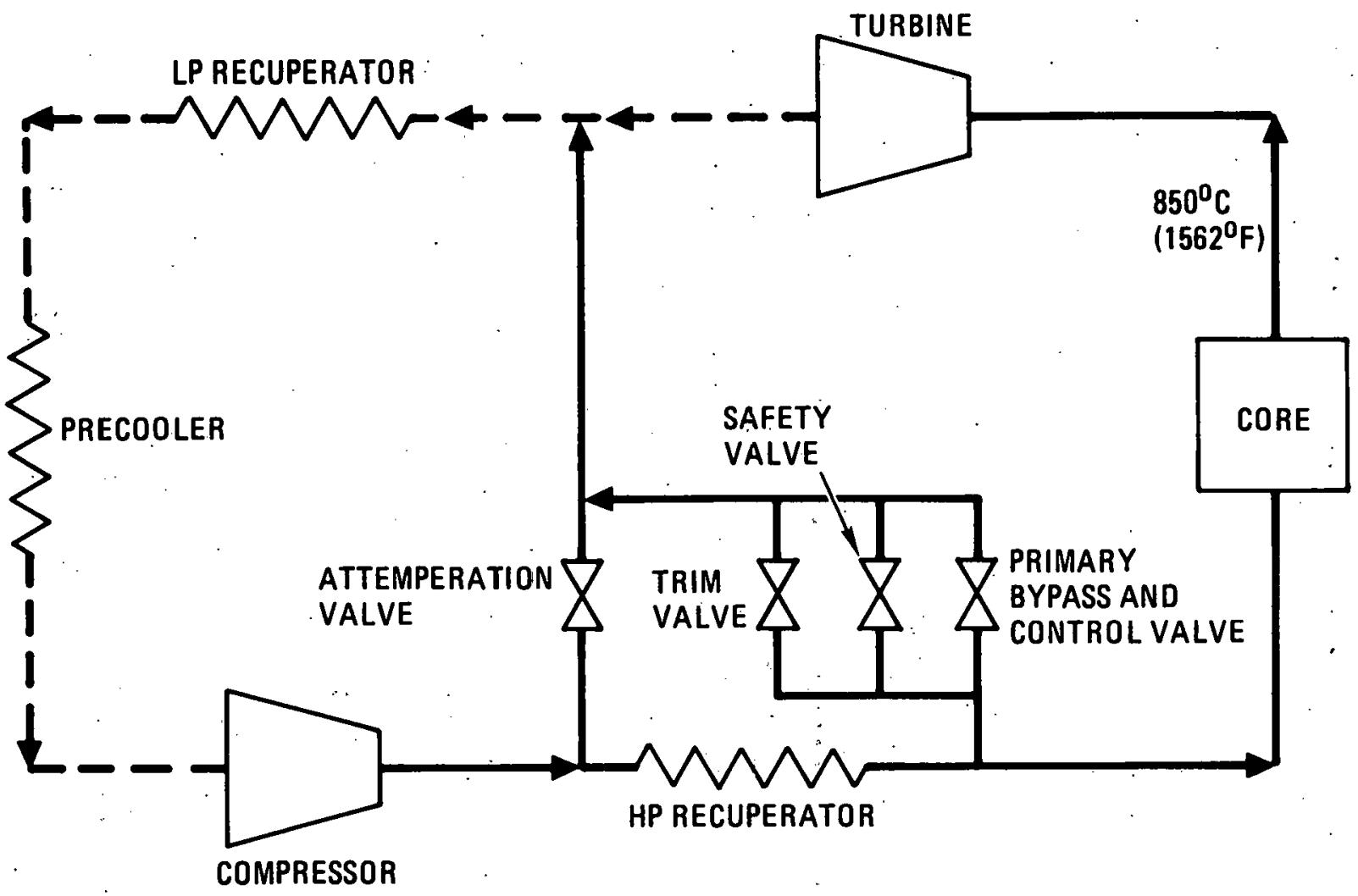

Fig. 3-3. Simplified control valve diagram for GT-HTGR power plant 
The turbomachinery is coupled to an all water cooled generator which is located inside the secondary containment in order to eliminate any shaft penetration of the containment building.

3.4.8.2. Recuperator. The recuperator is a tubular, straight tube, gas-togas counterflow heat exchanger which recovers heat from the turbine discharge helium by preheating the compressor discharge helium before it enters the core.

The recuperator is located entirely in the PCRV. High pressure helium from compressor discharge enters the recuperator near the top of the PCRV, flows downward through the tubes, turns $180^{\circ}$ and returns upward through a an integral return tube and exists the module at the top. Low pressure helium from the turbine exhaust enters the recuperator at the bottom, flows outside the tubes (counterflow to tubeside helium) and exits at the top.

The recuperator is of a straight tube design and embodies a modular configuration consisting of multiple modules, each having (later) tubes.

3.4.8.3. Precooler. The precooler is a helically coiled, finned tube, gas-to-water counterflow heat exchanger which removes heat from the hot gas leaving the recuperator after having been discharged from the turbine.

The precooler is designed so that all heat transfer surfaces are 1ocated in a single cavity in the PCRV. The cooling water (circulating water) inlet is at the bottom of the module and the exit is at the top. The recuperator discharge gas (hot) enters the precooler near the top of the $\mathrm{PCKV}$ and exits near the bottom into the compressor.

The precooler is designed so that cooling water flows in two parallel and separate circuits within the helical bundle; the circuits can be isolated and drained independently of each other. This provides the ability to continue operating the reactor in a single loop shutdown mode even if 
a failure has occurred in one of the circuits. This circuit avoids overheating of the compressor under backflow conditions.

3.4.8.4. Control Valves. There are four valves arranged in a split-flow bypass configuration in the primary conversion loop (see Fig. 4). The trim, safety and primary bypass valves function to control core-turbine bypass flow between the core inlet and the turbine outlet in each loop; the attemperation valve controls flow between the compressor exit and the turbine exit. The trim valve makes fine adjustments of turbine speed and load and is of particular use when synchronizing with the grid. The primary bypass valve can be operated in two modes: 1) it can be modulated by the plant control'system for plant load control, or 2) it can be operated as a safety bypass valve in an open/close mode by a separate actuator as part of the safety bypass valve system (SBVS) that is included in the plant protection system. The safety valve, used primarily for turbine overspeed/overpressure protection, is actuated by the plant protection system and is operated in an open/close mode. This valve cannot be used for load control. The attemperation valve is used to mix cold compressor discharge helium with cool turbine exhaust helium, thereby minimizing thermal shock to the power conversion loop components during transients.

\subsubsection{Rotating Machinery Service System (System 22)}

1. Turbomachinery Turning Gear System. Because of the length and weight of the turbomachinery rotor, a turning gear is required. In addition, during the low speed turning gear operation, a shaft jacking pump must be utilized to hydraulically lift the rotor to avoid bearing damage since the shaft speed is not adequate to create a hydraulic wedge in the bearings.

2. Turbomachinery Lubrication and Buffer System. The turbomachinery radial bearings and bearing housings are serviced by the Lubrication and Buffer System. This system provides lubrication to the 11 and $\left.\right|_{2}$ bearings and buffer helium to the bearing housing shaft seals. 
3. Main Shaft Penetration Seal 0il System. This system provides seal oil at 1010 psia to the multiple floating ring seal that forms the seal in the turbomachine cavity plug around the drive shaft between the turbomachinery and the generator.

4. Generator, \#3 Load Bearing and Thrust Bearing Lubrication System. The generator, the \#3 load bearing and thrust bearings are lubricated from a common oil system. The sump for this system must be located near and below the generator since a gravity oil return system is utilized. As in the case of the turbomachinery, the generator rotor requires jacking oil pumps to hydraulically lift the rotor during low speed operation of the generator.

5. Generator Deionized Water System. The generator water cooling system provides separate water cooling systems to the rotor, stator and air gap cooling passages.

6. Auxiliary Circulator Service System. The function of this service system is to provide a supply of purified buffer helium for preventing inleakage of motor bearing lubricant to the primary coolant system or leakage of primary coolant into the motor casing; motor cavity and bearing oil reservoirs; removal of oil vapor carried over in the purge helium from the circulators and removal and replacement of motor bearing lubricant.

\subsubsection{Helium Services System (System 23)}

The Helium Services System includes the helium purification system and the PCRV seat system.

The helium purification system withdraws helium from the primary coolant loop and processes it to remove particulates and chemical and radioactive impurities. The processed gas is safely used as a clean gas purge where needed throughout the plant. This system serves as the primary 
means of controlling the level of chemical impurities, long-lived noble gas nuclides and tritium in the primary coolant. Clean helium purge requirements throughout the reactor plant establish the helium purification system flow rate.

When the PCRV helium inventory is transferred to storage (BOP), the helium purification system removes radioactive impurities and most chemical impurities. The system compressors recycle purified helium from the turbomachinery and the auxiliary helium circulator service system; the recycled helium is used as purge gas. Also, this system periodically processes radioactive gas waste; it separates the chemical and radioactive impurities, and concentrates the radioactive impurities for retention.

The PCRV service system provides services to specified penetration closures, including piping, valves and instrumentation which are located outside of these penetrations. It pressurizes the seal interspaces of selected PCRV penetration closures which are equipped with dual elastometer seals, thus preventing leakage of primary coolant and permitting continuous monitoring of the integirity of these seals.

\subsubsection{Core Auxiliary Cooling System (CACS) (System 28)}

The RTS portion of the Core Auxiliary Cooling System (CACS) includes an auxiliary helium circulator and induction motor drive, an auxiliary primary coolant shutoff valve, a water-cooled heat exchanger and control instrumentation and hardware.

The function of the CACS is to provide a second means of cooling the core. The CACS is designed to maintain ample margins on limits of components within the primary coolant system following accidents which prevent operation of the main loops. As such, it is an engineered safety feature.

The CACS consists of three separate and independent cooling loops. The system is capable of removing the core residual and decay heat for safe 
cooldown following loss of circulation in the main power conversion loop and reactor shutdown from $102 \%$ of reactor steady state power level with the primary coolant pressurized or depressurized.

This function is accomplished by forced circulation of the primary coolant, with air and/or water inleakage, by the auxiliary circulator. The core cooling gas is circulated through the core auxiliary heat exchanger (CAHE) where the heat is delivered to the core auxiliary cooling water system (CACWS) for disposal to the atmosphere.

3.4.11.1. Auxiliary Circulator (System 28-1). The auxiliary circulators are axial-flow compressors with variable-speed, electric induction motors. The motor is submerged in helium; but it is separated from the primary coolant by labyrinth seals supplied with buffer flow. Power and circulator services penetrate the PCRV. For commonality of hardware with larger HTGR plant designs, the circulator motor is sized to a higher power rating than the maximum required in this application. The power supply sizing corresponds to the lesser figure.

An auxiliary primary coolant loop shutoff valve is installed in series with each circulator between it and its associated CAHE. This valve limits the reverse flow of the helium coolant through each auxiliary primary coolant loop when the main circulators are operating. The valve is a butterfly-type check valve. It is opened by the pressure developed by the auxiliary circulators when the CACS is actuated. Table 3-10 provides general circulator data.

TABLE $3-10$

CORE AUXILIARY CIRCULATOR DATA

$\begin{array}{ll}\text { Auxiliary circulators, qty } & 3 \\ \text { Compressor type } & \text { (later) stage axial flow } \\ \text { Drive type } & \text { Electric-induction motor } \\ \text { Design power, kWe (horsepower) } & 671(900) \\ \text { Maximum power, kWe (horsepower) } & \text { (later) }\end{array}$


3.4.11.2. Core Auxiliary Heat Exchanger (System 28-2). The CAHE is a straight-tube bayonet water-cooled heat exchanger installed in each of the auxiliary core cooling loops. Hot gas from the lower cross duct enters the top of the straight bayonet tube bundle and flows downward through the tube bundle parallel to the CAHE tubes. The CAHE penetrates the PCRV at the bottom of each auxiliary cavity, where water enters and exits the bayonet tubes. Water flows counter to the helium flow through an annulus between the outer CAHE tubes and smaller diameter "core. tubes" to the top of the tube bundle, gaining heat through the outer tube wall. Water turns at the upper end and returns to the bottom of the CAHE through the core tubes. Table 3-11 provides general CAHE data.

TABLE 3-11

CORE AUXILIARY HEAT EXCHANGER MODULE DATA

Core auxiliary heat exchangers, qty

Heat transfer tubes, qty each

Tube size (o.d. $\mathrm{x}$ wall thickness), cm (in.)

Heat transfer area - effective, $m^{2}\left(f t^{2}\right)$, each

Heat exchanger type

Penetration location in PCRV
3

(1ater)

(1ater)

(later)

bayonet tube

bottom 
3.4.11.3. Core Auxiliary Cooling Control (System 28-3). This subsystem is made up of the instruments and controls associated with the RTS portion of each CACS loop, including the equipment which provide power conditioning and speed control for the auxiliary circulator motors.

Instrumentation includes equipment for non-safety related measurements for system surveillance and for maintenance, and it includes safety-related displays for surveillance and for performance monitoring. Controls are provided for the circulator speed and for testing and as otherwise required to interface with CACWS.

The motor power supplies include static inverters to provide variable frequency control. Each motor is operated by an independent speed controller.

\subsubsection{Plant Protection (System 32)}

The Plant Protection System (PPS) includes all of the equipment from and including the sensors to the input terminals of the actuated devices that are involved in providing actions that lead to a function which provides protection to the public.

The Plant Protection System prevents any unacceptable releases of radioactivity which could constitute a hazard to the health and safety of the public by initiating actions to protect the fission product barriers and to limit the release of radioactivity if failures occur in the barriers. To accomplish these functions, the PPS provides systems to:

1. Initiate rapid reduction in power level following reactivity excursions, loss of adequate core cooling or other events in order to minimize the damage to fuel coating and preserve the integrity of the primary coolant system boundary. 
2. Limit the quantity of water that can leak into the PCRV following failures in the precooler in order to minimize damage to the fuel and protect the integrity of the PCRV (precooler isolating and dump sys tem).*

3. Prevent any damage to the PCSB that might result from turbomachine failure at excessive speeds (main loop shutdown system).

4. Initiate auxiliary core cooling following the loss of effective main loop cooling in order to preserve the integrity of or minimize the damage to the fuel coating and/or the PCSB (CACS initiation system).

5. Limit the maximum PCRV internal pressure in order to preserve the integrity of the PCSB (main loop shutdown system, reactor trip system, and safety bypass valve system).

6. Prevent simultaneous withdrawal of more than one control rod pair in order to restrict the possible reactivity excursions that can be initiated by control rod withdrawals (single control rod withdrawal interlock).

Table 3-12 presents a summary of the PPS protective functions. The table describes each protective function, the signals that initiate each function, the purpose of each function, and remarks concerning the system actions and/or interfaces involved in these protective functions.

\footnotetext{
* In the event of a leak in a precooler, the plant protection system and detection instrumentation protect against the release of primary coolant by isolating the precooler and dumping its water inventory to a surge tank.
} 
TABLE 3-12

SUMMARY OF PROTECTIVE FUNCTION OF THE PLANT PROTECTIVE SYSTEM

\begin{tabular}{|c|c|c|c|c|}
\hline $\begin{array}{l}\text { Protective } \\
\text { Function }\end{array}$ & $\begin{array}{l}\text { Initiating } \\
\text { Condition }\end{array}$ & Purpose & Remarks & $\begin{array}{l}\text { System Action/ } \\
\text { Interfaces }\end{array}$ \\
\hline $\begin{array}{l}\text { Reactor } \\
\text { Trip }\end{array}$ & $\begin{array}{l}\text { High reactor-power-to- } \\
\text { flow ratio at high } \\
\text { flow }\end{array}$ & $\begin{array}{l}\text { Prevent damage to core and } \\
\text { PCRV internals following } \\
\text { a power excursion or loss } \\
\text { of flow. }\end{array}$ & $\begin{array}{l}\text { Primary (primary } \\
\text { means designated } \\
\text { to provide princi- } \\
\text { pal protection } \\
\text { against a condi- } \\
\text { tion) }\end{array}$ & $\begin{array}{l}\text { 1.Drop all control } \\
\text { rods } \\
\text { 2. Initiate PCS } \\
\text { load reduction } \\
\text { (not required } \\
\text { for safety) } \\
\text { 3. Initiate main 1oop }\end{array}$ \\
\hline $\begin{array}{l}\text { Reactor } \\
\text { Trip }\end{array}$ & $\begin{array}{l}\text { High reactor power } \\
\text { at low flow }\end{array}$ & $\begin{array}{l}\text { Prevent damage to core and } \\
\text { PCRV internals following } \\
\text { a power excursion }\end{array}$ & Primary & $\begin{array}{l}\text { shutdown on "high } \\
\text { primary coolant } \\
\text { pressure" only } \\
\text { (internal pressure }\end{array}$ \\
\hline $\begin{array}{l}\text { Reactor } \\
\text { Trip }\end{array}$ & $\begin{array}{l}\text { High reactor flux } \\
\text { during refueling } \\
\text { or low-power } \\
\text { testing }\end{array}$ & $\begin{array}{l}\text { Prevent damage to core and } \\
\text { PCRV internals following a } \\
\text { power excursion }\end{array}$ & Primary & relief) \\
\hline $\begin{array}{l}\text { Reactor } \\
\text { Trip }\end{array}$ & $\begin{array}{l}\text { High helium tempera- } \\
\text { ture at the turbine } \\
\text { inlet }\end{array}$ & $\begin{array}{l}\text { Maintain integrity of pri- } \\
\text { mary coolant pressure } \\
\text { boundary and prevent } \\
\text { damage to core in the } \\
\text { event of power-to-flow } \\
\text { mismatches following a } \\
\text { power excursion or loss } \\
\text { of flow. }\end{array}$ & $\begin{array}{l}\text { Diverse backup for } \\
\text { reactor trip on high } \\
\text { reactor-power-to- } \\
\text { helium-flow ratio }\end{array}$ & \\
\hline $\begin{array}{l}\text { Reactor } \\
\text { Trip }\end{array}$ & $\begin{array}{l}\text { High primary cool- } \\
\text { ant pressure }\end{array}$ & $\begin{array}{l}\text { Limit primary coolant } \\
\text { pressure }\end{array}$ & Paimary & \\
\hline $\begin{array}{l}\text { Reactor } \\
\text { Trip }\end{array}$ & $\begin{array}{l}\text { High containment } \\
\text { radiation level }\end{array}$ & $\begin{array}{l}\text { Prevent damage to core and } \\
\text { PCRV internals following } \\
\text { reactor depressurization } \\
\text { into the containment }\end{array}$ & Primary & $*$ \\
\hline
\end{tabular}


TABLE 3-12 (Continued)

\begin{tabular}{|c|c|c|c|c|}
\hline $\begin{array}{l}\text { Protective } \\
\text { Function }\end{array}$ & $\begin{array}{l}\text { Initiating } \\
\text { Condition }\end{array}$ & Purpose & Remarks & $\begin{array}{l}\text { System Action/ } \\
\text { Interfaces }\end{array}$ \\
\hline $\begin{array}{l}\text { Reactor } \\
\text { Trip }\end{array}$ & $\begin{array}{l}\text { High containment } \\
\text { pressure }\end{array}$ & $\begin{array}{l}\text { Prevent damage to core and } \\
\text { PCRV internals following a } \\
\text { reactor depressurization } \\
\text { into the containment }\end{array}$ & $\begin{array}{l}\text { Diverse backup to } \\
\text { high containment } \\
\text { radiation level }\end{array}$ & \\
\hline $\begin{array}{l}\text { Reactor } \\
\text { Trip }\end{array}$ & $\begin{array}{l}\text { Loss of preferred } \\
\text { bus voltage }\end{array}$ & $\begin{array}{l}\text { Prevent damage to core and } \\
\text { PCRV internals following } \\
\text { loss of preferred power }\end{array}$ & Primary & \\
\hline $\begin{array}{l}\text { Reactor } \\
\text { Trip }\end{array}$ & $\begin{array}{l}\text { Two or more main } \\
\text { loop shutdown } \\
\text { signals }\end{array}$ & $\begin{array}{l}\text { Prevent damage in upper } \\
\text { plenum and prevent } \\
\text { reaching the high reactor } \\
\text { power-to-helium-flow limit }\end{array}$ & $\begin{array}{l}\text { Single loop shutdown } \\
\text { cannot result in ex- } \\
\text { cessive temperature } \\
\text { in the upper plenum }\end{array}$ & \\
\hline $\begin{array}{l}\text { Reactor } \\
\text { Trip }\end{array}$ & $\begin{array}{l}\text { Manual reactor } \\
\text { trip }\end{array}$ & $\begin{array}{l}\text { Allow reactor trip at } \\
\text { operator's discretion }\end{array}$ & & \\
\hline $\begin{array}{l}\text { CACS } \\
\text { Initia- } \\
\text { tion }\end{array}$ & $\begin{array}{l}\text { Low plant } \\
\text { helium flow }\end{array}$ & $\begin{array}{l}\text { Prevent damage to core } \\
\text { and PCRV internals fol- } \\
\text { lowing loss of primary } \\
\text { coolant flow }\end{array}$ & Primary & $\begin{array}{l}\text { 1. Initiate main } \\
\text { loop shutdown } \\
\text { 2. Commence startup } \\
\text { of all CACS loops }\end{array}$ \\
\hline $\begin{array}{l}\text { CACS } \\
\text { Initia- } \\
\text { tion }\end{array}$ & $\begin{array}{l}\text { Manual CACS } \\
\text { initiation }\end{array}$ & $\begin{array}{l}\text { Allow CACS initiation at } \\
\text { operator's discretion }\end{array}$ & . & \\
\hline $\begin{array}{l}\text { Main Loop } \\
\text { Shutdown }\end{array}$ & $\begin{array}{l}\text { High PCL exit } \\
\text { temperature }\end{array}$ & $\begin{array}{l}\text { Prevent damage to upper } \\
\text { plenum thermal barrier }\end{array}$ & Primary & $\begin{array}{l}\text { 1. Trip the Safety } \\
\text { Bypass Valve System } \\
\text { (SBVS) } \\
\text { 2. Initiate non-safety } \\
\text { reactor power set- } \\
\text { back (not required } \\
\text { for safety) }\end{array}$ \\
\hline
\end{tabular}


TABLE 3-12 (Continued)

\begin{tabular}{|c|c|c|c|c|}
\hline $\begin{array}{l}\text { Protective } \\
\text { Function }\end{array}$ & $\begin{array}{l}\text { Initiating } \\
\text { Condition }\end{array}$ & Purpose & Remarks & $\begin{array}{l}\text { System Action/ } \\
\text { Interfaces }\end{array}$ \\
\hline $\begin{array}{l}\text { Mair: Loop } \\
\text { Shutdown }\end{array}$ & $\begin{array}{l}\text { High turbomachine } \\
\text { speed }\end{array}$ & $\begin{array}{l}\text { Limit peak turbomachine } \\
\text { speed to within design } \\
\text { limits of the burst- } \\
\text { shield }\end{array}$ & Primary & $\begin{array}{l}\text { 1. Trip the SBVS } \\
\text { 2. Initiate non- } \\
\text { safety reactor } \\
\text { power setback (not } \\
\text { required for safety }\end{array}$ \\
\hline $\begin{array}{l}\text { Main Loop } \\
\text { Shutdown }\end{array}$ & CACS initiation & $\begin{array}{l}\text { To allow proper function- } \\
\text { ing of CACS }\end{array}$ & & \\
\hline $\begin{array}{l}\text { Mair: Loop } \\
\text { Shutdown }\end{array}$ & $\begin{array}{l}\text { Precooler isolation } \\
\text { and dump }\end{array}$ & $\begin{array}{l}\text { Prevent damage to } \mathrm{PCL} \\
\text { components }\end{array}$ & Followup action & \\
\hline $\begin{array}{l}\text { Main Loop } \\
\text { Shutdown }\end{array}$ & $\begin{array}{l}\text { Detection of PCS } \\
\text { main loop trip } \\
\text { failure }\end{array}$ & $\begin{array}{l}\text { Discretionary loop } \\
\text { shutdown }\end{array}$ & Followup action & \\
\hline $\begin{array}{l}\text { Main Loop } \\
\text { Shutdown }\end{array}$ & $\begin{array}{l}\text { Manual loop shut- } \\
\text { down }\end{array}$ & $\begin{array}{l}\text { To allow shutdown at } \\
\text { operator's discretion }\end{array}$ & & \\
\hline $\begin{array}{l}\text { Main Loop } \\
\text { Shutdown } \\
\text { All Loops }\end{array}$ & $\begin{array}{l}\text { Isolation and dump } \\
\text { of both halves of } \\
\text { any precooler }\end{array}$ & $\begin{array}{l}\text { Prevent dryout of pre- } \\
\text { cooler and consequent } \\
\text { overtemperature of } \\
\text { thermal barrier/liner and } \\
\text { damage to turbomachinery }\end{array}$ & & . \\
\hline $\begin{array}{l}\text { Precooler } \\
\text { Isolation. } \\
\text { and Dump }\end{array}$ & $\begin{array}{l}\text { High activity in } \\
\text { precooler water } \\
\text { outlet line }\end{array}$ & $\begin{array}{l}\text { Limit fission product } \\
\text { release following a } \\
\text { failure in a precooler }\end{array}$ & Primary & $\begin{array}{l}\text { 1. Close isolation } \\
\text { valves ( } \frac{1}{2} \text { pre- } \\
\text { cooler) }\end{array}$ \\
\hline $\begin{array}{l}\text { Precooler } \\
\text { Isolation } \\
\text { and Dump }\end{array}$ & $\begin{array}{l}\text { Manual precooler } \\
\text { isolation dump }\end{array}$ & $\begin{array}{l}\text { Allow precooler isolation } \\
\text { and dump at operator's } \\
\text { discretion }\end{array}$ & & $\begin{array}{l}\text { 2. Open dump valves } \\
\text { ( } 1 / 2 \text { precooler) } \\
\text { 3. Initiate main loop } \\
\text { trip }\end{array}$ \\
\hline $\begin{array}{l}\text { Single } \\
\text { Control } \\
\text { Rod Pair } \\
\text { Withdrawal } \\
\text { Interlock }\end{array}$ & $\begin{array}{l}\text { Deteztion of outward } \\
\text { command to two or } \\
\text { more control rod } \\
\text { pairs }\end{array}$ & $\begin{array}{l}\text { Prevent simultaneous } \\
\text { withdrawal of two or } \\
\text { more control rod pairs }\end{array}$ & & $\begin{array}{l}\text { Block motor controller } \\
\text { output to rod drive } \\
\text { mators }\end{array}$ \\
\hline
\end{tabular}




\subsubsection{Plant Conitrol (System 33)}

Figure 3-4 illustrates the plant model used in control studies and analysis. Turbine speed and electrical load are regulated by a bypass valve in each power conversion loop, which bypasses helium from the reactor inlet to turbine discharge. Load is controlled by this regulation in combination with automatic reactor outlet temperature control and manually initiated helium inventory control. * Load control by helium inventory or reactor outlet helium temperature control offers improved part-load efficiency relative to the use of bypass valve control. Reactor outlet helium temperature is regulated by the adjustment of control rods to regulate reactor power. The optimum combination of these modes of control will be determined as the plant design is developed.

\subsubsection{Plant Control System (PCS) Description. The PCS is designed to} regulate reactor power and to control electrical load, turbine speed, temperature of the helium delivered to the turbine, and thermal transients experienced by the power conversion loop (PCL) and reactor components.

The PCS gives the plant the capability of continuous operation under fully automatic control at any point between $100 \%$ and $25 \%$ rated $10 a d$. In addition, the PCS provides automatic load-following control capabilities for the various rates of electrical load changes, as discussed in Section 2.5.

To perform the PCS functions, several plant variables require manipulation by closed-1oop controllers. These are:

1. Turbine inlet temperature

2. Electrical power and turbomachine - generator shaft speed

3. High-pressure recuperator exit temperature ${ }^{* *}$ and low-pressure recuperator inlet temperature ${ }^{* *}$

4. Compressor surge margin

*Automatic helium inventory control may be implemented pending helium handling system development and justification of cost.

${ }^{* *}$ Active during bypass valve operation and for component protective action. 


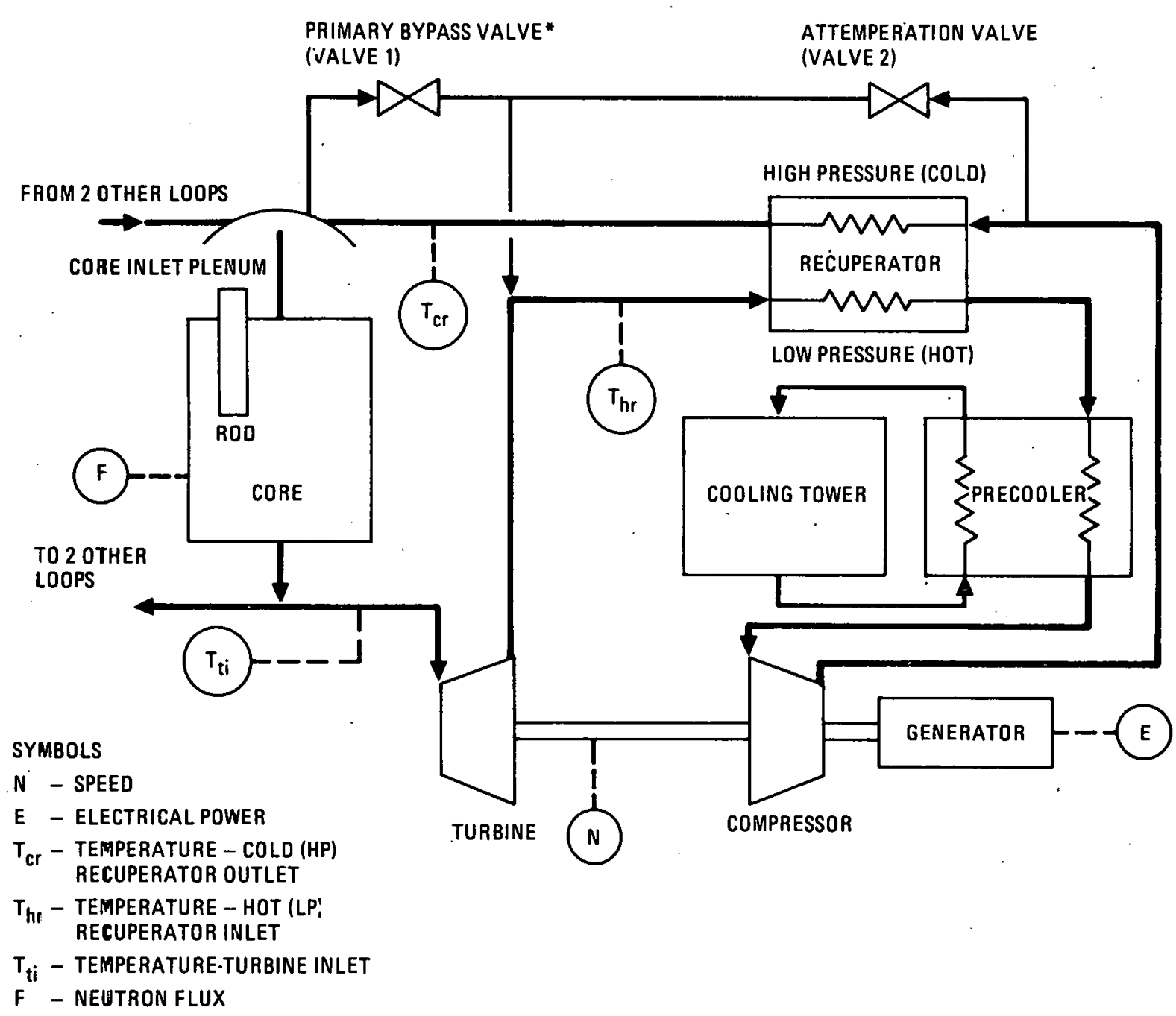

* the safety valve and the trim Valve are at this schematic position also.

Fig. 3-4. Plant schematic showing location of major plant parameters 
Figures 3-4 and 3-5 show the location of each manipulated variable and the load-following part of the PCS, respectively.

The control system operates the reactor control rods, producing reactivity changes to control reactor power and turbine inlet temperature. In addition, the control system operates the trim and primary bypass valves in each loop to control turbomachine shaft speed variations in response to electrical load fluctuations, and the attemperation valve in each loop to control thermal transients in PCL components. These valves are controlled independently in the three loops.

Desired electrical power $\left(E_{\mathbb{D}}\right)$ is the primary input to the control system; from this demand, the scheduled turbine inlet temperature is computed. Both of these quantities are then used to compute reactor power and control bypass valve system (CBVS) setpoints. Below full power, turbine inlet temperature is nominally scheduled in a manner that will allow a minimum of $10 \%$ of full electrical load to be picked up by actuating the CBVS. Reactor outlet temperature or helium inventory control may be used to maintain high plant efficiency below full power conditions.

The reactor neutron flux (F) and the valve setpoints have been obtained for steady-state conditions over the full operating range of the plant. The inclusion of these setpoints as feed-forward signals provides anticipatory control and, therefore, rapid response to changes in load demand. The regulation of the closed-1oop temperature and load/speed controllers is limited such that no major system transient can be caused by a failure of one of these controllers.

Helium inventory change to increase part load efficiency is currently designated as a manual operation. The automatic controls remain compatible with this manual option.

There are three automatic control loops and two supplementary control functions which are described in more detall below. 


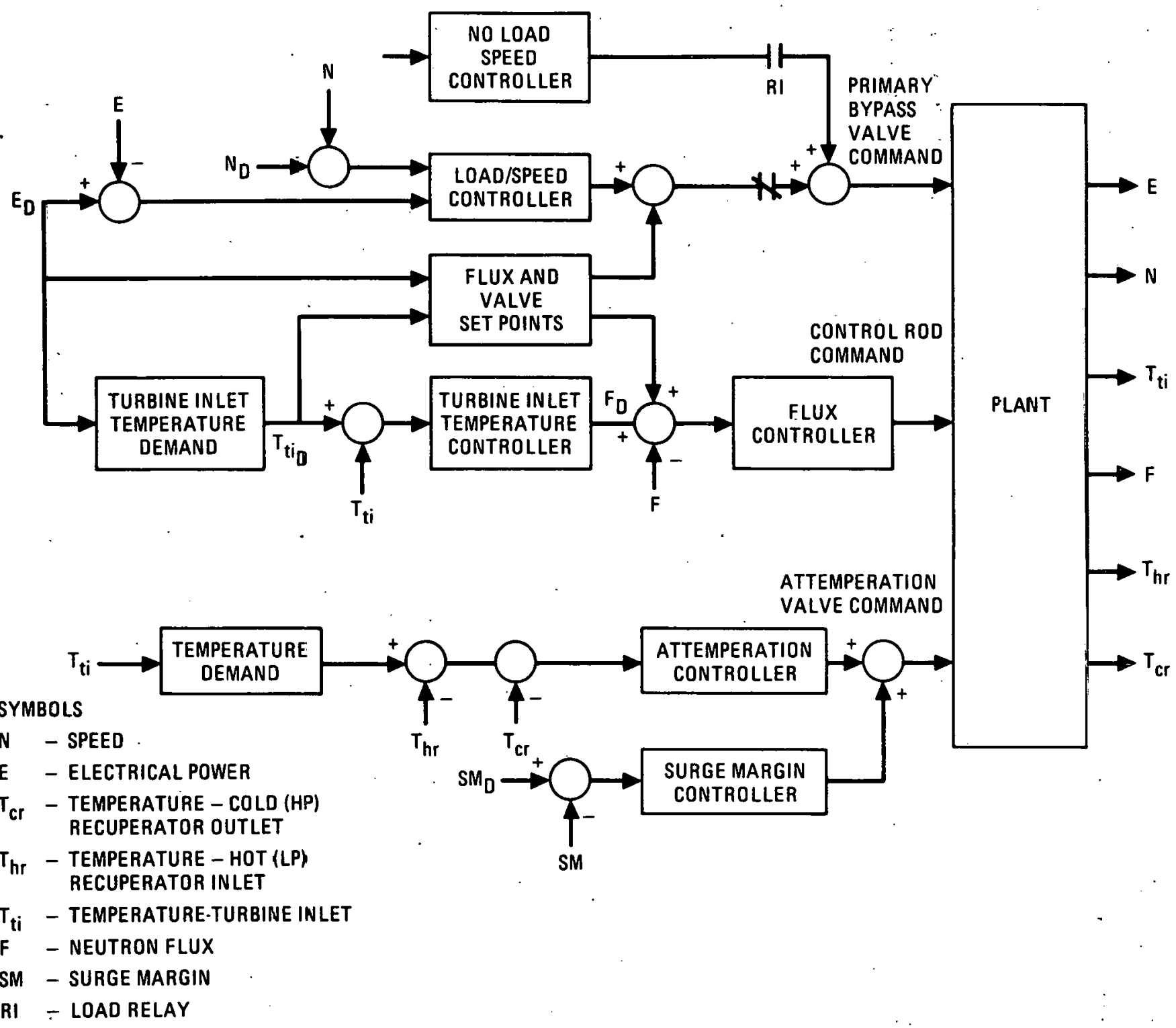

Fig. 3-5. Plant control system 
3.4.13.2. Turbine Inlet Temperature Control. The average inlet temperature of the turbines of the operating PCLs is controlled throughout the normal load range by adjustment of reactor power via the turbine inlet temperature controller, which provides a command signal to the reactor neutron flux controller. The neutron flux controller adjusts the position of the control rods to vary reactor power and, thus, the heat transferred to the helium.

The temperature control loop consists of a proportiona1-plus-integralplus-deviation (PID) controller with limited output. The limits have been chosen to prevent control-system-induced power transients from causing any unintentional reactor trip.

The flux controller provides commands to the rod control system to. regulate control rod position. The controller maintains the neutron flux as measured by an average of up to six out-of-core neutron detectors to within a prescribed tolerance about either a locally adjusted setpoint or a remotely controlled setpoint provided by the turbine inlet temperature controller. The flux controller consits of an on-off type of element with hys teresis.

In addition, the: neutron flux controller issues a runback signal to the rod control system to provide automatic shim action on several rods whenever a large load reduction occurs. The PCS initiates rod insertion whenever the reactor average flux exceeds the setpoint by more than $10 \%$. The runback control output will not reset until the deviation is reduced to $4 \%$.

\subsubsection{Electrical Power and Turbine Speed Control. The control system} uses the primary bypass valves to provide the coarse control necessary to establish an operating point for large load changes. The trim valves are used to provide fine control for load and speed resolution about the established operating point. Actuation of either the primary bypass valves or the trim valves causes partial diversion of helium from the core inlet plenum to the low-pressure recuperator inlet, thus reducing turbine drive by reducing the turbine pressure ratio, and consequently, the turbine flow. 
The turbine inlet temperature control subsequently operates to adjust the bypass control to its minimum level at reduced loads.

Gains and limiters in the controller are set to limit excursions about the setpoints to values compatible with $10 \%$ step load changes.

3.4.13.4. Attemperation Control. Thermal transients experienced by. PCL and reactor components are controlled in each loop throughout the normal load range by the attemperation controller. The controller manipulates the highpressure recuperator exit and low-pressure recuperator inlet temperature to a demanded value that is a programmed function of average turbine inlet temperature. Control is accomplished by actuation of the attemperation valve, diverting helium flow from the compressor exit to the turbine exit. The controller forces the sum of the two measured temperatures to a demanded value.

The temperature demand signal is designed to hold the attemperation valve closed under normal operating conditions. The command signal is nominally rate-limited to $1^{\circ} \mathrm{F} / \mathrm{sec}$ to control the rate of change of temperature that components experience. The remainder of the loop consists of a proportional-plus-integral (PI) controller with limiters to prevent integrator saturation.

3.4.13.5. No-Load Turbomachine Speed Control. Direct control of turbomachine speed in each loop is required for plant startup or shutdown, controller manual or automatic shutdown, synchronization, and overspeed protection. In these instances, turbomachine speed is controlled by the no-load speed controller. The controller commands actuation of the primary bypass and trim valves to maintain speed at a demanded value. This demanded value may be a fixed setpoint, as in the event of loss of load with return to idle, or it may be a programed ramp profile for purposes such as plant startup. 
3.4.13.6. Surge Margin Control. The surge margin controller in each loop prevents reduction of compressor surge margin below a setpoint. Control is accomplished by actuation of the attemperation valve. Opening of this valve increases the compressor surge margin. The measurement of surge margin for the control is not feasible in terms of measuring and processing "real" parameters. Direct measurement of the compressor inlet pressure and pressure rise, however, can be translated into pressure ratio and related to surge margin for control purposes.

\subsubsection{Component Operational Protection. In addition to accommodating} the plant system perturbations that result from normal load changes, the PCS acts to provide component operational protection by detecting out-ofbound parameters and initiating actions to limit conditions imposed on the system during loop trip or electrical load rejection. Under these conditions, reactor power and helium flow are regulated to minimize any temperature transients imposed on the PCL and reactor components.

On detection of conditions which could lead to a requirement for an overspeed protection or a main loop trip, the PCS initiates a reconfiguration of the control mode and a modification of control system demand levels; thus, the no-load speed controller prevents the turbomachine rotational speed from increasing to a point that would result in actuation of the plant protection system (PPS) overspeed protection.

The PCS will assist in any PPS inftiated actions to minimize system requirements. Proper PPS operation, however, does not depend on any part of the PCS.

3.4.13.8. Startup and Shutdown Operation. The PCS provides proper management of the systems required for normal plant and loop startup and shutdown. Manually initiated and automatically sequenced commands are issued to the turbine speed, turbine inlet temperature, and attemperation controllers to perform the startup and shutdown functions. 
Startup involves motoring of the generator through a Static Frequency Converter (SFC) from zero speed up to a speed (approximately 950 to $1000 \mathrm{rpm}$ ) where the turbomachine is self sustaining. Motoring of the generator through the SFC may also be used to extend normal main loop cooling beyond the point where the afterheat generation and temperature of the core have become insufficient for self-sustained operation. The operation of the SFC is limited, however, to low speed operation at reduced helium inventory based on limited power capability of the SFC.

\subsubsection{Plant DAP (System 35)}

The Data Acquisition, Processing and Display (DAP) System is a dualcomputer-based interface between the plant instrumentation and the plant operator. Redundancy of computers and critical peripheral equipment is used for maximum availability.

This system converts certain instrument signals to engineering units, tests for alarm conditions, and provides visual and audible alarms, periodic logs, point trending, sequence of event recording, post-trip review, and displays of various operator information and procedural instructions on multicolor cathode ray tubes (CRTs). Various applications programs are executed in the system computers to provide operational or plant performance information. Categories of these applications programs are:

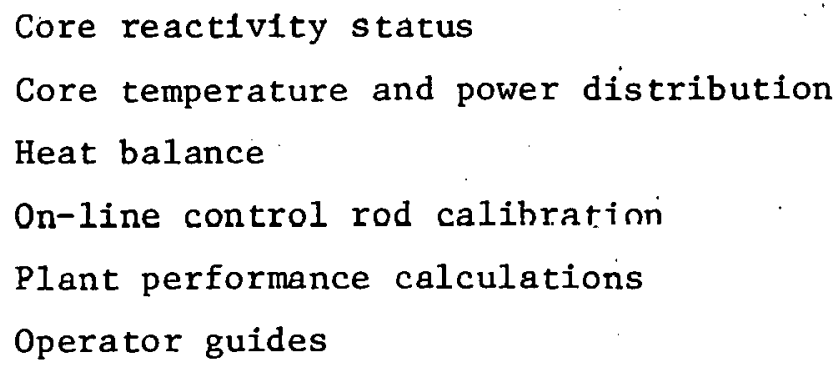




\subsection{BALANCE OF PLANT}

The proposed balance of plant (BOP) work on plant arrangement and system design was conducted to ensure the proper integration of the RTS with the total plant and to support the cost estimate.

\subsubsection{General Plant Arrangement (Fig. 3-6 through 3-15)}

Assumptions forming the basis for plot and arrangement are:

1. Grade Elevation is 0 .

2. Bedrock is $\mathrm{E} 1 .-50^{\prime}$.

3. Site has both road and rail access.

4. Forced draft cooling towers are utilized for the ultimate heat sinks of the core auxiliary cooling system and nuclear service water system.

5. Natural draft dry cooling tower is utilized for the precooler heat sink.

Basis for the building arrangements is similar to the HTGR steam cycle technology with the main difference being in the containment building.

The HTGR-GT utilizes electric generators and turbomachines that require access and removal through grade level penetrations in the containment. Horizontal removal of this equipment is attained by an air-pallet method that requires surfaced runways linking all turbomachine/generator access to an on-site maintenance facility. Access routes for the turbomachine/generator dictate a minimum distance for handling; which is also true for the electrical bus proximity to the switchyard. A penetration building is utilized to allow routing of vital electrical system cabling and other essential system equipment in close proximity to the containment. 


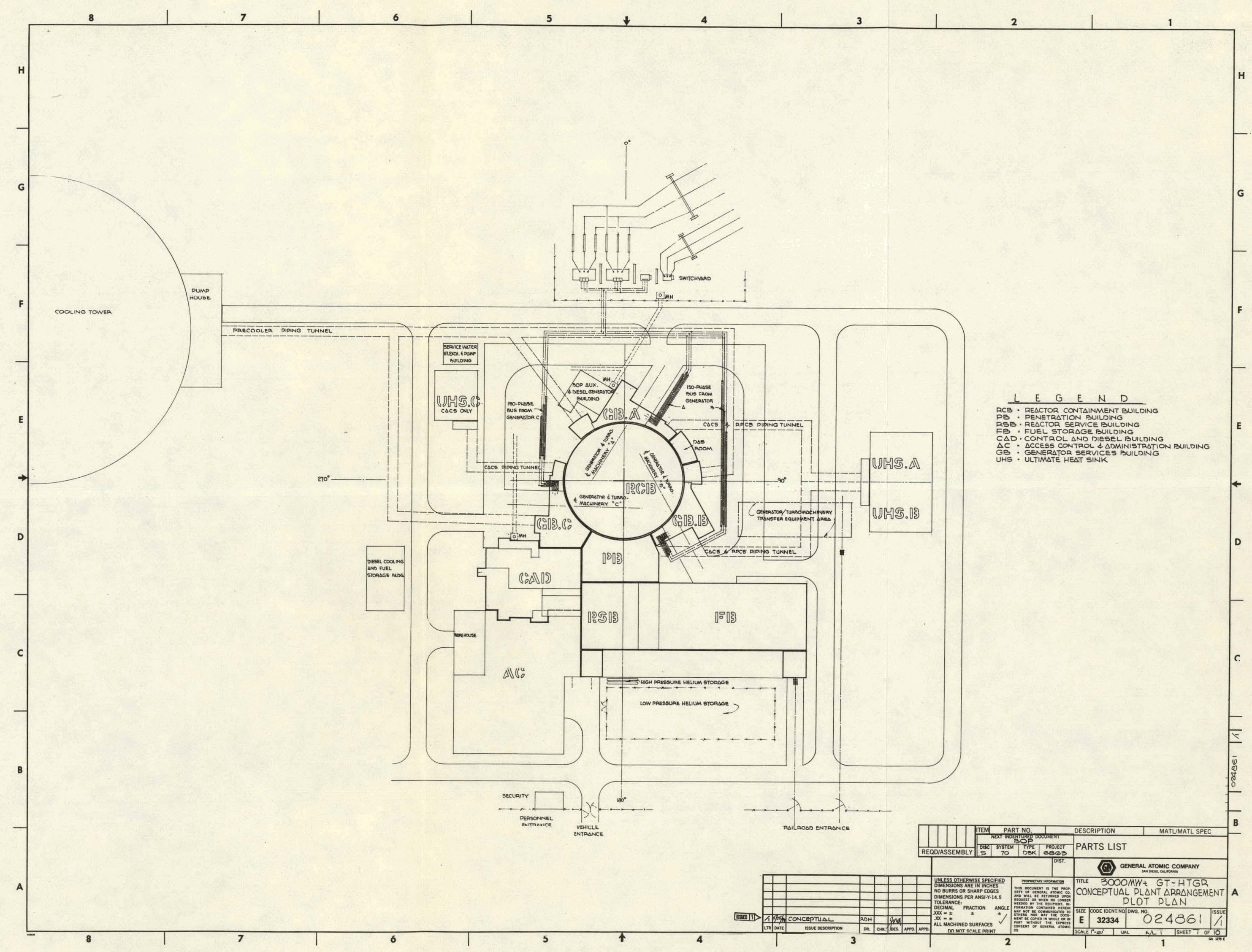

Fig. 3-6 
THIS PAGE

\section{WAS INTENTIONALLY LEFT BLANK}




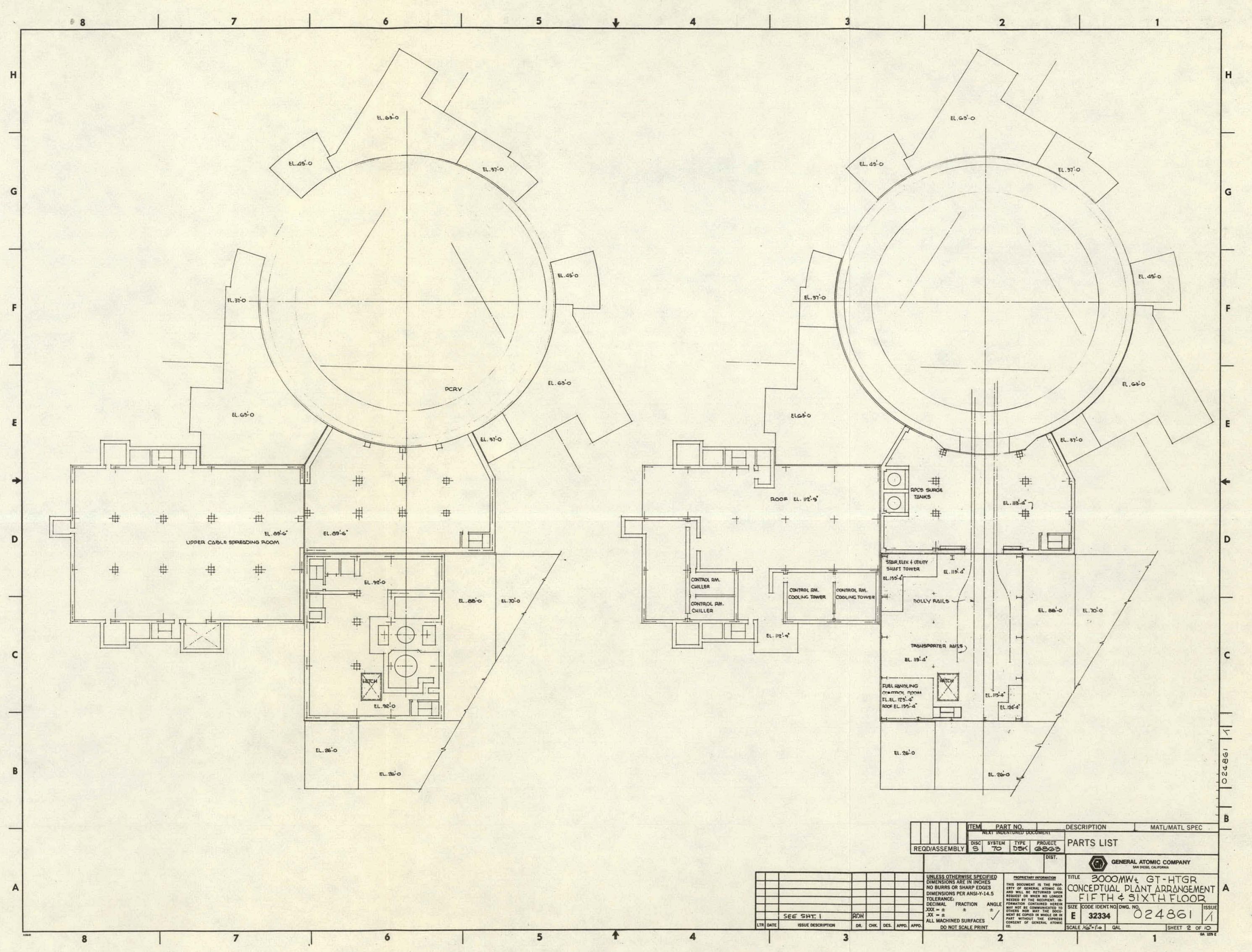

Fig. 3-7 
THIS PAGE

\section{WAS INTENTIONALLY LEFT BLANK}




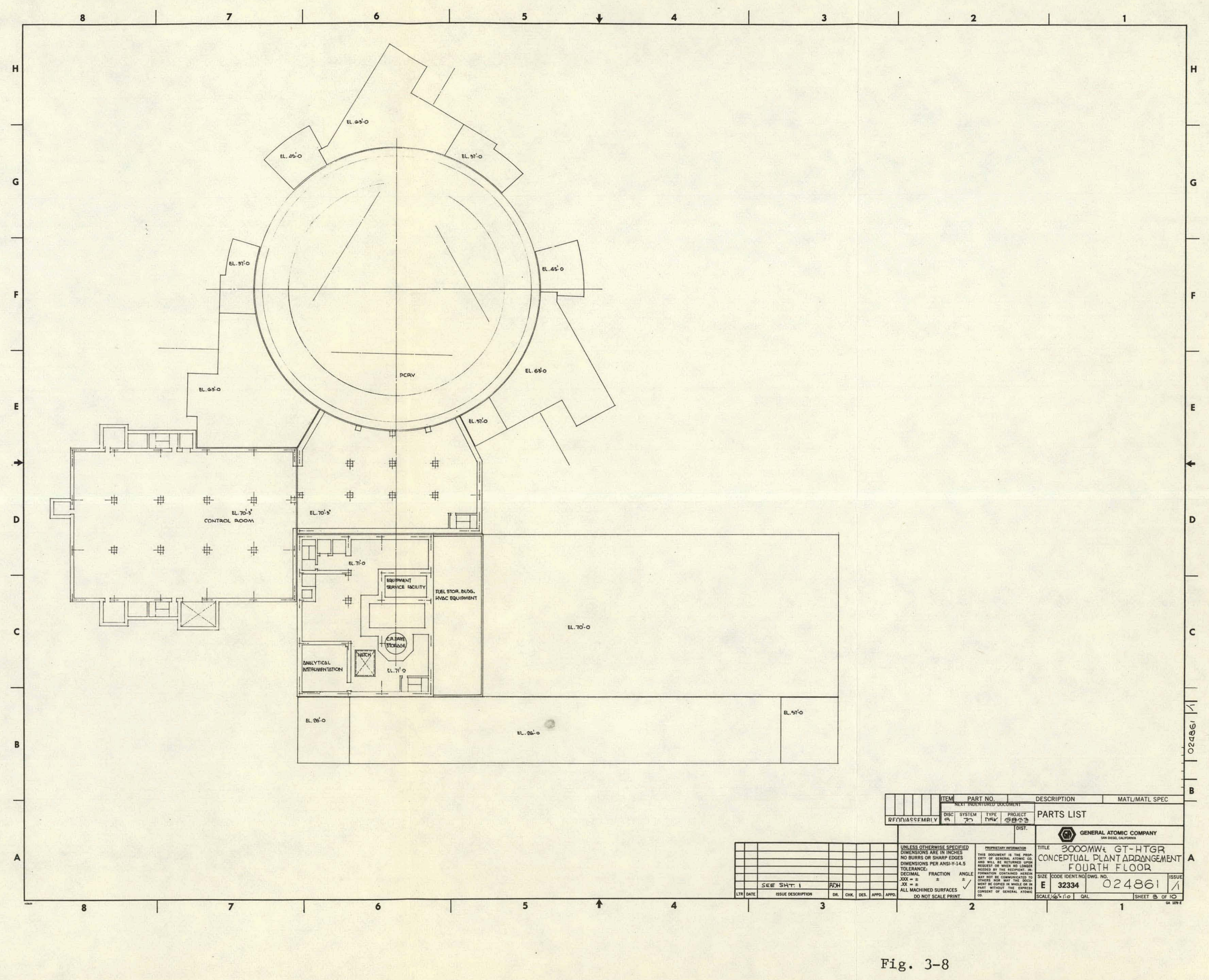


THIS PAGE

\section{WAS INTENTIONALLY LEFT BLANK}




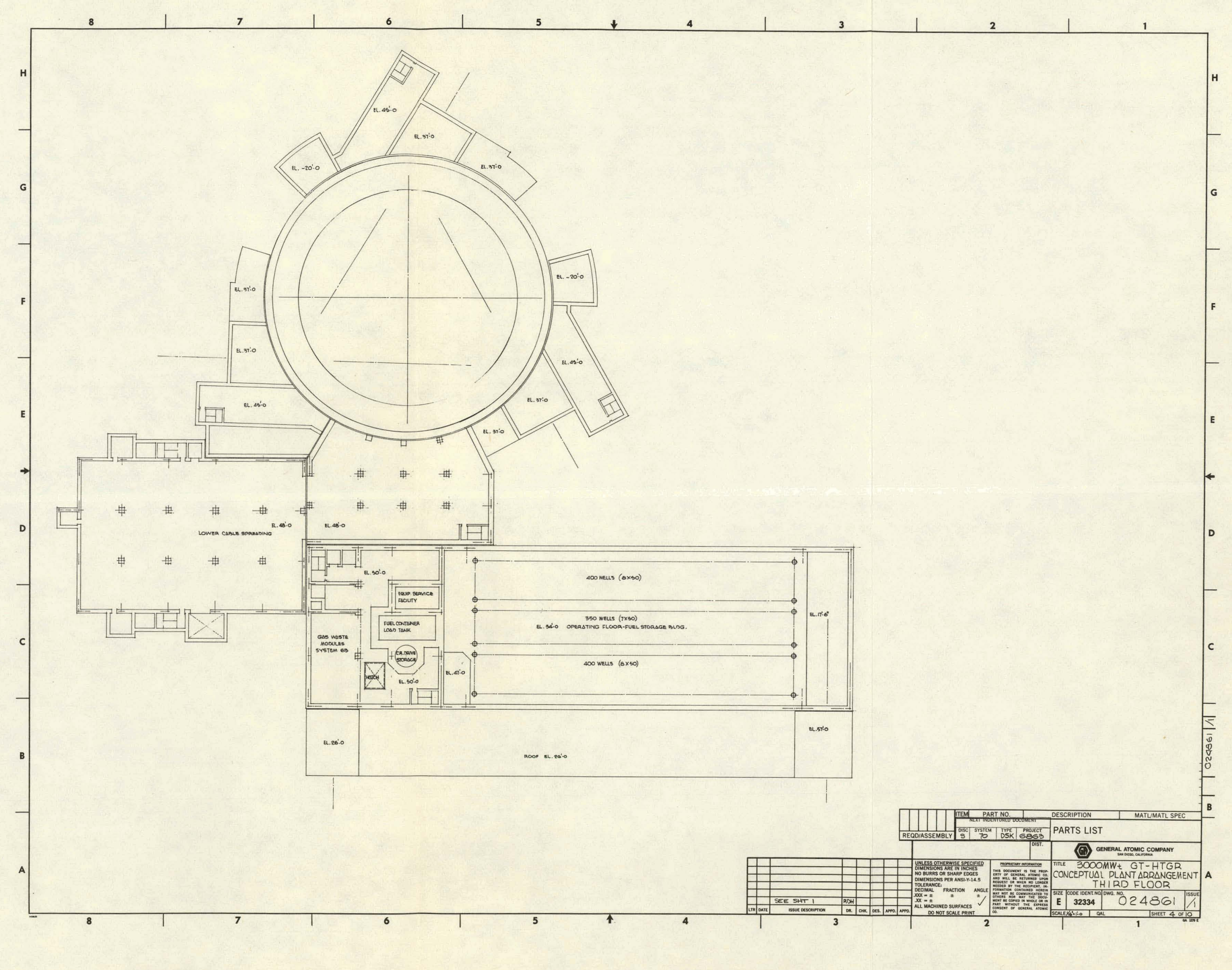

Fig. 3-9 
THIS PAGE

\section{WAS INTENTIONALLY LEFT BLANK}




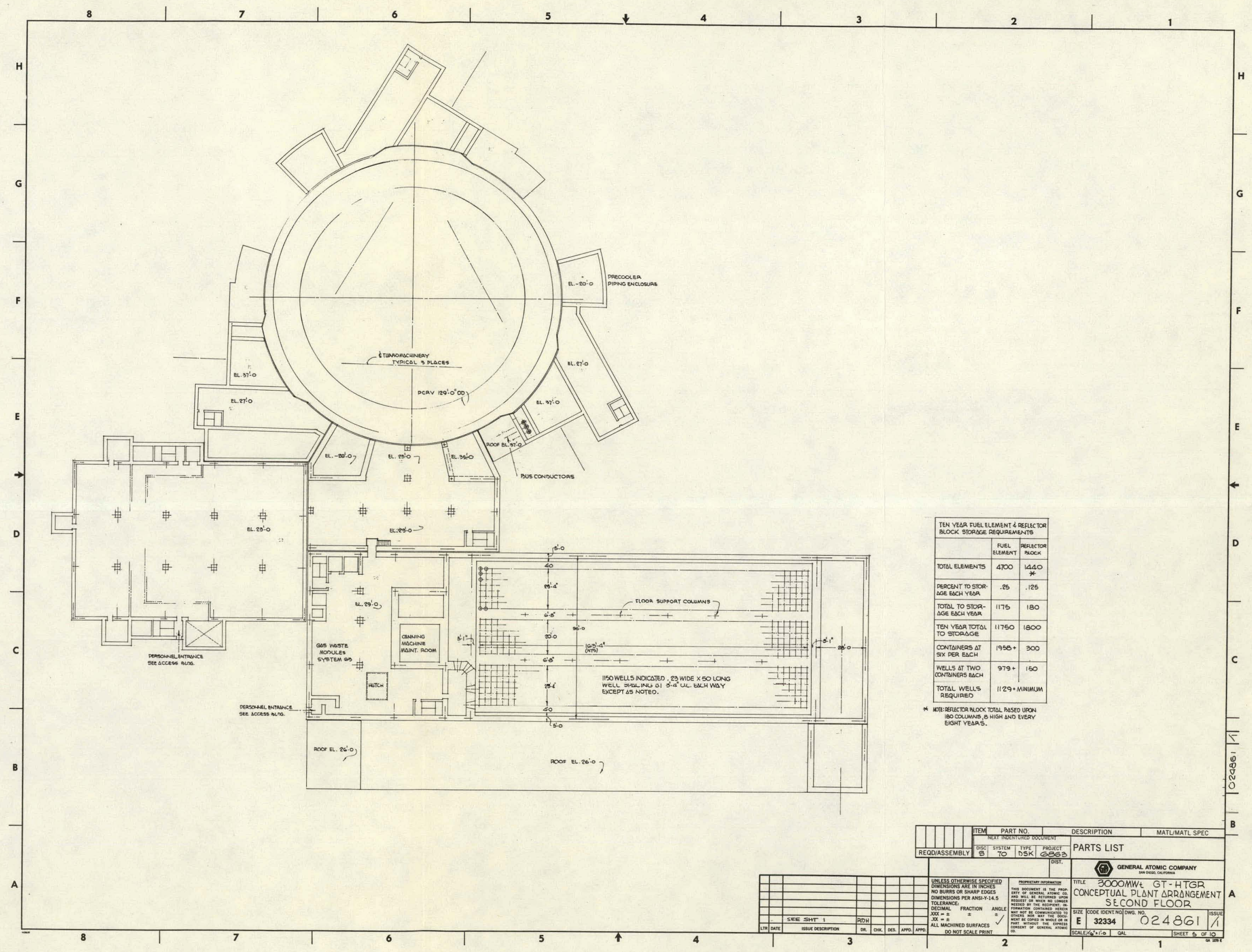

Fig. 3-10 
THIS PAGE

\section{WAS INTENTIONALLY LEFT BLANK}




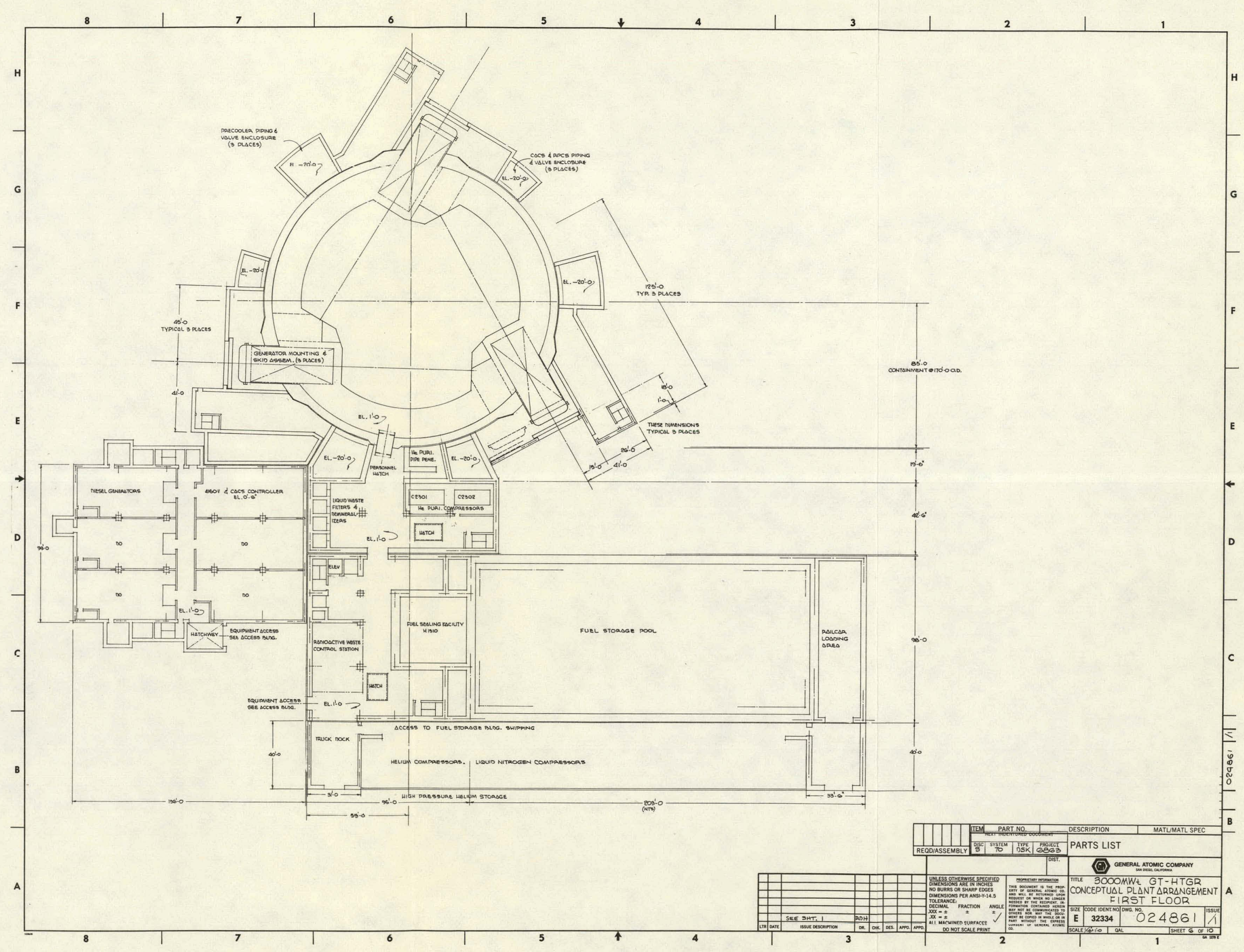

Fig. 3-11 
THIS PAGE

\section{WAS INTENTIONALLY LEFT BLANK}




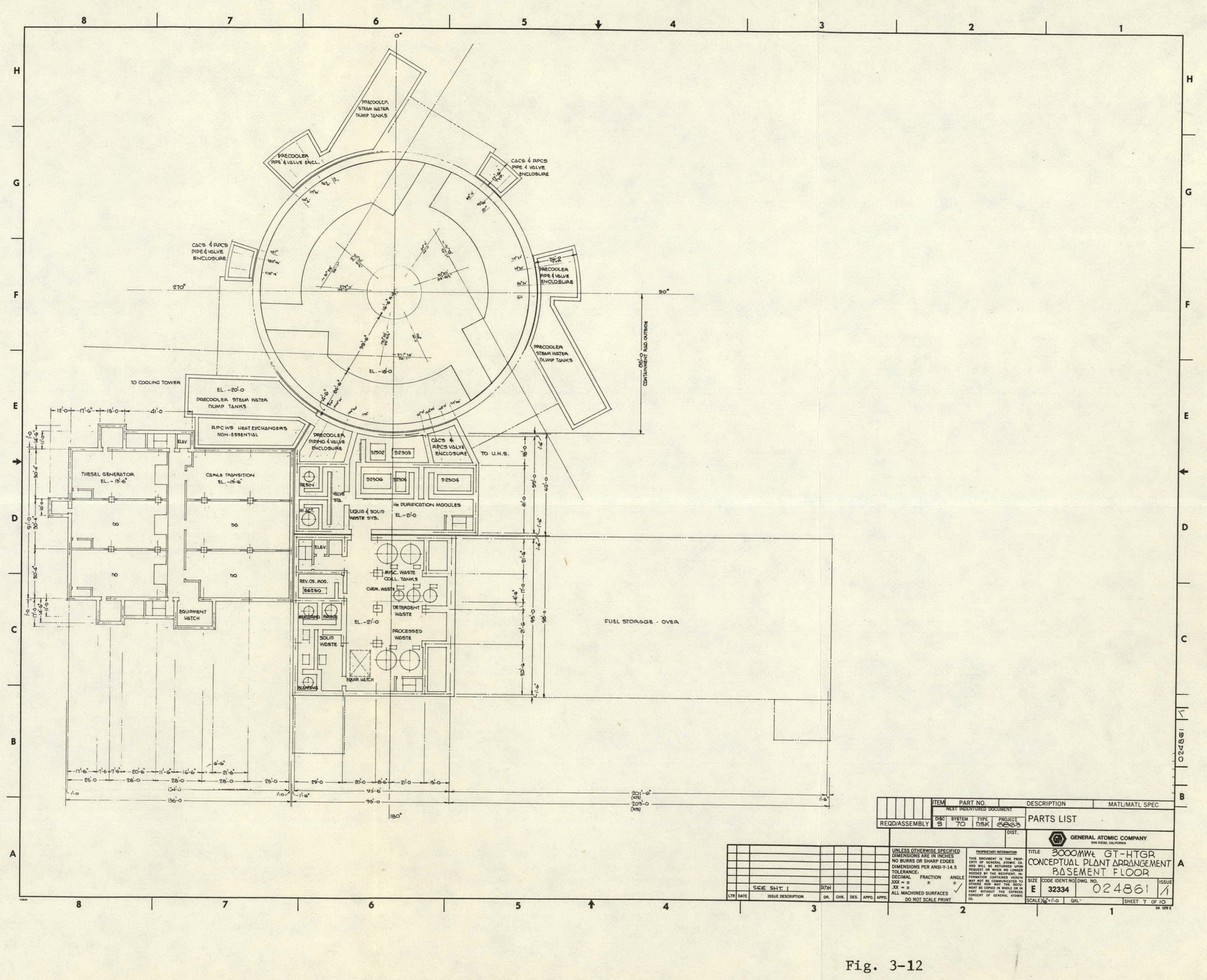


THIS PAGE

\section{WAS INTENTIONALLY LEFT BLANK}




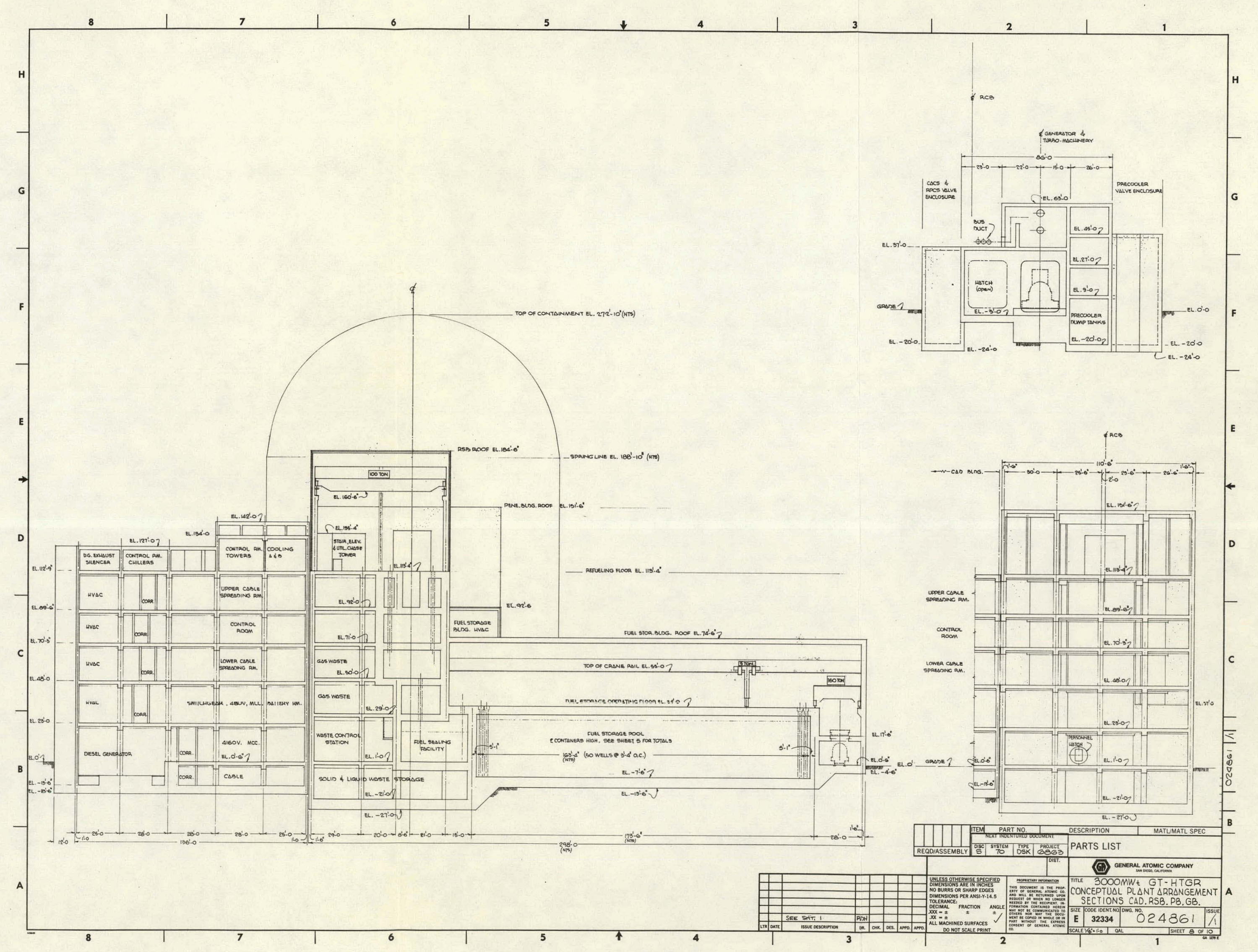

Fig. 3-13 
THIS PAGE

\section{WAS INTENTIONALLY LEFT BLANK}




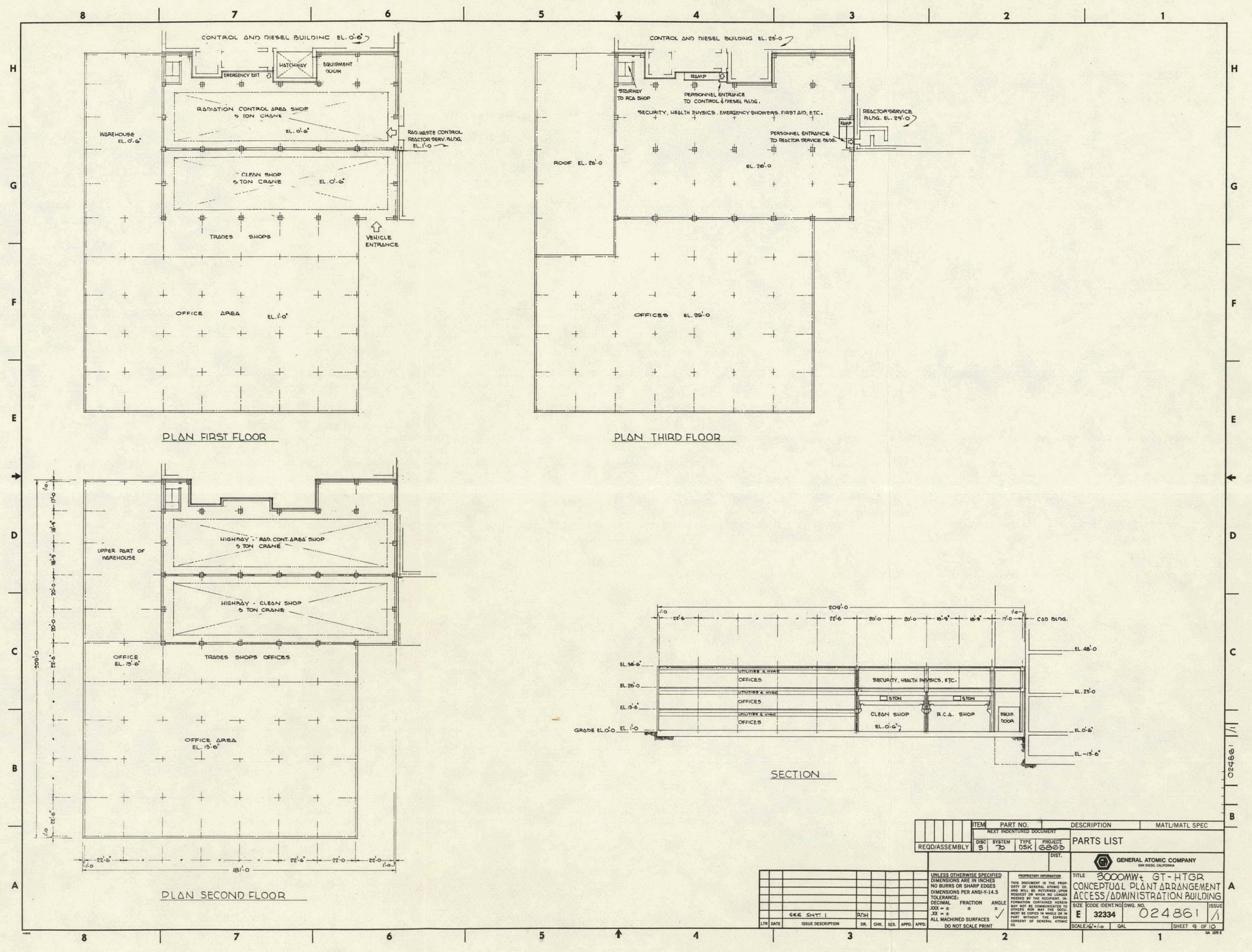


THIS PAGE

\section{WAS INTENTIONALLY LEFT BLANK}




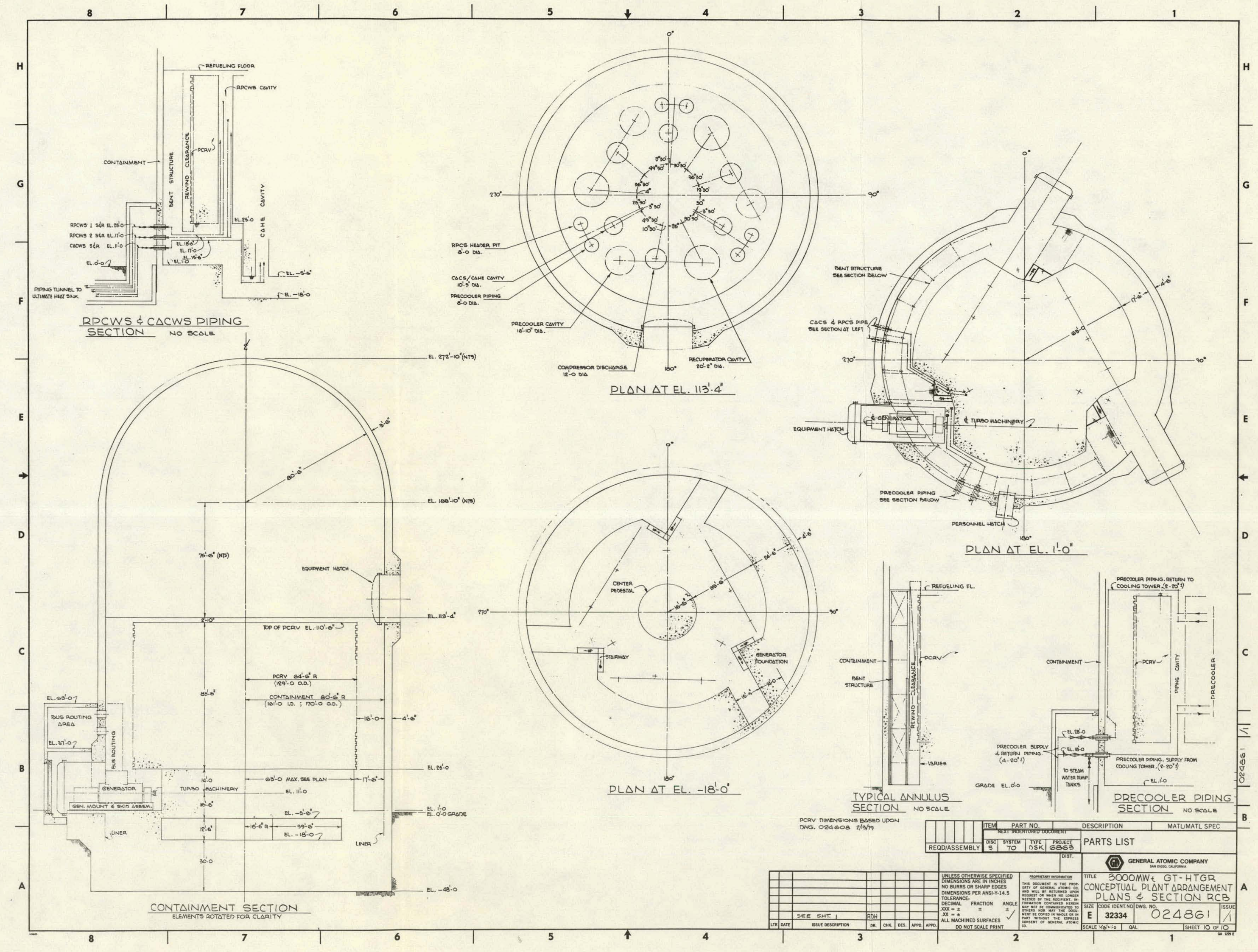

Fig. $3-15$ 
THIS PAGE

\section{WAS INTENTIONALLY LEFT BLANK}


Two of the ultimate heat sinks combine NSWS and CACWS systems as used in the SC-HTGR; the other cooling tower is CACWS only.

Three underground circulating water piping systems from the precoolers are routed from the reactor to the common recirculating pump house. Piping is then routed to the natural draft cooling tower and back to the precoolers.

Specific structures include:

1. Reactor Containment Building

2. Penetration Building

3. Reactor Service Building

4. Control, Auxiliary, and Diesel Building (CAD)

5. Fuel Storage and Shipping Building

6. Access Control and Administration Building

7. Diesel Cooling and Oil Storage Building

8. NSWS Cooling Tower

9. CACWS Only Cooling Tower

10. Service Water Wet Cooling Tower

11. Circulating Water Pump House

12. Main Natural Draft Cooling Tower

3:5.1.1. Reactor Containment Building. At this point in time, design pressure of the containment has not been established. Therefore, a reinforced concrete structure was assumed. Previous analysis has shown reinforced concrete structure limitations are approached near 62 psig.

The reactor containment building is a Category I cylindrical, reinforced concrete, steel lined structure with a hemispherical dome. The

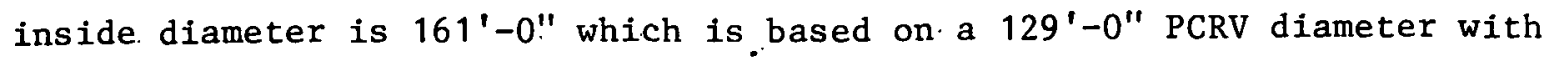
a $16^{\prime}-0^{\prime \prime}$ annulus all around. The vertical cylindrical wall is $188^{\prime}-10^{\prime \prime}$ high and $4^{\prime}-6^{\prime \prime}$ thick. The inside of the dome is $80^{\prime}-6^{\prime \prime}$ radius and $3^{\prime}-6^{\prime \prime}$ thick. 
The containment is supported on a $30^{\prime}$ thick reinforced concrete mat approximately $170^{\prime}-0^{\prime \prime}$. in diameter. The PCRV is supported integrally with the containment through a central core and three outer, seven feet thick, concrete membrane supports. The $16^{\prime}-0^{\prime \prime}$ annulus is derived from an initial wire-winding clearance of $8^{\prime}-0^{\prime \prime}$ plus a structural steel bench structure that supports HVAC, cable trays and auxiliary system equipment around the PCRV.

Fuel handling and equipment maintenance is accomplished by means of the special dual capability fuel handling crane system. This eliminates the need for a polar crane normally employed for this purpose.

The electrical generators are coupled to the turbomachines at grade. The generators are located in pressure vessels that are part of the containment pressure barrier which protrudes outward from the containment in three places. These vessels are fitted with pressure closure doors for generator/ turbomachine removal or access. Each pressure vessel is protected by a Category I, Safety Class 2, reinforced concrete structure with a removable, missile-proof door. These structures are separated from the containment proper by an elastomer membrane. The structural support for the generator is integral with the pressure barrier extension:

Each generator is permanently mounted to an air pallet frame. Removal or access to the turbomachine requires, 1) removal of the missile and pressure doors to one side, 2) uncoupling of the generator, which is "floated" out of the way, 3) removal of the turbomachine concrete plug, and 4) insertion of an air-pallet mounted removal cask into which the turbomachine is pulled for removal to the maintenance facility. Auxiliary equipment for the generator and turbomachine is located within the containment. Electrical auxiliaries for the generators are housed in the protective structure covering each pressure vessel over the generators. Adjacent to one of the generator missile structures is located, switchgear and an auxiliary diesel generator for BOP emergency functions. (Not to be confused with the three diesel generators located in the $\mathrm{CAD}$ Building.) 
The elevation of the surfaced runway for air pallet handling determines the containment elevation, as access to the machinery must be. at grade.

Adjacent to each generator is a compartment housing steam water dump tanks. for each precooler. The inventory of each precooler circuit dictates the volume of the tanks.

The iso-phase bus-duct connections off each generator, penetrate the containment above each generator, and proceed horizontally to connect to the remaining two generators. The iso-phase bus-duct is supported on an elevated structure. Connections are made that route the iso-phase duct to the switchyard. (See Section 9.6.2 for a discussion of the containment penetrations.)

Access to the containment for refueling is attained through an access hatch at the refueling floor level (E1. 113'-4') that allows the rail mounted fuel transfer casks to travel over the penetration building between the containment and the reactor service building.

A personnel air-lock is provided in the lower portion of the containment connecting with the penetration building.

Electrical cable trays penetrate the containment building wall adjacent to the penetration building. Three division separation of cables is maintained to satisfy the two-out-of-three logic utilized for safety, and electrical supply required per 10CFR50 requirements.

HVAC equipment is located on platforms above the refueling floor and at other intermediate levels.

Hydraulic actuation modules for the bypass control, safety, trim, and attemperation valves in the PCRV ( 4 per loop), are located in the annular bench structure surrounding the PCRV. Pull space and maintenance access are provided for these modules. 
Stair towers and an elevator provide vertical access to platforms within the containment.

3.5.1.2. Penetration Building. The penetration building is a Category I, reinforced concrete structure $110^{\prime} \times 62^{\prime} \times 172^{\prime}$ high that abutts the containment at the refueling access region. It provides an area for routing control and electrical systems to the control building and the required separation dictated by 10 CFR50 requirements. In addition, the multilevel structure provides location for helium purification system modules requiring close proximity to the containment structure. Rad liquid and solid waste tankage is also located here, as are RPCS surge tanks. Remote safe shutdown can be controlled from here and the building HVAC systems are housed within the structure also.

The refueling equipment rail system passes through the building at the refueling fioor level dictating that the structure must be missile-proof for the containment entrance. A personnel access hatch is provided at a lower elevation (El. 1'-0") to allow personnel to enter the lower levels of. the containment.

\subsubsection{Reactor Service Building. The reactor service building is a} Category I, Safety Class 2 structure from the basement to refueling floor. Above the refueling floor to roof is non-category and non-safety class structure. It is a multilevel structure providing for control rod drive storage, fuel container loading equipment, spent fuel sealing, general storage and maintenance of refueling equipment during reactor operation, gas waste storage and process equipment, equipment servicing facility, fuel handling control, radwaste control, and solid/liquid waste process equipment.

The refueling floor is located at E1. 113'-4" with intermediate floors spaced between the basement floor (E1. $-21^{\prime}-0^{\prime \prime}$ ) and the refueling floor. The grade floor is at El. 1'-0". The building is designed as a Category I, 
Safety Class 2, reinforced concrete structure, except for the' crane bay enclosure which extends from the refueling floor (E1. 113'-4') to E1. 184'-6". The crane bay enclosure is structural steel covered with metal siding. The structure is designed to withstand SSE effect, but the siding is not intended to provide missile protcction above the refueling floor. The siding is equipped with blowout panels to relieve tornado over-pressure; with the main structure designed to withstand the full effect of maximum wind loadings.

- $\because$ The refueling transport system penetrates the north wall to the containment. The control rod indexing storage system is located between the refueling rails. The control rod storage system is located in a monolithic structure that also includes circulator storage, fuel container loading equipment, sealing and inspection and service areas. The monolith concrete walls extend from the refueling floor to the building mat at basement elevation. The fuel handling control room is located above the refueling floor on the southwest corner of the building allowing full access and viewing of operations on the refueling floor. Also located on the refueling floor are storage areas for various refueling equipment. A 100 ton overhead crane covers the maintenance operations required on the refueling floor and equipment entry or removal through the floor hatch.

The floor at elevation 92'-0" contains building HVAC and low level vent system, the building HVAC recirculating unit, and decontamination equipment utilized by the equipment service facility. The floor at elevation 71'-0" contains chillers and pumps for building HVAC and an analytical instrumentation facility. Gas waste modules are located at E1: 50'-0", and E1. 29'-0". Also at this lower level, access to the fuel sealing machine room is attained. At grade E1. 1'-0", truck access for receiving and shipping is provided, as is the radwaste control station, monitoring any shipments leaving the plant. The basement floor, El. -21'-0", houses solid and liquid waste process equipment, tankage and packaging components. Access to shipping is through the floor hatch, which also extends to the refueling floor. 
The fuel sealing and inspection facility (FSIF) is located on the east side of the building with its operating station at approximately E1. 15'-0".

The FSIF extends from the service building into the fuel storage building which is a feature allowing fuel containers to be moved by an overheat remote operated crane. Access for viewing and crane operation for this function is attained at E1. 29'-0".

Main access to the service building is through doors from access control at E1. 26'-0". Access to other floors is by either stairway or elevator.

3.5.1.4. The Fuel Storage Building. The fuel storage building, a Category $I$, Safety Class 2 structure, is attached to the east wall of the service building and extends $201^{\prime}-8^{\prime \prime}$ and is 97'-0" wide. It rises 74'-6" above grade and the fuel pool extends 13'-6" below grade at its base. Spent or refabricated fuel containers are stored in steel wells that are positioned below the storage area floor. Each well has a concrete shield plug recessed into the floor above it. Access to these wells is accomplished via an overhead, remotely operated, 5 ton crane. This specially designed crane handles fuel containers some $16^{\prime}$ long and also is capable of removing and replacing the concrete plug over each well. This facility is sized for 10-year storage of spent fuel blocks - the size being. based on the following information and assumptions:

- $\quad$ Total fuel blocks in core $=4700$

- Refueling $1 / 4$ each year $=\left(\frac{4700}{4}\right)=1175$

- 10 year storage basis $=(1175 \times 10)=11,750$ blocks

- No. blocks per container $=6,\left(\frac{11,750}{6}\right)=1958$ containers

- 2 containers per well $\frac{1958}{2}=979$ wells required 
$\underline{\text { Reflector }}-180$ columns every 8 years $x 8$ high $=1440$

- Change $1 / 8$ each year $=\frac{1440}{8}=180$

- 10 year storage basis $=(180 \times 10)=1800$

- No. elements per containers $=6,\left(\frac{1800}{6}\right)=300$ containers

- 2 containers per well $=\frac{300}{2}=150$ wells required.

Total wells: $979+150=1129$ wells required

Rounding out the storage area with spares, the total comes to 1150 wells.

At the extreme eastern end of the building is an area that allows for loading of spent or new fuel containers to or from the fuel shipping cask rail car. A 160 ton semi-gantry crane uprights and positions the cask for accepting fuel containers. The entire container handling operation is done from a remote control facility at El. 29' near the service building. The shipping operation is controlled from a remote operator position over the rail car. Construction of the building requires reinforced concrete walls $5^{\prime}$ thick that provides a general environment of less than $1 \mathrm{mrem} / \mathrm{hr}$ in outside areas adjacent to the structure. The fuel pool is cooled by redundant heat exchangers located below the control area. Pumps are located at grade level in the service building for the fuel pool cooling system. The fuel pool heat exchangers are cooled by safety-class heat exchangers which reject heat to the SWS or NSWS in an emergency. 
3.5.1.5. Control, Auxiliaries, and Diesel Generator Building (CAD). The CAD building incorporates all control and emergency safety power systems into one building.

It contains:

1. Control Room

2. Essential Power

3. 4160 V CACS Bus and Controllers

4. Upper and Lower Cable Spreading Separation

5. Diese1 Generators

6. $480 \mathrm{~V}$ MCC and Battery Rooms

7. HVAC for Control Room, Diese1s, Diesel Exhaust, Various spaces.

This building is designed to concentrate functions, equipment, and services, resulting in reduced structural and.building service costs. It is located at the west side of the penetration and reactor service buildings and is a Category I, Safety Class 1, reinforced concrete structure. Its location is determined by the containment structure housing the generator and allows major division cable routing which runs from the CAD through the penetration building to the containment. The majority of the cabling is dedicated to equipment on top of the PCRV. Cable division separation is attained by the upper and lower cable spreading areas. Cables are routed through these areas to the containment where they penetrate the wall and are then routed in cable trays to interface locations on top of the PCRV or other positions. Cabling from the top of the PCRV has been routed to interface at positions adjacent to the penetration building. 
The control room is located at El. $70^{\circ}-3^{\prime \prime}$ between the upper and lower cable spreading areas. Above the upper cable spreading area are located control room cooling towers, chillers, and diesel exhaust silencers. Below the lower cable spreading area are located switchgear, $480 \mathrm{~V}$ MCC, battery rooms, and HVAC. The three emergency diesel generators are located in the lower floor of the building along with respective motor control centers required for each. Each diesel and associated switchgear is separated from the others by a Category I concrete wall.

3.5.1.6. Access Control/Administration Building. The access control and administration building is a Non-Category I steel structure that houses the main security access to the plant. In addition, this building also houses administrative offices of the plant and is subdivided into radiation control area (RCA) shops, health physics, change room facilities, first aid, and the complex of offices for plant supervision functions.

Access to the $C A D, R S B$, or $R C B$ is through security. and then via enclosed stairways, elevators, or passageways.

\subsubsection{Balance of Plant Systems}

Certain of the systems in the GT-HTGR balance of plant (BOP) are significantly different from those found in an LWR or a fossil plant. The following brief descriptions of these systems summarize the information used in preparing the cost estimate.

3.5.2.1. Circulating Water System. The circulating water system (CWS) is a pressurized, non-nuclear-safety, closed-loop system (3 10op) which transfers heat from the three precoolers and rejects it to the environment through dry cooling towers. During all modes of normal plant operation the circulating water system provides the major means of plant heat rejection. The system also removes core heat during extended plant shutdowns with the PCRV depressurized at refueling conditions and the main cooling loops in 
operation, removes heat transferred to the precoolers by primary coolant bypassing through the main loops when the core is being cooled by the CACS and removes core heat during shutdown cooling on the main loops. The CWS is designed: to remove a heat load of 1,975 x. $10^{6} \mathrm{Btu} / \mathrm{hr}$ per loop.

The CWS consists of two (2) $50 \%$ capacity dry cooling towers, four 33-1/3\% capacity circulating pumps (normally. three operating), three dump tanks (one for each loop) and a pressurizing tank, as well as piping, valves and instrumentation.

The system provides for detection of any primary coolant leakage into the system should a precooler tube fail with the PCRV pressurized, and provides for isolation of the precoolers to contain the primary coolant. The system also provides for isolation and dump of the precoolers to limit water leakage into the PCRV should a precooler tube fail with the PCRV depressurized.

3.5.2.2. Service Water System. The plant service water system (SWS) is a non-nuclear-safety cooling water system providing cooling water for the generator plant and reactor plant and other heat loads throughout the plant. The SWS accepts heat from three other major water systems: the generator plant cooling water system (GPCWS), the reactor plant cooling water system (RPCWS), and the fuel storage pool cooling water system. Where appropriate, other components may use service water directly (such as large building chillers, etc.). The SWS is capable of removing a total of $181.0 \times 10^{6}$ $\mathrm{BTu} / \mathrm{hr}$.

The SWS consists of a mechanical draft, wet cooling tower, three $50 \%$ capacity circulating pumps, pipes and valves.

Conventional mechanical draft, wet cooling towers reject heat from the SWS to the environment. The wet towers were chosen primarily for their capability to provide lower temperature cooling water on hot days. Provisions for adding raw water make-up and discharging blowdown must also 
be provided. Since the plant incorporates dry cooling for the circulating water system, make-up requirements are low and are thought not to pose a problem for virtually any selected plant site.

3.5.2.3. Nuclear Service Water System. The nuclear service water system (NSWS) provides cooling to safety related NSS and BOP components undex emergency conditions, when the service water system is unavailable. The NSWS is the Ultimate Heat Sink for the PCRV liner, the fuel storage pool and the auxiliary circulator motor cooling water system when the SWS is inoperative: The NSWS satisfies the requirements of Regulatory Guide 1.27 (Uitimate Heat Sinks). by providing redundant safety class systems and wet evaporative cooling towers housed in seismic Category I, missile protected structures, with sufficient amounts of stored water to safely shut down the plant and maintain it in a safe shutdown conditions. The NSWS is supplied from a Class IE electrical supply.

The NSWS consists of two $100 \%$ capacity wet evaporative cooling towers, two $100 \%$ capacity circulating pumps, one $100 \%$ NSWS heat exchanger, two $100 \%$ NSWS cooling water pumps, surge tank, pipes, valves and instrumentation.

The NSWS cooling towers are each sized to reject the heat loads encountered in shutting down the plant. Since these are substantially less than the normally operating heat loads, the NSWS is not operational under normal plant conditions. When called upon to operate, the swS is isolated while the NSWS circulating pumps and towers are started to provide continued cooling to the fuel storage pool cooling water system and through the NSWS heat exchanger to the safety related portion of the reactor plant cooling water system: The NSWS removes a heat load of $99.8 \times 10^{6} \mathrm{Btu} / \mathrm{hr}$.

3.5.2.4. Generator Plant Cooling Water System. The generator plant cooling water system (GPCWS) provides cooling to the three generators and auxiliaries and the turbine/compressor service modules inside the reactor containment building. The GPCWS is a non-safety, closed water system of controlled water quality rejecting heat to the service water system. The major heat loads come from the generator rotor and stator cooling, other generator 
components, and the turbine compressor auxiliaries. Where appropriate, other plant components, such as air conditioning chillers, air compressors, etc., utilize the GPCWS for cooling. The GPCWS shall have the capability to remove a heat load of $68.3 \times 10^{6} \mathrm{Btu} / \mathrm{hr}$.

The GPCWS consists of a $100 \%$ capacity heat exchanger, two $100 \%$ capacity pumps, a pressurized surge tank, chemical control package, pipes, valves and instrumentations.

The cooling water is piped from the GPCWS heat exchangers to the three generators in the RCB via pipe tunnels. The water system also provides cooling to the turbine/compressor auxiliaries (headered inside the containment).

3.5.2.5. Reactor Plant Cooling Water System. The reactor plant cooling water system (RPCWS) provides cooling to NSS components and systems under normal and emergency plant conditions. The major NSS components cooled by this system include the PCRV liner, auxiliary circulator motors, helium purification system and the rad gas waste compressors. The system normally rejects heat to the plant service water system. Under emergency conditions, the NSWS serves as the Ultimate Heat Sink for the safety related components i.e., PCRV liner and auxiliary circulator motors. The RPCWS is a closed, controlled quality system consisting of two redundant, safety related loops, either one of which provides sufficient capacity to safely shut down the reactor. Each loop of the system contains sufficient redundancy (in pumps and heat exchangers) to ensure high reliability of the system. Each loop of the RPCWS is supplied from a separate Class IE electrical division.

3.5.2.6. Fuel Storage Pool Cooling Water System. The fuel storage pool cooling water system is a closed loop, controlled quality safety related system that provides couling for the fucl storage ponl. The system rejects heat to the SWS under normal conditions and to the NSWS under emergency conditions. The system removes a heat load of $22.0 \times 10^{6} \mathrm{Btu} / \mathrm{hr}$. 
The system consists of two $100 \%$ capacity pumps operating during normal conditions, circulating water through the SWS heat exchanger; and two $100 \%$ capacity pumps operating during emergency conditions, circulating water through the NSWS heat exchanger.

3.5.2.7. Core Auxiliary Cooling Water System. The core auxiliary cooling water system (CACWS) is a nuclear safety class system supplying cooling water to the heat exchanger in the core auxiliary cooling system (CACS) loops. A separate, independent cooling water system is provided for each of the three CACS loops. The primary function of the system is to transfer heat from the core auxiliary heat exchangers to air blast heat exchangers during accident conditions involving loss of main loop core cooling.

Each CACWS loops is sized to remove approximately $205 \times 10^{6} \mathrm{Btu} / \mathrm{hr}$ during the loss of a pressurized main loop core cooling accident:

The system is also designed to remove parasitic heat transferred to the core auxiliary heat exchangers during normal plant operation as well as heat generated during refueling operation.

Each of the three loops of the CACWS consists of two $100 \%$ capacity auxiliary pumps, one $100 \%$ capacity main pump, one $100 \%$ capacity air blast heat exchanger, surge tank, chemical control package and the associated piping, valves, and controls.

The air blast heat exchanger fans are powered by separate class IE electrical divisions. These exchangers provide the Ultimate Heat Sink for this system and are located in seismic Category I missile protccted structures.

3.5.2.8. Helium Storage System. The helium storage system (HSS) stores and transfers the helium inventory of the reactor plant. Additional functions of the system are to provide high pressure helium for make-up, purging and pressurtzing various system and components, control of primary 
coolant pressure during refueling, and venting of the primary coolant through the purification system if depressurization of the reactor plant is required when the helium storage system is inoperative.

The helium storage system is a non-safety related system and contains non-radioactive helium.

The HSS consists of two $100 \%$ capacity transfer compressors, two oil absorbers, helium storage tanks, high pressure supply tanks, piping, valves, and instrumentation.

The HSS is designed to provide a storage capacity for -56.000 * pounds of helium. The total helium make-up requirement is approximately $4,000 *$ lbs/year.

3.5.2.9. Miscellaneous Systems. The following BOP systems are essentially standard for all types of plants and not significantly different from LWR plants.

Diesel/Generator Cooling System. There are three independent safety class 1, Category I emergency diese1/generator cooling systems. Each system is provided with its own independent dry cooling tower: Cooling water from the aftercooler, jacket cooler and lube oil cooler is pumped through a finned tube heat exchanger located within a seismic Category I structure. Separate motor driven fans, powered from a separate class IE electrical division, provide the required air flow for each tower.

Control Room Chiller Heat Rejection System. The safety-related control room HVAC system utilizes two redundant wet cooling towers to provide the Ultimate Heat Sink for the chillers. Make-up water for the recirculating

* These numbers are based on rough estimates since the helium inventory has not been determined accurately. 
spray is stored in the NSWS basins, and is pumped to the towers by the NSWS. Two $100 \%$ capacity condenser cooling water circulating pumps per chiller are provided. The system is safety Class 3, seismic Category I, located within the upper floor of the CAD building, and is powered from Class IE electrical sources.

The system is capable of removing $1.4 \times 10^{6} \mathrm{Btu} / \mathrm{hr}$.

Decontamination and Radioactive Waste Systems. The decontamination system provides for storage and circulation of solutions used in the decontamination of reactor plant equipment. Provision is made for the use of both simple detergents and stronger, special-purpose decontamination solutions.

The radioactive (liquid and gaseous) waste systems are designed to limit release of activity from the plant to "as low as is reasonably achievable" as established by 10CFR50, Appendix I guidelines, and in any case (including unusual operating conditions), still within the limits specified by 10CFR20. Adequate hold-up capacity is provided so that releases will not be necessary under adverse environmental conditions or when inadequate liquid dilution is available.

These systems are not particularly sensitive to plant capacity and type. Estimates were on the basis of previous HTGR plants.

\subsubsection{Comparison of HTGR-GT and LWR Plants}

The HTGR-GT balance of plant has a number of features which are more favorable than the LWR balance of plant. The major differences are described briefly below:

3.5.3.1. With the turbomachinery and generator located inside the containment, the turbine building can be completely eliminated. 
3.5.3.2. No main steam piping is required either inside or outside the containment.

3.5.3.3. No feedwater heaters, pumps, condenser, and condensate treatment equipment are required.

3.5.3.4. The circulating water flow is significantly lower and the temperature is considerably higher than that for an LWR of the same power output. The higher temperature permits the use of a dry cooling tower which eliminates the need for most of the plant make-up water. However, this, advantage is offset to some extent by the need to keep the circulating water pressurized to avoid boiling in the precoolers.

\subsection{FUEL}

Efficient performance of the HTGR-GT plant requires a high gas temperature at the turbine inlet. State of the art development permits gas inlet temperatures of approximately $850^{\circ} \mathrm{C}$ during plant equilibrium operation. While the core outlet temperature (i.e., turbine inlet temperature) is governed by the turbine performance, the coolant temperature at the core. inlet depends upon plant optimization (recuperator performance) and the thermal/structural integrity of the core components. Thus, the core design is strongly influenced by the important considerations listed below:

1. Selection of coolant operating parameters such as pressure, inlet temperature, and outlet temperature.

2. Fuel cycle selection.

3. Fuel particle design and neutron fluence characteristics.

4. Core fuel zoning and refueling.

5. Thermal/fluid flow conditions in the core for limiting fuel temperatures. 
6. Probabilistic determination of fuel particle failure.

7. Safety-related aspects concerning the release of radioactive gaseous and metallic fission products from the core.

8. Structural and mechanical design of core components capable of sustaining high temperature effects while maintaining structural integrity.

For the $3000 \mathrm{MW}(t)$ HTGR-GT Reference Design, review of core design considerations has resulted in selection of the core configuration shown in Figure 3-16 through 3-18. The basic core parameters are presented in Table 3-13. The $3000 \mathrm{MW}(t)$ core, which employs graphite as the moderator (in the form of hexagonal blocks or elements) and helium gas as the coolant, contains 534 standard fuel columns and 91 control fuel columns. Each fuel column consists of eight elements for a total of 5000 fuel elements in the core. The details of the fuel element and the control element are shown in Figures 3-19 and 3-20. The control element contains a small control rod hole, the control rod pair, and the reserve shutdown system.

Each of the fuel reload segments represents approximately the same core volume. All the fuel in a given segment is reloaded during the same refueling shutdown period.

During normal operation, the core is controlled by small control rods located in each control column. These rods are operated in four banks; a bank corresponds to a fuel age segment. This means that each bank is uniformly distributed throughout the core, which minimizes power perturbations due to insertion of the rods. The control system, consisting of control rod pairs, small control rods, and the reserve shutdown system, is located in the central column of each refueling region.

The core is fueled with a mixture of maximum fissile particles (20\% enriched with U-235), and thorium fertile particles. Individual fuel rods contain the fissile TRISO-coated and fertile. TRISO-coated particles distributed within a graphite matrix, and are placed into the fuel holes to 


\section{Core Parameters}

Thermal Power, MW( $t$ ) 3000

Power Density . . . 7.0

Core He Temperature, ${ }^{\circ} \mathrm{C}-$ in 498

- out 850

Fuel Lifetime, Yrs 4

Fue1 MEU

U-235 Enrichment, \% $\quad 19.9$

C/Th Ratio, Initial/Equilibrium 350/600

Avg. Peaking Factor, Peak $\quad \leq 1.40$

No. of Axial Zones 4

No. of Fue1 Element/Columns 8

No. of Fuel Columns - standard 534

- contro1 91

Fuel Element Configuration

No. of Rows of Holes/Element 10

$\begin{array}{ll}\text { Element Height, } \mathrm{cm} & 79.3\end{array}$

Distance Across Flats, cm 36.0

Fuel Hole Diameter, cm . 1.01

Coolant Hole Diameter, cm - large. 1.59

- small 1.27

Fuel Hole Pitch, cm 1.88

Fuel Particle Configuration

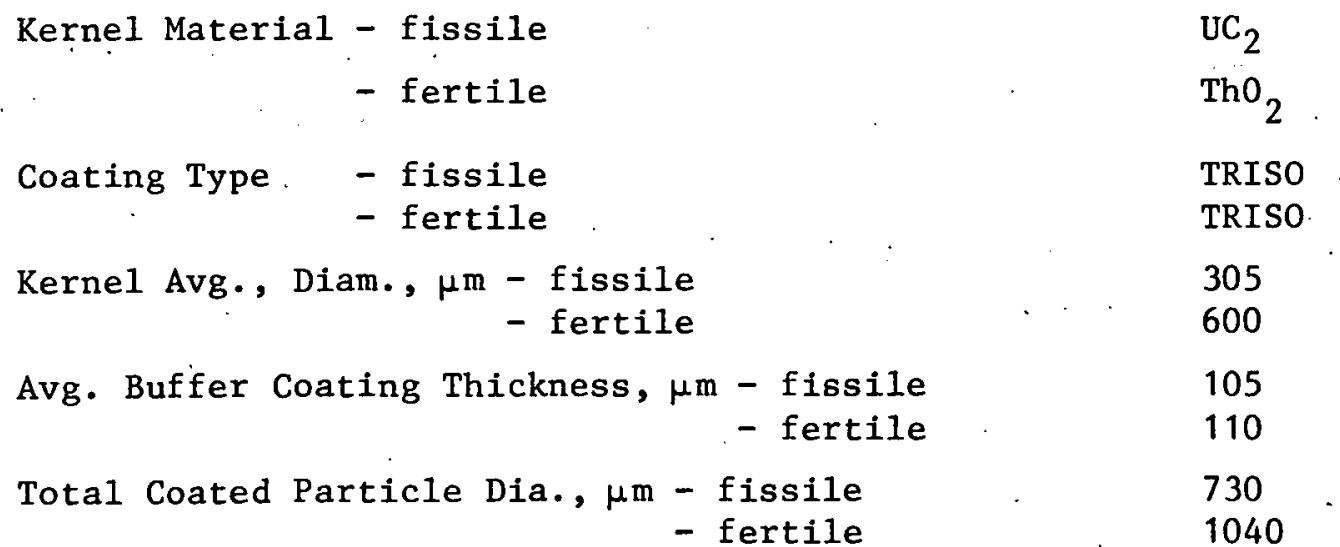




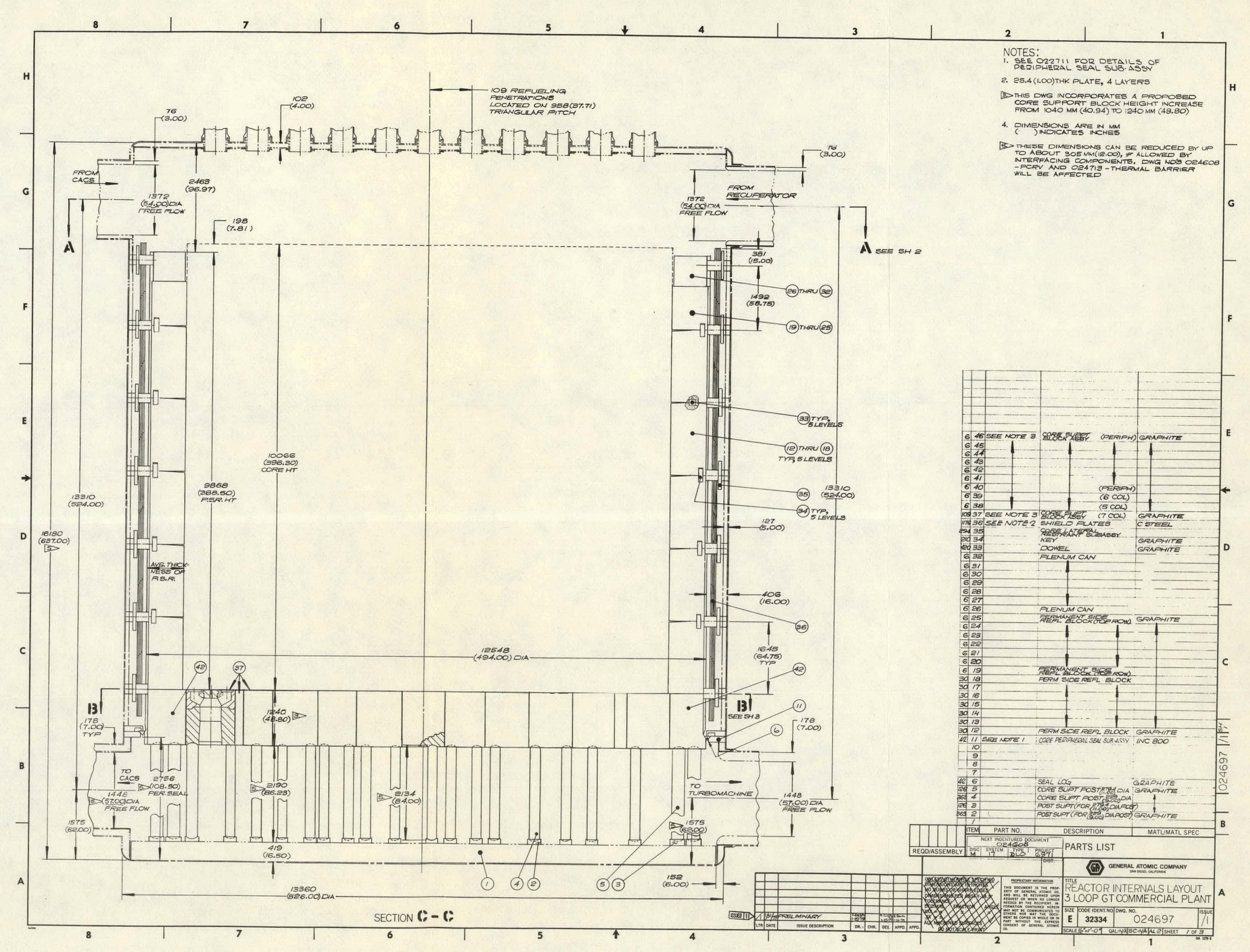


THIS PAGE

\section{WAS INTENTIONALLY LEFT BLANK}




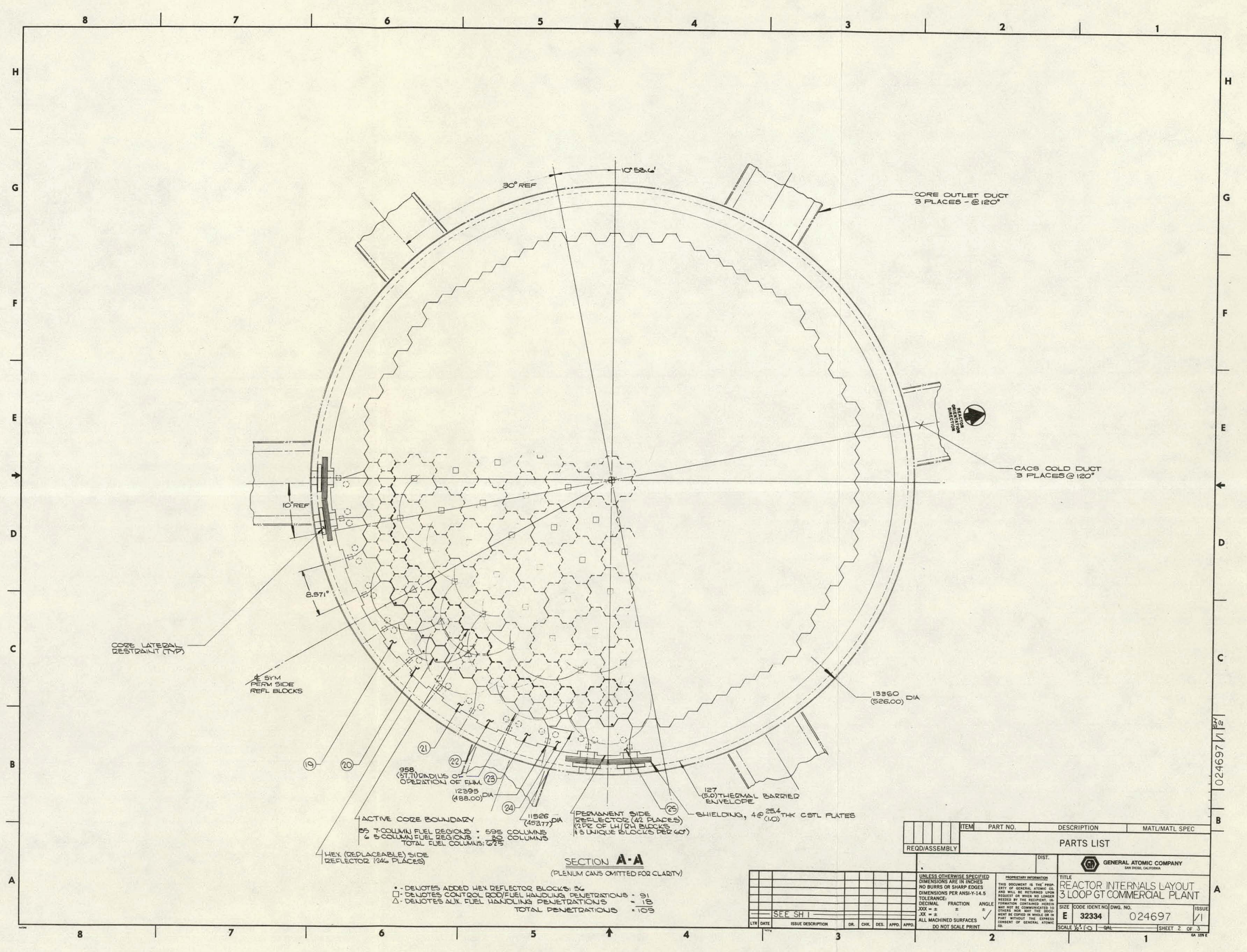

Fig. $3-17$ 
THIS PAGE

\section{WAS INTENTIONALLY LEFT BLANK}




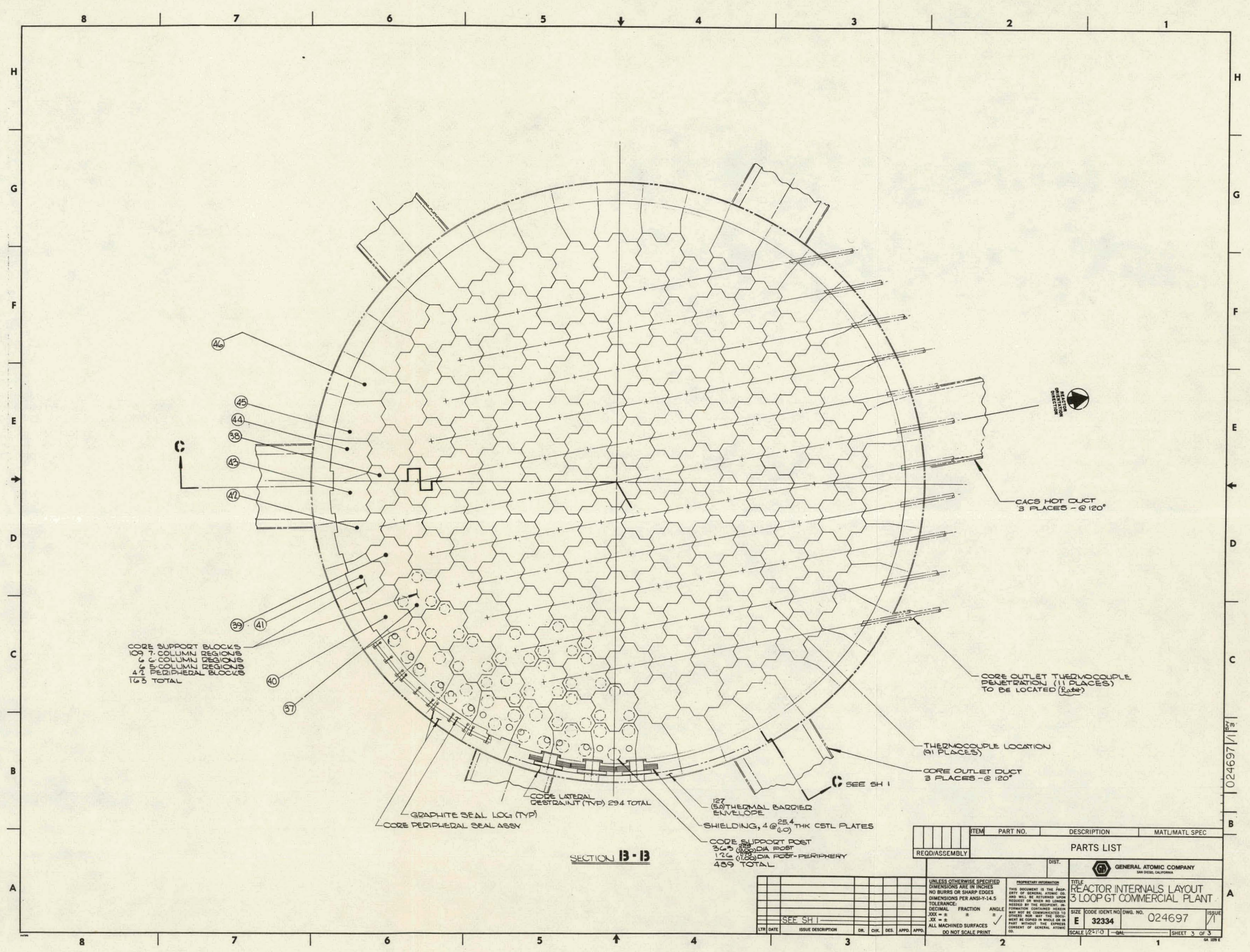

Fig. $3-18$ 
THIS PAGE

\section{WAS INTENTIONALLY LEFT BLANK}




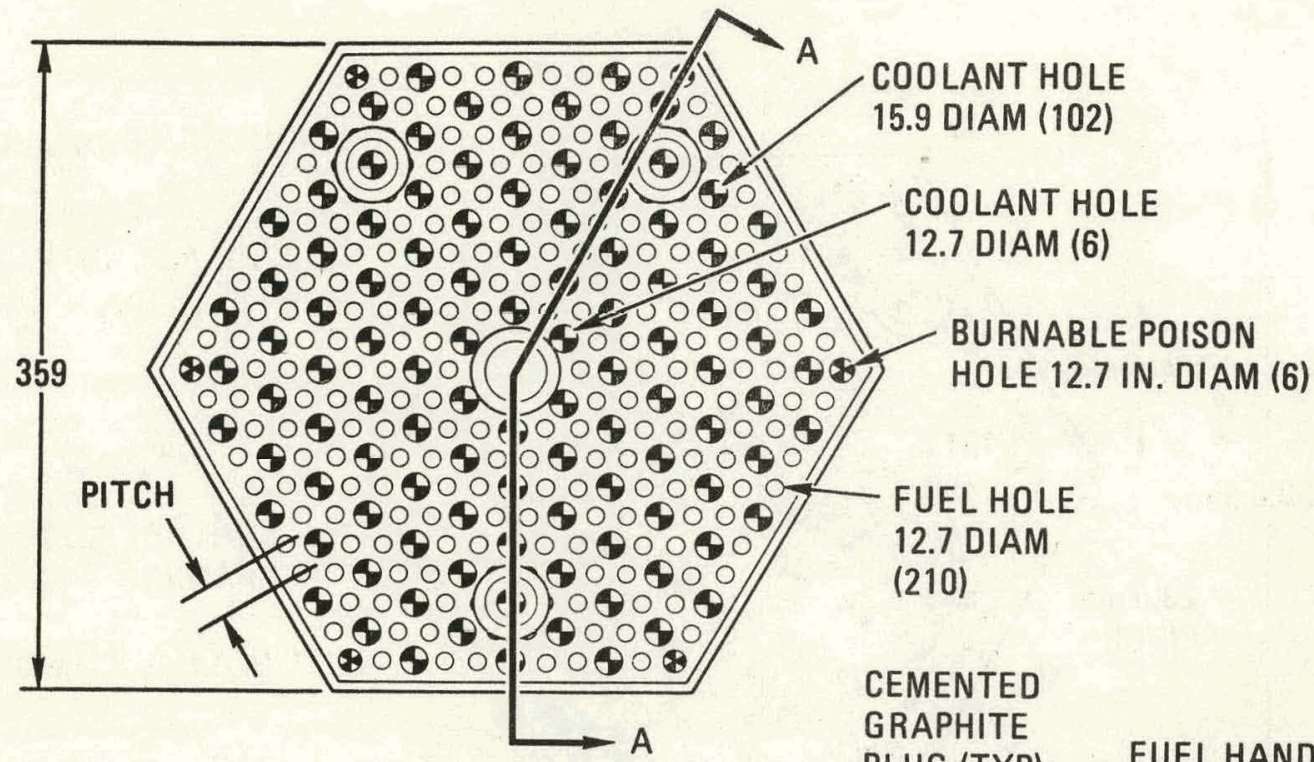
GRAPHITE
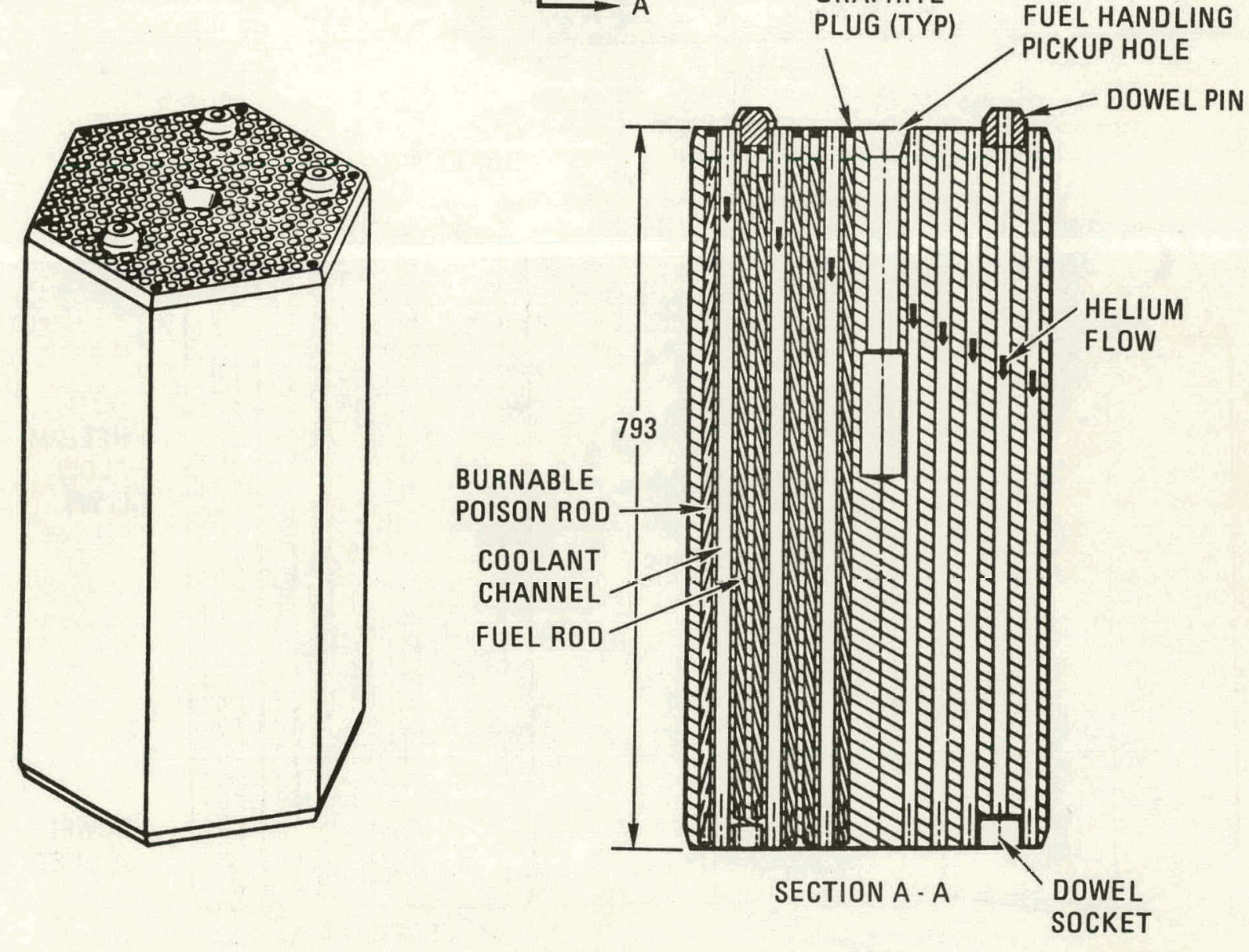

Fig. 3-19. HTGR-GT standard fuel element $3000 \mathrm{MW}(\mathrm{t})$ 


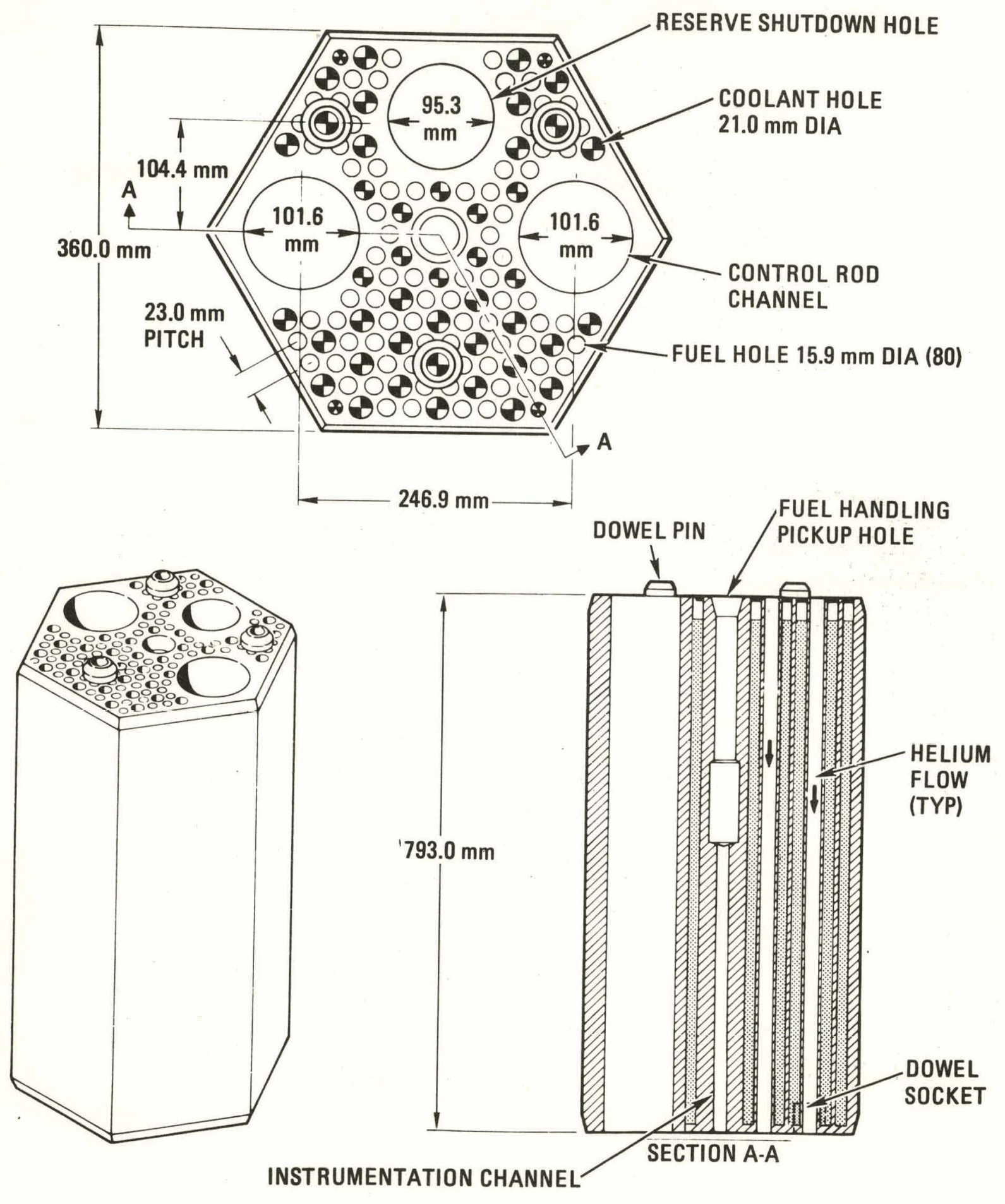

Fig. 3-20. HGTR-GT control fuel element $3000 \mathrm{MW}(\mathrm{t})$ 
form a fuel element and are placed into the fuel holes to form a fuel element. The initial core elemtns and the reload elements, whether containing fresh or recycle fuel, are of identical geometry. However, the particle sizes can be adjusted to minimize resonance absorption effects in U-238, thus raising conversion ratio, or to minimize fissile inventory requirements.

A fissile particle consists of a uranium carbide kernel (MEU-20\% enrichment) with a TRISO coating. The TRISO coating has four layers: an inner buffer layer of low density pyrolytic carbon, a thinner layer of high density pyrolytic carbon, a layer of silicon carbide that provides containment of diffusive metallic fission products at high burnups, and an outer layer of high density pyrolytic carbon which provides additional strength to the coating.

A fertile particle consists of a thorium oxide kernel with a TRISO coating. Fuel particle dimensions are shown in Table 3-13.

Each fuel element resides in the core for four years and is removed and/or replaced by means of a fuel-handling machine while the reactor is in a shutdown, depressurized mode.

The following advantages are perceived for the HTGR-GT fuel cycle/design.

1. The HTGR-GT displays inherent safety characteristics that are superior to other reactor concepts e.g., large heat capacity of the graphite moderator and ceramic fuel.

2. The HTGR-GT fuel cycles are very flexible, i.e., use of any fissile material can be implemented without necessitating plant changes or fuel block design changes. Further, the HTGR-GT fissile and fertile fuel loadings can be readily modified without perturbing coolant flow (vary $\mathrm{C} / \mathrm{Th}$ ratio or fissile loading). 


\section{PLANT CAPABILITY}

\subsection{LOAD FOLLOWING CAPABILITY}

Three primary means are available for obtaining and controlling part load operation of the HTGR-GT. Bypass valve operation (bypass control), which effectively provides a shunt flow, path across the core and turbine, provides rapid (fraction of a second) load change. Adjustment of turbine inlet temperature (temperature control) allows load adjustment at a slower rate (minutes). Adjustment of system pressure by increase or decrease of primary system inventory (inventory control) provides the third and most efficient means of load adjustment. Standard helium cleanup and transfer systems result in hours being required for large changes in inventory. Supplemental helium transfer systems are currently being evaluated to establish the rate and amount of inventory control which will be provided as a part of the standard HTGR-GT. This evaluation will also determine what degree of increased inventory control may be provided as an option.

Figure 4.1-1 presents the plant efficiency versus load for the three methods of control. The very high part load efficiency using inventory control is apparent. Temperature control provides reasonable efficiency in the upper range of load. Bypass control is poor in efficiency with approximately $80 \%$ of the load reduction via bypass going to waste heat. The reference load control concept currently being evaluated is set up to take $10 \%$ load change on bypass control, with further reduction by temperature control. In addition manually initiated inventory change is accepted by the control system and results in adjustment of the programmed setpoints of valves and temperature versus load. 


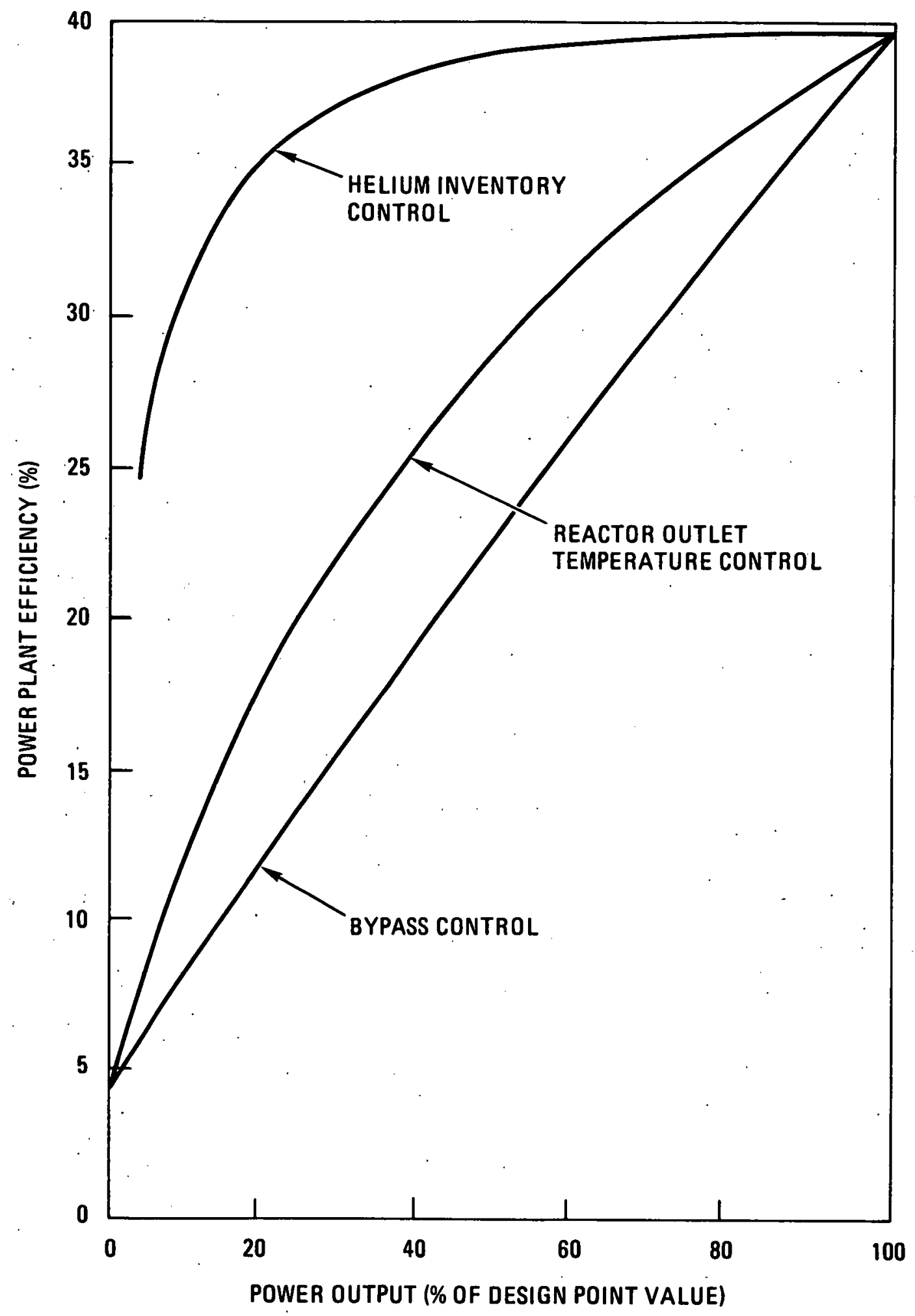

Fig. 4.1-1. Part-load efficiency for the various control modes 
The valve/temperature relations with plant efficiency at full inventory and reduced inventory are shown in Figure 4.1-2. Curve a-a illustrates the plant efficiency versus load with full inventory. Curve b-b illustrates the plant efficiency for a condition where inventory is reduced $50 \%$ and bypass and temperature control are used for any remaining load reduction. In reality for this latter case, the system would move on a trajectory between curves $a-a$ and $b-b$ as inventory was reduced and would ultimately move to the appropriate load level on curve b-b. Further inventory change would, of course, move the curve further to the left and up, with the limit being the pure inventory control curve; The difference in efficiency, at $25 \% 10$ ad, between pure inventory control and 50\% inventory plus $10 \%$ via bypass and $15 \%$ via temperature is approximately 3 points. This indicates the relatively small efficiency loss which would be associated with a slower "catchup" reduction of inventory below $50-60 \%$ inventory as opposed to "immediate" inventory reduction.

Automation of Inventory control, for limited rates of inventory change, may easily be accomplished by turning on or off the helium flow into or out of the primary coolant system on the basis of signals derived from bypass valve position and turbine inlet gas temperature: With limited rates of inventory change, and when operating at less than full load, a certain amount of "rapid load pickup" margin may be provided as desired by operating the plant with bypass valves somewhat open and with turbine inlet temperature somewhat below the full load value. The amount of this margin would be adjustable by the operator, and for each amount of margin, the load dependent curves of valve position and inlet temperature are adjusted. Deviations of the valve position and temperature from these curves would generate the signals to control inventory flow.

For "rapid" helium inventory control which would essentially accommodate any load changes via inventory, a load control of helium flow would also have to be provided. Such a provision does not appear difficult. Preliminary functional analyses of various inventory control capabilities has shown well controlled stable operation with simple control functions. 


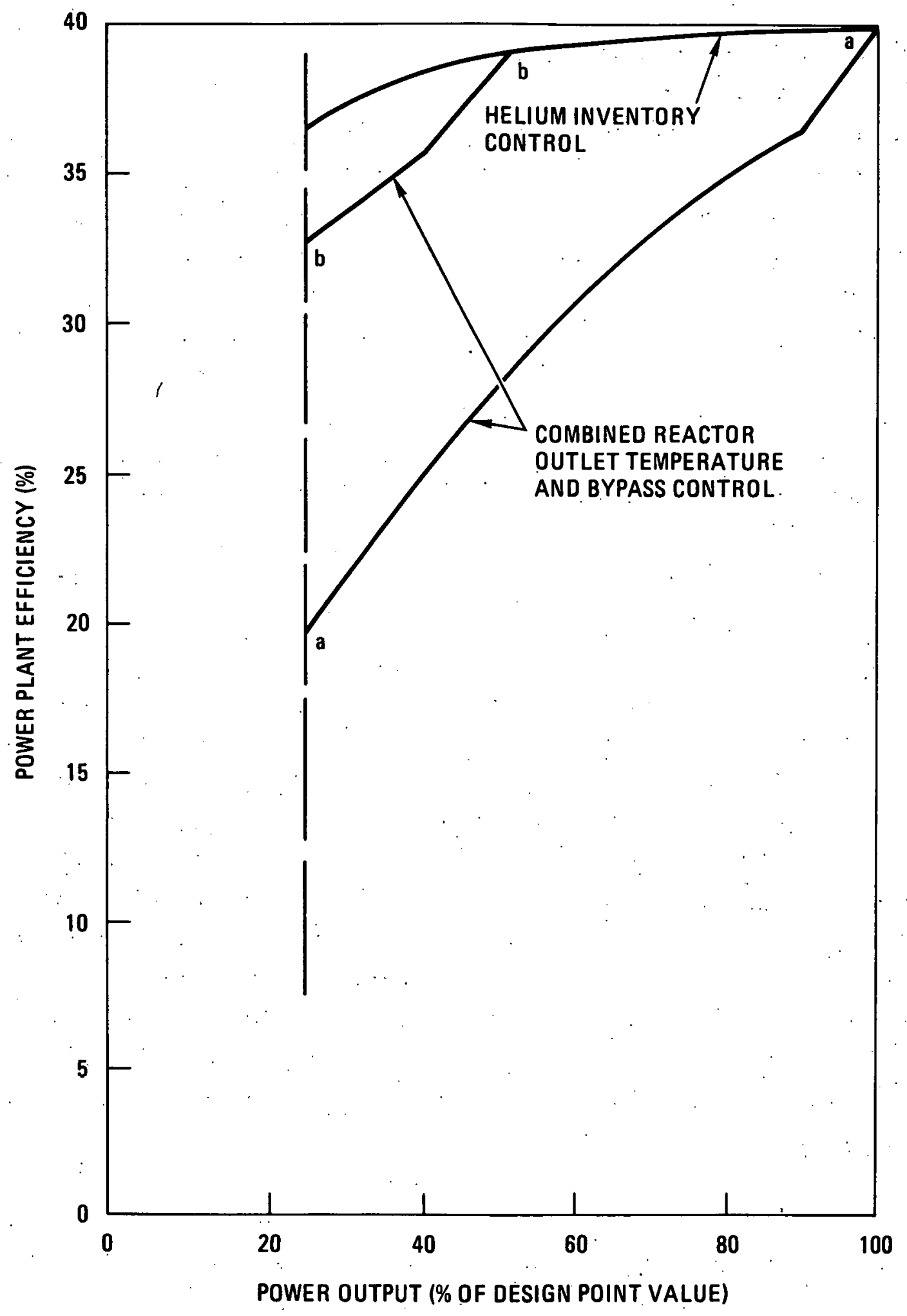

Fig. 4.1-2. Part-load efficiency for the valve/temperature control mode 
For "rapid" helium inventory control which would essentially accommodate any load changes via inventory, a load control of helium flow would also have to be provided. Such a provision does not appear difficult. Preliminary functional analyses of various inventory control capabilities has shown well controlled stable operation with simple control functions.

\subsection{DROP LOAD RECOVERY}

A unique feature of the HTGR-GT is the ability to rapidly recover load following a drop load event. Reloading may be initiated after resynchronization from the more probable condition of maintained "house 1oad," or from the less likely case of loss of both network and house load. Either resynchronization will be accomplished by phase adjustment from an existing nearsynchronous speed. Reloading rate will, of course, be controlled by the operator, however, essentially a step demand may be imposed with moderate thermal transient impact on the primary system.

If the standby condition is maintained strictly by bypass control, the rejected heat load will be relatively high. It is, in part, the re-transfer to the turbines of the power going into rejected heat which enhances load pickup. After several minutes of operation, the higher rejected heat load will be reflected in a slightly elevated return water temperature to the precooler inlet. If load is recovered prior to this increase in return water temperature, a capacity to attain $100 \%$ load exists. In this case, some subsequent temporary reduction in maximum load would occur as the higher level of rejected heat is finally reflected in the return water temperature. Conversely, if the reloading is not made until the return water temperature has risen, the initial maximum load will be limited by the cycle bottom temperature. Again, as the reloading (and hence lower rejected heat) is reflected around the Circulating Water System (CWS) loop, the return water temperature. will drop and allow a recovery to full load.

Two cases were evaluated for a preliminary assessment of the rapid reloading operation. The first case was a sequence of total load rejection to standby condition, and after resynchronization at approximately 2.5 minutes, 
a step load demand to full load. The second case was an approximation of reload from conditions which would exist (higher return water temperature, and hence, higher gas temperatures in the low temperature region of the loop) following a prolonged hold in standby. Both cases are extreme reload rates to assess maximum capability, and it would not be anticipated in an operational case that load demand would simply be stepped to $100 \%$. The actual reload rate would probably depend to a large degree on the existing grid conditions and would be controlled by the operator.

\subsubsection{Early Reload}

A total load rejection is postulated, beginning with the simultaneous trip of all 3 generator breakers (at $0 \mathrm{sec}$ ). A breaker trip signal to the Plant Control System (PCS) switches the turbomachines from Load/Speed regulator control to Speed Control.

Loss of generator load accelerates the turbomachine (see Fig. 4.2-1a). As the speed increases, the Speed Controller opens the primary bypass valve, which rapidly collapses the turbine pressure ratio (increases turbine backpressure), and begins to reduce turbomachine speed (max speed $3863 \mathrm{rpm}$ ). The time for recovery to essentially constant design speed was $\sim 6 \mathrm{sec}$.

Following the loss of electric load the feedforward and turbine inlet temperature controller signals to reactor power are decreased such that the inlet temperature is essentially maintained. As the core power equilibriates ( $140 \mathrm{sec}$ ), the core outlet gas temperature returns to nominal (Figure 4.2-1b) and the power delivered to the turbines is totally used as compression power.

When the turbine outlet temperature increased, the bypass flow and the attemperation flow maintained the hot recuperator inlet and cold recuperator outlet temperatures constant (Fig. 4.2-1b). Heat load to the precoolers was increased by the increase of flow in the loops, which in turn slightly increased the compressor inlet gas temperature causing a slight reduction of the loop flow. 


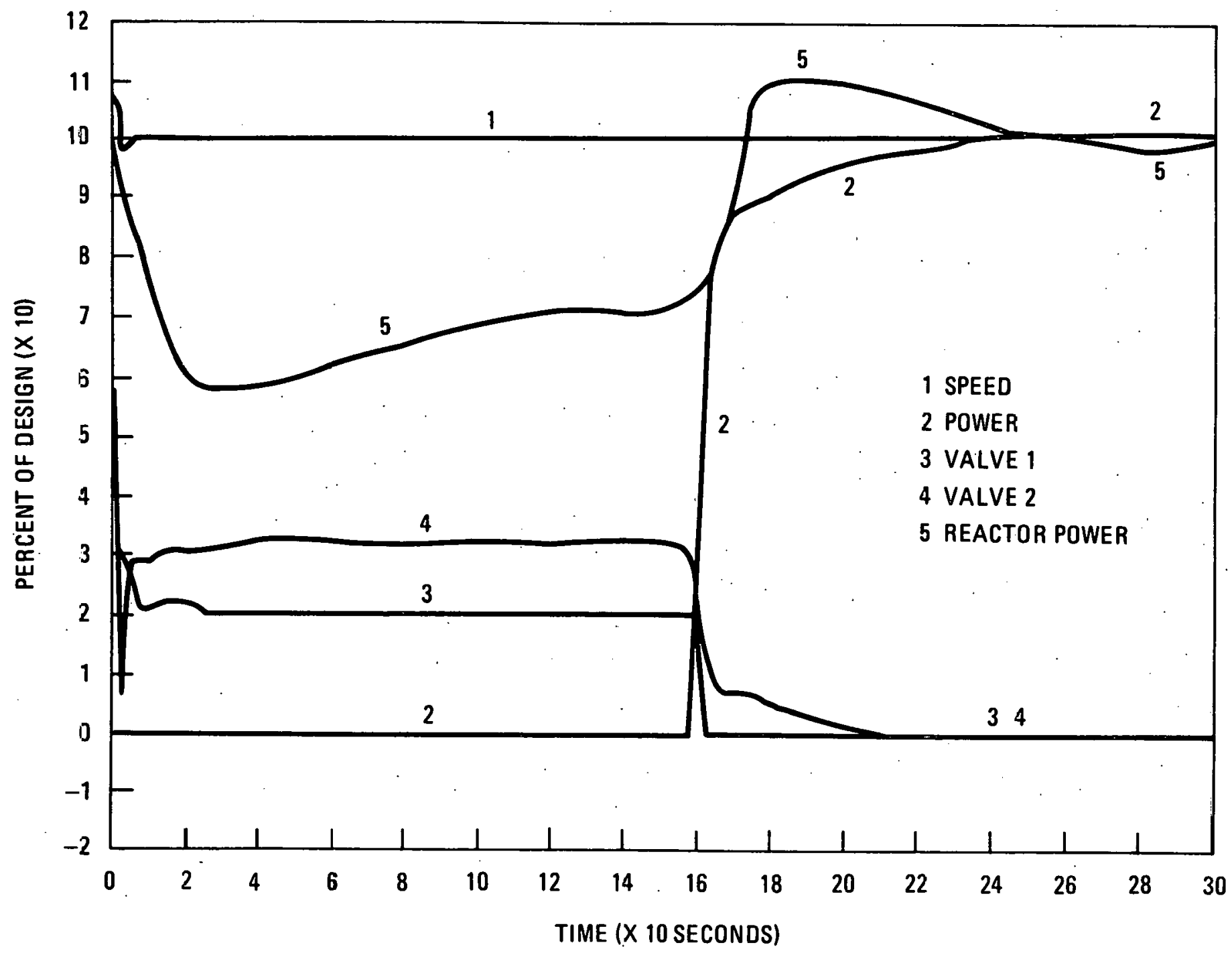

Fig. 4.2-1a. Ref commercial plant - plant loss of load turbine transients (multi-loop, early reload) 


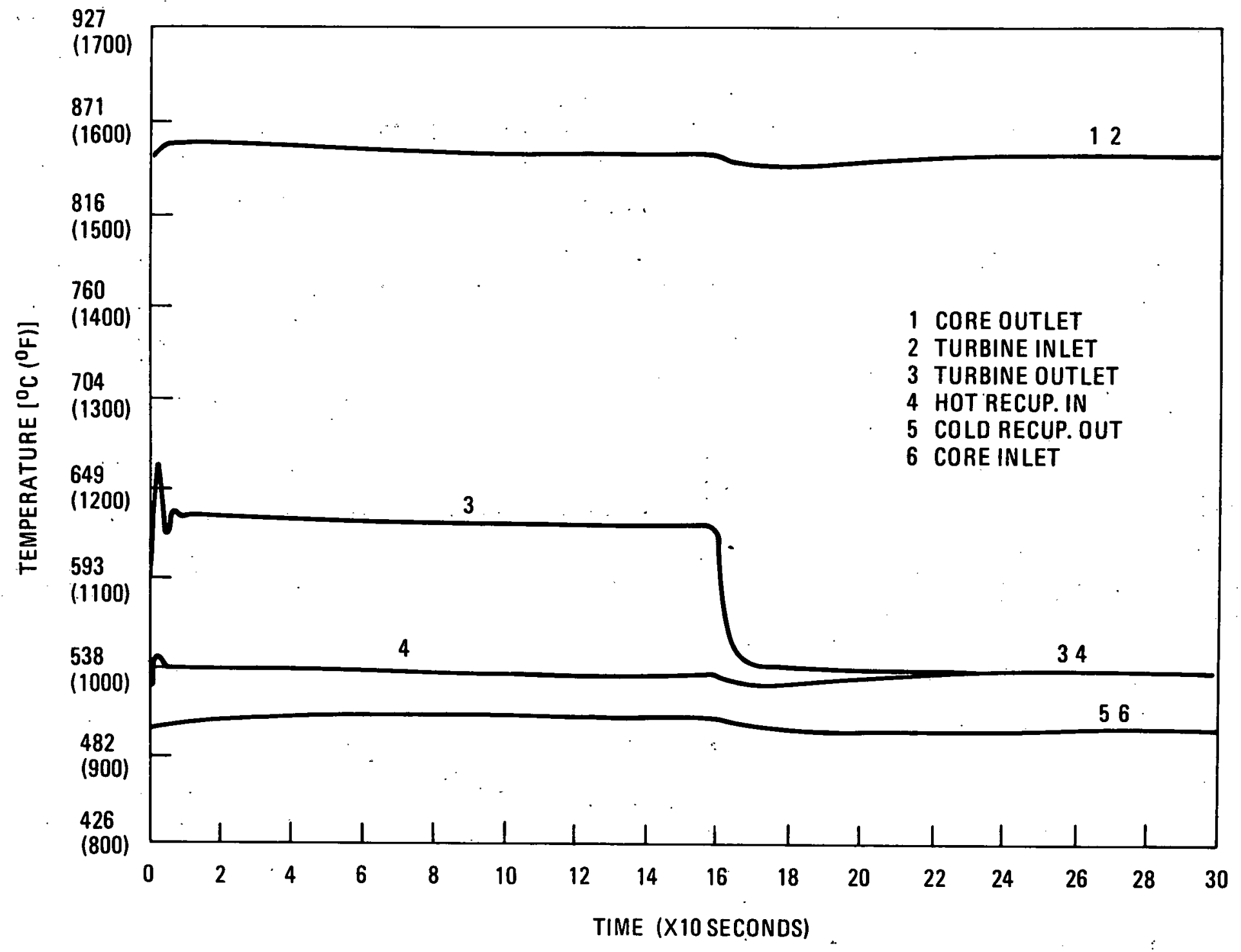

Fig. 4.2-1b. Ref commercial plant - plant loss of load high temperature transients (multi-loop) 


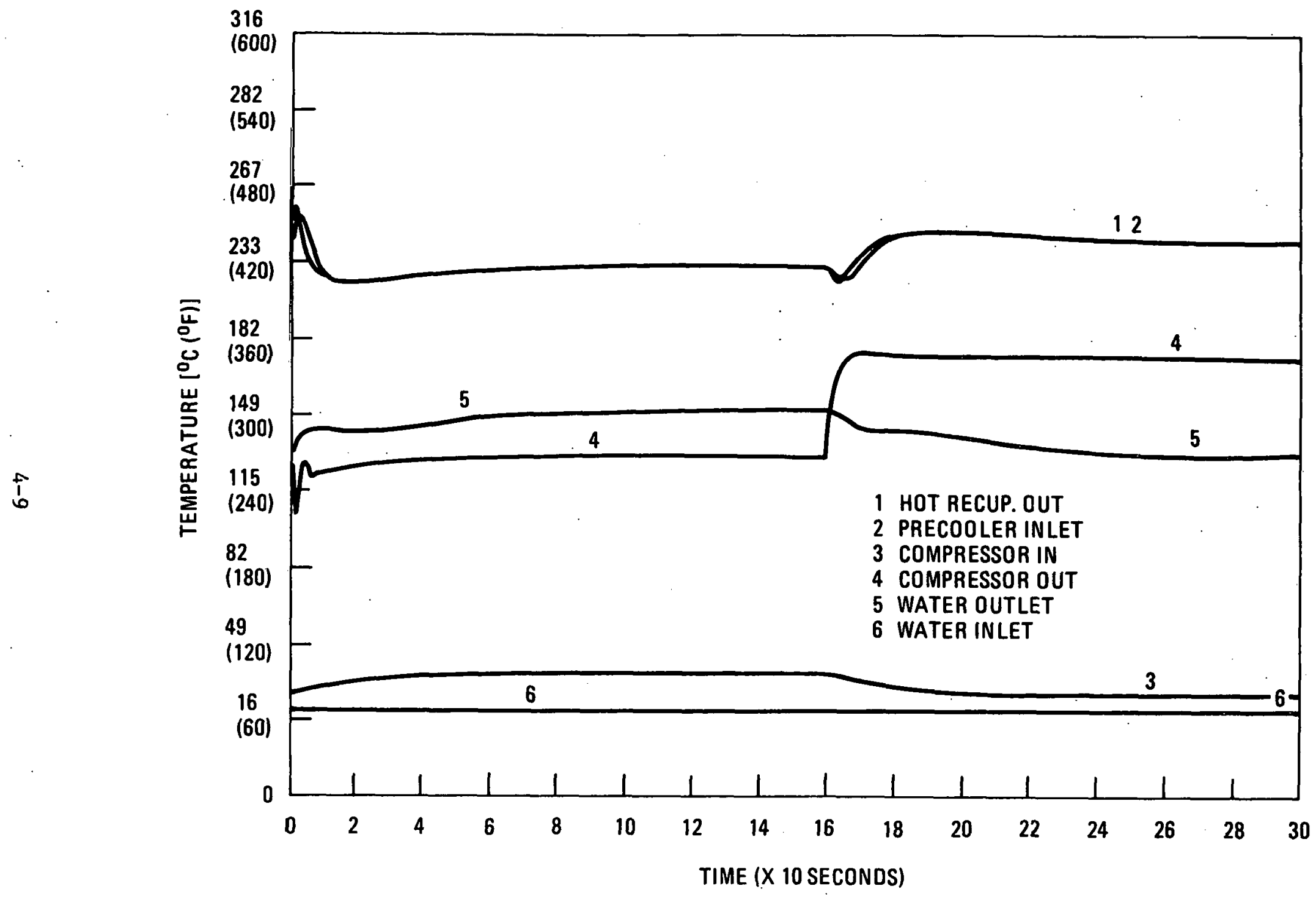

Fig. 4.2-1c. Ref commercial plant - plant loss of load low temperature transients (multi-1oop) 
Precooler water inlet temperature (Fig. 4.2-1c) has not changed since the circulating water system circuit time is approximately $420 \mathrm{sec}$.

With the plant operating in "Hot Standby" at $\sim 160 \mathrm{sec}$ the reactor power is at $\sim 70 \%$ nominal, and core outlet temperature is at nominal. At this time full load demand is established (after the turbomachines are synchronized and the generator breakers closed). The primary bypass valves are closed by command of the load/speed controllers. Consequently, the flow to the turbine increases and turbine $\Delta \mathrm{T}$ also increases. This drop in turbine outlet temperature permits the reclosure of the attemperation valves.

Turbine load is recovered quickly (Fig. 4.2-1a) - $80 \%$ of nominal electric load in $\sim 5 \mathrm{sec}$. The reactor power increases rapidly due to the feedforward from load demand, which changes at its limit rate to $100 \%$ nominal and the signal from the turbine inlet temperature controller, which detects the drop in core outlet temperature and rapidly attains its maximum demand for increased reactor power ( $10 \%$ of nominal).

As the electric load is totally recovered, temperatures throughout the loops equilibrate. Core outlet temperature returns to nominal, loop flow rate reduces back to nominal. (all valves closed), and precooler heat load returns to nominal.

Full load operation is established by the end of the transient $(300 \mathrm{sec})$. However, the previous operation at higher than normal heat rejection loads would result in a subsequent rise in return water temperature (to the precooler) which would cause some sag in power output for a brief period.

\subsubsection{Late $\operatorname{Reload}{ }^{*}$}

The simulation of a Late Reload differs from the previous transient in only one aspect. The precooler coolant inlet temperature, in this case,

\footnotetext{
* This case was simulated by a step in precooler inlet temperature from $69^{\circ} \mathrm{F}$ to $90^{\circ} \mathrm{F}$ at the beginning of the load rejection transient and does not reflect a meaningful condition until approximately the time of reload. 


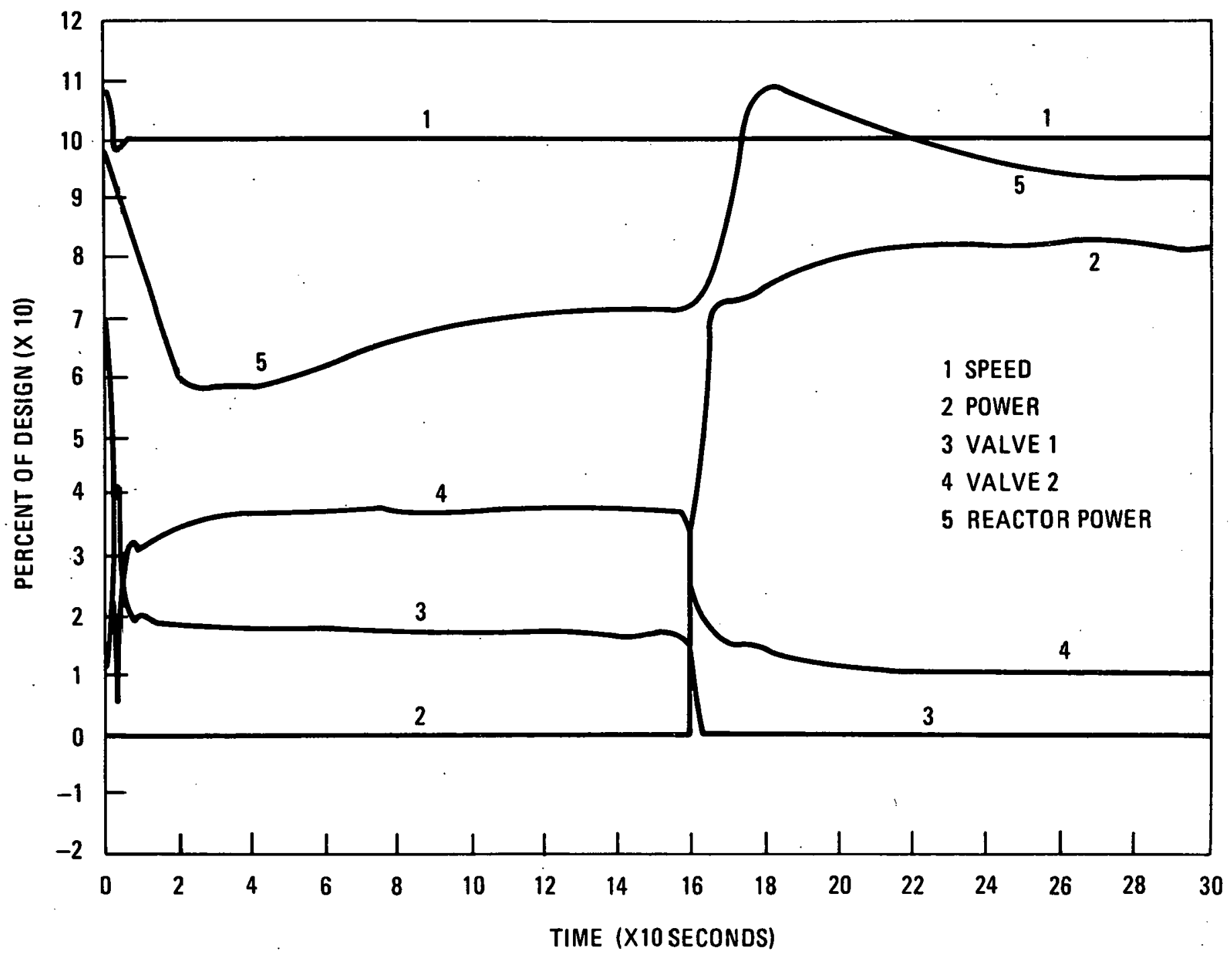

Fig. 4.2-2. Ref commercia1 plant - plant loss of load turbine transients (multi-loop late reload) 
was increased from $69^{\circ}$ to $90^{\circ} \mathrm{F}$. This higher temperature will be the result of prolonged plant operation in the "Hot Standby" mode (higher precooler heat load). As a result of this mode of plant operation the temperatures in the low temperature regions of the loops have increased (25 $\mathrm{F}$ ), and therefore the overall cycle efficiency has been reduced.

The reload proceeds as indicated previously (plant control actions and plant transient behavior is the same). However, the initial static core power ( $95 \%$ of nominal) and plant electric output ( $82 \%$ of nominal) are lower. This derated plant operation is due to the reduction of the cycle efficiency, which results from the previously. existing higher waste heat load. With the reloading the waste heat load is reduced, and when this is reflected back through the CWS (several minutes), the output will increase to the design level.

Figure 4.2-2 presents the load, speed, power and valve data for this case in a format similar to that of the case previously discussed (Figure 1a) for early reload.

\subsection{AVAILABILITY}

\subsubsection{Summary}

This section describes a preliminary evaluation of the availability achievements that may be expected of an HTGR-GT power plant. The report proceeds by first defining the availability parameter that is to be evaluated, then describing the importance of that parameter to the commercial viability of HTGR-GT concept, and subsequently selecting an availability goal of $90 \%$, consistent with industry experience and projections, against which to measure the expected HTGR-GT performance.

The scope of the study reported herein has been limited so effort has attempted to make use of previous availability analyses from HTGR-SC programs and to concentrate on those components and features which are unique to the HTGR-GT. Within this framework, the availability evaluation 
proceeds by comparing the HTGR-GT plant, in terms of scheduled and unscheduled outage, with the HTGR-SC. For scheduled outage, this comprises a comparison of the estimated duration of refueling operations, inservice inspection (ISI) and turbine-generator overhaul for the GT plant with their counterparts for the SC plant. For unscheduled outage, the comparison is made by contrasting the estimated expected values of forced outage hours associated with the systems and components exclusive to the SC plant with those estimated for systems and components unique to the GT plant. The remaining SC systems and components are assumed to have counterparts in the GT plant that have the same value of unscheduled outage hours for the GT plant as for the SC plant.

In this report, the number of expected unscheduled outage hours per year (UOH) for each component or system is estimated by the approximation:

$$
\mathrm{UOH}=\lambda(\mathrm{x}) \tau
$$

where

$$
\begin{aligned}
& \lambda=\text { failure per year } \\
& \tau=\text { mean time to restore the system. }
\end{aligned}
$$

Since the HTGR-GT design is at the conceptual stage and most of the key components are prototypes, including the turbomachine, it is difficult to select appropriate values of $\lambda$ with a high degree of confidence. The values used are from equipment that is judged sufficiently similar to be representative. Values for $\tau$, while also unknown because of no experience on the actual hardware of interest, has been estimated from maintenance task analysis and from experience on similar equipment.

The value of $\mathrm{UOH}$ so obtained for a given component or type are extended to the plant level by multiplying by the number of like components in the plant. The overall UOH for the plant would then be the sum of all estimated system UOH. 
The results of the limited study indicate that the HTGR, like any power plant that requires a long scheduled outage each year for refueling and maintenance, has difficulty in achieving a $90 \%$ availability, per se. However, the calculated availability (i.e. $87 \%$ to $88 \%$ ) indicates a possibility of achieving $90 \%$ through improved design, manufacturing and operational concepts and controls.

\subsubsection{Definitions of Availability and Capacity Factor}

Plant operating availability is defined by the Edison Electric Institute $(E E I)^{(1)}$ and the Nuclear Regulatory Commission ${ }^{(2)}$ as:

$$
\text { Operating Availability }=\frac{\text { (Available Hours) } \times 100}{\text { Period Hours }}
$$

where

Available Hours: Total clock hours in the report period during which the unit operated on line or was capable of such operation (i.e. (period hours) - (forced full outage hours) - (scheduled outage hours)).

Period Hours: Total clock hours in the period being considered.

There are variations of this definition also in use. One of these variations (also defined by EEI) is Equivalent Availability which is defined as follows.

$$
\text { Equivalent Availability }=\frac{\text { (Equivalent Available Hours) } x^{\prime} 100}{\text { Period Hours }}
$$

where

Equivalent Available Hours $=$ The full power hour equivalent of the available hours [i.e. (period hours) (forced full outage hours) $-\sum[$ (partial forced outage hours) $x$ (part power output level) $\div$ (full power output)] - (scheduled outage hours). 
Another variation of availability is Full Power Availability which is simpler to apply but provides results which are generally adequate.

$$
\text { Full Power Availability }=\frac{(\text { Full Power Available Hours }) \times 100}{\text { Period Hours }}
$$

where

$$
\begin{aligned}
\text { Fu11 Power Available Hours }= & \text { Total clock hours the plant is or can } \\
& \text { be operated at full power [i.e. period } \\
& \text { hours - (forced full outage hours) } \\
& - \text { (forced partial outage hours) } \\
& -(\text { scheduled outage hours).] }
\end{aligned}
$$

Another factor of interest for operating plant availability evaluations is Capacity Factor which is defined as:

$$
\text { Capacity Factor }=\frac{(\text { Net Electric Energy Generated) } \times 100}{(\text { Period Hours) } \times \text { (Design Electric Rating Net) }}
$$

From the standpoint of the nuclear plant designer the plant capacity factor goal is a measure of how much fuel must be put in the core for the plant operator to use (i.e. an $80 \%$ capacity factor goal is interpreted as a requirement to produce the equivalent of 292 full power days per refueling). From the standpoint of the plant operator the plant capacity factor achieved, when compared to the plant availability, is a measure of how effectively the plant's capability was utilized.

Plant capacity factor is normally less than plant availability factor because of outages and power reductions required for administrative purposes (i.e. for economy and policy reasons). Because the plant capacity factor difference from plant availability is principally a function of operator requirements and not of plant capability, capacity is not separately evaluated herein. 
If the three definitions of availability above are applied to a period in which a plant is operated without forced partial outages, each definition will yield the same numerical result. If the three definitions are applied to a period in which a plant does incur forced partial outages they will yield values decreasing in the order they are defined. The amount of the differences are estimated to be sufficiently small, for the reasons discussed below, to preclude the need to evaluate forced partial outages at this conceptual design stage.

The amount of the differences'are a function of the duration and the power level of the forced partial outage. How large the difference in availability might be is evaluated by examining the duration and partial power levels that may result.

The three factors which might affect the duration of a forced partial outage are:

1. The plant can remain at partial power while the repairs are made.

2. The plant can remain at partial power while spare parts procured.

3. The plant can remain at partial power until an off-peak system load period occurs so that shut down for repair can be planned for and thereby cause less of a system perturbation.

The actual effect of these possible duration factors are sma11 because:

1. The mean repair time used for evaluation may already reflect the ability to repair while operating for relatively minor failures.

2. There is no spares plan for the plant at this time. and so any procurement time required is assumed to be included in the mean repair time. This generally assumes spares are immediately available in the plant. 
3. Forced partial outage incurred to delay and mitigate the system perturbations caused by a forced full outage for repair at or near the peak load time is a convenience for the system operator and a useful plant capability when required. However, to regularly include it in evaluations would result in a numerical decrease in "equivalent" and "full power" plant availabilities for a convenience in operating flexibility for which a utility evaluator might give no credit.

At the present level of conceptual design, however, there is insufficient information to perform a comprehensive evaluation of the ability to operate at part power while on-line repair or deferred maintenance is performed. Therefore, the concept of Full Power Availability, as defined above, has been employed to simplify the analysis. Furthermore, with the assumption that spare parts are immediately on hand at the time of any component or system failure, it can be seen that full power availability is the maximum of equivalent availability wherein immediate shutdown and repair lead to least lost power generation.

\subsubsection{Availability Goals}

Availability goals are employed as benchmarks against which to measure availability accomplishments and to guide availability improvement efforts. Without establishing goals for the plant and the individual systems, it is difficult to determine when sufficient and cost-effective reliability or maintainability have been provided in the design specifications, etc. In the past, partly because of low fuel and plant costs, the power industry has not taken aggressive actions to improve plant availability and the resulting record shows what has been achieved: the average operating availability factor for all U.S. LWRs for the year 1978 was only $74.8 \%$ but is an improvement over the previous two years. Because of the rising costs of fuel and plant construction, it became evident that such poor performance was economically unacceptable. So, in about 1975, the power industry began to take action to determine the causes of unavailiability and then to take action to eliminate the causes and to minimize the resultant outage times. 
Significant progress is being made in identifying the major causes of outages in nuclear ${ }^{(3)}$ and fossil-fired ${ }^{(4)}$ power plants. None of the studies to date has demonstrated a statistically significant, general change in the average availability of all power plants ${ }^{(5)}$ but the trend appears to be an improvement. That is, the average operating availability factor for U.S. LWRs was $69.3 \%$ in $1976^{(6)}$, and $73.4 \%$ in $1977^{(7)}$ and, as noted above, $74.8 \%$ in 1978. There is confidence in the industry that plant availability will continue to increase as a result of availability engineering programs that are being instituted in power plant projects. EPRI ${ }^{(8)}$ presents availability factors of approximately $80 \%$ for use in current planning of $R \& D$ for $L W R$ and coal or oil fired power plants. In 1977, it was noted that a major architect-engineer was using an availability goal of $86 \%{ }^{(9)}$. Similarly, the recent Sundesert PWR project adopted a goal of $90 \%$ availability. If availability goals of $86-90 \%$ are achieved by competing reactors or appear likely to be achieved by the 1990 s and beyond, then the HTGR-GT must establish similar goals if it is to compete in the marketplace with these other projected designs, or offer significant compensating factors.

To provide a reference value for preliminary estimates of plant downtime associated with the HTGR-GT design, an availability goal of $90 \%$ is assumed. This means that all causes of outage, scheduled or unscheduled, must not exceed 876 hours per year, on the average, i.e. 36 days per year. Knowing that scheduled events like refueling have been known to take a month or more for some LWRs, it is realized at the outset that achievement of $90 \%$ availability will require 1 ) rapid and reliable refueling scheme and expedient execution of any other activities planned for an annual shutdown, and 2) very reliable and easily maintained systems plus an adequate spare parts inventory.

To establish subordinate goals for requirements 1) and 2), it is assumed that an equitable preliminary allocation is an equal share of the allowed downtime: 18 days per year for scheduied outage and 18 days per year for unscheduled outage. The breakdown of these goals is shown in Table 4.3-1. It is emphasized that these goals are selected herein only as a basis for evaluation. There are not necessarily the goals that are to be adopted in the HTGR-GT program. 
TABLE $4 \cdot 3-1$

ASSUMED BREAKDOWN OF HTGR-GT AVAILABILITY PARAMETERS

\begin{tabular}{l|c|c|c}
\hline & & \multicolumn{2}{|c}{ Equivalents } \\
\cline { 2 - 4 } & $\%$ & Days/Yr & Hours/Yr \\
\hline $\begin{array}{l}\text { Allowed Unavailability } \\
\text { (Outage) }\end{array}$ & $90 \%$ & 328.5 & 7884 \\
$\begin{array}{l}\text { Allowed Scheduled Outage } \\
\text { Allowed Unscheduled Outage }\end{array}$ & $5 \%$ & 18.2 & 438 \\
$\quad$ TOTAL & $-100 \%$ & 365.0 & 8760 \\
\hline
\end{tabular}


It is to be noted also that, unless specified otherwise, the values of goals, allocations, failure rates and repair time discussed herein are those expected to apply to a mature plant. These are the values that should set the inherent capability of the design. The values do not allow for design inadequacies, manufacturing errors, inspection oversights, or incorrect operation. This approach recognizes, but does not condone, that errors may occur, but the values employed herein presume that all such errors have been corrected before the plant's performance is measured against the goal. It is recommended that the HTGR-GT program maintain an availability assurance program including special studies to identify significant errors that could occur and then.take steps to preclude their occurrence.

\subsubsection{Effect of GT Unique Features on Plant Availability}

This section describes the results of a preliminary evaluation of HTGR-GT plant availability with respect to meeting high performance goals discussed in section 4.3.3. The evaluation considers both scheduled and unscheduled outage contributions to the total plant outage (unavailability).

4.3.4.1. Scheduled Outage. It scems possible that scheduled maintenance operations required during the plant's operating part of each year may be limited in number and scope so as to be performed during administrative shutdowns or deferred until unscheduled outages occur. Therefore, it is assumed that this is accomplished and therefore the annual refueling-maintenance shutdown is allowed to consume all of the 21 days allocated to scheduled outages in Table 4.3-1.

There are two major task areas that must be performed simultaneousiy during the annual scheduled outage: refueling itself and replacing the turbomachine. One of these will be controlling of the length of the outage. In addition, a considerable amount of inservice inspection (ISI) must be done in parallel with these major tasks. However, additional time must be allocated for certain ISI tasks that must be done in sequence with refueling in order to avoid competition for cranes and other equipment and interference within the space limitations around the top head of the PCRV. 
Refueling Downtime. The HTGR-GT reference design employs the rapid refueling equipment which was also used in the design of the 900 . MWe HTGR-SC Reference Plant. The rapid refueling procedure is performed almost totally automatically and under computer control. The principal human action required in the installation and relocation of the fuel handling machine to the locations of the various refueling penetrations. Hence, with sufficiently reliable equipment and trained personnel, refueling is to be accomplished expeditiously. Design studies for the HTGR-SC indicated that the actual refueling operations could be achieved in about 9.2 days if not interrupted by equipment failure or other cause. It is noted, however, that refueling of the HTGR-GT may require a somewhat longer time because of potential interference and congestion on the refueling floor due to an increased number of major penetrations, in the PCRV top head relative to the HTGR-SC. Further analysis is required to determine whether the additional penetrations have a significant effect on refueling time.

Another factor that must be kept in mind concerning refueling operations time is that if the fuel cycle were to be decreased to 3 years for the GT plant instead of the 4 years assumed for the SC, the number of regions to be refueled each year would Increase by $33 \%$ and the outage required for refueling would also increase.

The amount of ISI which must be accomplished in sequence with refueling may require more time than the 2 days est1mated for the HTGR-SC. Such increases may be due to the presence of four control valves in each power conversion loop as well as the effect of top head congestion. Additional. analysis is required to further define the sequential ISI time requirements.

The other task area that has the potential for setting the length of the scheduled outage duration is scheduled replacement of the turbomachines. Reference 13 states that a turbomachine and generator may be removed and replaced with a spare set in 21 days of 2 shift work. It is immediately apparent that the 21 days plus 1.8 days for plant shutdown and startup exceeds the 18 days allocation proposed previously for the total refueling 
outage. However the 21 days is a preliminary estimate and change from the reference 2 shift schedule to a 3 shift schedule may be one way to shorten that time.

Another factor to consider in evaluating refueling outage time is that the turbomachine is currently being planned for at least a 6 year cycle for periodic removal for inspection and refurbishing. For a three loop plant this would result in one planned turbomachine removal (and a resultant larger refueling outage) only every other year. By judiciously scheduling ISI operations that are not needed every year to be done the same year as turbomachine replacement the alternate year refueling outage, (i.e. when turbomachine replacement is not required) might be significantly shortened. Further analysis is required to determine how these tasks might be integrated to reduce outage time.

4.3.4.2. Unscheduled Outage. Unscheduled outage is caused by failure and subsequent shutdown to effect repair. As noted above, the average annual plant outage forced by failure of a given component or system is estimated by the product of a failure rate, $\lambda$ failures/yr, and a restoration time (repair time plus shutdown and startup time, if required) symbolized by $\tau$, hrs. As noted in Section 4.3.2, this evaluation addresses availability at full power as a representative parameter'since operational availability, per se, is not particular useful for economic comparisons, and an accurate estimate of equivalent availability is not possible for the present level of design detail.

Over several years of reliability and maintainability analyses of various HTGR-SC systems and components, unscheduled downtime predictions have been generated for many such components and systems. These predictions were employed to derive downtime allocations for the reactor systems based on an overall goal of $90 \%$ availability ${ }^{(17)}$. It is noted that these allocations include some margin to cover systems which have yet to have detailed availability predictions performed. In this report it is assumed that those allocations for the HTGR-SC are achievable with proper care and dedication to an availability assurance program. 
Figure 4.3-1 contrasts the system complement of the SC and GT concepts and groups the main components which are employed exclusively in the SC. These are the Feedwater and Condensate, the Turbine Steam, and the Steam Turbine System plus the major components of the Primary Coolant System including circulation and steam generators. The differences in plant control and plant protection systems are not developed in this study. It may be determined that the total allocation for these items amounts to 240 hours per year for the $900 \mathrm{MW}(6)$, HTGR-SC Reference Plant. This is not meant to imply that these SC systems can meet this goal, but for comparison establishes a projected allocation of $240 \mathrm{hrs} / \mathrm{yr}$ as a goal for the HTGR-GT components which replace these SC items.

In the evaluations discussed below, the expected annual downtime for each of the systems exclusive to the GT (see Fig. 4.3-1) is estimated and the total is compared against the goal of $240 \mathrm{hrs} / \mathrm{yr}$ established above.

4.3.4.2.1. Turbomachine (TM). In the HTGR-GT conceptual layout, the TM is to operate inside the PCRV. Although provisions have been considered in the design for access to inspect and repair the TM bearings, some potential failures of the TM will require removal and replacement of entire TM. The current policy is that a spare TM will be available so that actual repair and planned overhauls will be done without delaying restart of the plant. Maintenance task analysis for TM removal and replacement has indicated that even these operations are time consuming: 21 days assuming two shifts per day. Since plant startup and shutdown require about 1.8 days, the total downtime associated with a TM failure would be about 22.8 days (547 hours).

To estimate the expected average unscheduled outage because of TM failures, an appropriate failure rate must be applied. The failure rate(s) of interest, for mature plants, is that for those random failure events which dictate removal from the PCRV. Some failure modes of interest are any which produce disruption of the TM internal components (blades, disk, shaft). A major difficulty in the evaluation is to find a representative failure rate for the TM. Since there are no experience data for nuclearheated, closed-cycle helium TM, a failure rate must he estimated from those of similar machines. The following summarizes the data evaluation. 
The TM is similar in design to other large closed cycle gas turbines and steam turbines rather than to open cycle gas turbines. However, for systems where the heat source is combustion gas, the advantages of the closed cycle operation (e.g., clean working fluid) are offset in part by the inherent low efficiency. Consequently, there are few large, closedcycle gas tutbines and no statistically significant data is available on their failure rates or outage durations. Open-cycle gas turbines, including jet engines are much more numerous than closed-cycle units and more failure rate data is available. However, many of the failures observed for the open-cycle machines have been attributed to the effects of combustion products or inlet contaminants or debris which will not exist in the HTGR-GT application.

Failure rate data for modern steam turbines are available for reference, but the causes of many of their failures are not applicable to gas turbines. That is, blade failures have most often occurred in the last row of the lowpressure stage because of erosion of the long blades by wet steam.

Considerable operating experience with gas circulators and their steam turbine drives has been accrued in the MAGNOX program. (22) These machines employ single-stage axial or centrifugal compressors to circulate $\mathrm{CO}_{2}$ and are driven by either single-stage steam turbines or electric motors.

A summary of gas- and steam-turbine failure rates from representative literature is presented in Table 4.3-2. Fallure rates for modes of interest range from a low of 0.05 to about 3.1 per unit year. However, none of the tabulated data appears to be directly applicable to the TM for the reasons reiterated in the discussion below.

At the high end of the data in Table 4.3-2 are failure rates for all modes in aircraft engines, 1.6 and 2.7 per year, and that for failures of shafts and disks, etc., for steam turbines, 0.8 to 3.1 per year. These failure rates are judged to be too high to be representative of the TM because the jet engine data are suspected to include failures caused by combustion products and inlet impurities and debris, as well as minor failure 
TÁBLE 4.3-2

GAS AND STEAM TURBINE FAILURE RATES

\begin{tabular}{|c|c|c|c|c|}
\hline \multirow{2}{*}{$\begin{array}{c}\text { Data } \\
\text { Reference }\end{array}$} & \multirow{2}{*}{$\begin{array}{l}\text { Type of Unit, } \\
\text { Source of Data }\end{array}$} & \multirow[b]{2}{*}{ Type of Failure } & \multicolumn{2}{|c|}{ Failure Rate } \\
\hline & & & Per Hour & Per Unit Year \\
\hline 20 & $\begin{array}{l}\text { Stationary, General } \\
\text { Electric (open cycle GT) }\end{array}$ & $\begin{array}{l}\text { Fracture of First Row } \\
\text { Turbine Blades }\end{array}$ & $25 \times 10^{-6}$ & 0.2 \\
\hline 12 & $\begin{array}{l}\text { Aircraft, Rolls Royce } \\
\text { Conway } 500 \text { (open cycle GT) }\end{array}$ & All Modes & $350 \times 10^{-6}$ & 2.7 \\
\hline 23 & $\begin{array}{l}\text { Aircraft, P\&W JT3D } \\
\text { (open cycle GT) }\end{array}$ & A11 Modes & $200 \times 10^{-6}$ & 1.6 \\
\hline 12 & $\begin{array}{l}\text { Stationary, Rolls Royce } \\
\text { (open cycle GT) }\end{array}$ & Blade and Disc Failures & $6.4 \times 10^{-6}$ & 0.05 \\
\hline 22 & $\begin{array}{l}\text { MAGNOX } \\
\mathrm{CO}_{2} \text {-Circulator and } \\
\text { Steam Turbine Drive } \\
\text { Data }\end{array}$ & $\begin{array}{l}\text { Circulator }(0.007 / \text { stage-yr }) \\
\text { Turbine }(0.025 / \text { stage-yr })\end{array}$ & & $\begin{array}{l}0.12^{* *} \\
0.20^{* *}\end{array}$ \\
\hline 23 & $\begin{array}{l}\text { Steam Turbine } \\
>600 \mathrm{MW}\end{array}$ & $\begin{array}{l}\text { Full Forced Outage } \\
\text { Al1 Modes* } \\
\text { Shaft, Disk, Blades, } \\
\text { Vibrations } \\
\text { Bearing and Lubrication } \\
\text { Net Equivalent Forced Outage } \\
\text { All Modes } \\
\text { Shaft, Disk, Blades } \\
\text { Vibrations } \\
\text { Bearings and Lubrication }\end{array}$ & & $\begin{array}{l}2.1 \\
0.1 \\
0.7 \\
0.16 \\
7.6 \\
0.7 \\
2.4 \\
0.38\end{array}$ \\
\hline
\end{tabular}

*Includes failures of controls, governors, valves, nozzles, and general items.

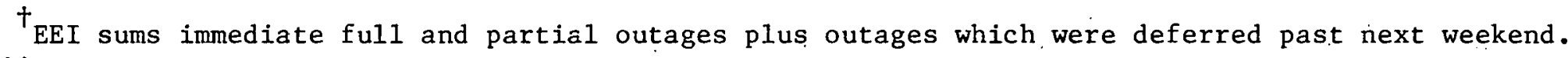

${ }^{* *}$ Assumes 18-stage compressor and 8-stage turbine for GT unit. 
modes which would not be applicable to the TM or would not require removal from the PCRV. Similarly, the steam turbine failures and vibrations are, as noted above, attributed in many cases to erosion wear on the long blades of the last stage.

At the low end of the data is the rate of 0.05 per year for blade and disc failures of the stationary Rolls-Royce engine. While these types of failures are a principal mode which would require TM removal, it is belleved that allowance for other failure modes should be included. Therefore, this value is judged to be too low for the present evaluation.

The data for the stationary General Electric open-cycle gas turbine addresses the observed mean time to fracture of the first row of turbine blades, (20) from which is derịed a failure rate of 0.2 per year. From the content of Reference 20, however, it is not apparent that this failure rate is applicable to an entire gas turbine.

It is believed that the MAGNOX circulator data provides a reasonable source for this evaluation in that the compressors operate in a closed cycle circulating a reactor coolant, although the steam turbine drive data are not necessarilly representative of the TM. The experience data indicate failure rates per stage (MAGNOX uses one-stage machines) of 0.007 and 0.025 per year, respectively, for the compressor and turbine. For the present evaluation, these data were weighted by 18 compressor and 8 turbine stages and assumed to estimate a TM failure rate of 0.32 per year per unit.

Based on the survey presented in Table 4.3-2, a failure rate of 0.2 per year per unit is assumed for the TM. This is less than the median value of an assumed $\mathrm{log}$ normal distribution over the entire set of data of Table 4.3-2, but is greater than the average of the Rolls-Royce engine data. For the three-loop HTGR-GT, the plant level fallure rate for TMs would be 0.6 per year.

Based on this failure rate and the restoration time discussed above (22.8 days), the estimated unscheduled outage bccause of TM fallures is 
328 hrs (13.7 days) per year averaged over the life of the plant. Recalling that the total allocation for unscheduled outage is $438 \mathrm{hrs} / \mathrm{yr}$ for $90 \%$ availability, this evaluation emphasizes the need to assure high reliability for the TM so that a failure fate significantly less than 0.2 per year per unit is achieved. In addition, efforts should consider reduction in the restoration time, including the use of three rather than two shifts.

\subsection{Precoolers. The precoolers for the HTGR-GT are currently} planned to be helically coiled heat exchangers. The tubes are headered into separate water flow sections either half of which can operate independently. The fluid and metal temperatures are relatively low and both the helium and water are expected to be very low in impurities. There is normally no boiling on the water side.

The precoolers have potential impact on availability from leaks developing in the heat exchanger tubing, etc. When such leaks occur and are detected, it is necessary to shut down the loop and take remedial action. Generally, this would be tube plugging. If multiple failures were to accumulate or occur in some common-mode failure, it may be necessary to remove and replace one or more precoolers. The contribution of the latter to availability is not treated in the present evaluation because it is expected to be small relative to the unscheduled outage required for tube plugging. To estimate the effect of independent tube failure, appropriate failure rate and repair time must be determined.

There is no failure rate data available for heat exchangers operating in service identical to that of the HTGR-GT precoolers. Therefore, to obtain a value suitable for use in this evaluation, several data sources were reviewed for values which may be representative of the precooler service. Values selected are listed in Table 4.3-3. Because of the characteristics and operating conditions discussed above and the belief that the precoolers will be carefully constructed, they are expected to exhibit better reliability than many heat exchangers, and should be near the bottom of this range of failure rate. Therefore, for this evaluation, value of 0.02 failures per year is selected. 
TABLE $4 \cdot 3-3$

REPRESENTATIVE HEAT EXCHANGER FAILURE RATES

\begin{tabular}{|c|c|c|c|}
\hline \multirow{2}{*}{$\begin{array}{l}\text { Source } \\
\text { Reference }\end{array}$} & \multirow[b]{2}{*}{ Heat Exchanger. Type } & \multicolumn{2}{|c|}{ Failure Rate } \\
\hline & & Per Hour & Per Year \\
\hline 20 & Steam Generator & $3 \times 10^{-6}$ & 0.02 \\
\hline 20 & Core Auxiliary Heat Exchanger & $3 \times 10^{-6}$ & 0.02 \\
\hline 14 & Al1 Heat Exchangers $(1)$ & $9 \times 10^{-6}$ & 0.07 \\
\hline 14 & Helical Coil Vertical Shell and Tube ${ }^{(2)}$ & $6 \times 10^{-6}$ & 0.05 \\
\hline 14 & Helical Coil Horizontal Shell and Tube ${ }^{(3)}$. & $4 \times 10^{-6}$ & 0.03 \\
\hline 18 & Heat Exchangers $(5)$ & $5 \times 10^{-6}$ & 0.04 \\
\hline 15 & Feedwater Heaters $(4)$ & $2 \times 10^{-6}$ & 0.014 \\
\hline
\end{tabular}

(1) Based on 749 units having $9.7 \times 10^{-6}$ total service hours and 87 total failures.

${ }^{(2)}$ Based on 12 units having $2 \times 10^{-5}$ total service hours and zero failures.

(3) Based on 28 units having $4 \times 10^{-5}$ total service hours and 1 failure.

(4) Based on presented 0.11 failure per plant year and assumed 8 feedwater heaters per plant.

(5) The reference presents a range of failure rates from $1 \times 10^{6}$ to $30 \times 10^{-6}$ failures per hour. The value tabulated above is the approximate $\log$ mean of the range. 
This value appears to be compatible, (perhaps conservatively) with the failure rates cited from Reference 20 for similar service HTGR-SC steam generators and auxiliary heat exchangers. The value selected for the precoolers is considered to be compatible also with the failure rates from Reference 14 which are believed to represent units of lesser quality in less clean service. Finally, the selected failure rate appears to be supported by the approximate unit failure rate derived from Reference 15.

Precooler leakage results in primary coolant helium flowing into the cooling water. If this happens, the affected precooler segment must be isolated and dumped until it can be repaired. Repair requires plant shutdown and precooler tube plugging. The time required for precooler leak location and tube plugging has not been estimated from maintenance task analysis. . Therefore, tube plugging times previously estimated for HTGR-SC steam generator repair were reviewed for applicability.

The steam generator functional specification ${ }^{(16)}$ set a maximum time for plugging and subsequent leak testing of one steam generator tube at 50 hours, including a preparatory time of 5 hours following plant shutdown. Adding an estimated 12 hours for reclosing and leak testing of headers plus 46 hours for plant shutdown and startup, the total restoration time was estimated to be 113 hours (about 4.7 days). This value is believed to be an idealized time that would be found too short to locate and plug leaking tubes under less than ideal conditions.

On the other hand, in an analysis performed to compare the availability of alternate HTGR-SC configurations ${ }^{(21)}$, a repair time of 513 hours (about 21 days) was used. This time included startup and shutdown, gaining access, locating and plugging leaking tubes in a steam generator. Since the HTGR-GT precooler is separated into two, independent water sections with provisions for access, this should expedite the maintenance additions. Therefore, it is believed that 513 hours is too pessimistic for precooler maintenance. For the present evaluation, a nominal repair time of one week (168.hours), including time to shutdown and startup the plant, is selected. 
Using the estimated failure rate of 0.02 failures per year and the estimated repair time of 168 hours, yields $3.4 \mathrm{hrs} / \mathrm{yr}$ of unscheduled outage per precooler. Since there are three precoolers in the plant, precoolers account for. unscheduled downtime of approximately $10 \mathrm{hrs} / \mathrm{yr}$. It is emphasized that this result is based on estimates, interpretations, and. judgments and therefore contain considerable uncertainty. It is presented to indicate the relative importance of precoolers to plant availability.

4.3.3.2.3. Recuperators. The recuperators for the HTGR-GT are unique because they will function only in primary coolant environment. The failure rate data for heat exchangers presented in Table 4.3-3 is used as a guide for selecting a failure rate appropriate to the recuperator. The effective failure rate for recuperators is expected to be extremely low; the effective failure rate takes into account the fact that tube leaks in the recuperator result in a primary to primary leak and only loss in plant efficiency would recessitate a shutdown for repair.

Since a recuperator has primary helium on both sides of the tubes, a leak does not create a safety problem that must be repaired but only causes a decrease in plant efficiency. This appears to permit the plant owner/ operator to defer recuperator repairs indefinitely or until the decrease in plant efficiency becomes unacceptable. In order to define an effective failure rate, then, a minimum efficiency threshold or a corresponding recuperator leakage rate would have to be developed. At the present, this has not been done.

In addition, a proper derivation of an effective failure rate would require a probability distribution of leak sizes for all potential causes within a recuperator. Leak size is a variable because leaks may result from microscopic defects in the tube material, minute cracks or inclusions at tube welds, pinholes eroded or corroded in tube walls, offset rupture of a tube, vibration induced fretting, fatigue, or other causes. It is noted for example, that the modularized vertical tube recuperator employs gasketed joints and bellows at 162 intersections of lead tuhes and tube sheets. These joints are a potential source of leaks. Obviously, if a 
certain leak rate is allowable, more small leaks than large leaks can be accepted before a plant shutdown is dictated. However, the rigorous analysis outlined has not been performed in this study. Instead, the effective failure rate has been evaluated in terms of the number of independent leaks that must occur before recuperator repair is required. This is developed below.

Assume, conservatively, that the physical failure rate at which leaks occur in the recuperators are the same as for precoolers, 0.02 per year. This yields a leak occurrence rate of 0.06 per year for a plant having three recuperators. Further assume that the average leak size is such that five leaks or fewer may be tolerated for the three-loop plant without requiring shutdown and repair. In this approximation, no distinction is made between leaks in module tubes or lead tubes; whenever five leaks of various sizes accumulate, leakage exceeds the allowable value.

Assuming that number of leaks experienced follows a Poisson distribution, it may be shown that the probability of exceeding five leaks in the 40 year life of the plant, with the assumed leak occurrence rate of 0.06 per year, is 0.036 . The effective annual failure rate leading to plant downtime is $9 \times 10^{-4} \cdot(0.036 / 40) \mathrm{yr}^{-1}$. Thus, this numerical development indicates that indeed forced outage because of recuperator failure appears to be improbable. Nevertheless, the impact on availability could be finite if the corresponding repair time is exceedingly long. This is discussed below.

At present, there has not been a detailed quantification of the time required for recuperator maintenance and repair, although many of the actions have been identified. (13) From the descriptions, in Reference 13, it is realized that location and repair of recuperator leaks would be very time consuming. The operations are expected to require remote operation. In addition, the procedure for finding leaking modules appears to be a slow operation: a holddown nut and thermal barrier assembly must be removed and a pressurizing device and pressure gauge must be applied to the inlet and outlet tubes of each module. Subsequent lead tube plugging and refueling must also be done remotely. It is easily envisioned that such operations could require a month or more, at $24 \mathrm{hrs}$ per day, co accomplish. For the 
purposes of this preliminary evaluation it is assumed that the recuperator repair requires one month ( 720 hours).

Using this assumed repair time and the effective failure rate derived above, the unscheduled plant outage attributed to recuperators if $0.6 \mathrm{hrs} / \mathrm{yr}$ on the average over 40 years. Note that in an actual operating plant, recuperator repair would most likely be deferred until an annual refueling shutdown. However, little availability credit can be taken for this since (1) recuperator repairs are done from the top head of the PCRV and are unlikely to be done concurrently with refueling operations, and (2) the extended time for repair so greatly exceeds the allocation for scheduled outage that it must be considered unscheduled downtime.

Again, it is emphasized that the numerical evaluations presented herein is based on estimates and judgments and therefore entails considerable uncertainty. It is intended to illustrate the relative importance of recuperator failures compared to other items. More detailed failure mode and frequency analysis and maintenance task evaluation should be performed to reduce this uncertainty.

Control Valves. There are four control valves in each power conversion loop. One is a safety valve, one main bypass, one trim valve, and one is an attemperation control valve. The safety valve is a two position unit; the other three are modulating units. It is likely that the trim valve will be partly open a portion of the time because rapid load increases must be accommodated by closing a bypass valve to increase turbine output. Excessive bypass flow resulting from valve failure (e.g., leakage) is undesirable in that it decreases plant efficlency. However, small amounts of leakage would likely not be detectable. The valve designs are not firm and a detailed study of valve failure modes and frequencies has not been made at this time. For this preliminary study, a single representative failure rate was employed for the four types of valves.

Failure rates for control valves are observed to vary from about $2 \times 10^{-6}$ to $50 \times 10^{-6}$ per unit hour. (18) As a reasonable estimate, it is 
assumed that the mean failure rate of the HTGR-GT control valves is equal to the log-mean of the above range: $10 \times 10^{-6}$ failures per hour. This is equal to 0.079 failures per year per valve. Since the plant has 12 of these valves altogether, the total failure rate is 0.95 per year, i.e. almost one per year on the average.

As for most of the hardware of the HTGR-GT, the maintenance time for the valves has not been quantified through detailed evaluation. The present concept is to incorporate the pressure retaining valve body structure into the PCRV structure so that the removable portion of the valve consists of the movable spool piece and a cage like structure that contains the seat. There is a closure plug at the top of this structure through which the valve steam reaches the actuator. The actuator assembly is located in a wall on top of the PCRV for easy access without plant shutdown. Only signal leads are required to pass through the boundary. Removal and replacement of the valve assembly is planned to be done remotely.

The installation and the handling of a valve is judged to be very similar to that for a control rod and drive assembly (CRDA) although the valve has fewer electrical leads and is considerably larger in diameter and heavier. The total time required for removing and replacing a CRDA has been estimated previously in HTGR-SC maintenance studies to be 3.2 days ( 77 hours), assuming no delays. This value seems appropriate for a preliminary estimate of unscheduled outage duration for control valve repair assuming spares are available and the operation is only removal and replacement.

Using the failure rate and repair time discussed above, the annual average unscheduled outage attributed to the PCL valves is estimated to be $73 \mathrm{hrs} / \mathrm{yr}$. This is a significant amount and implies that further efforts and attention should be given to reducing the uncertainty in the present evaluation.

It is noted that the effective failure rate for the valves may be lower than that employed if leakage, up to a certain level, can be discounted as a failure that requires shutdown for repair. On the other hand, the 
assumed repair time may be optimistic; maintenance task analysis should be performed and spare parts policy should be considered in defining a more appropriate repair time.

4.3.3.2.4. Contrast of Other SC and GT Systems. There are other systems that will have differences between their HTGR-GT and SC versions. At this time it appears that the effect of their differences on plant scheduled and unscheduled outage (and thus on plant availability) will be less significant than the effects of the hardware previously discussed. However, the more significant systems and their differences are briefly reviewed in the following paragraphs for the sake of completeness.

The PCRV for the GT plant requires internal cavities and penetrations for the turbomachines, precoolers, recuperators and valves which appear to increase the complexity.

The Plant Control System and Plant Protection systems appear to have fewer parameters to monitor and control in the GT plant than the SC plant. Therefore, the GT plant control system may have lower unscheduled outage than the SC plant control systems.

Some differences are expected in the cooling water systems for the GT and SC plants. The circulating water system. for the SC plant provides water to the condenser. For the GT plant it provides water to the precoolers inside the PCRV. Since each precooler has 2 independent water pathways, a large variety of water supply configurations are possible. The configuration is still not firm and has not been evaluated for availability considerations.

Another area in which cooling water systems are anticipated to differ results from the differences in turbomachine-generator arrangement. The HTGR-SC housed its turbine generator machinery in a structure of its own which requires various services including cooling water. In the HTGR-GT the turbomachines are installed in the bottom of the PCRV with shaft connection directly to the generators which are outside the PCRV and outside 
the containment. The generators are dispersed about equally spaced about the containment building periphery and each has its own enclosure. For the HTGR-GT, cooling water must be supplied to each of the turbomachines to cool lubricating oil and to each of the generators to provide a heat sink for deionized cooling water system that each generator requires. The details of these cooling. water systems have not been worked out in sufficient detail to allow availability analysis. However they are based on existing design, it is believed that judicious design may result in their having little effect on the water systems unscheduled outage.

The 3 loop HTGR-GT requires 3 generators and their associated transformers and circuit breakers. The HTGR-SC requires 2 generators and associated equipment whether cross compound or tandem compound arrangements are used. Generators for large plants have demonstrated significant unscheduled outage times in current power plants with the larger units having greater outage hours. It is noted in this comparison that the HTGR-GT has the greater number of generators but each generator is smaller. It is anticipated that the difference in generator outage will be small and the outage differences. from transformers and circuit breakers will also be small because they inherently have small unscheduled outage values. 


\section{REFERENCES}

1. "Report on Equipment Availability for the Ten Year Period, 1967-1976."; Edison Electric Institute Report No. 77-64, dated December 1977.

2. "Operating Units Status Report - Liscensed Operating Reactors", Department of Energy, Nuclear Regulatory Commission Report No. NUREG0020, Vol. 3. No. 1, Dated January 1979.

3. "A Summary of Nuclear Power Plant Operating Experience for 1975", Electric Power Research Institute Report No. EPRI NP-263, Dated October 1976.

4. "Availability Patterns in Fossil-Fired Stream Power Plants", Electric Power Research Institute Report No. EPRI FP-583-SR, Dated November 1977.

5. "Performance of Nuclear Power Plants in 1977", POWER ENGINEERING, Dated July 1978.

6. "Operating Units Status Report - Liscensed Operating Reactors", Department of Energy, Nuclear Regulatory Commission, Report NUREG 0020, Volume 2, No. 1, Dated January 1978.

7. "Operating Units Status Report - Liscensed Operating Reactors", Department of Energy, Nuclear Regulatory Commission, Report NUREG 0020 Dated January 1977.

8. "Tehcnical Assessment Guide", Electric Power Research Institute, Report No. EPRI PS-866-SR, Dated June 1978.

9. "Industry Report - Maturing in a Lean Economy", NUCLEAR NEWS - BUYERS GUIDE, Page 40, Dated Mid-February 1977.

10. "Sun Desert Nuclear Plant Availability Improvement Design Plan". Paper by R.J. Nath and Dr. L. Bernath, Presented at the American Power Conference, Chicago, Illinois, April 24-26, 1978.

11. "Stationary Gas Turbines - Stage of Developments, Experience Regarding Operation and Losses", Paper by J. Leupold, Munich, Translator Dr. S.A. Nang, Memo 1040-D, Dated May 1976. 
12. "3000 MW(t) 3 Loop Non Intercooled Commercial: HTGR-GT", General Atomic Company unpublished data, Dated 19 April 1979.

13. "GT-HTGR Plant Maintenance Studies", General Atomic Report No. GA-A14858, Dated March 1979.

14. "Nuclear Plant Reliability Data Systems 1977 Annual Reports of Cumulative System and Component Reliability", Prepared by Southwest Research Institute of San Antonio Texas for American National Standards Institute commit tee $\mathrm{N} 18-20$.

15. "Nuclear Unit Productivity Analysis". Electric Power Research Institute, Report No. EPRI SR 46, Dated August 1976.

16. "HTGR Steam Generator. Functional Specification" General Atomic Company unpublished data.

17. "Design Report: Availability Studies Summary for HTGR-SC 900 MW(e) Ref. Plant", General Atomic Company, unpublished data, Dated 4 June, 1979.

18. "Reliability and Maintainability Manual - Process Systems" Atomic Energy of Canada Limited Chalk River Nuclear Laboratories, Report AECL 4607, Dated January 1974.

19. "A Reassessment of Turbine-Generator Failure Probability", Nuclear Safety, Vo1. 19, No. 6, November-December, 1978 .

20. "GCR Reliability Data Bank Status Report" General Atomic Report, No. GA-A14839, Dated July 1978.

21. "HTGR Steam Cycle Configuration Evaluation Report" General Atomic Co., Report No. GA-A14900, Dated April 14, 1978.

22. 'The Central Electricity Generating Boards' Nuclear Power Stations: A Review of the First 10 years of Magnox Reactor Plant Performance and Reliability", by F. Dikon and H.K. Simons, British Nuclear Energy Society Journa1 13, January 1974.

23. "Availability of Fossil-Fired Steam Power Plants", Electric Power Research Institute, EPRI FP-422 SR, June 1977. 


\section{SAFETY AND LICENSING}

The excellent safety of the HTGR-SC, demonstrated via the AIPA study (Ref. 5-1), is attributed to inherent and passive safety features such as single-phase helium coolant, coated fuel particles, graphite moderator and PCRV. As shown in Table 5-1, the HTGR-GT encompasses these same features. Section 5.1 discusses these features in somewhat more detail. The inherent safety features are augmented by engineered safety features which are discussed in Section 5.2. Although a comprehensive risk assessment study of the HTGR-GT has not been performed, it is reasonable to assume that this concept can match the safety excellence of the steam cycle plant.

There are, however, a number of unique features of the HTGR-GT which will require substantial investigation before 1 ts safety characteristics can be determined better. For example, turbomachine deblading accidents can cause rapid pressure transients within the primary coolant system. Preliminary analyses have been performed and new models are currently being developed to simulate the deblading accidents. Considerable effort is also being directed at this particular accident by HRB and EIR for the HHT project. General Atomic is developing several programs, TUBE and RATSAM-GT, for the analysis of these and similar accidents involving pressure transients in the HTGR-GT primary coolant system.

Based on preliminary. reviews of both jet aircraft engine and steam turbine experience, serious deblading accidents are estimated to occur at a frequency between $10^{-3}$ to $10^{-5}$ /year. While these frequenctes may be considered relatively high, 1 is is expected that the consequences of such accidents, in terms of dose to the public, are relatively low thereby reducing risk to acceptably low values. These expectations can only be verified with a detailed risk assessment study of the direct cycle plant. 
TABLE 5.1

KEY INHERENT AND PASSIVE SAFETY FEATURES OF THE HTGR

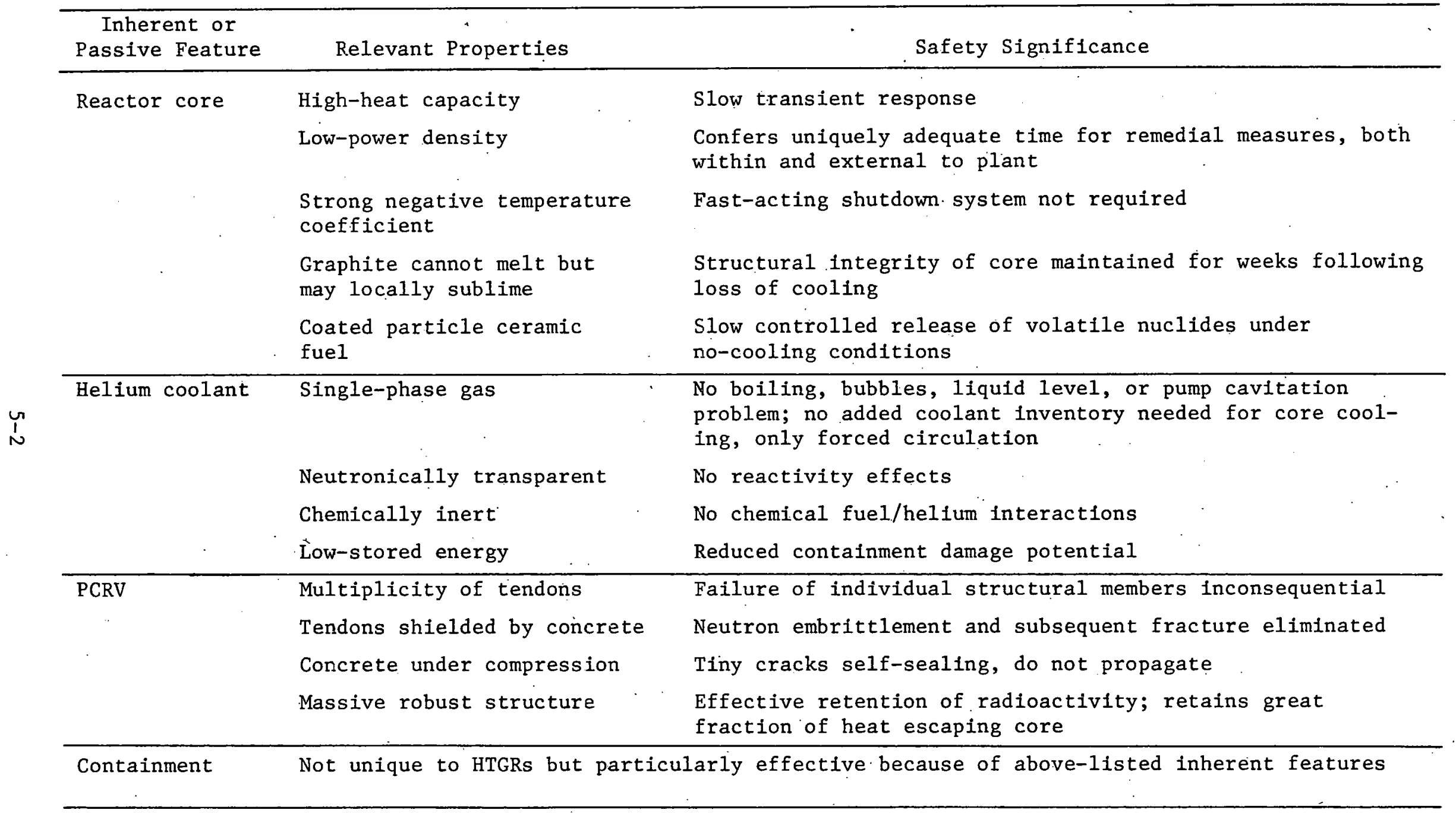


There are other specific areas of concern such as the effect of higher core temperatures on fission product release and reduced safety margins in general. For the same fuel system, increases in normal fuel temperatures will result in a slightly larger fraction of falled fuel and a corresponding slightly greater release of fission products to the primary coolant system. In addition to increasing steady state levels of radioactivity in the primary coolant system 'and an increased duty for the helium purification system, the Design Basis Depressurization Accident (DBDA) source term will be more severe. In general, the off-site doses resulting from a DBDA are relatively small compared to other postulated accidents, especially with a conventional lined containment. Increased fuel temperatures are not expected to alter the conclusions regarding the DBDA. Increased steady state fuel temperatures will also reduce the margins to fuel particle failure during core heatup events. It is not expected that the consequences of an HTGR-GT core heat-up event would be significantly different from that of an HTGR-SC with the same power rating. However, since there are other differences in design between the two plants, this area must be studied thoroughly. Higher graphite temperatures will accelerate the reaction.with any steam/water which is introduced into the core. However, water ingress events such as pre-cooler failure are not expected to introduce significant quantities of steam/water into the core and therefore, such events are not expected to be a significant problem area. Additional analyses of the potential for water ingress is planned.

Although a decalled risk assessment of the HTGR-GT concept has not been performed, a preliminary assessment of the Loss of offset Power (LOSP) initiating event has been completed and is discussed in Section 5.3. This study was performed to obtain some perspective of the safety of the HTGR-GT: concept relative to the HTGR-SC.

\section{5:1. INHERENT AND PASSIVE SAAFTY FEATURES}

As noted earlier, the safety excellence of the HTGR is attributed to inherent and passive safety features. These features are summarized in Table 5.1 and diecusacd in this section. 
The HTGR core is constructed exclusively of ceramic materials, primarily graphite, which maintain their integrity at very high temperatures, well above normal operating conditions. The core itself weighs almost 3 million pounds, and this, together with a low power density and strong negative temperature coefficient of radioactivit-, insures that reactor temperatures and power transients will proceed very slowly. In the event of loss of core cooling capability, the graphite acts as a crucible by maintaining its structural form for weeks with only some local sublimation and with no possibility of melt-down. Volatile radionuclides are released gradually over a period of days, while the nonvolatile nuclides are retained. Because of the inability to melt-down, the integrity of the prestressed concrete reactor vessel (PCRV) and containment is maintained as a retardant to fission product transport. Interruptions of more than 30 minutes can be tolerated without any damage to primary coolant system components. At least three hours would always be available to restore cooling system operation after interruptions in core cooling before any fuel damage or radioactivity release could occur because of the slow rate of temperature rise and the retention characteristics of the fuel at elevated temperatures.

Another inherent characteristic of the HTGR of importance to safety is the choice of primary coolant, helium. Because helium is chemically inert, has a low-stored energy content, and remains in the gaseous phase under all conceivable operating conditions, it cannot chemically react with the core, vessel, or containment structures in a destructive way and results only in mild pressure transients in the containment subsequent to blow-down. Since heat can be removed from the reactor core with any misture of gases present even at low pressures, it is not necessary to maintain an inventory of coolant in the reactor vessel to prevent overheating of the fuel. Hence, coolant injection systems are not needed. The single-phase gas coolant permits the design of cooling systems that minimize the dependence on operator actions to bring the reactor to a safe cool-down, a feature which has great benefit during an accident. 
A special passive feature of the HTGR is the use of a PCRV, which was introduced in gas-cooled reactors in Britain because of its safety characteristics. The PCRV is a massive, structurally redundant monolith that encloses the entire primary coolant system boundary with the exception of small process and instrument tubing. During postulated core heat-up accidents, the PCRV retards the transport of fission products to the containment and helps protect the containment from the degrading effects of the core heat-up environment. The strength of the PCRV is provided, in part, by a large number of steel tendons that run axially through and circumferentially around the vessel. The concrete shields the tendons from neutron irradiation, thereby preventing embrittlement, and since the concrete is under compression, tiny cracks tend to be self-sealing and are not subject to propagation.

The containment structure is the final barrier to the release of radioactive material. Despite the fact that its design is conventional, the containment structure of the HTGR is particularly effective because of the unique HTGR features described above. The passive features of the core and PCRV and the choice of coolant ensure that rapid releases of energy do not occur and that low leakage characteristics of the containment. are maintained. As a result, the consequences of even severe HTGR accidents are inherently low.

\subsection{ENGINEERED SAFETY FEATURES}

In addition to the inherent and passive safety features discussed in Section 5.1, the HTGR-GT concept contains a number of engineered safety features to mitigate the consequences of accidents, including:

1. the Core Auxiliary Cooling System, (CACS),

2. the Reactor Reserve Shutdown System,

3. the PCRV Overpressure Protection System. 
4. the Precooler Leak Detection, Pressure Relief, Isolation and Dump Systems,

5. the Turbomachine Overspeed Control System,

6. the Penetration Shaft Protection System,

7. the Generator Missile Protection System, and

8. the Turbocompressor Burst Shield.

The CACS provides an independent means of reactor cooling whenever the main loops are unavailable. The HTGR-GT system is expected to be similar to the system employed by the steam cycle HTGR, but with the design bases changed to reflect the higher core inlet temperature, different gas pressure, and a different back pressure following a design basis depressurization accident (DBDA).

The reactor reserve shutdown system provides a means, independent of the normal control rod system, for shutting down the reactor. The system for the HTGR-GT will be similar to that of the steam cycle plant.

PCRV overpressurization will be prevented by discharging the gas from the high-pressure region of the PCRV into the low-pressure region of the PCRV. The pressure relief valves in the HTGR-GT are the safety bypass valves. Overpressure protection is provided in spite of the fact that all HTGR-GT water systems are at pressures below the primary coolant pressure and all other systems that could supply fluid at pressures near the primary coolant pressure (such as the bearing and seal fluids) have limited flow rates or small inventories.

The precooler leak detection, pressure relief, isolation and dump systems are designed to prevent the release of radioactivity to the environment and the ingress of significant quantities of water to the precooler cavity in the event of a precooler failure. 
The overspeed control system will open valves, causing a bypass flow, to prevent theturbomachines from exceeding their overspeed limit. The penetration shaft protection system protects the shaft and its seals from the consequences of seizure of either the generator or the turbocompressor. The shaft has a corss-sectional area which is much greater than 100 in $^{2}$ or any other reasonable free-flow area which might be specified for the DBDA, so the shaft integrity must be preserved.

The purposes of the generator missile protection system are to contain missiles created by generation failure and to contain or prevent an explosion or fire from ignition of the bearing lubricant. The turbocompressor burst shield ensures that the consequences of turbine failure do not prevent safe shutdown of the reactor. 


\section{RESOURCE CONSERVATION}

\subsection{WATER CONSERVATION}

Dry air cooling as a solution to the problem of thermal discharge to natural water resources, has not been used in the U.S. for large thermal power plants because of the great expense required. This has been true even though dry air cooling has four main attributes that can be of great importance in particular situations: (1) the large increase in possible plant sites, (2) near zero requirement for makeup water, (3) the avoidance of secondary problems such as fogging, icing, etc., which occur with evaporative cooling water systems and (4) elaborate once through cooling associated equipment and regulations.

Because of thegrowing limitations on the availability of natural water reserves, especially in the south, south-west and northwest regions of the U.S., the selection of sites for electric generating stations utilizing once-through or evaporative towers (wet cooling) is becoming an increasingly difficult task.

In order to satisfy the growing demand for electrical generating capacity, heat rejection systems combining wet cooling tower and dry cooling tower systems can be designed to meet site and plant requirements and provide the necessary heat rejection capabilities while minimizing impact on local water supplies and total plant capital and operating costs.

The wet/dry cooling tower concept is ideally suited for application to the HTGR-GT. The high temperature of the reject heat from the precooler of the closed-cycle HTGR-GT plant allows the system to make greater use of the dry cooling towers for heat rejection than electric generating stations which operate at lower reject heat cycle temperatures (eg. LWR's). 
Preliminary studies indicate that the makeup water requirements for the HTGR-GT are significantly less than the makeup water requirements of a LWR of similar output capability. To demonstrate this feature, a simplistic evaluation comparing the annual water usage of a 1186 MW(e) HTGR-GT to a $1380 \mathrm{MW}(\mathrm{e})$ LWR is made below.

The wet/dry cooling tower concept discussed in this section is one which combines physically separated wet towers and dry towers into an operational unit.

A typical layout for the wet/dry cooling tower system is illustrated in Figure 6.1-1. The dry cooling tower is sized to carry the plant heat rejection load at a low ambient temperature (dry tower design point) within specified limits. A separate wet tower is added to augment the heat rejection capability of the dry tower at higher ambient temperature conditions. During peak ambient temperature conditions, both the wet cooling tower and the dry cooling tower are operated at full capacity. As ambient temperature falls, the wet cooling tower cells are taken out of service in succession until the dry tower design point temperature is reached where all wet cells would be out of service. This action minimizes water usage without panalizing plant output.

The histogram shown in Figure 6.1-2 depicts the annual wet bulb/dry bulb temperature profile for Modesto, California. Figure 6.1-3 shows the anticipated plant response of the HTGR-GT over varying ambient tempexatures. This figure assumes that the dry tower design point is $59^{\circ} \mathrm{F}$ dry bulb temperature and that $20 \%$ of the reject heat load is rejected by the wet cooling tower at $100^{\circ} \mathrm{F}$ dry bulb temperature. This design assumption implies that approximately 1 - 10\% of the yearly plant reject heat load is accomplished by evaporative (wet tower) cooling. As ambient temperature increases above $59^{\circ} \mathrm{F}$ dry bulb, the wet cooling tower cells are brought into operation in such a manner as to maintain the plant electrical output nearly constant. 


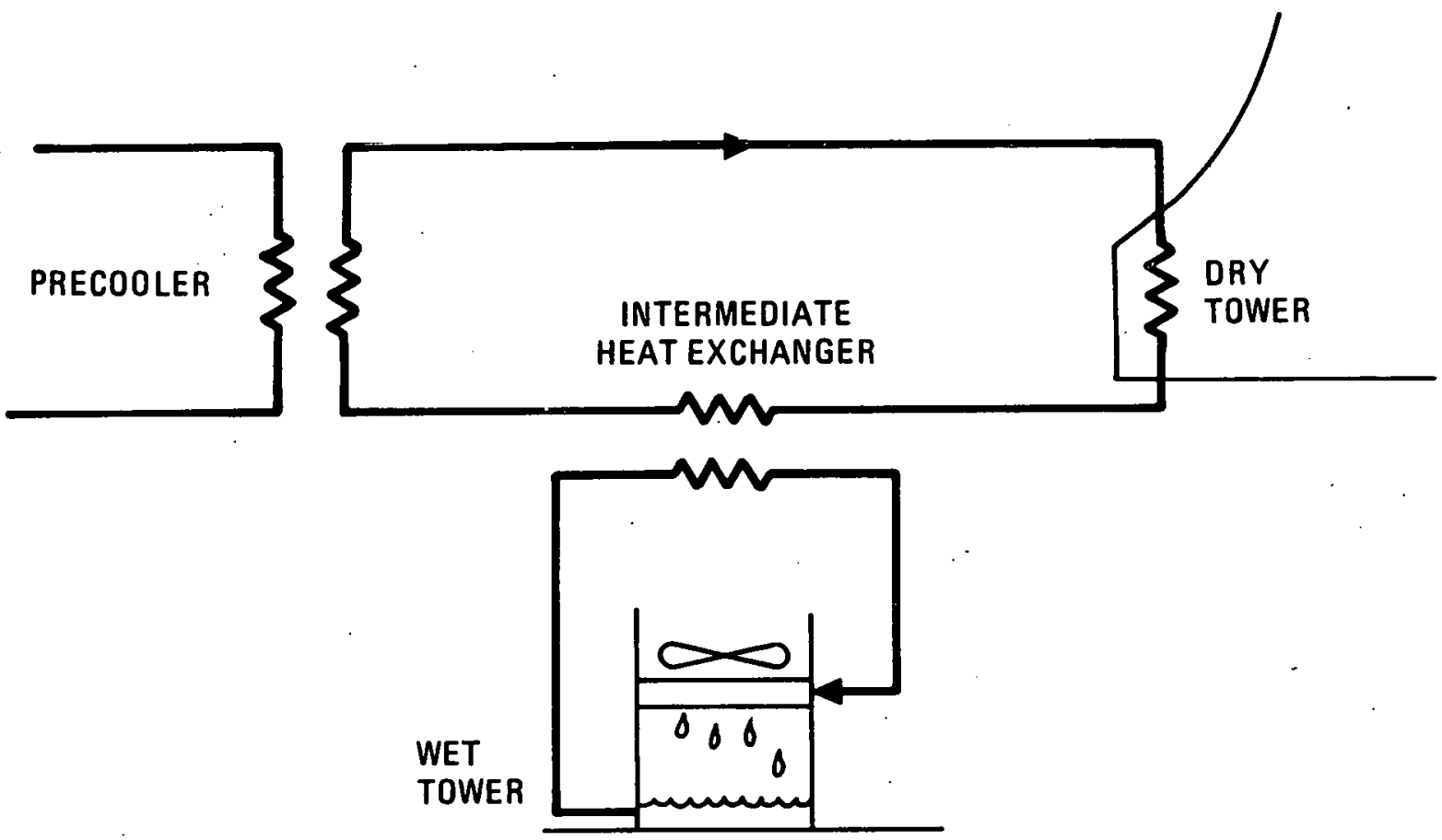

F1g. 6.1-1. Wet/dry cooling tower system 


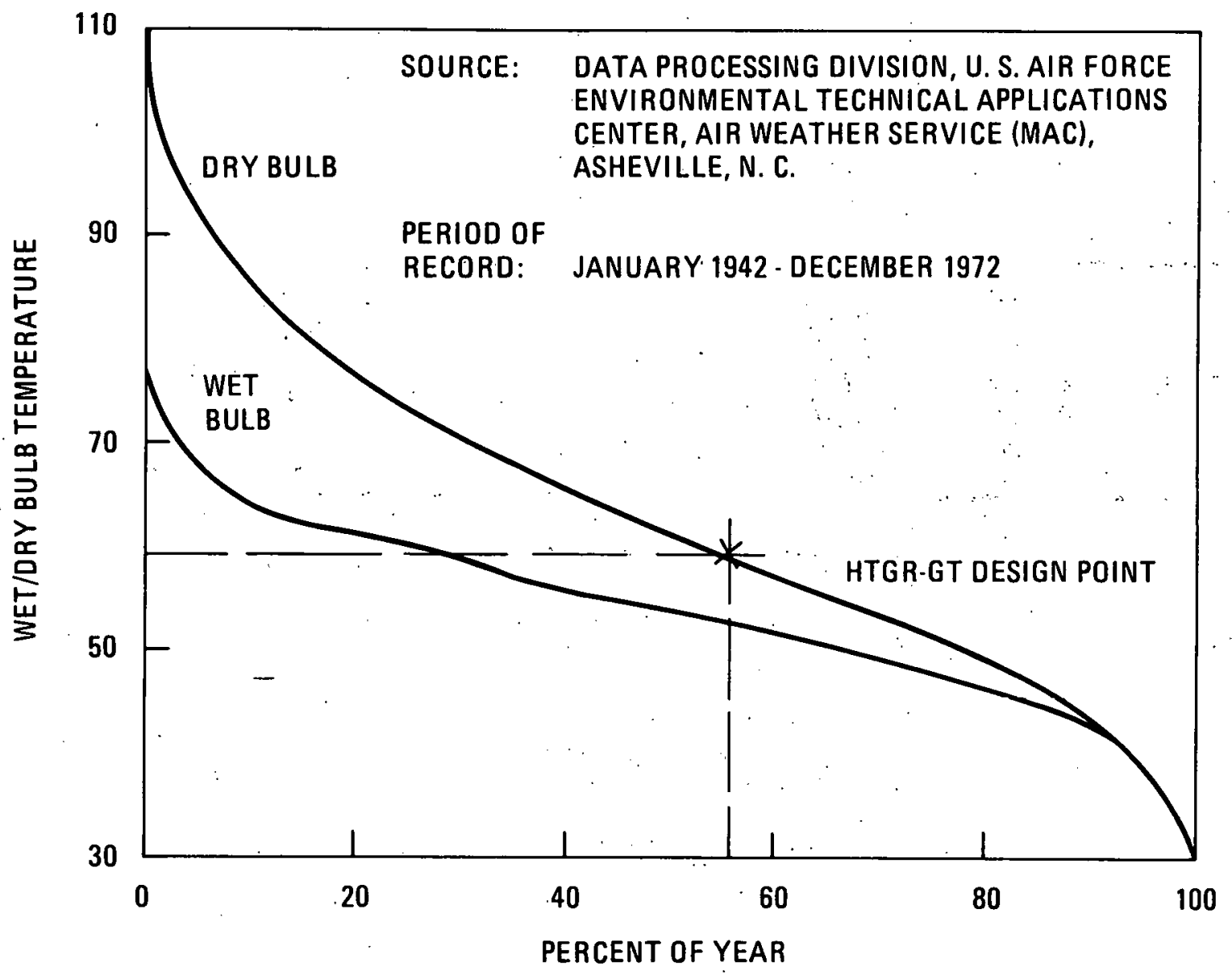

Fig. 6.1-2. Annual wet/dry bulb temperature histogram for Modesto, California 


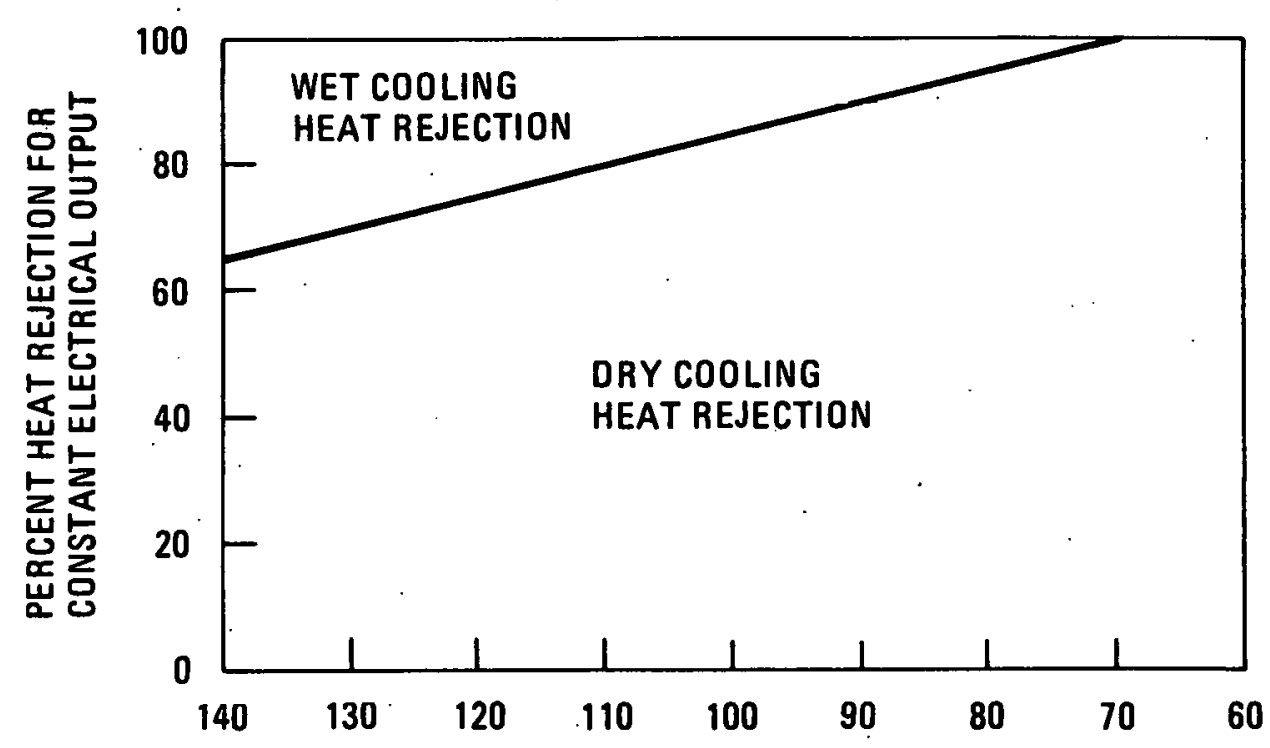

Fig. 6.1-3. Percent heat refection as dry bulb temperature 
The wet cooling towers could be operated to provide additional cooling in excess of the heat rejection loads shown in Figure 6.1-3 when the ambient air temperature is below the dry tower design point temperature. There may be incentives to operate in this manner, i.e., possible increase in plant efficiency and/or plant net electrical output, however, such operation would increase the makeup water requirements above the amount required to maintain a constant plant electrical output and for the purpose of this analysis is not being considered.

Table 6.1-1 provides the evaluated annual water usage associated with the wet/dry cooling tower configuration for the HTGR-GT described above at the Modesto, California site for a total reject heat load of $1746 \mathrm{MW}(t)$. Table 6.1-2 provides data for comparison of makeup water requirements for the HTGR-GT and a LWR of similar capacity. It should be noted that the makeup water requirements due to evaporative cooling for the HTGR-GT as indicated in this data analysis are less than $6 \%$ of the requirements for an all wet tower cooled LWR and less than $60 \%$ of the makeup water: requirements for a 10\% wet cooled LWR. The LWR makeup water requirements were obtained from a study of HTGR/LWR circulating water systems prepared for General Atomic Company by Burns and Roe, Inc., titled "HTGR/LWR Nuclear Power Plant Circulating Water Systems Utilizing Wet and Dry Cooling Towers in Combination", January 1976. The LWR makeup water requirements were evaluated for the Modesto, California site.

A preliminary economic analysis is presented below to show the economic incentives of going from an all-dry cooling tower system to a wet/dry cooling tower configuration for the HIGR-GT. Table 6.1-3 presents the expected differences of capital investments between an all-dry and a wet/dry cooling system. The data is normalized to the total capital investment for the al1dry cooling system and is evaluated for the wet/dry system configuration and reject heat requirements previously discussed. Except for dry cooling costs, the main piping cost remains constant. The dry cooling tower cost is reduced significantly because of the reduced sizing requirements $(80 \%$ total 
TABLE $6.1-1$.

\begin{tabular}{l|c|c}
\hline & & $\begin{array}{c}\text { Required Water } \\
\text { Annual Acre-Ft }\end{array}$ \\
\cline { 2 - 2 } HTGR-GT & 80\% Dry Cooled & 998 \\
LWR & ALL Wet Cooled & 17,394 \\
LWR & $90 \%$ Dry Cooled & 1,739 \\
\hline
\end{tabular}

TABLE 6.1-2.

\begin{tabular}{c|c|c|c}
\hline $\begin{array}{c}\text { Temp Range } \\
\text { Dry Bulb }\end{array}$ & $\begin{array}{c}\text { \% of Cooling } \\
\text { Accomplished } \\
\text { by Wet Tower }\end{array}$ & $\begin{array}{c}\text { Duration of Plant } \\
\text { Operation in This } \\
\text { Range }\end{array}$ & $\begin{array}{c}\text { HTGR-GT } \\
\text { Required Water } \\
\text { Annual Acre-Ft }\end{array}$ \\
\hline $60-70^{\circ} \mathrm{F}$ & $6 \%$ & $52-31=21 \%$ & 231 \\
$70-80^{\circ} \mathrm{F}$ & $10 \%$ & $31-15-16 \%$ & 290 \\
$80-90^{\circ} \mathrm{F}$ & $16 \%$ & $15-6=9 \%$ & 261 \\
$90-100^{\circ} \mathrm{F}$ & $19 \%$ & $6-1.5=4.5 \%$ & 156 \\
$100-110^{\circ} \mathrm{F}$ & $22 \%$ & $1.5-0=1.5 \%$ & 60 \\
\hline
\end{tabular}


TABLE 6.1-3

HTGR-GT NORMALIZED COST EFFECTS

\begin{tabular}{|c|c|c|}
\hline . & All Dry & Wet/Dry \\
\hline Nonnuclear Piping & 12.77 & 12.77 \\
\hline Circulator Water Pumps & 3.20 & 3.86 \\
\hline Makeup Pumps, Pressurization Tank, Filters & 0.90 & 0.90 \\
\hline Instrumentation, Electrical & 1.46 & 1.46 \\
\hline Excavation and Backfill, Foundation & 0.52 & 0.52 \\
\hline Testing & 0.59 & 0.59 \\
\hline Miscellaneous and Unspecified & 1.53 & 1.53 \\
\hline . & 20.97 & 21.63 \\
\hline Contingency (20\%) & 4.20 & 4.33 \\
\hline$\cdots \quad \cdot$ & $25: 17$ & $\begin{array}{c}25.96 \\
:\end{array}$ \\
\hline Dry Tower Cost & 62.36 & $3 i .18$ \\
\hline Contingency on Dry Tower (20\%) & 12.47 & 6.23 \\
\hline Wet Cooling. Tower Cost (Including Pumps and Piping) & 0 & 8.38 \\
\hline Intermediate Heat Exchanger & 0 & 12.74 \\
\hline Water Treatment (Wet Tower) & 0 & 1.38 \\
\hline Raw Wațer System & 0 & 1.65 \\
\hline & & 24.16 \\
\hline TOTAL Direct Capital Costs & 100 & 87.53 \\
\hline
\end{tabular}


plant reject heat load). The wet tower and intermediate heat exchanger adds a significant percentage to the total system cost, however, the final totals show a $15 \%$ reduction in wet/dry system capital costs.

Table 6.1-4 shows the effects of combining capital costs and capacity penalties for the HTGR-GT and an LWR of similar capacity. The combined savings for the HTGR-GT are very similar to the amount of savings for the LWR that are obtained in going from an all-wet to a wet/dry cooling configuration. The LWR capital and penalty cost data were obtained from a study evaluating wet/dry cooling tower systems for water conservation prepared by United Engineering and Constructors, Inc. for ERDA titled "Engineering and Economic Evaluation of Wet/Dry Cooling Towers for Water Conservation".

The combined savings for the HTGR-GT are very similar to the amount of savings for the LWR due to a change from all-dry to wet/dry cooling. Therefore, the economic incentives for the HTGR-GT should remain about the same regardless of whether all-dry or wet-dry cooling is used as the basis of the designs. Because the water consumption for the HTGR-GT is not known exactly, one can only compare the data to the 1 to $10 \%$ water consumption cases for the LWR, since the HTGR-GT water consumption will fall somewhere near this range. The exact figure to be compared to the HTGR-GT is probably closer to the $10 \%$ wet/dry case than the $1 \%$ wet/dry area.

\subsection{URANIUM CONSERVATION}

The HTGR is characterized by very flexible fuel cycles which may be used interchangeably without signiflcant changes in plant design. Flexibility is achieved as a result of the fuel element particle concept. The fuel material consists of very small ceramic coated particles which ocrupy a relatively small but readily adjustable fraction of the fuel element volume. As a result, the fuel particles do not contribute to the fuel element structural integrity. The use of helium coolant, which does not have an 
TABLE 6.1-4

ALL-DRY AND WET/DRY COOLING COMPARISONS OF NORMALIZED

CAPITAL AND CAPACITY PENALTY COSTS

\begin{tabular}{|c|c|c|c|c|c|}
\hline & \multicolumn{5}{|c|}{ Cooling Mode } \\
\hline & \multicolumn{2}{|c|}{ HTGR-GT } & \multicolumn{3}{|c|}{ LWR } \\
\hline & A11-Dry & Wet/Dry & Al1-Dry & Wet/ & Dry \\
\hline Water Consumption & 0 & 1 to $10 \%$ & 0 & $1 \%$ & $10 \%$ \\
\hline Total Capital Cost & 100 & 88 & 379 & 300 & 243 \\
\hline Capital Penalty & 47 & (33) & 220 & 106 & 84 \\
\hline Sum of Above & 147 & 55 & 443 & 406 & 327 \\
\hline Savings Compare to Al1-Dry & 0 & 92 & 0 & 37 & 116 \\
\hline
\end{tabular}


effect on the reactor physics characteristics, combined with the relatively low power density, makes it possible to design fuel elements with the desired degree of heterogeneity of fuel material that is appropriate for a particular fuel cycle.

From an economic and resource utilization standpoint, the optimal fuel cycle in the HTGR-GT is the High Enriched Uranium/Thorium (HEU/Th) cycle. The use of fully enriched uranium, however, has become a subject of concern from the standpoint of possible proliferation of materials suitable for nuclear weapons production. As a result of this concern, the reference HTGR-GT fuel cycle is now based on the use of Medium Enriched Uranium-Thorium (MEU/Th) with the fissile U-235 being enriched to $20 \%$. The reference cycle is based on the assumption that the $\mathrm{U}-233$ bred from the thorium will be recovered and recycled as denatured MEU-233 with a fissile U-233 enrichment of $12 \%$, or if permissible, as highly concentrated U- 233 .

\subsubsection{Reference Fuel Cycle}

The initial HTGR-GT fuel design was based upon the HEU/Th fuel with U-233 recycle and provided for flexibility in reducing fuel cycle costs in case of high uranium price escalation and/or limited HEU availability.

As a result of nuclear proliferation concerns and current U.S. national policy, the reference fuel cycle design is now based upon the MEU/Th cycle.

The major parameters of the reference fuel cycle are:

$\begin{array}{llc} & \underline{\text { Recycle }} & \text { Once Through } \\ \text { - Fuel Cycle } & \text { MEU/Th } & \text { MEU/Th } \\ \text { - Core power density } & .7 .0 \mathrm{w} / \mathrm{cm}^{3} & 7.0 \cdot \mathrm{w} / \mathrm{cm}^{3} \\ \text { - Fuel lifetime } & 4 \text { years } & 4 \text { years }\end{array}$




$\begin{array}{lcc}\text { - Refueling cycle time } & 1 \text { year } & 1 \text { year } \\ \text { - Carbon/Thorium ratio } & 600 & 850 \\ \text { - Fissile material } & \mathrm{UC}_{2} & \mathrm{UC}_{2} \\ \text { - Fertile material } & \mathrm{ThO}_{2} & \mathrm{ThO}_{2} \\ \text { - Conversion ratio } & 0.61 & 0.55 \\ \text { - Fast fluence } & 6.4 \times 10^{21} \mathrm{nvt} & 6.4 \times 10^{21} \mathrm{nvt} \\ \text { - Burnup } & 103,500 \mathrm{MWD} / \mathrm{MT} & 128,200 \mathrm{MWD} / \mathrm{MT}\end{array}$

The HTGR-GT design permits the use of different fuel cycles without plant modification. Changes in or a combination of these fuel cycles can be effected during the life of the plant. Possibilities are discussed below.

\subsubsection{Fuel Cycle Variations}

6.2.2.1. MEU/Th Cycle Stowaway. The fuel particle design used in the HTGR-GT allows a significant degree of flexibility for altering the reactor conversion ratio and/or the heavy metal burnup achieved over cycle. This flexibility allows the designer to choose the optimum fissile/fertile loading combinations for specific design assumptions. In the case of the MEU/Th stowaway cycle, a high-fuel burnup is desired so that the discharged fissile fuel value will be as low as possible.

The minimum cost design for the MEU/Th throwaway or stowaway cycle results at a burnup of about 128,200 MWD/MT. The heavy metal loading which results in this burnup is characterized by a fairly light thorium loading, i.e. C/Th-850. The $\mathrm{C} / \mathrm{Th}$ ratio can be changed in later fuel cycles for a plant that has started operation if that is desired. For example, an early plant optimized to operate on the stowaway cycle, could be reoptimized to a recycle uranium condition after reprocessing facilities are put into operation.

6.2.2.2. MEU/Th Cycle With Recycle. The flexibility of the HTGR-GT fuel form allows a variety of recycle options including no recycle, recycle of bred U-233, and recycle of all uranium. It is assumed that recycle of the 
plutonium produced from U-238 in the MEU/Th cycle would not be allowed in any situation that did not also allow the use of the HEU/Th cycle. For the HTGR-GT, the amount of plutonium discharged in the MEU/Th cycle is relatively small and does not represent a large penalty. to the fuel cycle economics if it is assumed to have zero value.

The reference MEU/Th fuel cycle described in 6.2 .1 is based on cycle optimization results assuming the recycle and/or recovery of discharged uranium, including both the bred U-233 as well as the residual fissile makeup uranium. The ability to physically separate the bred uranium from the residual feed uranium during reprocessing allows a number of recycle options. These include:

- recycling $12 \% \mathrm{MEU}-233$.

- recycling U-233 (HEU-233 or MEU-233) as well as the higher enriched portion of the discharged residual fissile uranium.

- recycling U-233 and re-enriched residual fissile uranium.

Any of these partial or total uranium recycle strategies result in net $\mathrm{U}_{3} \mathrm{O}_{8}$ resource requirements and fuel costs appreciably lower than those for the LWR with uranium recycle.

\subsubsection{Resource Utilization. An important parameter in the comparison} between LWR and HTGR design variations is the uranium ore requirements. This comparison is shown in Table $6.2-1$.

For any specific assumption on cycle varients, i.e., throwaway, MEU or LEU uranium recycle, or $\mathrm{HEU}$ and $\mathrm{Pu}$ recycle, the HTGR requires significantly less $\mathrm{U}_{3} \mathrm{O}_{8}$ than the comparable LWR cycle. 
TABLE $6.2-1$

30 YEAR $\mathrm{U}_{3} \mathrm{O}_{8}$ AND ENRICHMENT REQUIREMENTS

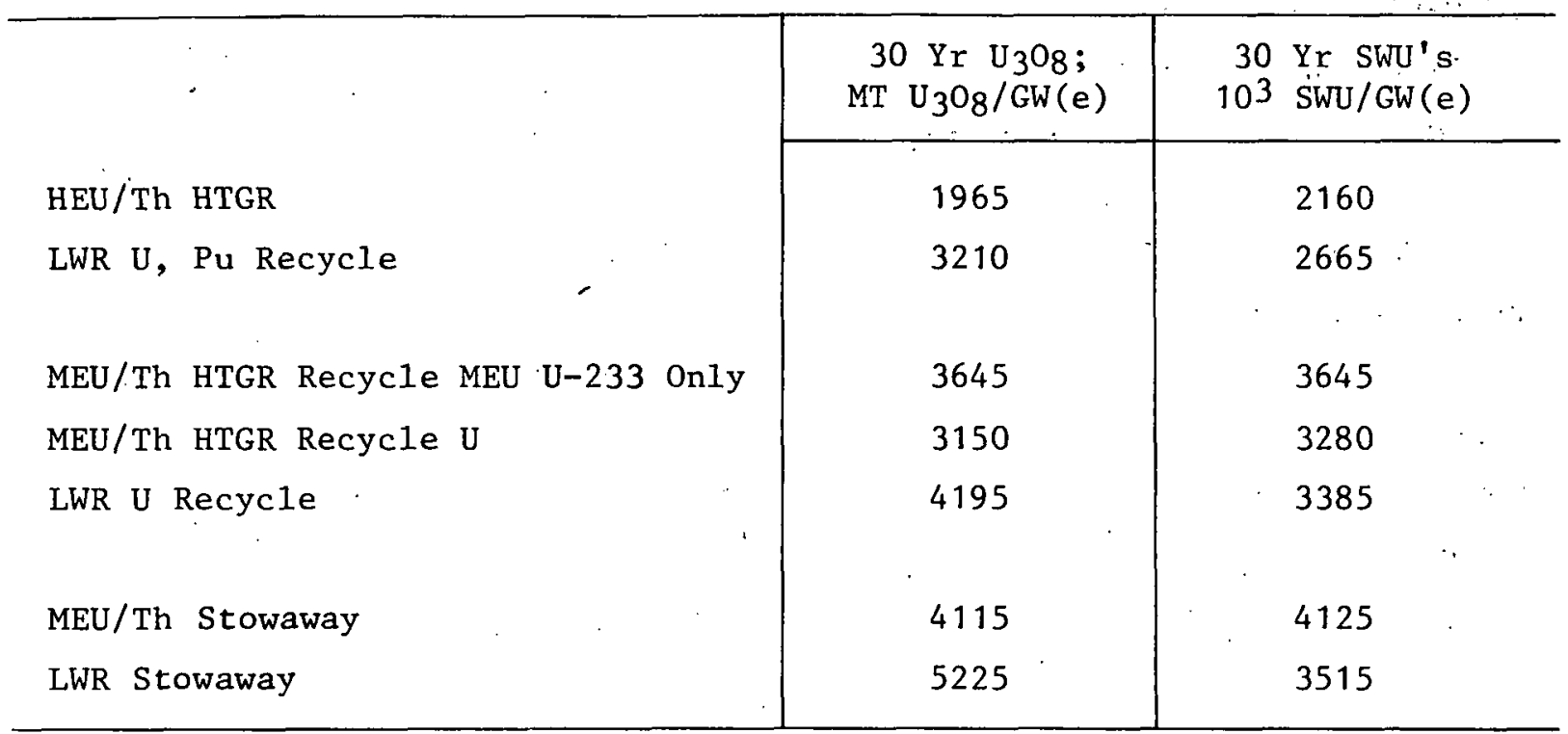

Based on $70 \%$ annual capacity factor and $0.2 \%$ tails assay. Plant efficiency $=39.7 \%$. 
Even in a national economy initially dominated by LWRs, the reduced ore requirement is a significant factor to the individual utility owner. The reduced $\mathrm{U}_{3} \mathrm{O}_{8}$ requirement for the HTGR provides an effective hedge aginst inflation as well as against any real increase in $\mathrm{U}_{3} \mathrm{O}_{8}$ costs due to future scarcities of supply. 


\section{ENVIRONMENT IMPACT}

\section{7.i. RADIOACTIVE WASTE}

During normal operation of an HTGR-GT power station, radioactive material will be produced by fission and by neutron activation of constituents of the primary helium coolant. Most of the fission products will remain within the coated fuel particles, however, small quantities may escape through the pyrolytic graphite coatings into the graphite of the fuel elements and finally diffuse into the primary helium coolant. Reactor core components may be expected to be contaminated with graphite dust and lightly adherent films of plateout activity. Additionally, the primary coolant and its attendant fission products may be expected to leak at a very low rate from the operating reactor to the containment and subsequently to the environment. The HTGR-GT plant will have installed waste treatment systems designed to collect and. process the gaseous, liquid and solid waste that will be produced by coolant purification processes, decontamination procedures, and various system leakages that may occur during plant operations.

Specific estimates of the quantities of radioactive waste generated during the operation of the GT plant have been made. The following discussion briefly summarizes the information on HTGR-GT radioactive wastes and compares estimates of HTGR-GT waste quantities to LWR plants of similar thermal power rating.

\subsubsection{Liquid Wastes}

During operation of the HTGR-GT plant, a number of radioactive liquid wastes are generated, collected, and subsequently processed by the liquid waste processing system, A tabulation of the expected sources of the liquid radioactive waste is as follows: 
- Decontamination System Fluids ( 3000 ga1/year).

- Water drained from the helium regeneration cooler and from the radioactive gas recovery system (if installed) ( $\sim 5$ gal/year).

- Low level laundry and contaminated slower liquid waste $(\sim 120,000 \mathrm{gal} /$ year $)$.

- Infrequent operational occurrences of a precooler dump may result in water condensate $(\sim 4000 \mathrm{gal})$.

Most high specific activity liquids will not be processed for reuse, but will be solidified or otherwise fixed and treated as solid waste. Other lowspecific activity fluids (e.g. laundry and contaminated shower water) will be sampled, analyzed and processed if necessary.*

Normally, no water from the liquid waste system would be released to the environment. However, if the processed water is not recycled as makeup water to various plant systems, and if its concentration satisfies discharge limits, the liquid may be discharged to elther recelving water bodies or sanitary sewage systems.

Estimates of the quantity and activity levels present in liquid waste effluent for the HTGR-GT are summarized in Table 7.1-1. Also provided in Table 7.1-1 are similar estimates of the liquid waste effluents for LWR (both BWR and PWR) plants. It is apparent that anticipated HTGR-GT radioactive liquid waste discharges to the environment are but small fractions of similarly sized LWR plants in terms of both activity levels and quantities.

${ }^{*}$ Presumably, processed liquids could be recycled into plant systems. 
TABLE 7.1-1

ANNUAL RADIOACTIVE WASTE GENERATION - NORMALIZED TO A REACTOR THERMAL POWER OF 3150 MW

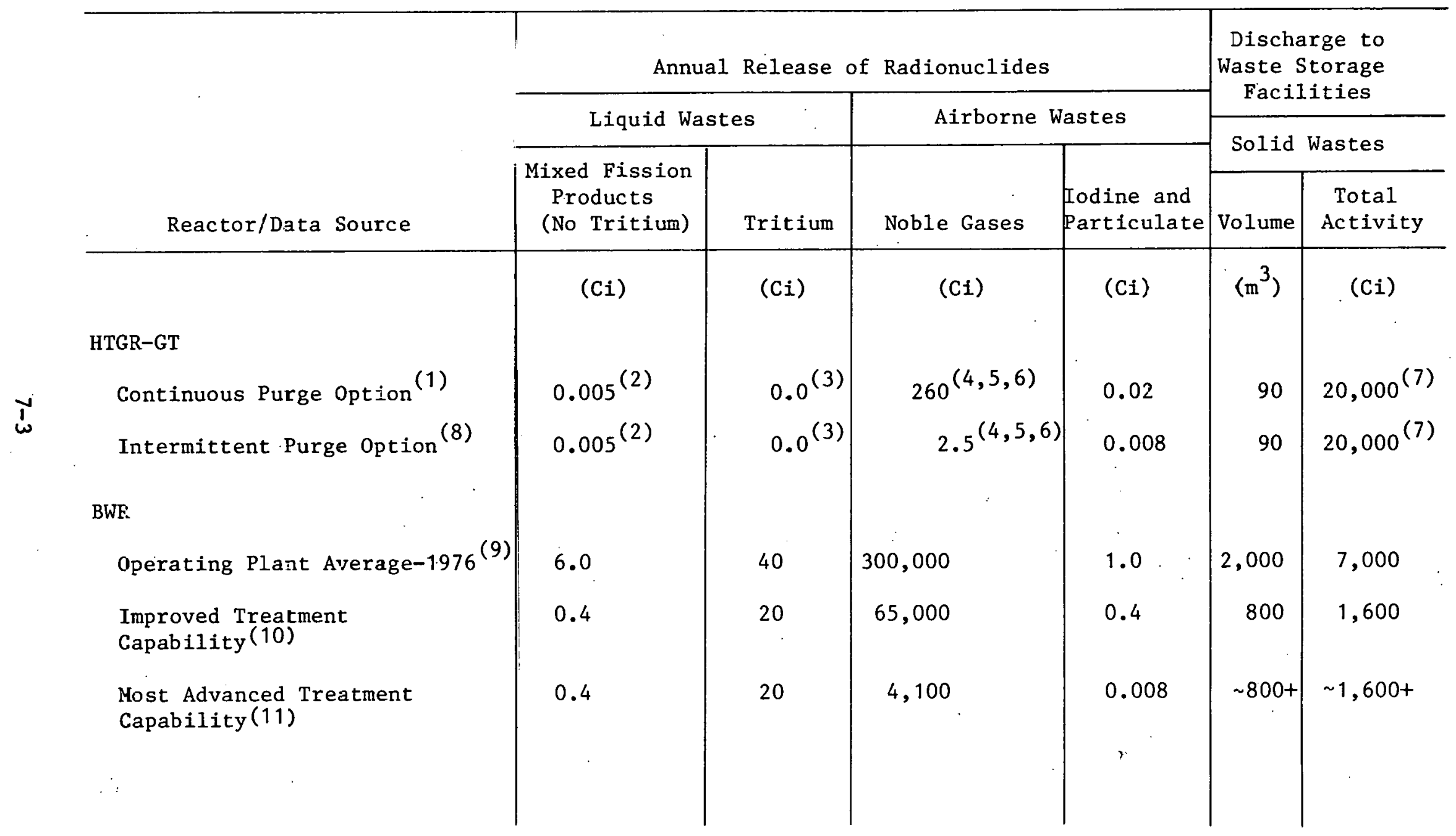


Table 7,1-1 (Continued)

\begin{tabular}{|c|c|c|c|c|c|c|}
\hline & \multicolumn{4}{|c|}{ Annaul Release of Radionuclides } & \multicolumn{2}{|c|}{$\begin{array}{c}\text { Discharge to } \\
\text { Waste Storage } \\
\text { Facilities }\end{array}$} \\
\hline & \multicolumn{2}{|c|}{ Liquid Wastes } & \multicolumn{2}{|c|}{ Airborne Wastes } & \multirow{2}{*}{\multicolumn{2}{|c|}{ Solid Wastes }} \\
\hline & Mixed Fission & & & & & \\
\hline Reactor/Data Source & $\begin{array}{l}\text { Products } \\
\text { (No Trịtịm) }\end{array}$ & Tritium & Noble Gases & $\begin{array}{l}\text { Todine and } \\
\text { Particulate }\end{array}$ & Volume & $\begin{array}{l}\text { Total } \\
\text { Activity }\end{array}$ \\
\hline PWR & (Ci) & (Ci) & (C1) & (C1) & $\left(m^{3}\right)$ & (Ci) \\
\hline Operating Plant Average-1976 & 7.0 & 1000 & 20,000 & 0.2 & 1,000 & 400 \\
\hline $\begin{array}{l}\text { Improved Treatment } \\
\text { Capability }(10)\end{array}$ & 0.03 & 350 & 4,000 & 0.05 & 200 & 6,000 \\
\hline $\begin{array}{l}\text { Most Advanced Treatment } \\
\text { Capability(11) }\end{array}$ & 0.002 & 350. & 1,300 & 0.006 & $\sim 200+$ & $\sim 6,000+$ \\
\hline
\end{tabular}

\section{NOTES:}

1. The continuous purge option employed assumes once through containment ventilation at a rate of 0.5 volume/hour. Effluent is filtered at an efficiency of $99.97 \%$ for particulate and $99 \%$ for Halogens. No extrapment of noble gases is possible.

2. Essentially only low specific activity fluids (e.g. laundry and contaminated shower water) would be available for release after sampling and processing. Discharge would be to either cooling tower blowdown (if wet cooling tower option selected) or to receiving water bodies, streams, lakes, etc. or perhaps sanitary sewers if MPC levels are satisfied. [Ref. Fulton PSAR Table 11.2.2-1.]

3. Waste containing tritium in significant concentrations occur only in high specific activity liquids which are subsequently solidified and processed as solid waste. No release of $\mathrm{H}-3$ contaminated liquid to the environment in liquid waste discharge is anticipated. 


\section{TABLE 7.1-1 (Continued)}

\section{NOTES (Continued)}

4. Airborne Tritium release of $0.24 \mathrm{Ci} /$ year included in total.

5. Discharge of noble gases from the gas waste system not anticipated. Recycle of $\mathrm{Kr}-85 \mathrm{with}$ the eventual license. disposal at plant decommissioning is planned.

6. Airborne release indicated is primarily due to containment building ventilation and leakage. Reactor service building ventilation release of Noble Gases are expected to be less than $0.2 \mathrm{Ci} /$ year and are primarily the result of Gas Waste Compression and gas recovery system expected leakage [Ref. Delmarva PSAR, Table 11,3.6-2].

7. Approximately $70 \mathrm{~m}^{3}$ as low level waste $(900 \mathrm{Ci}), 5 \mathrm{~m}^{3}$ as titanium sponge waste $(12,000 \mathrm{Ci})$ and $15 \mathrm{~m}^{3}$ as replaceable rəflector block waste $(6000 \mathrm{Ci})$. [Ref. Fulton SER, NUREG-75/033]

8. Intermittent purze for HTGR-GT anticipated to be 2 complete containment purges per year. The containment atmosphere enginəered clean-up system is actuated 24 hours prior to containment ventilation to the atmosphere. Ventilation of the containment atmosphere is assumed to be filtered during discharge to the environment, effluent is filtered at an efficiency of $99.97 \%$ for particulates, $99 \%$ for Halogens and $0 \%$ for noble gases.

9. Information reported in NUREG-0367, "Radioactive Materials Released from Nuclear Power Plants (1976)," T.R. Decker 3/78 was.: normalized to form a "typical" $3150 \mathrm{mw}(t)$ PWR or BWR plant for the year 1976. For the year 1975, NUREG-0367 reports a total BWR thermal capacity of $26.3 \mathrm{GW}(t)$ and PWR thermal capac1ty of $41.9 \mathrm{GW}(\mathrm{t})$.

10. Ref. WASH-1258, 'Numerical Guiles for Design Objectives and Limiting Conditions for Operation to Meet the Criterion" As Low As Practicable" for Radioactive Material in Light-water-Cooled Nuclear Power Reactor Effluent:3." Volume 1, July 1973, NOTE: Treatment Systems BWR-3 and PWR-5 selected as representative of improved treatment capability.

11. Most advanced treatment capability of WASH-1258 selected as follows: Airborne treatment system BWR-7 and PWR-8, and liquid treatment system BWR-3 and PWR-6. 


\subsubsection{Gaseous Wastes}

In the normal conduct of plant operations, small quantities of radioactive material will be released to the atmosphere in gaseous effluents. Included in the tabulation of radioactive gaseous sources terms are the following:

- PCRV leakage of primary coolant to the containment building.

- Helium purification system regeneration off-gas.

- Radioactive gas recovery system off-gas (if this option is employed).

- Radioactive analytical instrument sampling effluent.

- Fuel handling operations (auxiliary service cask off-gas, fuel handling machine off-gas during refueling, fuel shipping cask off-gas).

- Liquid and solid radioactive waste processing systems off-gas.

- If a wet cooling tower option is selected, and if radioactive liquids are discharged to the cooling tower blowdown stream, some evaporation of activity may be anticipated. Dry cooling towers, would not release airborne radionuclides.

The reactor containment structure will be purged with air on a oncethrough basis to maintain airborne radioactive material at a level below allowable limits for access to the containment. This ventilation air, which contains PCRV leakage, will be exhausted through prefilter, HEPA and activated charcoal filters to the atmosphere. For the HTGR-GT, the remaining environmental discharge of gaseous wastes is through reactor service building leakage and normal operation and discharge from the gas waste system. 
Table 7.1-1 summarizes the expected release of gaseous wastes to the environment for the HTGR-GT operating with a once-through air purge basis. Additionally, Table 7.1-1 also dislays expected gaseous release estimates for a HTGR-GT closed containment/intermittent purge ${ }^{*}$ option. As would be expected, the intermittent purge option greatly reduces the release of gaseous waste, as containment ventillation to the environment is precluded between purges, thus allowing radioactive decay of the contained noble gases.

For comparison purposes, the LWR gaseous waste is displayed in Table 7.1-1. Two estimates of LWR gaseous release are displayed: 1) actual measured releases for existing plants, averaged over 1976, and 2) estimates of BWR and PWR release with moderate and extensive liquid and gaseous waste treatment system installed.**

It is apparent, after inspection of Table 7.1-1, that HTGR-GT gaseous waste releases to the environment are but small fractions of measured LWR discharges in 1976. Extensive gaseous waste stream treatment would reduce LWR releases, however, it is felt that HTGR-GT releases would continue to be less than LWR discharges.

\subsubsection{Solid Waste}

Solid radioactive waste will be generated during plant operations and will require disposal. Sources of solid waste tor the H'l'GK-G' are as follows:

- Reactor core components such as replaceable reflector blocks, in-core instrumentation, control rods and drive mechanisms.

\footnotetext{
* Intermittent purge for the HTGR-GT is anticipated to be two containment purges per year. The containment atmosphere clean-up system is assured to be activated 24 hours prior to containment ventilation to the atmosphere. Ventilation of containment atmosphere contents is assumed to be filtered during discharge to the environment.

** See WASH-1258, "Numerical Guidelines for Design objectives....," for more information on BWR and PWR gaseous and liquid radwaste systems.
} 
- Spent resins resulting from demineralizer use, $\mathrm{CO}_{2}$ absorber of present in the helium purification system.

- Low specific activity material resultant from plant operation such as paper, plastic film, tape, protective clothing, small tools, air filter elements, miscellaneous electronic equipment from contaminated areas.

- Spent tritium absorbtion medium - titanium sponge from the helium purification system.

- Spent high temperature filter absorber material.

- Solidified liquid waste.

Solid wastes are processed and packaged on-site and shipped off-site to a licensed burial site in accordance with NRC and DOT Regulations. Gaseous and liquid wastes potentially generated in the operation of the solid waste processing and packaging system will be collected and processed by their respective waste systems.

Estimates of the annual quantities of solid waste anticipated for HTGR-GT operations are summarized in Table 7.1-1. Additionally, this same table summarizes: 1) reported LWR solid rad waste generation for the years 1976, and 2) estimates of LWR solid wastes generated by rad waste treatment systems of moderate capability. $*$ The quantity of solid radioactive waste anticipated for HTGR-GT operation is substantially less than that produced in LWR operations, however, the total activity present in HTGR-GT solid waste is slightly higher than LWR estimates.**

\footnotetext{
${ }^{*}$ See.WASH-1258 for additional information on projected solid rad waste processing system characteristics. $* *$

The higher specific activity of some HTGR solid waste, noteably the replaced reflector blocks and the titanium sponge tritium content, make HTGR-GT total activity in solid waste somewhat larger than LWRs.
} 


\subsection{SITING FLEXIBILITY}

The siting flexibility of the HTGR-GT plant was investigated and intercompared to a LWR plant. For this study only the radiological impact of the GT and LWR concepts was examined, future work should also focus on the nonradiological aspects as well.

From the standpoint of radiological impact, the HTGR in general has greater flexibility in siting than the LWR. This fact is born out when the radiological wastes projected for the HTGR-GT are compared to those of the BWR and PWR as was done in Table 7.1-1. This table graphically illustrates the small quantities of HTGR-GT wastes in comparison to actual LWR operations* and a favorable comparison still exists when HTGR-GT expected release are compared to LWR systems with advanced waste treatment capability.

\subsubsection{Site Boundary Dose - Gaseous Releases}

The radiological impact of GT and LWR effluents have been estimated for this study in terms of boundary dose levels for the corresponding airborne and liquid effluents reported in the Table 7.1-1 summary of radiological wastes. Table 7.2-1 provides the estimated site boundary airborne effluents dose levels for normal and off-normal conditions for both HTGR-GT and LWR operations.

For normal operations (annual release) the HTGR limiting airborne radlological impact is whole body exposure from immersion in the gaseous airborne wastes, primarily noble gases. Nevertheless, the HTGR limiting pathway exposure ranges from 5 to 2500 times below the 10CFR50 Appendix I "as. low as reasonably achievable". 1imit of 5 mrem. Additionally the projected HTGR gaseous dose levels are significantly below BWR and PWR comparable doses for the HTGR-GT intermittent purge design.

\footnotetext{
* The year 1976 was selected as representative of expected BWR and PWR operations.
} 
TABLE $7.2-1$

ESTIMATED SITE DOSE LEVELS FOR NORMAL OPERATION, DESIGN BASIS.ACCIDENTS AND THE SITING EVENT. AIRBORNE EFFLUENTS ONLY, HTGR-GT, BWR AND PWR.

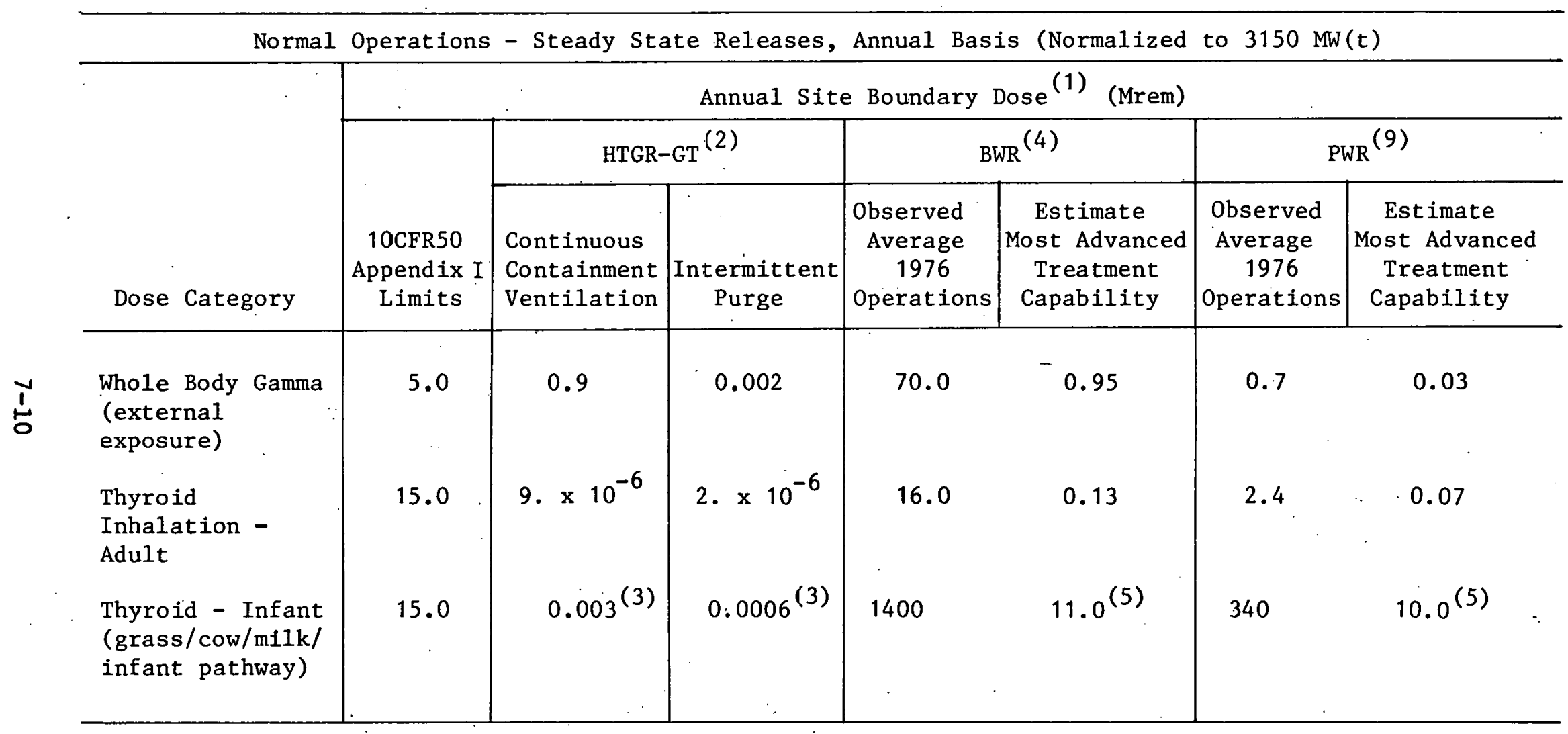


TABLE 7.2-1 (Continued)

\begin{tabular}{|c|c|c|c|c|c|c|}
\hline \multirow[b]{2}{*}{ Representative Accident } & \multicolumn{2}{|c|}{$\begin{array}{l}10 \text { CFR } 100 \text { Limits } \\
\text { (REM) }\end{array}$} & \multicolumn{2}{|c|}{$\begin{array}{l}\text { 0-2 Hour Exclusion } \\
\text { Area Boundary Dose } \\
\text { (REM) }\end{array}$} & \multicolumn{2}{|c|}{$\begin{array}{c}\text { 0-30 Day Low } \\
\text { Population Zone Dose } \\
\text { (REM) }\end{array}$} \\
\hline & $\begin{array}{l}\text { Whole Body } \\
\text { Gamma }\end{array}$ & \begin{tabular}{|c|} 
Inhalation \\
Thyroid
\end{tabular} & $\begin{array}{c}\text { Whole Body } \\
\text { Gamma }\end{array}$ & $\begin{array}{l}\text { Inhalation } \\
\text { Thyroid }\end{array}$ & $\begin{array}{c}\text { Whole Body } \\
\text { Gamma }\end{array}$ & $\begin{array}{l}\text { Inhalation } \\
\text { Thyroid }\end{array}$ \\
\hline HTGR-GT & & & & & . & \\
\hline $\begin{array}{l}\text { Design Basis Depressurization }(6) \\
\text { Accident (DBDA) }\end{array}$ & 25 & 300 & 0.0014 & 0.04 & 0.0004 & 0.005 \\
\hline $\begin{array}{l}\text { Maximum Hypothetical } \\
\text { Fission Product Release } \\
\text { (HHFPR) }\end{array}$ & 25 & 300 & 0.0014 & 0.04 & 0.5 & 24 \\
\hline PWR & & & & & & \\
\hline $\begin{array}{l}\text { Loss of Coolant Accident } \\
\text { (IOCA) }\end{array}$ & 25 . & 300 & 2.6 & 140 & 1.8 & 120 \\
\hline
\end{tabular}

\section{NOTES :}

1. For the HTGR-GT, exclusion area boundary distance (EAB) at $425 \mathrm{~m}$, Population Zone Distance (187) at $1600 \mathrm{~m}$ ):

2. Notes $3^{1}$ and 8 of Table 7.1-1 apply. Also annual average $X / Q$ of $2.0 \times 10^{-5}$ $\mathrm{sec} / \mathrm{m}^{3}$ used. 


\section{NOTES (Continued)}

3. Adult thyroid inhalation dose to child milk pathway thyroid dose conversion factor of 320 used.

4. Doses obtained by scaling BWR-3 and PWR-5 doses as reported in WASH-1258 (intermediate treatment capability category of Table 7.1-1). NOTE: The BWR and PWR doses of Tables 7-20 to 22 and 7-23 to 25 of WASH-1258 were weighted by the site occurrance frequency of $60 \%$ river sites. $15 \%$, 1 ake sites and $25 \%$ sea sites (see pp 7.24 discusșion, WASH-1258). See Table 7.1-1 for definition of annual average "1976", intermediate treatment capability (BWR-3 and PWR-5) and most advanced treatment capability airborne waste release of noble gas and iodine/particulates.

5. Adult inhalation to child pathway conversion factor of $85 \mathrm{x}$ BWR and $145 \mathrm{x}$ PWR employed (developed from BWR-3 and PWR-5 (WASH-1258) gas treatment categories, child milk thyroid dose/adult inhalation thyroid dose).

6. Analysis conditions assumed: lined containment with leak rate of $0.1 \% /$ day first 24 hours, $0.05 \% /$ day times $>24$ hours. Lift off fractions - Gail 10op, Reference site (lead plant) meterology, 2285 MW(T) level $B$ gas borne and plateont radiociclide inventories results adjusted to thermal power level of $3150 \mathrm{MW}$.

7. Analysis conditions of Note 6 apply. Standard Site GASSAR Fuel Source thru 100 in ${ }^{2}$ hole: DBDA with Gail loop.liftoff, Instant PCRV transport rate, 1 vol/hr. recirc., no cont. deposition.

8. The Sundesert Nuclear Power Plant was selected as Representative of PWR LOCO events. (See SNP PSAR Table 15.0-8.) 
For the LWR, the normal operation (annual release) airborne limiting impact is the thyroid exposure from the lodine-cow-milk-infant pathway. From Table 7.2-1 it is evident that only the most advanced rad-waste treatment systems of the LWR satisfy the thyroid/infant dose criterion of 10CFR50 Appendix I, while actual operation in 1976 in all probability greatly exceeded the criterion. HTGR-GT infant thyroid dose is negligtble in comparison to LWR values.

For severe accidents such as the HTGR-GT design basis depressurization accident (DBDA), the HTGR-GT maximum hypothetical fission product release (MHFPR), and the PWR loss of coolant accident (LOCA), estimates of the off-site dose levels have been made and appear also in Table 7.2-1. Both the HTGR-GT and representative PWR conform to 10CFR100 dose limits; however, the HTGR-GT exhibits significantly more dose margin than does the LWR.

\subsubsection{Liquid Pathway Individual Dose}

Due to the small quantity of liquid radioactive wastes generated in HTGR-GT operation, it is anticipated that environmental release would be low as would be the resultant dose to the exposed population. Table 7.2-2 presents estimates of liquid pathway annual doses for HTGR-GT and LWR operations. The favorable nature of the HTGR-GT is immediately apparent. Since the liquid radioactive waste for the GT are of such minute magnitude, and since the option may be taken to reprocess and recycle these waste bearing fluids, a lower bound dose level of zero for the HTGR-GT is given in Table 7.2-2 and represents no discharge of radioactive liquids from the site to the environment.

Accidental release of HTGR-GT or LWR radioactive wastes was not felt to be particularly important and was not analyzed. 
TABLE 7.2-2

ESTIMATED SITE DOSE LEVELS FOR NORMAL OPERATIONS.

LIQUID EFFLUENTS ONLY, HTGR-GT, BWR AND PWR

\begin{tabular}{c|c}
\hline \multicolumn{2}{c}{$\begin{array}{c}\text { Normal Operations - Steady State Releases, Annual Basis } \\
\text { (Normalized to } 3150 \mathrm{MW}(\mathrm{t}))\end{array}$} \\
\hline \multirow{2}{*}{ Reactor Type } & $\begin{array}{c}\text { Liquid Pathway Individual Dose } \\
\text { (Mren/Year) }\end{array}$ \\
\cline { 2 - 2 } 10CFR50 Appendix I Limit & Total Body \\
HTGR-GT & 3. \\
BWR & $0.003-0$. \\
PWR & $0.8-0.05$ \\
\hline
\end{tabular}

NOTES :

(1) Doses derived from information in Tables 7.14 and 15 of WASH-1258. Site weighting used: $60 \%$ river sites, $15 \%$ lakeshore sites, $25 \%$ sea sites, Liquid Effluent quantities reported in Table 7.1-1 used.

(2) Rangc given for LWR represent 1976 average liquid release for given reactor type (higher value) and the installation of the optimum treatment capability of WASH-1258 (low value). For HTGR, range represents the $0.005 \mathrm{Ci}$ release of Table 7.1-1 (high value) to no release (low value). 


\subsection{PROLIFERATION RESISTANCE OF HTGR FUEL}

\subsubsection{Introduction}

The objective in increasing proliferation resistance for nuclear fuel materials is to sever any path which might exist between the commercial use of potentlal weapons grade materials and the spread of nuclear weapons. Commercial nuclear power systems could, in principle, contribute to the risk of weapons proliferation by providing all or portions of the materials, equipment, or technical expertise necessary for weapons construction.

For many years the development of HTGR fuel was based upon the highenriched ( $83 \%$ enriched) urantum-thorfum (HEU/Th) cycle. Fuel cycle economics and resource utilization were both very good with the HEU configuration, better than with any other fuel cycle. However, because of the high enrichment, the HEU cycle presented a concern from the proliferation point of view. This concern prompted the consideration of alternate fuel cycles, which culminated in the selection of the mediumenriched (20\% enriched) uranium-thorium (MEU/Th) fuel cycle for the HTGR-GT. The HEU/Th, MEU/Th, and U fuel cycles are shown for comparison on Table 7.3-1. The $U$ cycle, often referred to as the uranium cycle, in the non-recycle mode is the current reference cycle for the LWR. Tt. appears that the LEU is not economically attractive compared to the $\mathrm{MEU} / \mathrm{Th}$ cycle.

\subsubsection{The HTGR Fuel Cycle}

The HTGR fuel element is a hexagonal graphite block containing parallel arrays of fuel and coolant holes as discussed in section 3.3. The fuel kernels are oxides or carbides of fissile uranium or plutonium, and fertile thorium. The uranium can be either hlgh, medium, or low enriched. 
During operation, conversion of bred material occurs in both the fissile and fertile fuel particles and yields both plutonium and U-233. The plutonium results from neutron capture in U-238 within the fissile particle, and the U-233 from neutron capture in thorium within the fertile particle.

Processing of the thorium fertile particles to extract the U-233 for recycle is expected at the end of cycle. However, the MEU particles would be stored intact, without chemical processing, unt1l each time as the plutonium is needed for use in thermal reactors or fast breeders.

In contrast, LWR fuels are low-enriched ( $3 \%$ enriched) urantum contained by zirconium alloy rods. During operation, plutonium is bred by neutron capture in U-238. Thus, processing LWR fuels for recycle would be for the recovery of plutonium, as well as the sunburned U-235.

With regard to fuel preference in thermal reactors, U-233 is superior to plutonium in that approximately $20 \%$ more neutrons are produced per neutron capture. Thus, for U-233, higher conversion ratios are possible resulting in better resource utilization. Further, U-233 can be denatured while from a realistic point of view, plutonium cannot. That is, there are no non-active 1sotopes of plutonium that are available for use as denaturants.

From a health hazards standpoint, plutonium is much more toxic than U-233 due to 1ts high alpha activity and tendency to seek the bone when taken into the body. However, plutonium can be easily handled provided care is exercised to avold ingestion or inhalation.

U-233 fuel displays higher activity because of an inevitable presence of small amounts of U-232. Daughter products of U-232 (in particular T1-208) emit hard gamma radiation, so that U-233 must be handled behind heavily shielded walls. This radioactivity from U-233 complicates recycle, but improves proliferation resistance. 
TABLE $7.3-1$

PROLIFERATION-RESISTANT FEATURES OF THORIUM CYCLE IN HTGR

\begin{tabular}{|c|c|c|}
\hline Basic Feature & Relevant Property & Proliferation Related Consequence \\
\hline \multirow[t]{3}{*}{ Thorium cycle } & Bred U-233 contains trace U-232 & $\begin{array}{l}\text { U-233 has high associated gamma activity: } \\
\text { - complicates diversion } \\
\text { - complicates weapons manufacture } \\
\text { - eases safeguards and security. }\end{array}$ \\
\hline & $\begin{array}{l}\text { Bred U-233 can be denatured } \\
\text { Potentially high conversion } \\
\text { ratio }\end{array}$ & $\begin{array}{l}\text { Recycle fuel not directly usable for weapons. } \\
\text { Low makeup fuel requirements; several HTGRs } \\
\text { could be sustained with fuel from one safe- } \\
\text { guarded breeder. }\end{array}$ \\
\hline & $\begin{array}{l}\text { Use of medium enrichment } \\
\text { uran-um ( } 20 \%) \text { for inventory } \\
\text { and makeup fuel }\end{array}$ & $\begin{array}{l}\text { Pu production low; 1sotopic unfavorable. } \\
\text { MEU not directly usable for weapons. }\end{array}$ \\
\hline Low core power density & Large core volume & $\begin{array}{l}\text { Fuel elements are bulky and heavy; difficult } \\
\text { to construct "quick and dirty" repro plant. } \\
\text { One fuel element contains little fissile } \\
\text { material } \\
\text { - about } 200 \text { elements must be processed } \\
\text { to obtain a critical mass. }\end{array}$ \\
\hline \multirow[t]{3}{*}{ "Particle" fuel } & $\begin{array}{l}\text { ThO } 2 \text { (fertile) particle can } \\
\text { be separated from uranium } \\
\text { (fissile) particle at repro- } \\
\text { cessing plant }\end{array}$ & $\begin{array}{l}\text { U-233 can be recovered and recycled without } \\
\text { processing Pu } \\
\text { - uranium particle can be stored } \\
\text { indefinitely. }\end{array}$ \\
\hline & & $\begin{array}{l}\text { Many recycle options: } \\
\text { - U-233 alone, denatured or undenatured } \\
\text { - al1 uranium } \\
\text { - all uranium and } \mathrm{Pu} .\end{array}$ \\
\hline & Difficult to process & $\begin{array}{l}\text { Difficult to construct "quick and dirty". } \\
\text { repro plant. }\end{array}$ \\
\hline
\end{tabular}




\subsubsection{Inherent Proliferation Resistance Advantages}

Proliferation resistance advantages of HTGR fuel using the MEU/Th cycle are summarized in Table 7.3-2.

The HTGR fuel elements are heavy and bulky, and their handing and processing requires special equipment. The volume of material that must be processed and disposed of to extract the fissile material is large.

There is relatively little fissile material in discharged fuel elements, less than 100 gms per element. Hence, about 200 fuel elements would require processing to accumulate a critical mass. Th1s is a formidable task. For fresh unirradiated fuel, about 170 fuel elements would require processing.

The particles themselves are a deterrent to diversion. Experience during manufacturing operations show that to crack open the particle coatings and chemically recover the contained fissile fuel is a very difficult job. Further, when a coating is fractured, gaseous fission products are released. This airborne radioactivity is detectable by appropriately situated radiation detectors.

The only practical way to separate the fissile material from the graphite (particle coatings, fuel rod binder and hexagonal block) is burn away as much of the graphite as possible. If this is done without highly specialized facilities, the radioactive nuclides krypton-85 and carbon-14 w111 be released to the atmosphere. These nuclides can be detected at a distance.

If a once-through mode of operation is adopted, the HTGR fuel elements may be the nearly ideal long term storage vehicle. Graphite is an inert material that does not react with air, water or other materials. The HTGR fuel element provides three nearly ideal barriers to dispersion of nuclear wastes to the environment: 
TABLE 7.3-2.

GENERIC SAFEGUARDS ADVANTAGES OF HTGR MEU/Th FUEL AND FUEL CYCLE

- Bulky, heavy elements

- Fissile fuel dilute

- less than $100 \mathrm{gms}$ per $120 \mathrm{~kg}$ element

- Particle configuration of fuel

- facilitates safe storage without reprocessing

- complicates recovery of fissile fuel if diverted

- permits recovery of fertile (thorium) particle separately from spent fissile (uranium) particle

- U-233 can be recovered while disposing of particles containing $\mathrm{Pu}$ without processing

- Radioactivity associated with U-233 will deter diversion - facilitate discovery of diverted material

- Pu production is low

- Isotopics not optimum for weapons use

- Reprocessing for $\mathrm{Pu}$ not economic for foreseeable future 
- graphite and silicon carbide coatings about the fuel kernels;

- the graphitic rods within which the particles are encased; and

- the graphite blocks which contain the rods.

The particle configuration provides an option for recycling the U-233 without at the same time processing the Pu. The discharged MEU particles contain all of the $\mathrm{Pu}$, while the discharged thorium particles contain all of the U-233. In a properly equipped recycle factlity, it is possible to recover the particles separately. The MEU particles can be stored intact, without chemical processing. The thorium particles can be processed to recover the U-233 for recycle. The U-233 could, of course, be denatured prior to recycle.

If "in-situ" denaturing were desirable, a small amount of U-238, typically 10 to $15 \%$, could be mixed with the throium. Then, the U-233 would be denatured when formed.

As noted earlier, the radioactivity assoclated with the U-233 will deter diversion, or facilitate detection if diversion were to occur. Safeguards and security procedures would be greatly facilitated by the radioactivity assoclated with the U-233.

The Pu discharged using MEU/Th fuel is 1ow. With $20 \% \mathrm{MEU}$, only about $70 \mathrm{~kg}$ of $\mathrm{Pu}$ are discharged per $\mathrm{GW}(\mathrm{e})$-year. If refueling were semi-annual rather than annual, then only about 150 to $20 \mathrm{~kg}$ would be contained in any single refueling batch. This is not much more than a critical mass, and about 500 fuel elements would require processing to extract it. This is approaching an ideal situation from the proliferation risk standpoint.

The Pu discharged from the MEU/Th cycle is only about $50 \%$ enriched. Moreover, typically $10 \%$ of the $\mathrm{Pu}$ is $\mathrm{Pu}-238$. These factors reduce the attractiveness of this material for weapons purposes. 
Finally, it is possible to design the MEU/Th cycle such that reprocessing and recycle of the small amount of $\mathrm{Pu}$ would not be economic, at least for the foreseeable future. In such a case, if a reprocessing plant were to be set up to recover the $\mathrm{Pu}$, one could infer an ulterior motive.

When uranium utilization, fuel cycle economics and proliferation concerns are considred, MEU/Th fuel in the HTGR appears optimum. Plutonium production $1 \mathrm{~s}$ low and $1 \mathrm{t}$ is distributed over several hundred elements. The bred U-233 also has two attractive features from the proIiferation point of view: an associated radioactivity, and it can be denatured.

The HTGR fuel configuration is a1so a deterrent to diversion. The graphite block and coated particles are difficult to process to obtain the contained fuel. The particle configuration also permits recovery of the U-233 without processing the Pu. Finally, the graphite fuel element is sultable for storage without reprocessing, should that prove desirable. 


\section{MAINTENANCE REQUIREMENTS}

\subsection{MAINTENANCE PHILOSOPHY}

From the onset of HTGR-GT plant activities in 1971 the following points of design philosophy were established as guiding principles from the onset of design studies, 1) make maximum use of existing HTGR and gas turbine technology, 2) simplify systems, 3) use accepted, proven technology, and 4) give major attention to safety, reliability, and maintenance early in the design. It is this latter point that forms the basis of this section of the report.

In the integrated HTGR-GT plant (as shown on Fig. 8-1) all of the helium turbine power conversion machinery operates on the reactor coolant helium and is installed inside the reactor vessel so it is important that maintenance aspects be considered during the plant conceptual design phase. The primary objective of the HTGR-GT plant maintenance and inspection plan is to provide facilities, equipment, and component designs of a reasonable cost that will yield good plant availability. It is therefore a matter of policy to design the reactor and the power conversion system installation as well as the related maintenance facilities for practical operation for both planned and unplanned maintenance.

All primary system equipment items are designed for full plant lifetime, with no limited-life parts with the exception of blades and of the turbomachine. Moreover, all components except some in the reactor cavity are designed for removal and replacement. The influence maintenance considerations have on the design of the major components and plant configuration are briefly discussed in this section. The removal and replacement of primary system components from the Prestressed Concrete Reactor Vesse1 (PCRV) after depressurization will, in general, be performed by remote handling techniques with equipment that provides for retention of the helium atmosphere within the PCRV, and also provides any needed radiation 


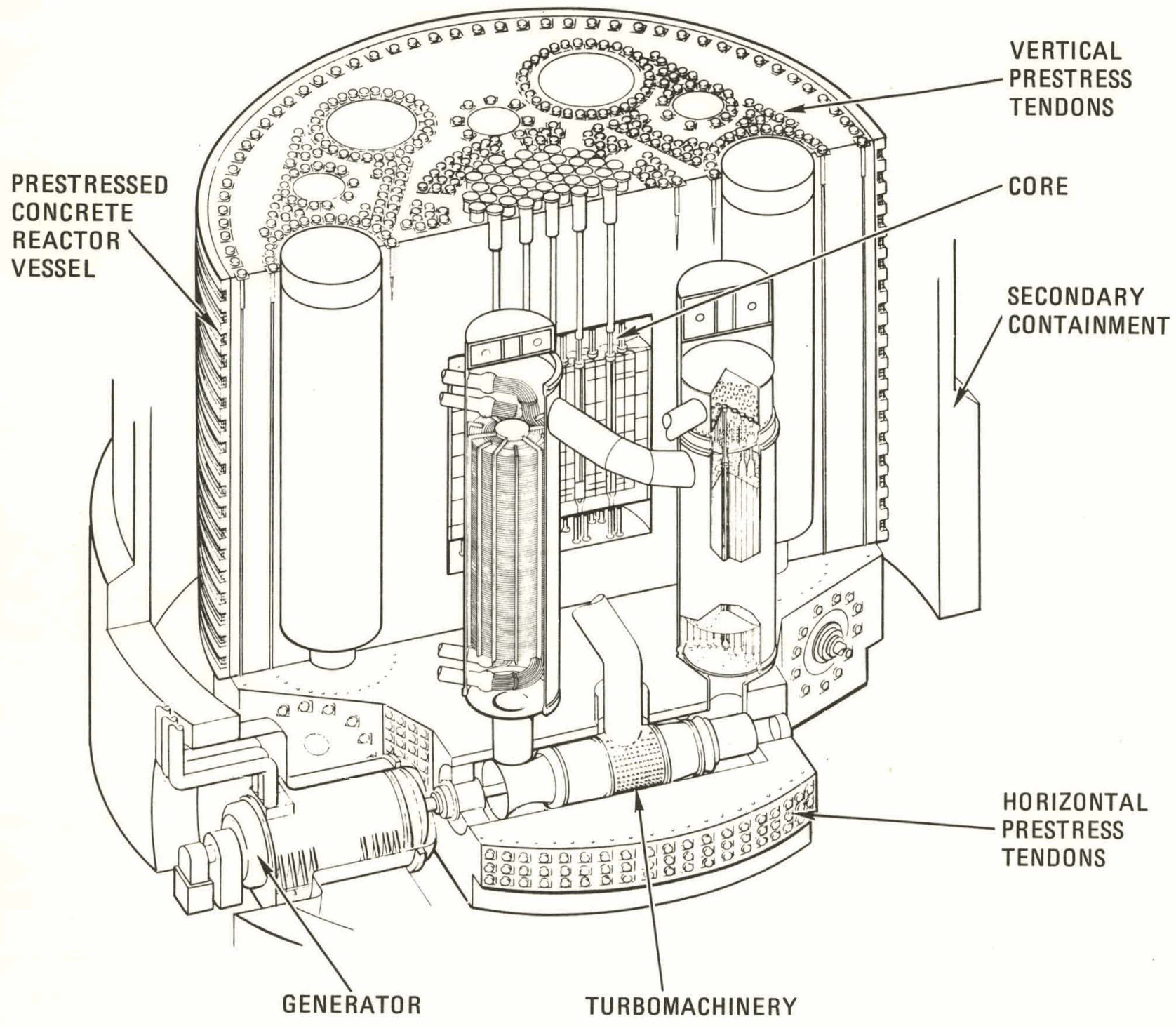

Fig. 8-1. Integrated GT-HTGR plant with $3000 \mathrm{MW}(t)$ core and three power conversion loops 
shielding. Typically, the primary system components are moved to a service facility for decontamination for either remote or contact maintenance work, or for shipment off-stte to other centralized facilities. The maintenance requirements must thus provide for the replacement of some items which have been designed to last the plant life-time, but fail due to unforeseen circumstances. The items in this category are the heat exchangers, valves, and some portions of the ducting. Turbomachinery change-out is regarded as a planned maintenance activity and the sequence of events, together with the necessary equipment items, for removal and reinstallation of the helium gas turbine are briefly discussed.

An important part of the formulation of the maintenance plan has been to provide for in-situ maintenance whenever practical. The degrees to which in-situ and service facility maintenance operations can be carried out depend upon the radiological environment in and around the equipment in question. Fission product deposition projections in various parts of the primary circuit have a strong influence on maintenance approach and studies in this area for the MEU. fuel are in progress. The maintenance equipment will be designed so that it is convenient for the more economical direct-contact approach if the activity levels are acceptable. The maintenance plan, however, will be formulated for conservatively high activity levels. The objective will be to provide equipment to deal economically with these high activity levels; at the same time, the plan wi.1.1. permit the advantages of low activity levels when they occur to be exploited. The time frame projected for commercial introduction of the GT-HTGR is the late 1990's; and for this plant heavy emphasis will be placed on diagnostics and, where possible, a large portion of the periodic inspection and repair will be performed in-situ. It is recognized that the helium gas turbine, installed inside the PCRV, represents a novel challenge to the maintenance planner, and in this section emphasis is placed on turbomachinery aspects. Turbomachine bearings, instrumentation, and service systems are to be accessible.

In general, equipment will be removed for maintenance and overhaul every six years. Reliance on performance monitoring and measurements 
of deflections, eccentricity, vibration, acoustics, critical clearances and lubrication parameters, in addition to temperature and pressure, and computerized integration of these diagnostic data, are key items in the successful implementation of this approach.

In the last year the HTGR-GT plant design-related activities have benefited from an on-going interaction with a Technical Advisory Committee (TAC) comprised of utility members who have an interest in, and have supported, the direct cycle plant. One of the roles of this committee has been to give guidance (from the utility owner and operators standpoint) in the conceptual design phase of the program. Utility technical inputs very early in the design are very valuable, and with ever increasing emphasis being. placed on maintenance and inservice inspection, it is thus prudent for designers to be cognizant of future plant owner's needs, and to embody the desired features in the plant right from the onset of layout studies. The main areas of concern identified by the utility PRC were (in order of importance); 1) turbomachine removal, 2) core-to-turbine duct, 3) precooler, 4) recuperator, and 5) helium control valves.

The primary objective of the on-going HTGR-GT. plant maintenance plan formulation is to provide sequences, facilities, equipment, and component designs of a reasonable cost that will yield good plant availability. Turbomachinery change-out is regarded as a planned maintenance activity, and the sequence of events for the removal and reinstallation of the helium gas turbine are discussed below. The maintenance and repair of the other identified salient components, such as the core-to-turbine, hot gas duct, heat exchangers, and valves, which, while designed to last the plant lifetime fail due to unforeseen circumstances, are also briefly discussed below.

\subsection{MAINTENANCE PLAN}

\subsubsection{Turbomachine Maintenance}

In-situ turbomachine maintenance will be performed during scheduled plant outages, when possible, because the reactor must be shut down and the 
PCRV depressurized before anyone can enter the vessel. Shielding requirements have been established to give a radiological environment in the turbomachine bearing cavity areas conducive to man access. The man access provisions will ensure that limited inspection and maintenance may be performed in-situ. It is recognized that the turbomachine internal surfaces will become radioactively contaminated by deposition of helium-borne condensible fission products, thus a procedure must be established for remote removal of a machine and replacement with a spare unit. Plant downtime will be held to a minimum by performing turbomachine change-out during a scheduled refueling period. As outlined below a study was performed to 1) establish the sequence of operations, 2) identify the major equipment items, and 3) estimate the time for turbomachine removal and replacement.

While the turbomachine removal is considered to be a scheduled maintenance operation, the current maintenance philosophy for a mature commercial plant is that the turbomachine will be removed only if the condition monitoring system indicates a problem or periodical inspection as required by utilities. The reliance on diagnostics to indicate operating problems together with the turbomachine maintenance philosophy are summarized on Table 8-1. The turbomachine-vessel interfaces will be engineered such that the machine can be installed and removed remotely, but provision will be made to accommodate other approaches should special apparatus fail to function. After depressurization, the removal and replacement of the Lurbumachine will, in general, be performed by remote handling techniques with equipment that retains the helium atmosphere within the PCRV and also provides any needed radiation shielding.

Procedures for removal and replacement of the turbomachine, together with details of the special purpose equipment required, have been documented in a comprehensive form in Reference 1 (and in a summary form in Ref. 2). The sequence of operations for machine removal is summarized on Table 8-2.

A time estimate of 21 days was made for the turbomachine removal and replacement with a spare unit based in 2-shift work day. The acrual. installation and removal of a large horizontal turbomachine by remote 
TABLE . 8-1

GT-HTGR TURBOMACHINE MAINTENANCE PHILOSOPHY

- Reliance on diagnostics to indicate operating problems

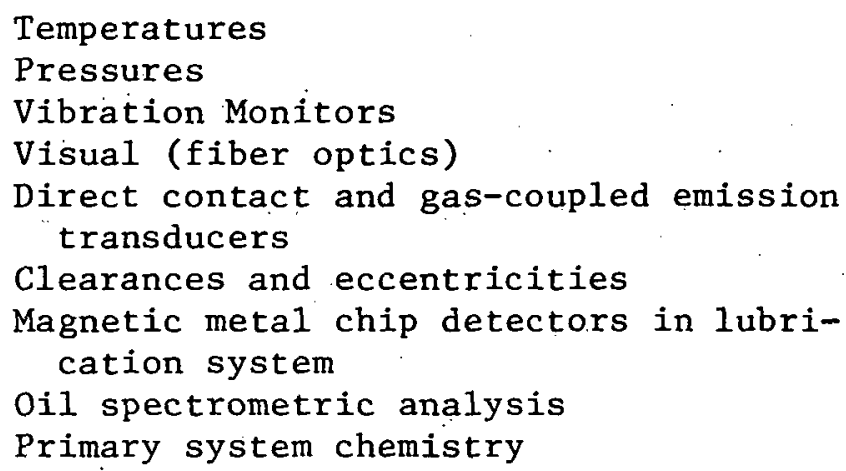

On-line computer system for condition monitoring

- Turbomachine installation and removal procedures established. Current design requires man access into the purged areas for connection/ disconnection of drive coupling and servicing of system line flanges.

- For mature commercial plant the turbomachine will be replaced only if diagnostic system indicates problems.

- Stress levels in turbomachine are commensurate with the full $280,000-h r$ plant operating life (i.e., no life-limited subcomponents).

- Journal bearing areas accessible for inspection and maintenance (bearing pad replacement, etc.).

- In situ balancing of rotor considered possible by UTC.

- For many maintenance operations experience from industrial gas turbines directly applicable. 
TABLE 8-2

TURBOMACHINE MAINTENANCE PROCEDURES

Removal of a turbomachine from the PCRV after a period of service entails the following basic procedures:

- Remove the generator. (Not necessary, depends on arrangement).

- Remove the high-speed shaft and containment closure.

- Remove the PCRV plug connections.

- Open the PCRV plug access port.

- Uncouple the PCRV plug to turbomachine connections and disconnect the shaft couplings.

- Instal1 runways for removal equipment.

- Remove the PCRV plug.

- Remove the turbomachine thrust ring.

- Install the support bearing assembly to the compressor inlet bell.

- Install the isolation valve to the turbomachine cavity.

- Install temporary rails between the end bell and the isolation valve.

- Disconnect piping and connections in the access tunnel at the turbine end of the machine.

- Install an alignment turret in the access tunnel.

- Install the turbomachine cask.

- Withdraw the turbomachine into the cask.

- Close the isolation valve.

- Close the cask valve.

- Remove the cask.

In addition to the usual rigging equipment involved in handling heavy machinery, certain special accessories are required in order to perform the foregoing functions. These are:

- PCRV plug handling equipment.

- Bearlng support.

- Alignment turret.

- Removable rails. 
means, while noval, is considered to be a relatively straightforward maintenance operation. Technology in the areas of machine handling, support means, and alignment techniques from large open-cycle industrial gas turbines and steam turbines will be applicable. Maintenance related technology generated for the steam cycle HTGR in the areas of remote removal/installation of contaminated components (e.g., circulator and steam generator) together with the design of special purpose mechanisms, handling machine, and casks will be applicable.

\subsubsection{Core-To-Turbine Hot Gas Duct Maintenance}

The metallic duct transporting high temperature helium from the core to the turbine is positioned in the vertical compressor discharge cavity in the PCRV. Access to this duct assembly is from the top of the PCRV. The plant maintenance requirements must provide for the replacement of the hot duct, even though it is designed to last the plant lifetime. Although this duct transports the gas at the highest temperature in the plant $\left[1562^{\circ} \mathrm{F}\right.$ $\left(850^{\circ} \mathrm{C}\right]$, the vertical portion of the metallic assembly is "immersed" in the much cooler compressor discharge gas $\left[345^{\circ} \mathrm{F}\left(175^{\circ} \mathrm{C}\right)\right]$, and with the appropriate insulation, metal temperatures considerably below the turbine inlet value are expected. This, together with the modest internal pressure differential of around $50 \mathrm{psi}(0.345 \mathrm{MPa}$ ) (compressive loading), results in an operating environment with is felt to be conducive to extend trouble free life.

To remove the turbomachine it is necessary to retract the hot gas duct a few inches from the machine casing using a remote mechanism. If during a routing ISI operation a flaw is observed in the duct assembly, or the plant condition monitoring system indicates a fallure, then provision must be made for removal and replacement of the assembly: While detailed fission product plate-out calculations remain to be done it is expected that the activity level on this duct inner face will be high after extended service. In the event that a faulted duct has to be removed it would be replaced by a new assembly with no attempt being made to repair the highly contaminated duct. To ensure the feasibility of such a duct removal/installation, and to evaluate possible impact on the primary system design a conceptual study has 
been performed to estabilish the maintenance procedure, and to identify the necessary special purpose equipment. A summary of maintenance considerations for the hot gas duct is given on Table 8-3.

As outlined in Reference 1 an initial study was performed to establish the sequence of operations for removal of the hot gas duct, and a summary is given on Table 8-4. While the actual duct replacement operation is unique to the direct cycle plant, initial work has indicated that the techniques necessary bear a resemblance to planned maintenance procedures established for the steam cycle HTGR. The duct handling cask, isolation valves and adapter are similar to the circulator handling equipment designed for the steam cycle lead plant.

\subsubsection{Heat Exchanger Maintenance}

Turbular types of construction were selected for both heat exchangers in the direct cycle plant. The main reason for this selection was that it represents the only type of construction that has been proven to have the structural integrity for long life electrical utility power service. A ground rule for the precooler and recuperator is that they must be designed to operate for the full life of the plant. Both heat exchangers will be lowered into the PCRV cavities by a system of hydraulic jacks during construction and they are expected to remain in place during the life of the plant. In both exchanger designs provision is made for replaceability and maintenance and repair. In the HTGR-GT plant the modest temperatures and pressures (compared with contemporary heat exchangers) are conducive to long-life trouble free operation of the heat exchangers. If a gross failure of a heat exchanger occurs due to unforeseen circumstances, although this is considered an unlikely event for the selected configuration, the complete assemblieo can bc removed and replaced.

8.2.3.1. Precooler Maintenance. The precooler is a helium-to-water heat exchanger that operates with a steady-state maximum metal temperature on the order of $360^{\circ} \mathrm{F}\left(182^{\circ} \mathrm{C}\right)$. This single-phase water side is pressurized to a 
- Duct assembly to be designed for full plant life (final geometries and materials selection yet to be made).

- Duct assembly to be replaceable without man access.

- Initial concept of telescoping bellows section (local retraction for machine installation/removal) felt to be a high risk design. because of:

Thermal barrier problem

Complex assembly

Additional mechanism necessary

Materials problems

- Proposed approach for conceptual design involves disconnection of assembly in plane of horizontal reactor outlet duct, permitting retraction of complete assembly upwards about $458 \mathrm{~mm}$ (18 in.) for turbomachine installation/removal.

- Conventional remotely actuated mechanism for duct removal.

- Duct assembly offset in compressor discharge cavity to allow access to flanged joint.

- Gulde rails provisioned in cavity for accuracy of duct assembly translation.

- TV camera coverage of duct insertion in turbomachine casing, together with sensors to. ensure register proper fit, desirable. 
TABLE 8-4

HOT DUCT MAINTENANCE PROCEDURES

Removal of the hot duct from the PCRV after a period of service entails the following basic procedures:

- Unbolt and remove the secondary closure flange.

- Unbolt the primary closure.

- Insta11 the hot duct flange adapter and isolation valve.

- Install the hot duct handling cask.

- Evacuate air in cask, between valves, etc., and backfill with helium.

- Open valves and use cask hoist and grapple to remove the primary closure.

- Close valves to maintain helium atmosphere in PCRV and transfer closure to temporary storage.

- Reinstall cask in isolation valve; open valves and lower hoist until grapple engages lifting adapter on the hot duct.

- Remove the access flange in the hot duct maintenance cavity and start helium purge flow to minimize air ingress.

- Install the extension on the hot duct release tool and engage the tool with the mating spline on the hot duct assembly.

- Open the flange clamp assembly.

- Change the tool position and retract the flange.

- Move the tool again to lock the flange in the retracted position.

- Disengage the tool from the hot duct.

- Raise the duct assembly with the cask hoist. NOTE: 2 to $3 \mathrm{ft}$ of motion will permit turbomachine removal.

- Close the cask and isolation valves.

- Transport the duct assembly to the service area. 
sufficlent extent to avoid local boiling. The helium pressure is higher than the water pressure and if leaks develop the section of the precooler containing the faulted tube must be quickly isolated and the water inventory rapidly drained into the dump tanks. The precooler maintenance efforts to date have been done in support of different heat exchanger evaluation studies, and overall plant layout work. It is recognized that the ability to repair this heat exchanger from outside the PCRV (without man access to the primary circuit) has a strong influence on design. Studies to determine the maintenance procedures and identify special purpose equipment (i.e., tube plugging machine) are reported in Reference 1, and a summary of the precooler maintenance approach is given on Table $8-5$.

8.2.3.2. Recupérator Maintenance. The recuperator is a helium-to-helium heat exchanger that plays an important role in the HTGR-GT plant from the standpoint of achieving high cycle efficiency. For the reference design recuperator the maximum metal temperature is on the order of $970^{\circ} \mathrm{F}\left(520^{\circ} \mathrm{C}\right)$, and a code approved ferritic material was selected (2-1/4 $\mathrm{Cr}-1 \mathrm{Mo})$. The stress levels in the recuperator are commensurate with a plant operating life of 280,000 hours. The recuperator is not subject to hot streak effects (from the reactor core) since the gas is well mixed in the turbine. Since the recuperator is a helium-to-helium heat exchanger the effect of leaks that may occur in service manifest themselves in the area of performance and do not affect the operation and safety of the plant.

A summary of the maintenance approach for the modular recuperator is given on Table 8-6. If failures occur in the small individual tubes the effect on plant performance will be minor. On the other hand, if failures occur in the lead tubes and the subsequent leakage is of the level that remedial action is necessary, then the faulted module can be plugged. Since the level of the dose rates in the recuperator cavity, above the support plate, are expected to preclude man access, the detection of the faulted module and the plugging operation must be done by remote means. The mechanical design of the recuperator top headering is thus strongly influenced by maintenance and is the subject of current studies. 
TABLE 8-5

GT-HTGR PRECOOLER MAINTENANCE APPROACH

- Removal/replacement capability without man access, but operation eased if access at lower end (from compressor inlet duct).

- Maintenance and repair work to be" performed remotely.

- Leak detection down to tube level.

- External instrumentation (pressure and radiation monitors) to detect leaks (helium into water).

- Tube plugging from outside PCRV using special-purpose machine. Manual repair work in plane of tubesheet also possible.

- Exchanger replaceability

In the event of significant loss of plant performance from excessive tube plugging or an unlikely major structural failure, the complete precooler could be removed and replaced. This situation is, however, considered remote because of the conservative nature of the design and the non-hostile operating environment. 
TABLE 8-6

GT-HTGR RECUPERATOR MAINTENANCE APPROACH

- Removal/replacement capability without man access

- Maintenance and repair work to be performed remotely

- Leak detection down to module level

- Lead tube plugging capability

- Repair of minor leaks could be delayed until plant refuel shutdown

- Man access would ease repair work

- Exchanger replaceability

In the event of significant loss of plant performance from excessive module plugging or an unlikely major structural failure, the complete recuperator could be removed and replaced. This situation is, however, considered remote because of the conservative nature of the design and the non-hostile operating environment. 


\subsubsection{Helium Control Valve Maintenance}

Each power conversion loop has four valves, namely, safety, bypass, attemperation, and trim valve to satisfy plant control and safety functions. All four valves are integrated in the PCRV and are installed in separate cavities in the PCRV top head. All four valves present similar maintenance and handling problems, and it was decided to base the study (as outlined in Ref. 1) on the primary bypass valve since this particular valve is one of the large units and presents the most severe actuator requirements. The generalized helium control valve maintenance philosophy is given on Table 8-7.

Each valve is bolted into its penetration at a flange located several feet below the top of the PCRV. Preliminary shielding studies indicate that limited access to these bolts should be possible following a ten-day shutdown. The valve actuator is accessable from the top of PCRV without depressurizing the primary system. However, actual removal of a valve will be performed remotely into suitably shielded cask, both for personnel protection and to prevent ingress of air to the primary coolant. It is proposed that the design of the valve be arranged to integrate the valve seat with the valve body thus permitting the two to be preassembled and peroperly matched. This also facilitates remote handing of the assembly as only. one grappling operation is involved. It appears reasonable to assume that the valves can be handled by the hot duct removal cask. Although of a smaller diameter than the hot duct, the valves are approximately the same overall length.

The sequence of operations to remove the valve is given on Table 8-8. An isolation valve and cask is installed over a valve penetration preparatory to removal of the bypass valve. Provision will be made in the cask to guide the grapple and valve in order to align the valve seat register and seals during installation. It is anticipated the grapple and grappling features will be similar to those used for control rod drives and other HTGR equipment. 
TABLE 8-7

GT-HTGR VALVE(S) MAINTENANCE PHILOSOPHY

- Valve assembly to be replaceable without man access.

- Valves accessible from top of PCRV.

- Conventional remotely actuated mechanisms for valve assembly (and lower seal unit) removal.

- Sequence of valve removal has been established.

- Maintenance will include period in situ testing of the valves.

- Actuator is accessible without primary system depressurization. 
TABLE 8-8

HELIUM CONTROL VALVE(S) MAINTENANCE

- Current valve is an integral unit with the internals, and seat element embodied in a single assembly with grapple engagement fittings for remote removal. The removal sequence has been conceptually established as follows:

Remove valve cavity closure

Remove hold down nuts and actuator connections

Install the reactor isolation valve

Position and secure the duct removal cask on the isolation valve

Engage the cask grapple with the top of the valve assembly

Change the atmosphere in the cask and actuator cavity to helium

Withdraw the valve into the cask

Close the cask valve

Remove the cask

- Dose rate calculations in progress on the valve assemblies to determine decontamination procedure necessary to permit "hands-on" maintenance. 


\subsection{MAINTENANCE RELATED STUDIES}

An important variable in reactor design studies is the extent of fission product release from the core and subsequent plateout of condensible nuclides in the primary circuit. The release of long-lived gamma emitters, such as Cesium-134 and Cesium-137, is of particular importance for the direct cycle plant because of maintenance requirements associated with the turbomachinery. The feasibility of using "hands-on" maintenance as opposed to remote handling is determined principally by gamma activity on the turbine after decontamination. This in turn is a function of the gamma activity initially present on the turbomachinery blading at the time of maintenance and the assumed decontamination factors that can be attained with the turbine blade alloy used. Studies are currently underway aimed at establishing dose rate criteria, identifying and quantifying the significant sources of radiation from the standpoint of turbomachine maintenance, determining the access and shielding requirements for turbomachine removal, and making preliminary estimates of remote maintenance requirement.

\subsection{GT-HTGR PLANT INSERVICE INSPECTION (ISI)}

For the direct cycle integrated plant the issue of ISI has added importance since all of the power conversion system components are installed inside the reactor vessel and are thus not accessible for direct visual inspection. ISI requirements are continually becoming more demanding to satisfy the various code requirements, regulatory guides, and licensing commitments.

Utility practices on ISI, where not part of the normal mandatory program imposed by regulations, may reflect a variety of concerns associated with past operating equipment. It is difficult to anticipate these supplemental ISI practices principally directed towards the curtailing of unplanned outages. An important aspect of ISI considerations, considering both regulatory requirements and projected utility owner's needs, is the impact 
on component deisgn, plant layout, and access provisions. It is prudent therefore to consider ISI requirements during the plant conceptual design, and to pursue a policy of providing inspectable designs where required.

The initial study of ISI requirements for the HTGR-GT plant have been directed towards the components unique to the direct cyele (i.e., turbomachine reactor-to-turbine duct, precooler, recuperator and control valves). While still in a very early stage of development the investigation has been aimed at identifying the type of inspection envisioned for key sub-elements in each of the aforementioned major component items. A summary of the ISI examination and testing possibilities for the internals of the GT-HTGR plant is given on Figure 8-2. These possibilities are, of course, tentative and will require special attention in developing a program of ISI and testing as the plant design matures.

In closing, it should be pointed out that while the HTGR-GT plant design studies are still in their early stages, it is recognized that aspects of maintenance are important, and in fact may well be influential in the actual choice of plant configuration and inputs from utilities need to be factored into the plant design right from the onset. While commercial introduction of the HTGR-GT plant will not occur before the 1990's, the formulation of realistic maintenance and inservice inspection plans, at an early stage in the design, are of the essence. An already established dialogue with the HTGR-GT Utility Technical Advisory Committee will intensify as the plant design proceeds, and the finally selected configuration will embody operational features acceptable to potential utility owners of the future.

\subsection{REFERENCES}

1. "GT-HTGR Plant Maintenance Studies," GA-A14858, March 1979.

2. "Maintenance Considerations in the Design of the Direct-Cycle Nuclear Gas Turbine Power Plant," GA-A14905, November 1978 (ASME Paper No. 79-GT-116). 


\section{LEGEND:}

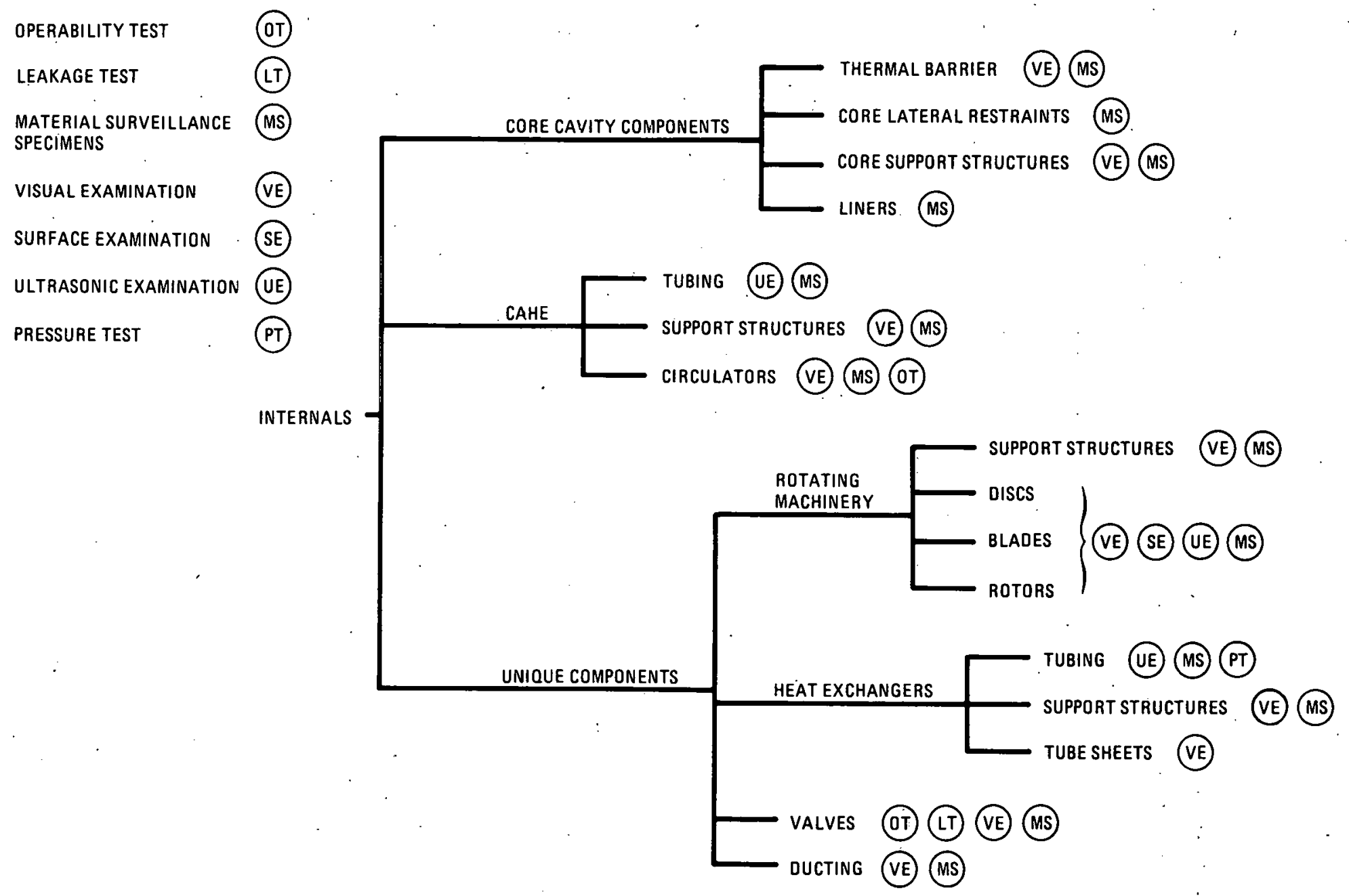

Fig. 8-2. Summary of preliminary inservice examination and testing possibilities for GT-HTGR plant primary system intervals 


\section{MAJOR DEVELOPMENT REQUIREMENTS}

\section{1. . HIGH TEMPERATURE MATERIAL}

The major materials challenges of the HTGR-GT arise from the fact that many reactor components are designed to provide very reliable service during long life $(280,000 \mathrm{hrs})$ at relatively high temperatures. It is important to emphasize that it is the combination of time, temperature and reliability requirements that constitutes the major challenge. Neither the design life nor temperature of the GT are, in isolation, either usual or challenging. There are many lower temperature structures that have lasted much more than 40 years. Similarly, there are many common industrial equipment items that operate at temperatures substantially above the GT temperatures. (Examples are steam reformers that operate at temperatures around $1700^{\circ} \mathrm{F}$ and jet engine burner cans that approach $2000^{\circ} \mathrm{F}$ during takeoff and landing.) What is not currently established is the capability of materials to perform reliably at these temperatures for the long design lives and in the unique environment of the HTGR-GT. Available information suggests that there is good reason for confidence that materials with the required perform capabilities exist. However, it is clear that a significant amount of materials testing and evaluation must be performed to allow optimum materials to be selected and to demonstrate expected performance with a confidence level consistent with the economic and safety requirements of the HTGR-GT.

The materials aspects of the GT-HTGR have been examined throughout the seven years since the inception of the HTGR-GT program. During that period, effort has been oriented toward identification of key materials data needs and on the identification and qualification of candidate materials. One part of the latter work was the screening tests (particularly helium-corrosion and creep-screening) performed at GA and at CIIR in Oslo under the DOE/GA/ HTMP joint program. In addition, and in parallel, a substantial steam cycle/ HTGR development program was underway in this same period - and a large part 
of that program was directed at resolving various materials issues, many of which were generic to GT as well as Process Heat and HTGR-Steam Cycle. Finally, in this same period, large amounts of relevant data have been generated overseas at CEA, FRG and in Japan on materials for high-temperature reactor systems.

As a result of all this work, considerable progress has been made in focusing in on candidate materials and key materials issues for the HTGR-GT. Typical candidate materials for key components are shown in Table 9-1 and current perceptions of major materials issues are shown in Table 9-2.

Details of current thinking on the key issues shown in Table 9-2 are as follows.

\subsubsection{Adequate High Temperature Strength}

In order to design elevated temperature components, it is necessary to select materials which have sufficient strength, at design temperature, to resist the various imposed cyclic and static loads. This is a minimum requirement and tends to be a governing factor in materials selection. As temperature is increased, material selections have to change toward materials with useful strength at the high temperature regim. Figure $9-1$ gives an indication of the temperature regimes in which various materials exhibit useful monotonic strength.

It is obvious from this figure that as temperature increases, there are fewer and fewer available materials from which to select. Once temperatures get high enough (say above $1000^{\circ} \mathrm{C}$ ), there are very few materials indeed capable of offering the potential for long-time service.

It should be emphasized, here, that there is a much less problem in meeting these temperature requirements for very short lifetime components. Jet engine burner cans, for example, typically run at temperatures close to $1100^{\circ} \mathrm{C}$ during takeoff and landing. However, the total cumulative exposure time is relatively short (only a few thousand hours). Thus, it is the combination of long design life and temperature that constitutes the materials challenge. 
TABLE 9-1

Class B Thermal Barrier

Class C Thermal Barrier

Hot Components of Turbine

Recuperator

CAHE

P1.enum Filements

Control Rod Structures

Turbine Control Valves

etc.
Wrought $\mathrm{Fe}$ and $\mathrm{Ni}$ Base Alloys $(304,316,800 \mathrm{H}$, Hast. $X$, Inc 625, etc.)

Cast Ni Base Alloys (In 713, IN100, etc.)

Oxide Dispersion Strengthened Alloys (MA754, etc.)

Ceramic Fiber Insulation (Saffil Alumina, Kaowool, etc.)

Carbon-Carbon Composite

Monolithic Ceramics (Alumina, Silicon Nitride, etc.)

Fibrous Ceramics (Saffil Alumina, Graphite Felt, etc.)

Cast Ni Base Alloys

Wrought Ni Base Alloys

Wrought $\mathrm{Fe}$ and $\mathrm{Ni}$ Base Alloys $(2-1 / 4 \mathrm{C}-1 \mathrm{Mo}, 12 \mathrm{Cr}, 304,316$, $800 \mathrm{H}$, etc.) 
- Adequate high temperature strength (including welds)

- Environmental Compatibility (i.e., carburization)

- Thermal aging

- Alloying element evaporation

- Effects of above on:

Creep rupture strength

Short time properties

Fatigue (LCF, CR-F, HCR)

Fracture toughness and crack growth

- Properties and compatibility of ceramics

- Welds or joint strength

- Fabrication feasibility

- Wear protection

- Effects of elevated temperature irradiation 


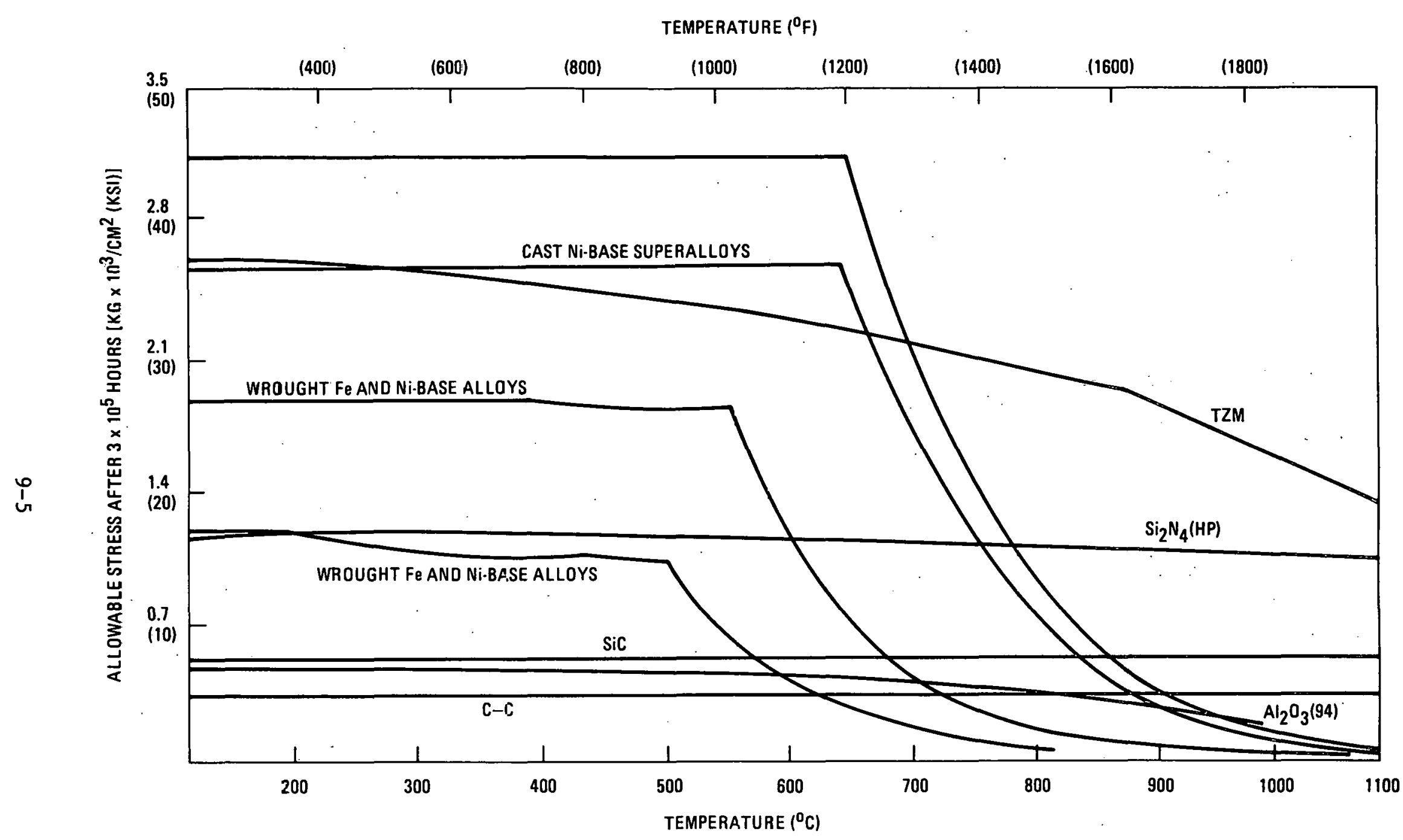

Fig. 9-1: Approximate 300,000 hours allowable stresses versus temperature for various metallic and ceramic structural materials 
It is also important to note that there is a general tendency, as temperature increases, for the properties of weldments (or other metallurgical joints) to become significantly weaker and less ductile than those of the parent metal. Thus, there is a need, in evaluation of strength properties, to determine the long-time strength characteristics of weldments. Aging response of weldments is generally poorer than base materials and needs to be determined. Both similar and dissimilar weldment properties should be determined.

At the current reference HTGR-GT turbine inlet temperature of $1562^{\circ} \mathrm{F}$ $\left(850^{\circ} \mathrm{C}\right)$, it is clear that there are a number of materials selections possible for the less heavily stressed components. However, the number of candidates for service in significantly loaded components (like turbine blades) is limited.

The foregoing refers, primarily, to resistance to steady state loads and resultant primary stresses. However, in a HTGR-GT, it is expected that startup/shut down operations, acoustic excitation, transients and similar conditions will induce important low cycle and high cycle fatigue stresses and strains. At elevated temperatures, these phenomena will be complicated by creep effects which will induce creep-fatigue damage. The resistance of the various candidate materials to these stresses and strains is very important and will require detailed evaluation.

\subsubsection{Environmental Compatibility}

It has been known, for several years, that the primary coolant helium of gas cooled reactors will contain low levels of impurity gases which have the potential to cause carburization, or internal oxidation of structural materials. These same impurities can also cause chemical changes to occur in ceramic materials - although this effect usually occurs at much higher temperatures than is encountered with metals.

One of the more significant phenomena is carburization. Available data clearly indicates that at temperatures below $850^{\circ} \mathrm{C}$, carburization rates 
become high enough, in some of the more common wrought structural materials, that significant end-of-1ife carburization depths are predicted (Fig. 9-2). Unless on-going work shows that such carburization is acceptable, from a design standpoint, it must be concluded that the use of metal of this type at these temperatures will be somewhat restricted.

However, there are other materials, for example IN100, which exhibit much enhanced resistance to carburization in HTGR helium. Thus, at HTGR-GT temperatures, it becomes necessary to attack the carburization problem in a similar manner as that used to combat the reducing strength problem - by the selection of different materials.

Another approach to resisting carburization (and, for that matter, internal oxidation - which can also become significant at high temperatures) is to apply coatings to the materials to inhibit these reactions. These coatings can be applied by a number of commercially available or by developmental methods. Yet a further possibility is to modify the composition of alloys in such a way that the materials tend to form inherently protective scales in HTGR helium. The above avenues require more study.

In addition to interaction between materials and the carburizing/ oxidizing impurity species present in the HTGR-GT primary coolant, there may also exist the potential for interaction between structural materials and fission products such as $\mathrm{Cs}, \mathrm{Te}, \mathrm{Ag}$, etc. The relative magnitude of this potential will require careful assessment once expected fission product release levels are more accurately defined.

\subsubsection{Thermal Aging}

At the temperatures of the HTGR-GT structural materials will tend to undergo some microstructural changes (with associated mechanical property changes) during elevated temperature exposure. These microstructural changes can cause materials to soften or harden or become more brittle, etc. It is necessary to develop adequate data on these effects to account for them in material selection/component design. 


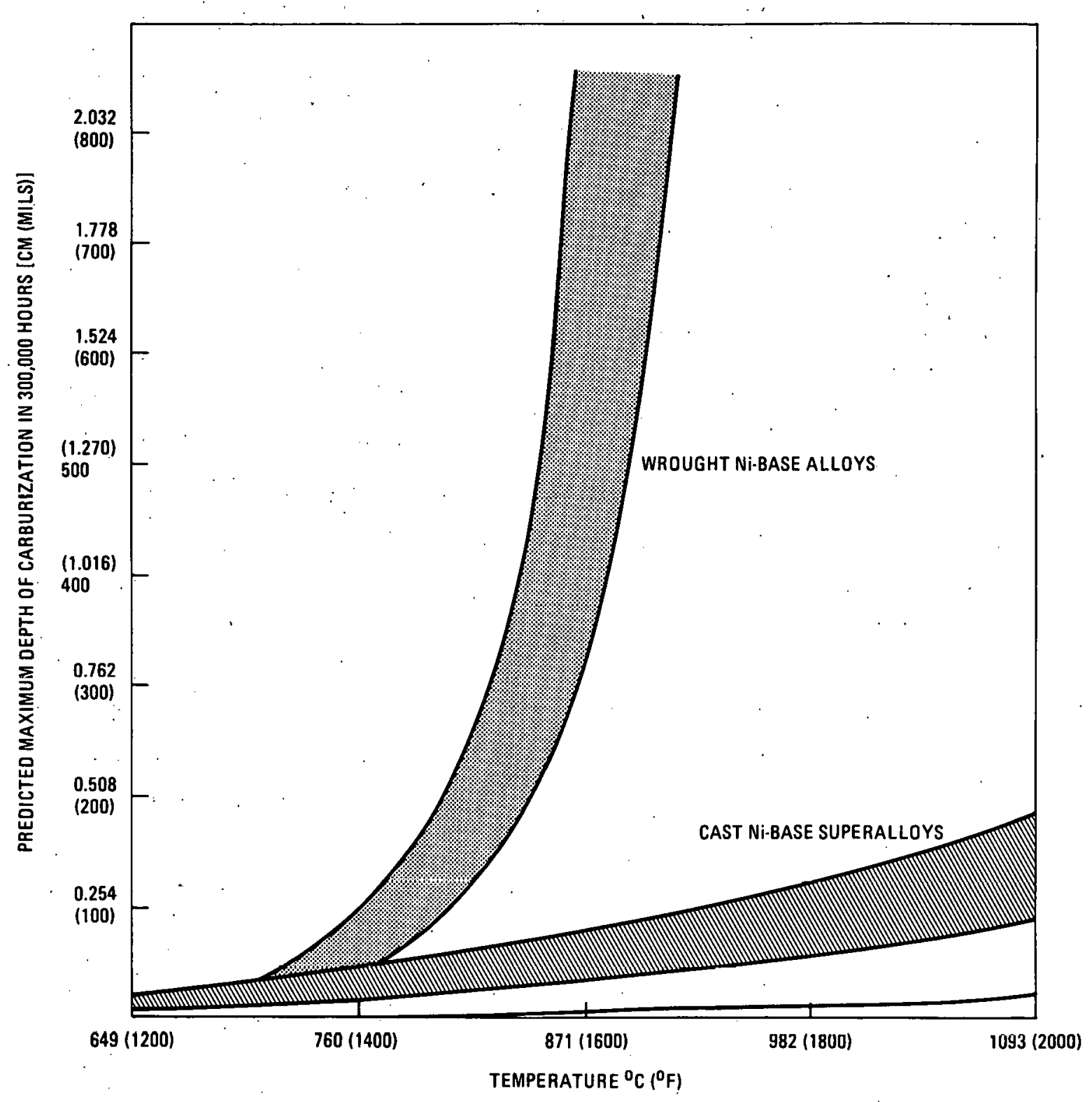

Fig. 9-2. Comparative carburization behavior of metals in HTGR-GT 


\subsubsection{High Helium Velocity Effects}

At the very high helium velocities encountered by the turbine blade tips (around 1500 feet per second) it is possible that alloying element evaporation phenomena may be encountered. The probability of encountering these effects will increase as temperature increases.

At $850^{\circ} \mathrm{C}$, present Indications are that conditions are marginal for onset of significant evaporation. (At $900^{\circ} \mathrm{C}$, on the other hand, it is anticipated that significant evaporation would occur.) Thus, study is required to quantify the potential significance of this effect under GT-HTGR conditions.

Another effect of helium velocity can be that of causing erosion on certain materials - particularly if the gas contains a particulate burden (for example, graphite dust). Materials of special concern are the carbon/ carbon composite which may be used in the turbine inlet ducting. At the present time, it is not clear whether this problem will be of significance at the $850^{\circ} \mathrm{C}$ and $300 \mathrm{fps}$ conditions that will occur in the ducting of the reference plant, and more study will be required to bring this issue into focus.

\subsubsection{Effects of Compatibility Phenomena on Mechanical Properties}

From a design standpoint, it is most important to establish what the effects of carburization, fission product impact, internal oxidation, thermal aging, element evaporation, etc. are on key design properties such as creep rupture strength, tensile properties, low cycle, high cycle and creep fatigue, fracture toughness, etc. It also is important to establish any effects of coatings that may be applied for corrosion or wear protection on the mechanical properties of substrate materials. 


\subsubsection{Properties and Design Methodologies for Ceramics}

It is evident from Figure 9-1, that, once temperatures become high enough, it is necessary to make extensive use of ceramic materials. Ceramic materials are, of course, generally very brittle, and it is not possible to design with them using the same design methodology as is used for metals. It is, for example, normally necessary to use probabilistic design methods for ceramics. At the present time, the methodologies required for ceramic design are not well developed. In addition, the basic properties of the ceramics, which are required in order to develop well-founded methodologies, are also not well characterized. Accordingly, it should be recognized that, at HTGR-GT temperatures, it will become increasingly necessary to deal with the state-of-the-art problem of design with ceramics for critical structural applications.

\subsubsection{Joining and Fabrication Feasibility}

Under HTGR-GT conditions, it becomes increasingly necessary to use materials which are generally not amenable to the more conventional forms of fabrication and joining. Examples here are the cast nickel-base alloys (which, in general, are not suitable for fusion welding) and the ceramic materials, the joining of which pushes the state-of-the-art. Special joining technique development will be required to facilitate engineering use of these materials in both similar and dissimilar combinations. Similarly, some of the materials that will be employed will need to be shaped into product forms significantly different from those for which relevant experience exists. The cast nickel-base alloys, for example, have not heretofore been made into shapes similar to those found, in thermal barrier cover plates. So considerable development work will be needed to show fabrication feasibility.

\subsubsection{Wear Protection}

It is generally necessary to provide protective coatings on metal surfaces that need to slide over one another, or are in vibrational contact, while in service in a hot, dry helium environment. Fairly well developed 
coating systems are available for the HTGR for temperatures up to around $760^{\circ} \mathrm{C}$. At the higher temperatures relevant to the HTGR-GT, a number of difficult phenomena are encountered. Coatings tend, for example, to spall with increasing rapidity as temperatures rise. Similarly, it can be anticipated that metal-to-metal adhesion (and maybe even coating-to-coating adhesion) will occur to a more significant extent as temperatures rise. Accordingly, HTGR-GT will require increasing emphasis on wear coating evaluation and development. Any effects of such coatings on behavior of the substrate materials also will need to be determined.

Wear of the heat exchanger tubes due to flow-induced vibration will be considered. While wear protection devices were applied to the tubes in HTGR steam cycle designs to protect the tubes from fretting wear at the tube supports, it is not clear that such protection is required in the GT due to lower operating temperatures. This issue can only be decided by a test program.

\subsubsection{Elevated Temperature Irradiation Damage}

A number of important components located within the core cavity are subjected to relatively high levels of irradiation by dominantly thermal neutrons (up to $5 \times 10^{21} \mathrm{n} / \mathrm{cm}^{2}$ ). Structures subjected to these conditions include parts of the Class $B_{1}$ and $B_{2}$ thermal barrier and the core restraint and peripheral seal structures. At those levels, and at the temperatures that prevail in these regions in HTGR-GT, structural materials can be significantly damaged. Trace quantities of boron, which are often in wrought nickel alloys, can transmute to helium with resultant severe loss in timedependent ductility. These effects may be more severe in the cast nickel base alloys, many of which contain significant deliberate boron additions. To combat these conditions, it may be necessary to utilize low boron materials like the Hastelloy XR alloy developed in Japan for use in the near-core components of their High. Temperature Gas Cooled Reactor experiments. 


\subsubsection{Materials Applications, Codes and Standards}

Many of the materials and processes which will be required for components of the GT have seen little or no prior use in nucelar reactors. Accordingly, many of these are not currently covered by reactor design codes such as the. ASME B\&PV code. Thus, it will be necessary to interact with the appropriate bodies (such as ASTM, ASME, NSMH, etc.) to develop required codes and standards and design correlations. Such interaction will also ensure that maximum use is made of pertinent data and technology being developed in other national and international programs.

\subsubsection{On-Going and Planned Materials R\&D Programs}

Programs to provide the data required to resolve these issues are currently underway at ORNL, GE and GA. These programs include determination of materials properties (e.g.: creep, fatigue, tensile strength, crack propagation, toughness, etc.), evaluation of the effects of the helium environment on behavior, development of wear coatings and joining methods, etc. Similar programs are underway in Europe at KFA, GHT, HRB, CIIR, HTMP, etc. Every attempt is being made to take maximum advantage of these international programs through the US DOE/FRG Umbrella Agreement. To this date, a number of specific cooperative materials programs have been agreed and initiated, and several more are currently under negotiation. It is expected that, with the maintenance of these programs at a strong level and with proper coordination of the efforts, timely resolutions to these important materials issues will be developed.

\subsection{GRAPHITE}

Graphite, in general, is an anisotropic, heterogeneous, quasi-brittle material, exhibiting moderate nonlinearity in its stress-strain response. Like most brittle materials, graphite has a much higher compressive strength than tensile strength, and its stress-strain behavior is dependent on the hydrostatic state of stress. Graphite is a necessary element in any HTGR design as: (a) a moderator, and (b) a structural material. The structural 
applications of graphite are safety-related, and its use in predicated on one primary advantage which is not shared with any other candidate material; i.e., the strength of graphite increases with temperature over the whole range of normal and accident temperatures predicted in HTGR service. All other possible material choices suffer rapid strength loss when certain critical temperatures are exceeded, and most of these occur well within the HTGR operating range.

GAC has been in a pioneering situation since first applying graphite in the Peach Bottom fuel and moderator components, with each successive use tending to be more critical. Also, as the exposure to regulatory review increased, so has the severity and sophistication of the criteria to be met. At the time of licensing the FSV plant, GAC proposed some relatively simple, self-imposed, design rules to the NRC which were accepted since no commonly accepted alternative was available. GAC's position at that time was simply to design to excessively high static load safety factors ( 8 to 20 times) on the assumption that any unknown factors would thus be accommodated. At the same time a more reasonable safety factor of 3 times was submitted for legal regulation. Ihis approach has been successful at FSV. Over the past few years much more sophisticated design analyses have been performed as the methods have improved and although several unexpected problems have surfaced, we have always had enough margin on hand to absorb the effect.

In contemporary discussions with NRC, however, it is obvious that this relatively crude approach will no longer be acceptable. The use of graphites in the nuclear industry will ultimately require the same option of understanding that now exists for metallic structures. In order to license any future HTGR, it will be necessary to verify the structural integrity of the graphite components at least as well as for any safety-related pressure vessels or piping. However, the understanding of fundamental properties needed in graphite structural design is in its infancy relative to metals. Therefore, the analytical techniques and materials data necessary to accomplish a comparable degree of design verification are not presently available. 
Unfortunately the use of graphite in critical structural applications is extremely limited and the data base consequently is small and narrow. Most data has been generated for designs supporting exotic space vehicle components, where, for the most part, the graphite components are subjected to a one-time, short term loading. By comparison, HTGR graphite components must be designed for long-term, multiple loading cycle usage. Similarly, rules of structural design suitable for HTGR applications (failure mechanisms, acceptable safety margins, etc.) have not previously been developed and accepted in general useage. Therefore, a comprehensive program to acquire the essential basic materials and application properties for graphite and to establish and verify the necessary design techniques and design criteria is mandatory.

Design analysis and prediction of failure using basic graphite physical and mechanical properties requires: (1) an appropriate stress model to describe the stress distribution; (2) an appropriate failure criterion or strength model; and (3) the graphite physical mechanical, and strength properties required by the stress model and the strength model.

Classical constitutive theories do not seem to work for graphite (analytical models). When properties are measured in uniaxial tests, and classical continuum theory is applied in the analysis, the calculated strengths and deformations do not agree with experiment: Measured strengths and flexibility of simple beams have been observed to be higher than prediction by a factor of 1.6 or more. Depending on the structure and the application, this may result. in a conservative stress analysis, but not necessarily so, The inability to predict stress states and deformed shapes in simple structures increases the uncertainty of analyses performed on actual structures which are far more complicated. At present we use a uniaxial maximum principle stress failure theory for naphite. This is known to be inaccurate and theoretically deficient, particularly for 3-D applications wherein material axes and principle stress axes do not coincide. A triaxial theory has been proposed but this is not yet sufficient data to support its use. 
It is important to recognize that the physical and mechanical properties that influence the stress distributions and the strength properties that influence failure will change with time due to various degradation mechanisms. It will be necessary to relate these changes in properties to suitable degradation parameters such as extent of oxidation (e.g., burn off) and fatigue damage parameters (e.g., stress range and number of cycles), and irradiation dose. The particular physical, mechanical and strength properties required will depend on the particular stress and strength models adopted.

The HTGR Generic Technology Graph1te Development Program currently being formulated has three components: 1) a program to characterize candidate graphite materials in terms of routine physical and mechanical properties, access the variability of these properties, and determine the susceptability of the materials to oxidation; 2) a series of special tests to establish the behavior of typical fine-grain and coarse-grain graphites under a variety of loading and environmental conditions to provide data supporting the selection and verification of specific graphite material models, analytical methods and failure criteria; and 3 ) standardized tests to obtain the material properties required by the material models and analytical methods established as a result of the test performed under the foregoing second part. The basic characterization work is a substantial portion of the graphite materials development program which has been underway for several years. Part 2 in an extension of a series of special tests which werc begun by the Reactor Internals Branch around 1977, and will require heavy emphasis in the next two or three years. The formulation, evaluation and verification of material models and failure criteria which utilizes the data from Part 2 will be performed under the HTGR Generic Technology, Structural Technolngy Program. Part 3 will be an entirely new effort, incorporating some parts of the earlier graphite development program, but. undoubtedly requiring several new types of material tests as established by Part 2 . 


\subsection{HTGR TURBOMACHINE DEVELOPMENT PROGRAM .}

\subsubsection{Program Approach}

The HTGR Turbomachine will inherit considerable design system and development technology from existing aircraft and industrial gas turbines. The design concept will be conservative without forfeiting the fundamental efficiency and reliability required for utility economics.

The sophisticated design system developed for aircraft and industrial gas turbines will yield an engine design of assured success. There will be little or no need to extend the fundamental state-of-the-art and so require feasibility tests (will it work?). There will be a need to run a design system verification program on components and on the system to the extent practical. This program will assure that all design requirements have been met. It will provide a base of data for licensing activities.

\subsubsection{Testing Required}

The HTGR Turbomachine is a reasonable extrapolation in size from current industrial power plants such as the FT-50 or the Frame 7. However, the closed cycle, helium working fluid configuration, and the size present a unique test facility requirement. A number of the turbomachine components must be tested and verified with the helium working fluid.

These include: bearings and seals, compressor performance rig, turbine performance rig, and materials compatibility. Other tests may be accomplished without a helium environment. These would include: disc and rotor spin and burst tests, complete rotor spin test, containment ring tests, and flow distribution tests. These tests will be run in air or in a vacuum. A vacuum would be pulled on spin test rigs to minimize drive power requirements. 


\subsubsection{Helium Testing}

A test facility would be designed and built which would provide a large volume, temperature controlled helium stream. The facility. would provide flows to 120 pps or $1 / 10$ rated power conversion loop flow. This flow would be sufficient to test tenth scale compressors and turbines. These rigs would be run in time sequence so as to provide economy in the helium supply system. Performance mapping of these components requires relatively short duration tests nad lend themselves to sequencing.

Bearing and seal tests would be both performance and life characteristics tests. Because of the small quantities of helium required for buffering and for simulating main loop pressure variations, (a few pounds per second) these tests would be run in parallel with the compressor and turbine tests.

\subsubsection{Bearing and Seal Testing}

The bearing and seal configurations in the HTGR-GT represent designs that have been successfully operated in other applications. In the HTGR application there is a very stringent oil leakage limit, (one cubic foot per year). $0 i 1$ ingress has a very harmful impact on the thermal barrier performance. In addition, the bearing diameters are large and the DN factor (surface speed) is high. The generator drive shaft seal is a safety class component because it seals a rotating penetration through the Prestressed Concrete Reactor Vessel (PCRV) and prevents contamination of the secondary containment building.

For these reasons extensive testing is planned to optimize bearing and seal configurations and flows, and to provide verification of the integrity of the designs. The rigs will be operated at design conditions and extreme transients and off-design conditions to assure that adequate margins are available. After the completion of tests that verify the designs meet all performance parameters, endurance testing will be run to identify and eliminate any random or wearout failure modes. 
The two main shaft bearings are tilted pad journal bearings: These main support bearings are identical to each other so that one journal bearing rig is planned. This rig will also include the double buffered, labyrinth seal arrangement and the lubricating and helium cleanup system.

The thrust bearing is a double acting tilted pad design. It is designed to handle the rotor thrust plus loads associated with an earthquake shock up to 6.7 on the Richter scale. It is located at the compressor end of the turbomachine near the PCRV shaft penetration. Its lubricating system is located in the secondary containment building so as to minimize oil ingress problems.

The PCRV penetration seal is a multiple piston rig floating oil lubricated seal. It incorporates a hydraulically operated shut-down face seal. It is a safety-class component.

It is planned that the bearing and seal rigs would share common drives for further economy. Although the thrust bearing rig does not require a helium supply it would be run along with the other bearing and seal rigs so that it might share common resources of equipment, instrumentation, techniques and engineering coverage.

\subsubsection{Compressor and Turbine Performance Tests}

The turbomachine computer model gas dynamic analysis for compressor and turbine design accurately describes the required gas path configuration. Although experience on numerous power plants designed by use of this computer program have shown excellent correlation between calculated and actual results, compressor and turbine performance tests are included in the HTGR program. Compressor and turbine efficiency and compressor surge. margin are very critical to the success of the installation. 'Also, although design with helium as a working fluid poses no serious concerns, actual experience is very limited and design assumptions should be proven. 
Gas dynamic design considerations readily yield to scaling effects. For economic and practical considerations $1 / 10$ scale helium compressor and turbine rigs would be built and run to confirm design efficiencies and compressor surge margin.

Compressor and Turbine performance mapping tests will be run so that pressure ratios versus corrected flow may be plotted for various rotor speeds. By measuring these parameters in test rigs as opposed to turbomachine operation, performance limits off the normal operating line may be evaluated.

\subsubsection{Rotor Stress Tests}

Stresses in rotors do not scale well. Some information on stress concentration effects is obtainable by scaled rig tests but the expense is not justified. Therefore, a spin test program on critical full scale discs and rotor segments will be run to verify the design margins. The discs and rotor sections will be run in a vacuum to minimize drive costs and to allow sufficient over stress conditions.

Containment of rotor failures is a plant safety consideration. Both compressor and turbine sections are shrouded by heavy wall containment rings designed to prevent blade, disc or rotor segment failures from making excursions to the cavity liner or other parts of the installation. Containment rings will be tested as part of the blade, disc and rotor segment spin tests to failure. These tests are normally conducted in pits with the shaft in a vertical orientation. Data from these tests will be critical for licensing considerations.

A rig is planned for balancing complete rotors. It will simulate the dynamic environment including the three main shaft bearings and their support cases. The rotor will be shrouded so that a vacuum can be drawn to reduce drive motor capacity requirements to a practical level. Vibration tests will be run after balancing to verify design analysis of critical speed mode and vibration energy levels. 


\subsubsection{Systems Test}

Considerable consideration has been given to methods of running a complete power conversion loop systems test. The possibility of employing a fossil fired facility for a system test has been tabled because of high "up front" capital investment requirements and its associated technical questions. Development of a large heat source and high temperature heat exchangers could interject pacing items into the programs "critical path".

Use of an experimental or demonstrator reactor may be the most practical vehicle to test the power conversion loop components, including the turbomachine. A nuclear heat source may be the most practical for a full scale test. An experimental unit on a remote government site should limit or remove licensing requirements which would inhibit testing flexibility.

A high premium would then exist for thorough fullfillment of the component and subsystem development tests. Application of a rigorous quality/product assurance system would be instituted and would cover system test hardware. The experimental facilities would have extended use for acceptance test of deliverable units.

\subsection{HEAT EXCHANGER DEVELOPMENT REQUIREMENTS}

The primary coolant heat exchangers for the HTGR-GT system are of two types: a recuperator which transfers heat from low pressure to high pressure helium and a precooler which transfers heat from helium to pressurized water. In a general sense, these heat exchangers are considered to be within the state-of-the-art although specific development will be required to develop configurations suitable for the current system context.

The current recuperator design employs a straight-tube counterflow heat transfer surface geometry that, in order to minimize PCRV and performance impact, requires large numbers of small diameter, closely spaced tubes. 
Modular tube bundle construction will allow for practically sized subassemblies since overall assembly sizes on the order of 20 feet in diameter, 75 feet long, and 800 tons in weight are required for demonstration size heat exchangers. As a point of reference, metal temperatures in the recuperator range from about $350^{\circ} \mathrm{F}$ to a maximum of about $1000^{\circ} \mathrm{F}$.

The precooler configuration currently being developed is a helical finned-tube design which represents an effective heat transfer solution for the intended service. Typically, the precooler will have about 800 to 1000 tubes leading to overall component dimensions of about 16 feet in diameter, 65 feet in height, and 500 tons in weight. Operating metal temperatures in the precooler range from $70^{\circ} \mathrm{F}$ to about $450^{\circ} \mathrm{F}$.

The development requirements for the heat exchangers may be defined in terms of four categories which are related to the various stages of demonstration or prototype heat exchanger design, fabrication and operation. In the conceptual phases of design, "feasibility confirming development" in the form of special analysis and testing is required to establish concept feasibility. In order to establish a basis for the initiation of fabrication, "envelop defining development" is needed to quantify heat exchanger envelops to the point where long lead procurement for fabrication may begin without undue risk of major perturbations to the heat exchanger envelop or system interfaces because of heat exchanger design uncertainties. "Fabricationrelated" development will be required to reduce risk of fabrication schedule slippages and cost overruns which might result from fabrication uncertainties. "Confirmatory and pre-operational" development will be required to confirm, clarify, verify, predict and/or quantify expected heat exchanger behavior in an operating environment.

\subsection{1. "Feasibility Conf1rming" Development}

The development activities required to establish concept feasibility cover a broad range of considerations including structural adequacy, performance, cost, manufacturability, maintellance/ISI and system impact. Specific items which must be addressed during the conceptual phase have 
been identified for each of the heat exchangers. The items noted are based on the current level of heat exchanger definition so that changes and/or additions can be expected as the designs evolve.

For the recuperator, the key feasibility issues are related to:

1. Definition of wear protection requirements for tubing and structural parts - If wear protection for tubing is required in the form of coatings and/or protective devices, a significant cost impact is anticipated. The emphasis of test work would be in determining wear characteristics for tubing in the anticipated operating environment.

2. Tube support feasibility - Determination of pressure loss and structural characteristics of tube support configurations. Pressure losses are particularly difficult to predict without. testing and in addition may be a significant component of recuperator pressure losses and have strong influence on overall cycle efficiency.

3. Module support structure - Structural adequacy and fabricability of the module support structure for hexágonal module concepts must be demonstrated to establish feasibility of the hexagonal module approach.

For the precooler, the key feasibility issues relate to:

1. Feasibility of finned-tubing, particularly with respect to inspection - A scoping demonstration of potential inspection techniques is needed to provide a basis for selection of the helical finned-tube approach.

2. Limitations on heat exchanger size - Studies and possible testing to determine practical limits on number of tubes and/or component diameter are needed to confirm the feasibility of the helical design approach. 


\subsection{2. "Envelop Defining" Development}

Following the confirmation of concept feasibility, additional development is needed to establish the heat exchanger envelops. To some extent this may be a continuation and/or expansion of the "feasibility confirming" development and would generally focus on the following categories (for both heat exchangers).

1. Flow distribution and pressure drop testing - Subscale testing to determine the need for, or configuration of, flow distribution devices will be performed. This will establish bases for verification of pressure loss predictions and help to establish boundary conditions for thermal and structural analysis.

2. Testing of key design features - Development of workable configurations for bellows expansion joints, bypass seals, sliding joints, etc. Such testing would not necessarily establish final configurations but would at least bracket their physical and/or performance envelop impacts.

3. Structural testing - Establish adequate configurations for support structures in accordance with imposed loadings (e.g., seismic, acoustic, vibration).

4. Heat transfer testing - Small scale heat transfer tests will be needed to verify thermal size and performance predictions and to establish performance envelop uncertainties.

5. Maintenance and ISI - Mock-ups and/or models will be needed to demonstrate adequate access for maintenance and ISI procedures.

\subsubsection{Fabrication Related Development}

During the detail design and fabrication phase, development activities will focus on fabrication support in the form of: 
1. Mock-ups to demonstrate and verify fabrication techniques.

2. Specialized tooling and welding equipment for fabrication.

3. Development of Heat Exchanger Installation Procedures and Equipment .

\subsubsection{Confirmatory and Pre-Operationa1 Development}

In-service operating characteristics of the heat exchangers will be determined through:

1. Moderate scale heat transfer tests.

2. Pre-operational testing and start-up of demonstration plant heat exchangers.

\subsection{HOT DUCT}

The hot ducts of all HTGR reactors have been a critical design issue , for many years. It is even more so in the Gas-Turbine plants. The particular challenge of designing the hot duct can be addressed in three parts; material design consideration, thermal barrier component design and hot duct assembly. All of these areas experience the impact of temperature, flow relocates, pressure gradients, and acoustic pressure levels. In addition, the hot duct assembly represents a pressure vessel in order to accommodate annular counterflow conditions. The complexity is increased due to the need for thermal movement allowance and replacibility.

\subsubsection{Materials Design Considerations}

The viability of wrought superalloy materials for structural. application in the thermal barrier rapidly becomes exhausted at temperatures in excess of about $1400^{\circ} \mathrm{F}$. (In conjunction with standard design requirements such as 40-year life etc.). Vacuum cast nickel-base alloys are thought to be able 
to extend the viable temperature range of structural metallics suitable for application to thermal barriers by offering strength and environmental stability (carburization resistance) generally at the expense of ductility and fatigue characteristics. This alternative, however, would necessitate extensive qualification fortheuseof such materials. It is doubtful though that this solution may offer temperature capabilities to satisfy completely the upper range of $\mathrm{PH}$ requirements. Nevertheless, the possible application of cast superalloys in thermal barrier component development is regarded as having a considerable potential which warrants being explored. With the general desire to utilize material candidates that would satisfy completely both GT and PH needs, non-metallic material component designs certainly will have to be developed. These designs will necessitate a much expanded program over that currently visualized for the SC plant. The SC utilizes an elementary load bearing ceramic block design in connection with the Class $\mathrm{C}$ thermal barrier. The PH and GT non-metallic component development efforts will involve a broader range of candidate materials (ceramics, carboncarbon) applied in considerably more ambitious design configurations. Ceramic materials will be employed in both load bearing (core support) as well as non-load bearing design functions. The viability of the advanced HTGR's will rest in part on the development of such sophisticated designs.

\subsubsection{Thermal Barrier Components and Assemblies}

Following Initial design application screening of candidate thermal barrier materials for sources of supply, material availability, component manufacturability and cost etc., the hardware performance qualification has to be approached. Structural and thermal performance tests entailing individual components as well as assemblies must be conducted. These designs are greately novel as derived on the basis of the activities defined uner ( 1 ) above. They are also generally applicable to both GT and $\mathrm{PH}$ programs. However, certain system characteristics will be specific to either advanced HTGR, and will require individual test qualifications. Flow and acoustic vibration environments, temperature (including accident excursions) requirements and parlicular pressure (including $\Delta P$ ) characteristics are examples of such spectfic considerations which dictate separate investigations. 
The present Generic Technology Program does not incorporate in its definition of thermal barrier related DV\&S tasks the above activities in that they are not also specifically required for the qualification of the SC plant.

\subsubsection{Hot Duct and Extension}

The hot duct and its associated extension to the turbo-machine inlet (in the GT plant) has come to be regarded as representing a special case thermal barrier assembly. Irrespective of whether the plant configuration dictates a co-axial or integrated hot duct, per se, the design requirements for this assembly greatly exceed those normally considered in thermal barrier design. For the sake of this discussion no attempt will be made to distinguish the GT and PH plant hot ducts in regards to their specific design requirements. Also, the issues noted under Section 9.5.1 apply to the extent that the hot duct and its extension serve as thermal barriers.

\subsection{GAS TURBINE BY-PASS VALVE DEVELOPMENT}

The bypass valves consist of four valves per loop, i.e. the attemperation, control, trim, and safety. The trill and attemperation valves are reasonably close in size to commercial control valves. The safety and control valves are large; they will require a 31 inch diameter seat. The large size, fast stroke time, high $\Delta \mathrm{p}$, and high temperature places these valves out of the normal commercial range; Table 9.6-1 lists the major valve parameters. Valve development will require the design of an overall integrated valve and actuator concept which will be compatible with a PCRV installation. During design and development testing, special concern needs to be addressed to the following problem areas: friction and self-welding, seat erosion, steam leakage, and remote removal for maintenance. Three possible schemes could be used to test the large bypass valves:

1. Full-scale flow testing in the existing.HHV loop.

2. Quarter-scale blow-down tests

3. Full-scale testing in a helium environment with a mechanical load. 
TABLE 9.6-1

BASIC BYPASS VALVE DATA

3 Loop, 400 MW(e) Turbomachine - Non-Intercooled, Reference Plant

\begin{tabular}{|c|c|c|c|c|}
\hline & Control & Trim & Safety & Attemperation \\
\hline Design Pressure & 1185 PSIG & 1185 PSIG & 1185 PSIG & 1185 PSIG \\
\hline Design Temp. & Per Analysis & Per Analysis & Per Analysis & Per Analysis \\
\hline Normal Press Inlet & 1150 PSIA & 1150 PSIA & 1150 PSIA & 1150 PSIA \\
\hline Normal Temp. & $928^{\circ} \mathrm{F}$ & $928^{\circ} \mathrm{F}$ & $928^{\circ} \mathrm{F}$ & $346^{\circ} \mathrm{F}$ \\
\hline $\begin{array}{l}\text { Flow Area - } 100 \% \\
\text { Open }\end{array}$ & 765 in $^{2}$ & 65 in $^{2}$ & 765 in $^{2}$ & 113 in $^{2}$ \\
\hline $\begin{array}{l}0-100 \% \text { Travel } \\
\text { Time Open }\end{array}$ & $1 \mathrm{sec}$ & $1 \mathrm{sec}$ & $1 \mathrm{sec}$ & $1 \mathrm{sec}$. \\
\hline Control Range & $0-100 \%$ & $0-100 \%$ & Not Req'd & $0 .-100 \%$ \\
\hline $\begin{array}{l}\text { Position } \\
\text { Resolution }\end{array}$ & $\begin{array}{l}0.2 \% \text { of } \\
\text { Stroke }\end{array}$ & $\begin{array}{l}0.2 \% \text { of } \\
\text { Stroke }\end{array}$ & $\mathrm{N} / \mathrm{A}$ & $\begin{array}{l}0.2 \% \text { of } \\
\text { Stroke }\end{array}$ \\
\hline $\begin{array}{l}\text { Loss of Power } \\
\text { Position }\end{array}$ & $\begin{array}{ll}\text { Open: } & \Delta p>20 \\
\text { Closed: } & \Delta p<20\end{array}$ & $\begin{array}{ll}\text { Open: } & \Delta \mathrm{p}>20 \\
\text { Closed: } & \Delta \mathrm{p}<20\end{array}$ & $\begin{array}{ll}\text { Open: } & \Delta p>20 \\
\text { Closed: } & \Delta p<20\end{array}$ & $\begin{array}{ll}\text { Open: } & \Delta p>20 \\
\text { Closed: } & \Delta p<20\end{array}$ \\
\hline $\begin{array}{l}\text { Maximum Press. } \\
\text { Drop }\end{array}$ & 675 PSI & 675 PSI & 675 PSI & 675 PSI \\
\hline $\begin{array}{l}\text { Type of Control } \\
\text { Contour }\end{array}$ & Linear & $\begin{array}{l}\text { Equal } \\
\text { Percent }\end{array}$ & $\begin{array}{l}\text { Quick } \\
\text { Open. }\end{array}$ & Linear \\
\hline Normal $\Delta p$ & 675 PSI & 675 PSI & 675 PSI & 675 PSI \\
\hline $\begin{array}{l}\text { Seat Leakage } \\
\text { Normai } \Delta p\end{array}$ & $1500 \mathrm{lb} / \mathrm{hr}$. & $15 \mathrm{lb} / \mathrm{hr}$. & $1500 \mathrm{lb} / \mathrm{hr}$ & $1500 \mathrm{lb} / \mathrm{hr}$ \\
\hline $\begin{array}{l}10 \% \text { Step Change, } \\
\text { Time Const. }\end{array}$ & $0.25 \mathrm{sec}$. & $0.25 \mathrm{sec}$ & $\mathrm{N} / \mathrm{A}$ & $0.4 \mathrm{sec}$ \\
\hline
\end{tabular}




\subsubsection{Bypass Control Valve Quarter Scale Test}

The normal position of the valves is closed and it would appear that most of the development problems will be associated with the quick opening cycle. It, therefore, seems that development testing could be conducted by performing cyclical blow-down tests between two insulated high pressure tanks. Initially, one tank would have helium at $685 \mathrm{psia}$ and $928^{\circ} \mathrm{F}$ while the other tank would be at 15 psia. The valve under test would be used to hold the pressure differential between the two tanks. The pressure differential would be the same as in the reactor installation, i.e. 670 psi. Upon command, the valve would be signaled to open and instrumentation would be used to measure valve position as a function of time and pressure differential. The valve travel time is to be 1 second so if sufficient tank volume is provided for, say about 2 seconds flow, a definitive test can be accomplished. Some data on valve closing could also be obtained by placing two valves in series and signaling one valve to open and the other valve to close simultaneously. Testing. a full-size valve, i.e., 31 inches seat diameter is not practical even for a period as short as 2 seconds, would require a $12,000 \mathrm{ft}^{3}$ high-pressure tank and a 24,000 $\mathrm{ft}^{3}$ low-pressure tank. A quarter-size valve would have a seat diameter of 7.75 inches which is still a rather large valve. This valve could be scaled down from the large valve so as to preserve the same ratio of forces and inertias. Blow-down cycle tests would then be conducted with hot helium and normal $\Delta \mathrm{p}$. The approximate tank size for a quarter-size valve test would be a $750 \mathrm{ft}^{3}$ high-pressure tank and a $1500 \mathrm{ft}^{3}$ low pressure tank.

\subsubsection{Mechanica1 Load Simulation}

Another possibility for a test of a full-size valve would be to simulate the pressure forces on the valve disc with a mechanical spring. The spring rate would be tailored to fit the expected forces on the valve seat during a typical stroke cycle. With this method a full-size valve could be placed in a heated chamber filled with helium to provide a simulated environment, and the valve could be stroked and various control characteristics could be 
measured. The hot helium environment would provide an adequate test of the friction and galling phenomenon and a mechanical spring could simulate the pressure and aerodynamic loads.

\subsection{ELECTRICAL PENETRATION}

With the decision to locate the alternator, as well as the gas turbine in the reactor containment, the availability of high-voltage, high-current electrical containment penetrations was studied. At present, penetrations may be obtained at ratings of 15,000 volts and 520 amperes maximum. Such penetrations are qualified for $150^{\circ} \mathrm{F}$ continuous duty or $340^{\circ} \mathrm{F}$ for 6 hours at 65 psig. They conform to the codes and standards listed in Section 3 of the 1976 IEEE Standard 317, Reference 1, on electrical penetrations.

The 3-loop $3000 \mathrm{MW}(\mathrm{t})$ gas turbine HTGR requires penetrations rated at 24,000 volts and 12,000 amperes continuous for transmitting the generator power through the containment walls. A recent Regulatory Guide, Reg. Guide 1.120 on fire protection, implies that all containment wall penetrations will meet the requirements for a three hour fire barrier. Present plant analysis indicates a DBDA will create containment temperatures to $600^{\circ} \mathrm{F}$ and pressures to about $30 \mathrm{psig.} \mathrm{Containment} \mathrm{test} \mathrm{pressures} \mathrm{have} \mathrm{not} \mathrm{been}$ determined but will present the maximum pressure to which penetrations will be subjected. Available penetration designs cannot meet the service requirements imposed by the GT-HTGR. The combination of voltage, pressure, and temperature dictate that a new, innovative design be developed.

Some initial design work and several discussions with R\&D personnel of Lapp Insulator indicate that ceramic insulators are available for 24,000 volts and new seallng procedures are available for ceramic to metal interfaces. A 6,000 ampere, 24,000 volt, 3-phase penetration seems feasible with the present state-of-the-art. This solution requires two penetrations per alternator. 
9.8. FUEL

The HTGR fuel has evolved from mixed thorium-uranium carbide used in the Peach Bottom and Fort St. Vrain HTGRs to the completely separable TRISO fissile/BISO fertile large HTGR fuel (F1g. 9.8-1). The development of separable fuel on the National Program started in FY-67 at Oak Ridge National Laboratory (ONRL) with accelerated tests in the High-Flux Isotope Reactor (HFIR). At GA, the program was initiated in FY-70 with irradiation testing in the Engineering Test Reactor (ETR) and the Peach Bottom HTGR. The Peach Bottom fuel test element program complemented the accelerated irradiation testing in the HFIR and ETR by providing confirmation of core design methods, nonaccelerated irradiation testing of large HTGR fuel, and large quantities of irradiated large HTGR fuel as feed material for recycle process development at ORNL (Fig. 9.8-2).

During FY-71, irradiation tests revealed the superior thermal performance of $\mathrm{UC}_{2}$ relative to $\mathrm{UO}_{2}$ which showed high-kernel mobility. During FY-73 and FY-74, the first Irradiation testing was successfully conducted on large HTGR type fuel rods containing TRISO fissile and BISO fertile particles. TRISO coated fissile particles of $\mathrm{UO}_{2}$ and $\mathrm{UC}_{2}$ with large diameter $(200 \mu \mathrm{m})$ needed for efficient metal loading were also irradiated, and the results provided the basis for selection of $\mathrm{UC}_{2}$ kernel materials as the reference fresh fuel because of superior thermal performance and the extensive data base. Both $\mathrm{HEU} \mathrm{UC}_{2}$ TRISO and $\mathrm{ThO}_{2}$ BISO showed adequate performance in accelerated tests and Peach Bottom HTGR Fuel Element tests conducted in the FY-71/75 time period.

In FY-75, results of irradiation tests, postirradiation heating, and analytical results were used to develop fuel performance models for use in core design. These models used the $\mathrm{UC}_{2} \mathrm{TRISO}_{\mathrm{ThO}} \mathrm{BISO} \mathrm{HEU}$ cycle (see Fig. 9.5-). The current emphasis on nuclear nonproliferation has caused the program to shift (in FY-77) from highly enriched uranium (HEU, 93\% U-235) to development of the medium enriched uranium/thorium (MEU/Th) fuel cycle (with 20\% U-235). 

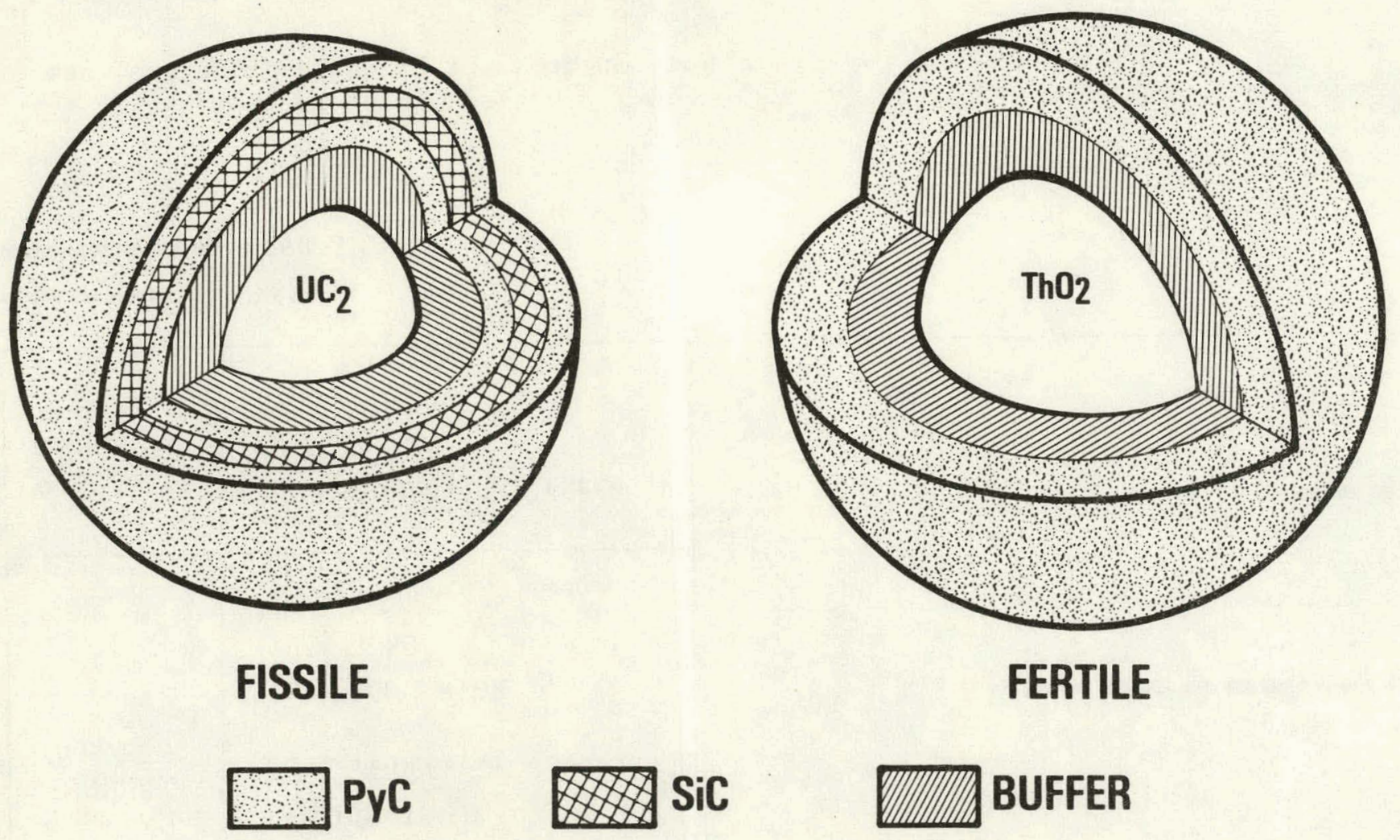

Fig. 9.8-1. Reference HTGR MEU fuel particles 


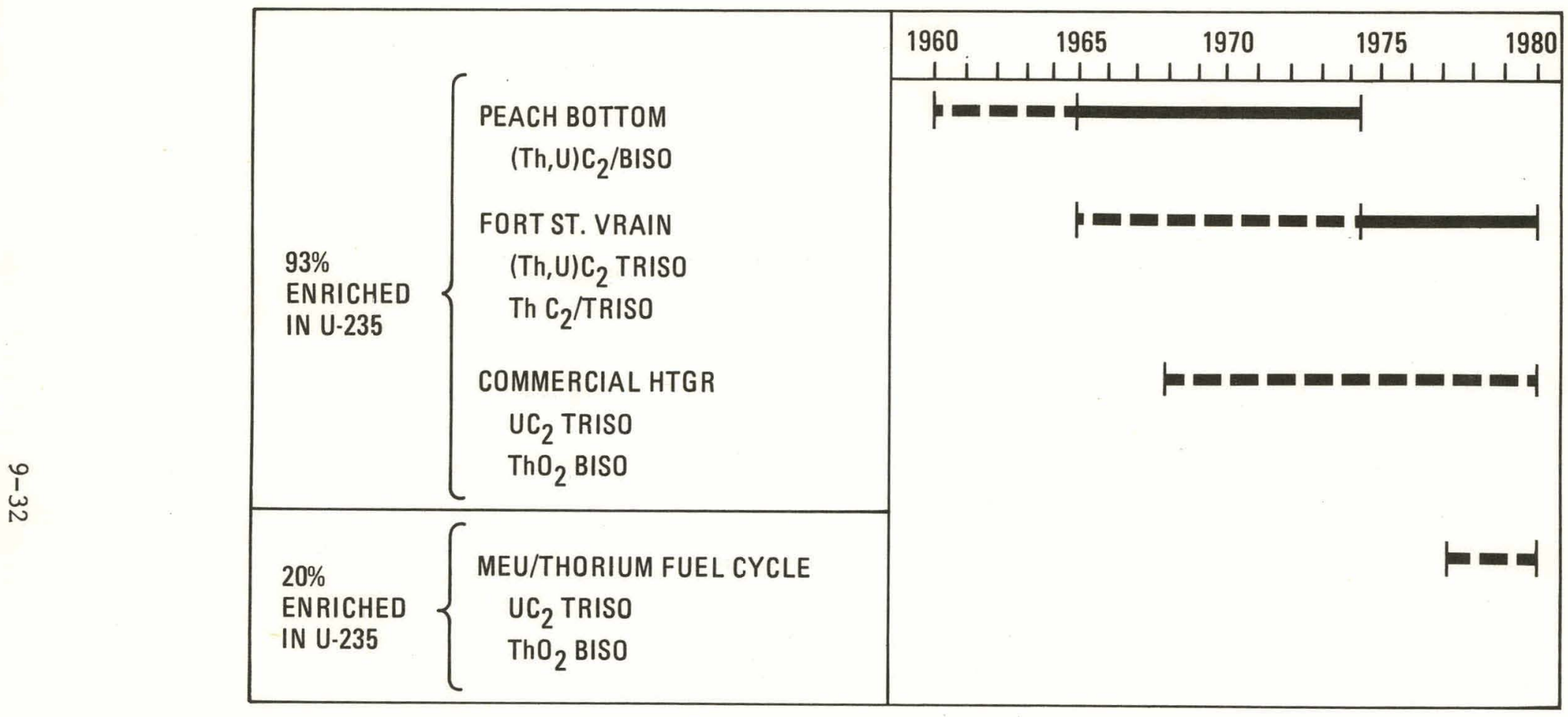

$=-1=\mathrm{R} \& \mathrm{D}=\mathrm{D}$

OPERATION

Fig. 9.8-2. The development of coated particle fuel in the United States has been an evolutionary process leading to an optimized fuel cycle 
The outstanding fuel development issues are:

- Must provide a statistically significant data base on processprepared MEU reference fuel to verify performance models for steady state, transient and accident scenario conditions.

- The effect of enrichment on fuel performance, safety and maintenance considerations must be assessed.

- Fuel specifications consistent with fuel manufacturing capability, core design and fuel cycle requirements must be fully developed and optimized.

- A backup fuel program that minimizes risk associated with the reference fuel process, and which is responsive to the long-term needs of advanced HTGRs must be provided.

Irradiation tests were initiated in FY-78 to provide fuel materials for postirradiation heating studies to characterize fuel thermal performance and qualification of the MEU fuel design. In addition, the shift to development of a medium enriched uranium/thorium fuel cycle has led to the need to consider new fuel performance factors resulting from the different fission product yield spectrum for MEU fuel relative to HEU.

Mnst recently, the DOE recommeudation to concentrate upon advanced HTGR concepts has led to consideration of "clean" primary circults, need for improved fuel performance, and better uranium resource utilization. All of which give strong impetus for development of improved MEU fuel. A National Program plan, including work at GA and ORNL, has been developed for an orderly completion of HEU fuel development, development of MEU/Th fuel including improved fuel, and for the levelopment of a generic fuel performance data base to support core design, licensing and safety analysis goals. This program is being updated to account for the recent emphasis on HTGR-GT. 
TABLE 9.8-1

REFERENCE MEU (20\% ENRICHMENT) FUEL PARTICLE DESIGNS

\begin{tabular}{c|c|c|c|c|c|c}
\hline & & \multicolumn{5}{|c}{ Nominal Dimensions (um) } \\
\cline { 3 - 7 } $\begin{array}{c}\text { Particle } \\
\text { Type }\end{array}$ & $\begin{array}{c}\text { Kernel } \\
\text { Composition }\end{array}$ & $\begin{array}{c}\text { Kernel } \\
\text { Dia. }\end{array}$ & $\begin{array}{c}\text { Buffer } \\
\text { Thk. }\end{array}$ & $\begin{array}{c}\text { IPyC } \\
\text { Thk. }\end{array}$ & $\begin{array}{c}\text { Sic } \\
\text { Thk. }\end{array}$ & $\begin{array}{c}\text { OPyC } \\
\text { Thk. }\end{array}$ \\
\hline Fissile & UC $_{2}$ & 550 & 115 & $\ddots 35$ & 35 & 40 \\
Fertile & ThO $_{2}$ & 500 & 95 & None & None & 80 \\
\hline
\end{tabular}


International cooperation plays a significant role in determining the fuel development program. Commercial agreements exist between GA-CEA and GA-HOBEG. The National HTGR fuel development program is now profiting from the US/FRG Umbrella Agreement on joint cooperation in specified areas.

Certain policy uncertainties associated with nuclear nonproliferation have influenced the fuel development direction:

- maximum allowable enrichment for HTGRs, and

- acceptability of undenatured U-233.

As a result, and for other reasons, several alternate particle designs are also under consideration.

\subsubsection{Alternate Particles}

The reference MEU fuel system (TRISO $\mathrm{UC}_{2} / \mathrm{BISO} \mathrm{ThO}_{2}$ ) (Table 9.8-1) is a rational selection from the standpoint of resource utilization and economics. However, a number of factors could make a change in the reference fuel desirable. These include the following:

- New nuclear nonproliferation criteria.

- Continued escalation of uranium prices that could make higher conversion ratios even more attractive.

- An improved fuel fabrication process that minimizes fuel cycle cost.

- New regulatory requirements that could require even higher levels of safety than those for the current generation of reactors, which could lead to the need for further improvements in fission product retention in the fuel.

- Improved temperature capability. 
In order to provide a measure of flexibility in the future, alternate fuel systems have been identified for development. The fuel systems selected for some future considerations are:

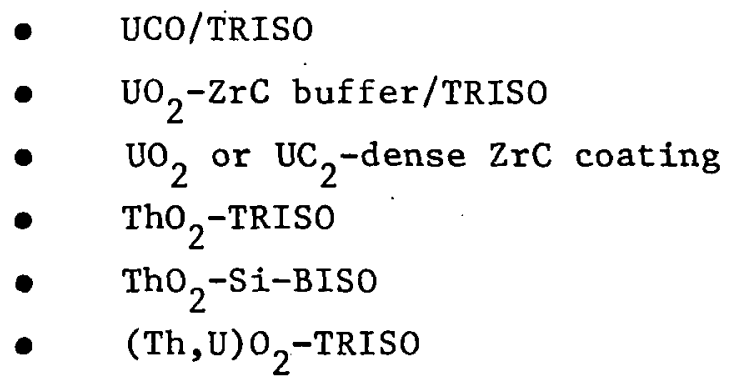

The UCO and $\mathrm{UO}_{2}-\mathrm{ZrC}$.buffer kernels with TRISO coatings are of interest because the high kernel migration rate normally exhibited by oxides may be reduced or halted completely by low co pressure in the buffer while the good rare earth fission product retention and resistance to hydrolysis is retained.

The dense $\mathrm{ZrC}$ coating on MEU fissile fuel is of interest because it may be more resistant to Pd attack than SiC. The ZrC coating would be used by itself or as an inner protective coating for SiC.

$\mathrm{ThO}_{2}$ TRIOS and Si-BRISO coatings on $\mathrm{THO}_{2}$ fertile particles are of interest because of improved fission product retention relative to $\mathrm{THO}_{2} \mathrm{BISO}$. The $\mathrm{ThO}_{2}$ TRISO would require significant size differential from the fissile particle for separation by ellutriation in recycle processes while the Si-BISO would lend itself directly to the burn-leach process.

The (Th,U)O $\mathrm{O}_{2}$ TRISO represents a conservative MEU fissile particle with a reduced burnup and least risk of unsatisfactory thermal performance. However, the dispersed nature of the uranium gives rise to a large neutron resonance absorption which requires increased uranium consumption relative to a dense all-uranium fissile particle.

During FY-78, work on alternate fertile fuel designs continued. In order to provide technical support for evaluation of alternate fissile 
fuel particles the HRB-14, $\mathrm{HRB}-15 \mathrm{~B}$ and R2-K13 irradiation experiments were started. In addition, the Fort St. Vrain Fuel Test Elements (FSV-FET-2, 4, 6) contain MEU (Th,U) $\mathrm{O}_{2}$ TRISO fuel.

\subsubsection{Reference Fuel Rod}

By FY-71, the HFIR tests conducted at ORNL provided confirmation that fuel rods rather than unbonded beds of particles should be used in the large HTGR because of reduced fuel-block interaction. The criteria for fuel rod performance are:

- Maintain integrity to peak exposure.

- Exhibit shrinkage behavior compatible with moderator graphite.

- No detrimental interaction between fuel rod matrices and particles.

Integrity of fuel rods at full exposure and beyond has been demonstrated by irradiation tests. Fuel rods for the FSV HTGR were carbonized in a bed of $\mathrm{Al}_{2} \mathrm{O}_{3}$. powder and then heated to $1800^{\circ} \mathrm{C}$ to outgas and stabilize the matrix. For the LHTGR, a process simplification was adopted in the form of the cure-in-place (CIP) technique which avoided the use of the $\mathrm{Al}_{2} \mathrm{O}_{3}$ bed for carbonizing. In this procedure, the green fuel rod was inserted into the fuel hole, carbonized and heated to about $1650^{\circ} \mathrm{C}$ to outgas and stabilize the matrix (Táble 9.8-2).

The perfurmance of fuel rods made by the CIP prucess has been demonstrated and thermal conductivity characterized with HEU fuel. The R2-K13 irradiation experiment was initiated in FY-78 to demonstrate the CIP fuel rod process with MEU fuel (UCO TRISO/Tho 2 TRISO). Results of that work will be available as part of the DOE/FRG Umbrella Agreement in FY-82.

Full scale demonstration of CIP fuel rod performance with HEU and MEU fuel, TRISO/TRISO and TRISO/BISO systems will be obtained from fuel test elements irradiated as part of the FSV-FTE program. In that program, six elements manufactured with the CIP technique will be irradiated and examined perindically to characterize performance up to full exposure. 
TABLE 9.8-2

FUEL ROD CHARACTERISTICS

\begin{tabular}{|c|c|c|}
\hline Parameter & Fort St. Vrain & Large HTGR \\
\hline Process & Hot Injection & Hot Injection \\
\hline Carbonizing & In Packed $\mathrm{Al}_{2} \mathrm{O}_{3}$ & In Block \\
\hline Heat-Treat Temp., ${ }^{\circ} \mathrm{C}$ & 1800 & $\geq 1650$ \\
\hline Shimming & Particle Size-Blending & Graphite Particles \\
\hline Binder Type & Coal Tar Pitch (15V) & Petroleum Pitch \\
\hline Filler & Natural Flake Graphite & $\begin{array}{l}\text { Petroleum-Derived } \\
\text { Flake Graphite }\end{array}$ \\
\hline Matrix Density, G/CC & $0.5-0.6$ & $0.8-1.2$ \\
\hline
\end{tabular}




\subsubsection{Fuel Element Graphite}

The status of graphite technology was reviewed in 1974. Grade H-327, a needle coke graphite, was developed by The Great Lakes Carbon Company (GLCC) and is being utilized in FSV. GLCC has developed H-451 graphite, a nearisotropic material, for use in advanced HTGRs. The evaluation of preproduction logs of $\mathrm{H}-451$ has been completed including irradiation to end-oflife HTGR fluences. Evaluation of production graphite material, manufactured for FSV reload segments, is underway. Grade H-451 has been submitted to NRC for licensing. AirCo Speer (AS) and Union Carbide Corporation (UCC) have produced backup grades 50818 and TS-1240, respectively. These materials have undergone preliminary evaluation for use in HTGRs.

The HTGR fuel cycles development can be summarized as follows:

- HTGR fuel has unique advantages over conventional metal clad fuel.

- HTGR fuel development rests on nearly 20 years of prior work.

- Factors influencing the performance of HTGR fuels are well understood.

- A fuel development program, responsive to the needs of design and licensing, has been defined to completion.

- Emphasis on nonproliferation has resulted in a shift to the MEUThorium fuel cycle.

- International cooperation has a prominent role in the fuel development program.

An extensive data base exists on fuel technology for HTGRs. The early work was in support of the Fort St. Vrain (FSV) 842 MW(t) HTGR prograll, and lacer screening and testing was in support of commercializing the 3000 and 2000 MW(t) HTGR designs. 
Several of the reference fuel design reatures for these commercial plants differed slightly from those for the FSV reactor. These differences were design evolution towards:

- improved recycle to permit better fuel resource utilization;

- improved fuel performance characteristics, and

- better fuel fabrication economics. 


\section{REJECT HEAT UTILIZATION}

\subsection{GT-HTGR THERMODYNAMIC CYCLE}

The two main advantages of the closed-cycle gas turbine power plant that are most frequently cited are 1) the adaptability to a wide range of heat sources, and 2) the many projected uses for the high grade reject heat, and these are illustrated simply in Figure 10-1. For the gas turbine HTGR plant case this section of the report covers potential uses for the reject thermal energy.

The heat rejection characteristics of the HTGR-GT power plant are conducive to cogeneration, which in the broadest sense of the word covers all possible uses of the waste heat reject energy after it is discharged from the prime-mover. The approaching era of strict energy conservation and eventual energy shortage will have a profound effect on the design of future power plants since high fuel utilization efficiency is of the essence, and in many cases this implies cogeneration. The intrinsic economic worth of power plant reject heat will be too great to merely discharge to the environment, and means of utilizing this energy must be quickly brought to the commercial stage.

Comparison between the steam cycle and two cycle variants of the HTGR-GT is shown on Figure 10-2. Several advantages of the direct-cycle can be discussed by studying these simplified temperature-entropy diagrams. It should be pointed out that a feature of the direct-cycle plant, sometimes cited as a thermodynamic disadvantage, is that its heat rejection occurs over a range of temperatures (as shown on Fig. 10-2) rather than at the one temperature of a condensing vapor as is the case for the Rankine steam

cycle. This, of course, does represent a departure from one of the criteria for the most efficient possible thermodynamic cycle, but in return the 


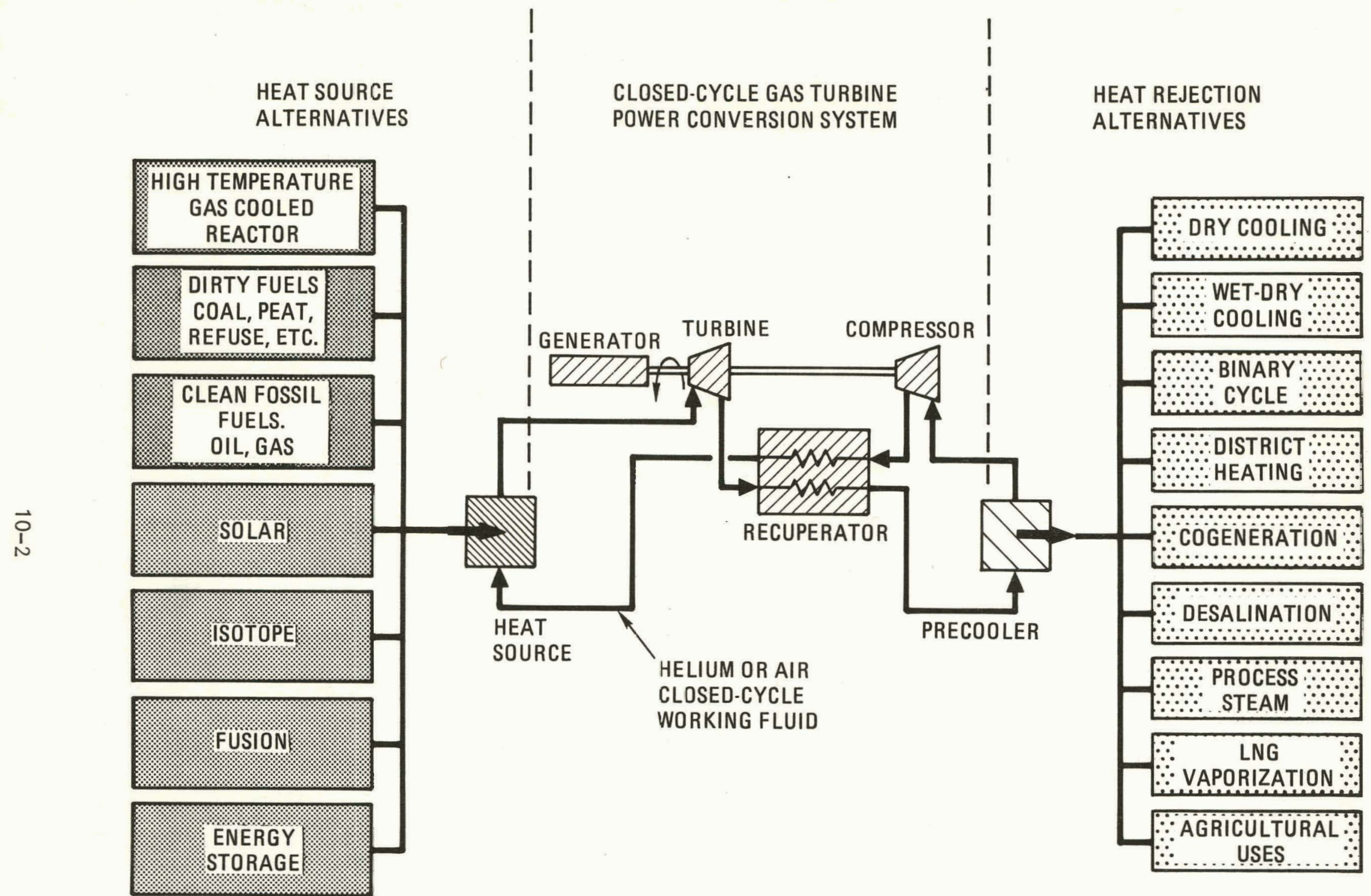

Fig. 10-1. Closed-cycle gas turbine adaptability to a wide range of heat source and waste heat rejection alternatives 


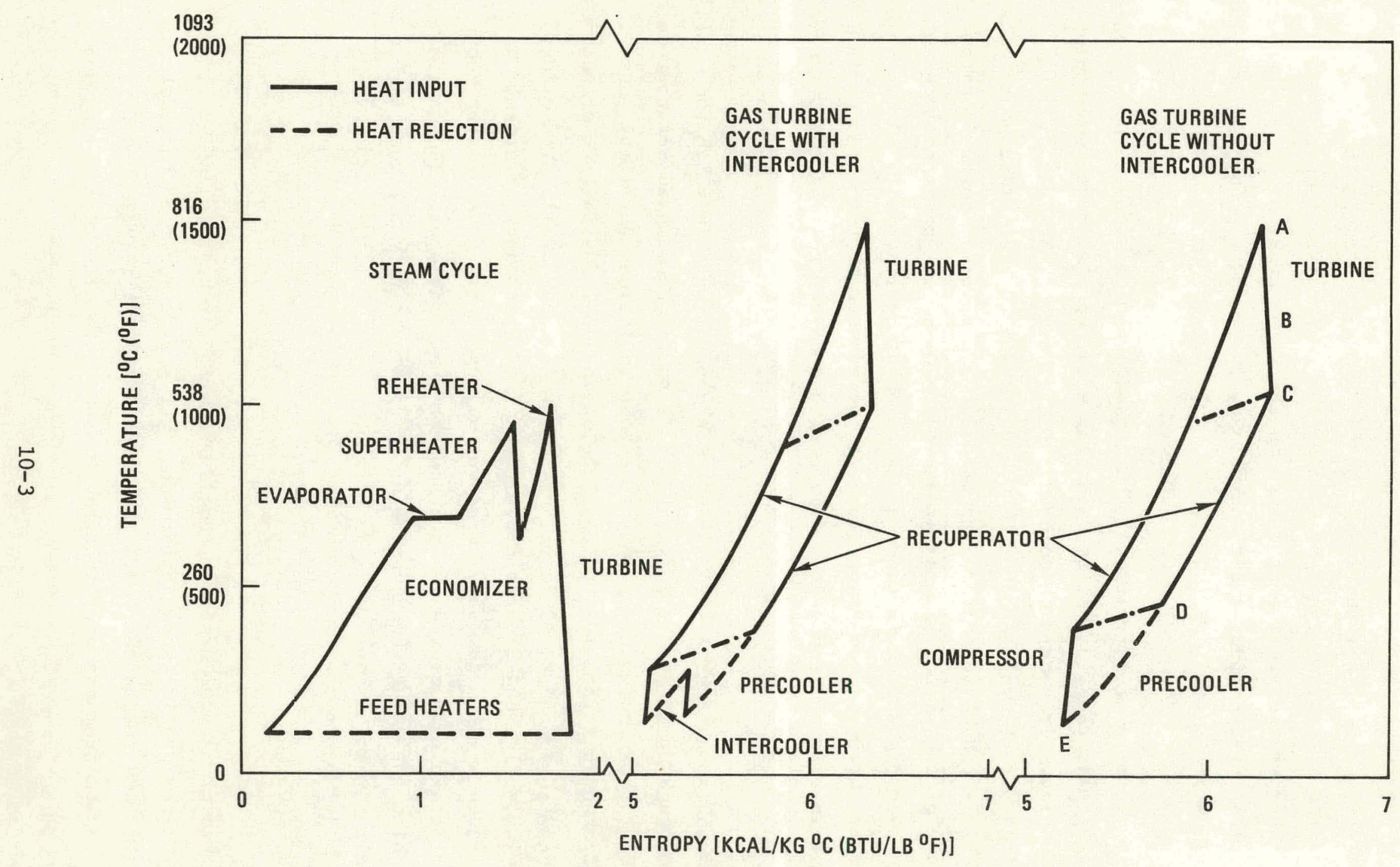

Fig. 10-2. Comparison of steam and gas turbine plant cycles 
higher average temperature of heat rejection can greatly ease the practical problem of reject heat dissipation. Indeed, as will be emphasized in this section of the report, a higher mean rejection temperature can become a valuable asset when a premium is placed on the temperature of the waste heat for economical dry-cooling, additional binary cycle power production, or for industrial use.

An important characteristic of the closed-cycle gas turbine power conversion system is the flexibility regarding combined electrical power plus heat production. It should be pointed out that all of the operational fossil-fired direct-cycle plants in Europe operate in a combined power plus heat mode. As can be seen from Figure 10-3 the electrical power is rather independent of the amount of heat production. Only for an extremely high demand on heat production is there a reduction of approximately $25 \%$ in electrical power output. From Figure 10-3 it can be seen that the change in compressor inlet temperature is a simple method of controlling the production of thermal energy.

The diagram on Figure 10-4 illustrates several ways in which the waste heat from the HTGR-GT can be dissipated. It should be pointed out that an owner operator may not want the multiple heat rejection capability, but it is illustrated in Figure 10-4 to show the operational flexibility of the HTGR-GT plant. The three modes of heat rejection, namely 1) dry-cooling, 2) bottoming cycle, and 3) heat production (i.e., hot water or steam) can be facilitated by incorporating three-way valves in the closed-water loop at the inlet and exit of the external reject heat exchanger. The various ways in which the reject heat can be utilized are briefly outlined in the following sections.

\subsection{DRY-COOLING}

The use of natural draft dry cooling towers for heat rejection from the GT-HTGR can provide good performance over a wide range of temperatures in virtually any region desired. The essential point relating to dry cooling results from the fact that the HTGR-GT naturally rejects its heat 
TEMPERATURE $\left({ }^{\circ} \mathrm{F}\right)$

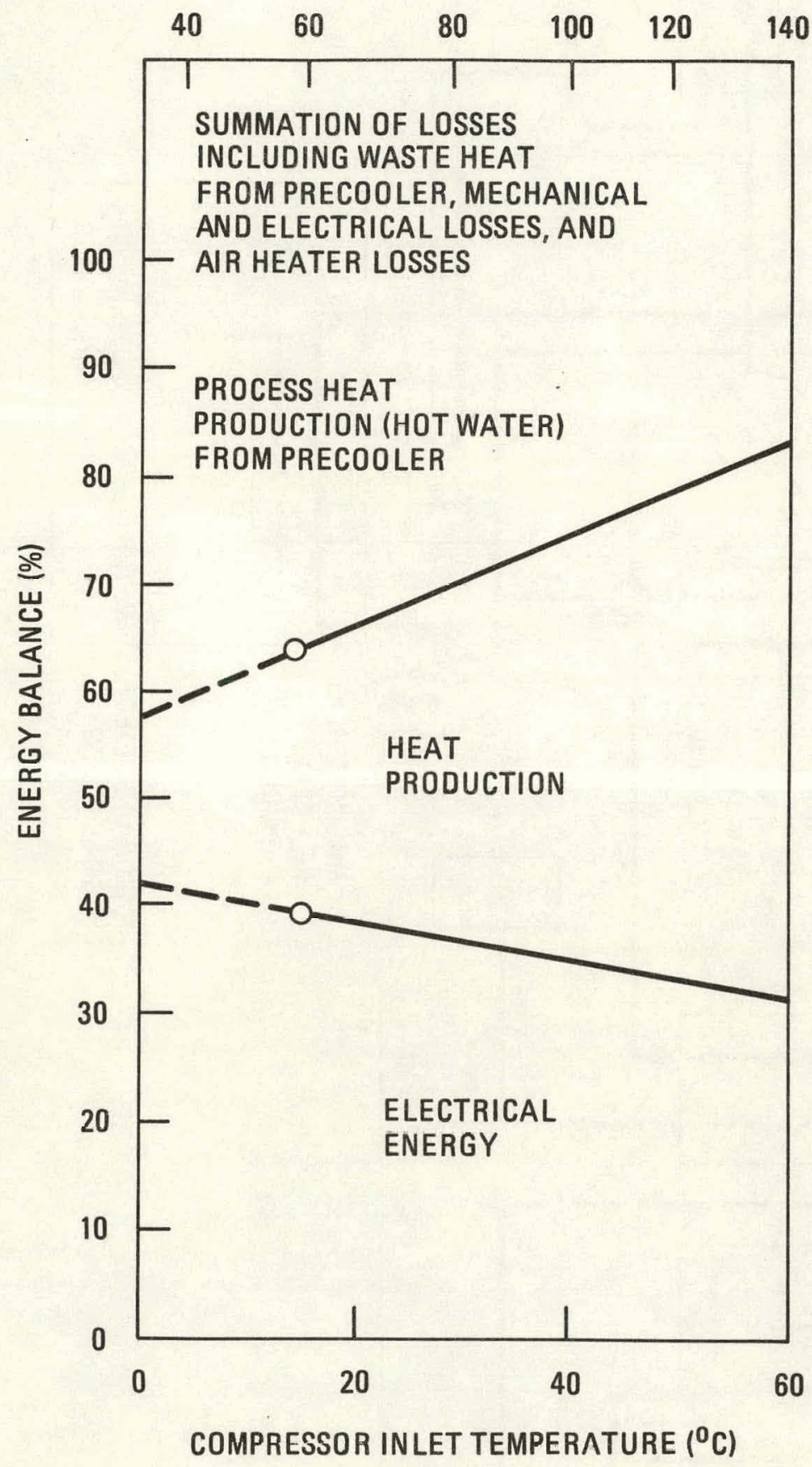

Fig. 10-3. Energy balance as a function of compressor inlet temperature for a closed-cycle gas turbine to illustrate combined power and heat production capability 


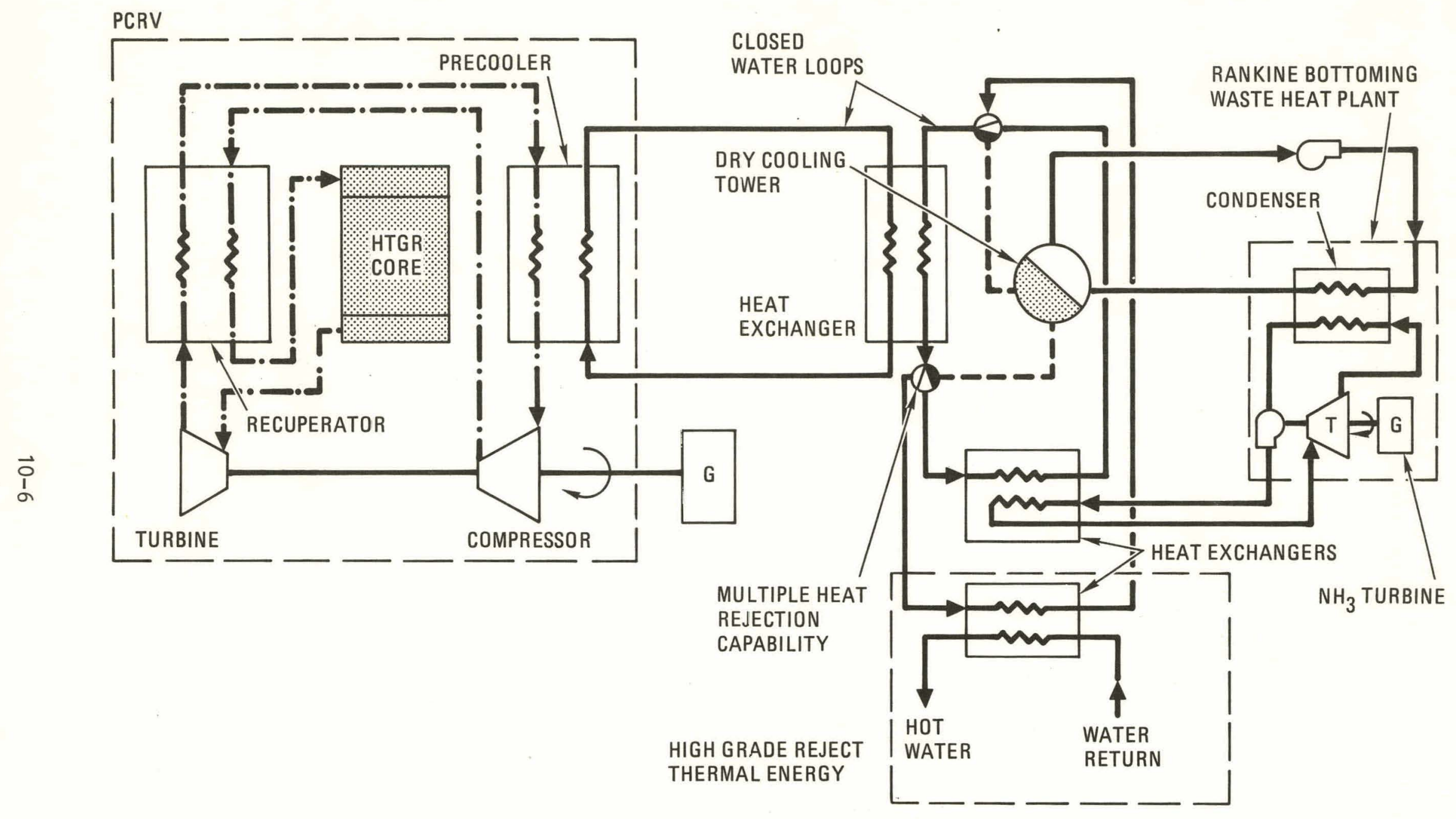

Fig. 10-4. Nuclear closed-cycle gas turbine (GT-HTGR) cogeneration power plant 
over a wide band of temperatures (as shown on Fig. 10-2), for the heat is derived from the sensible, rather than the latent, heat of the single phase working fluid. This temperature range is about an order of magnitude higher than permissible condensate temperature (associated with once-through cooling systems), and it follows then that dry towers for a HTGR-GT plant could be designed for about a tenth of the airflow needed for alternative Rankine cycle steam plant. The higher power conversion efficiency of the GT-HTGR results in less heat dissipation to the environment. The towers are therefore smaller and the higher exit air temperature induces greater buoyancy, causing an almost three-fold increase in air velocity to aid heat transfer and further reduce the tower size. The savings in water consumption compared with contemporary steam plant are therefore significant. Spray and evaporate losses from wet cooling towers would amount to approximately 12 million gpd for a power plant of 1200 MWe size with an efficiency equivalent to the GT-HTGR.

In Figure 10-5 a typical result in terms of skyline profile shows three alternative nuclear plants of approximately the same power, drawn to the same scale. The lower one uses a HTGR-GT power conversion system with dry cooling, and the other two use steam turbines. The major cycle parameters for the dry-cooled reference HTGR-GT plant are shown on Figure 10-6. Flexibility of siting for an economical dry-cooled plant (with minimum impact on the environment) is one of the most significant benefits of the GT-HTGR system foreseen by electric utility companies.

\subsection{BOTTOMING RANKINE CYCLE}

With added emphasis in the U.S. on fuel conservation and minimum environmental impact, cogeneration studies have been performed to evaluate the utilization of the waste heat from the HTGR-GT power plant in a secondary cycle that can put the overall efficiency of the combined cycle in the range of 50 percent. The attraction of usefully employing the relatively highgrade waste heat from a nuclear closed-cycle gas turbine goes beyond achieving high efficiency. Because the extra power is obtainable without major penalty to the output of the primary helium turbine system, this extra power 


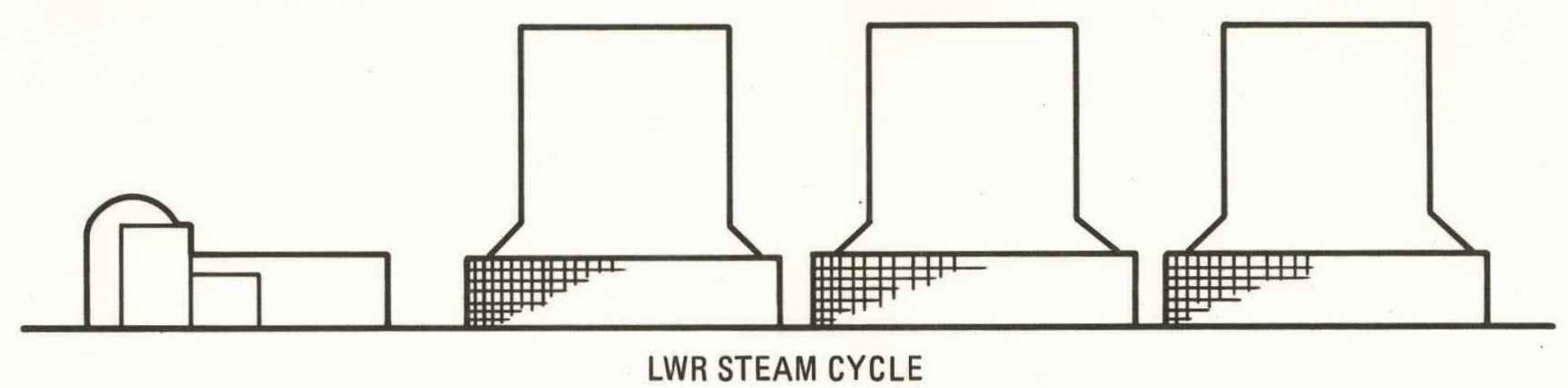

$\overrightarrow{0}$
1
$\infty$

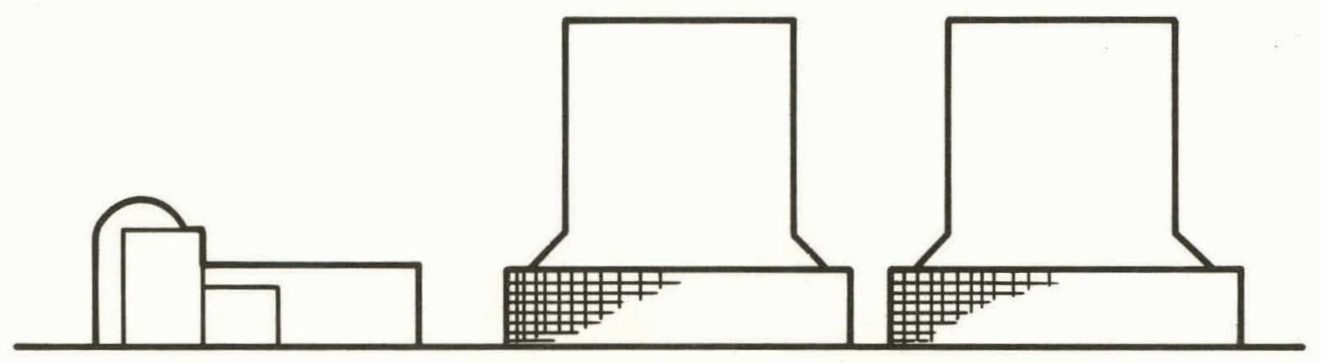

HTGR STEAM CYCLE

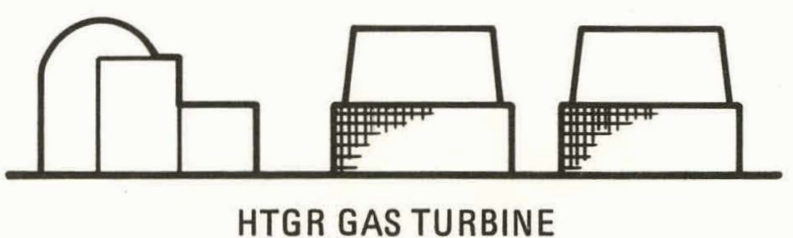

Fig. 10-5. Simplified comparison of steam cycle and gas turbine plant skyline profiles 


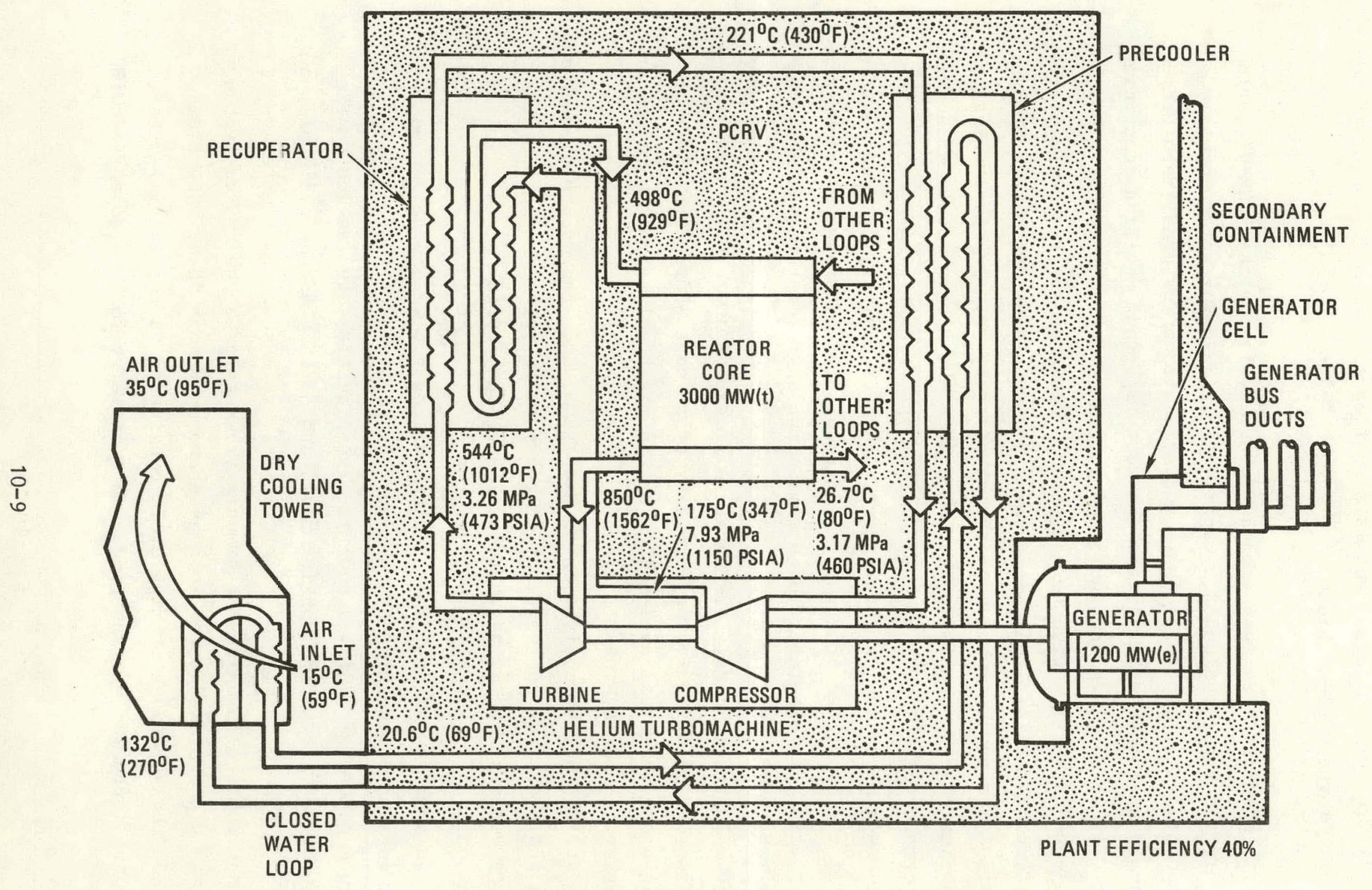

Fig. 10-6. Loop cycle diagram for dry-cooled GT-HTGR power plant 
is not only free of fuel cost, but is also free of the capital cost of most of the rest of the nuclear plant.

In its simplest form the secondary power cycle for the HTGR-GT would entail only the substitution of a vaporizable liquid for water normally in the precooler heat rejection loop (associated with an external vapor turbine, pump, and condenser). By far the most important decision concerning the binary cycle involves the choice of working fluid. To minimize novelties one would naturally wish to use steam. Based on the reference plant cycle discussed earlier steam has several disadvantages, which are perhaps best appreciated by observation of the simple temperature-entropy diagram shown on Figure 10-7. It is desirable to form the approximately triangularshaped bottom cycle diagram to best fit the space shown available for the bottom cycle's operation in this figure, and this can only be done in the absence of the input temperature plateau associated with normal evaporation. Since the critical temperature of steam is too high for the available temperature levels in the HTGR-GT, steam is at a considerable efficiency disadvantage. In other words, looking again at Figure 10-7 it is beneficial to minimize irreversibility in the secondary cycle heat source exchanger by utilizing a supercritical cycle since it can match well the heat rejection characteristics from a HTGR-GT. Because of conventionality considerations there is still a strong motivation to use steam, and studies are planned to evaluate modifications to the plant thermodynamic cycle to determine the efficiency potential using a subcritical secondary cycle.

System studies and equipment conceptual designs were done for an advanced version of the HTGR-GT in an effort to evaluate the economic and performance potential (Refs. 1 and 2). These initial studies led to the selection of ammonia as the working fluid and details of the cycle diagram are shown on Figure 10-8. The supercritical cycle shown on Figure 10-9 is for a plant variant in which the ammonia flows through the helium exchanger rather than via a closed water loop as shown on Figure 10-4. The flow diagram for the ammonia bottoming cycle considered in the initial studies is shown on Figure 10-10. The projected efficiency for the advanced twin 


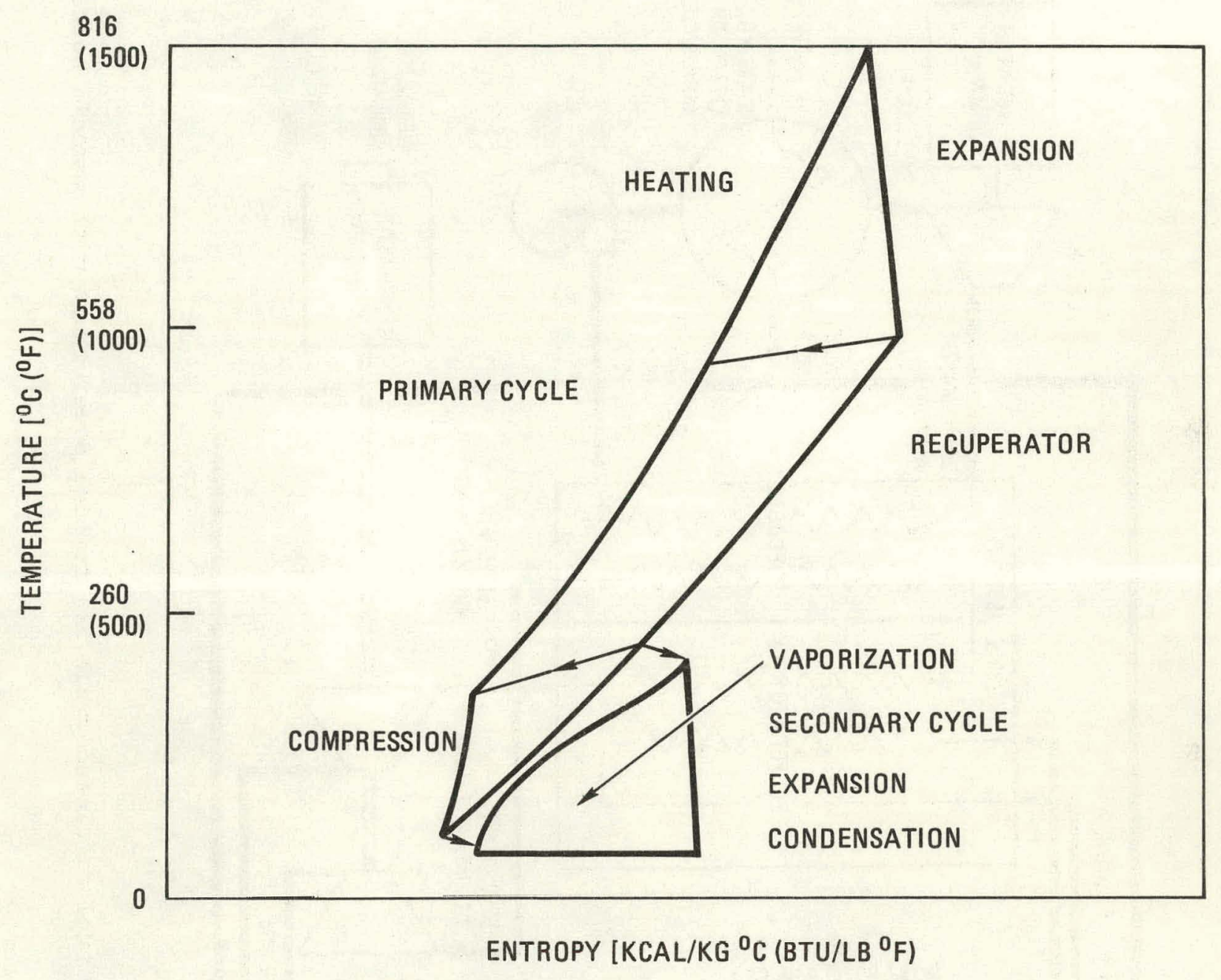

Fig. 10-7. Simple temperature - entropy diagram for GT-HTGR binary cycle 


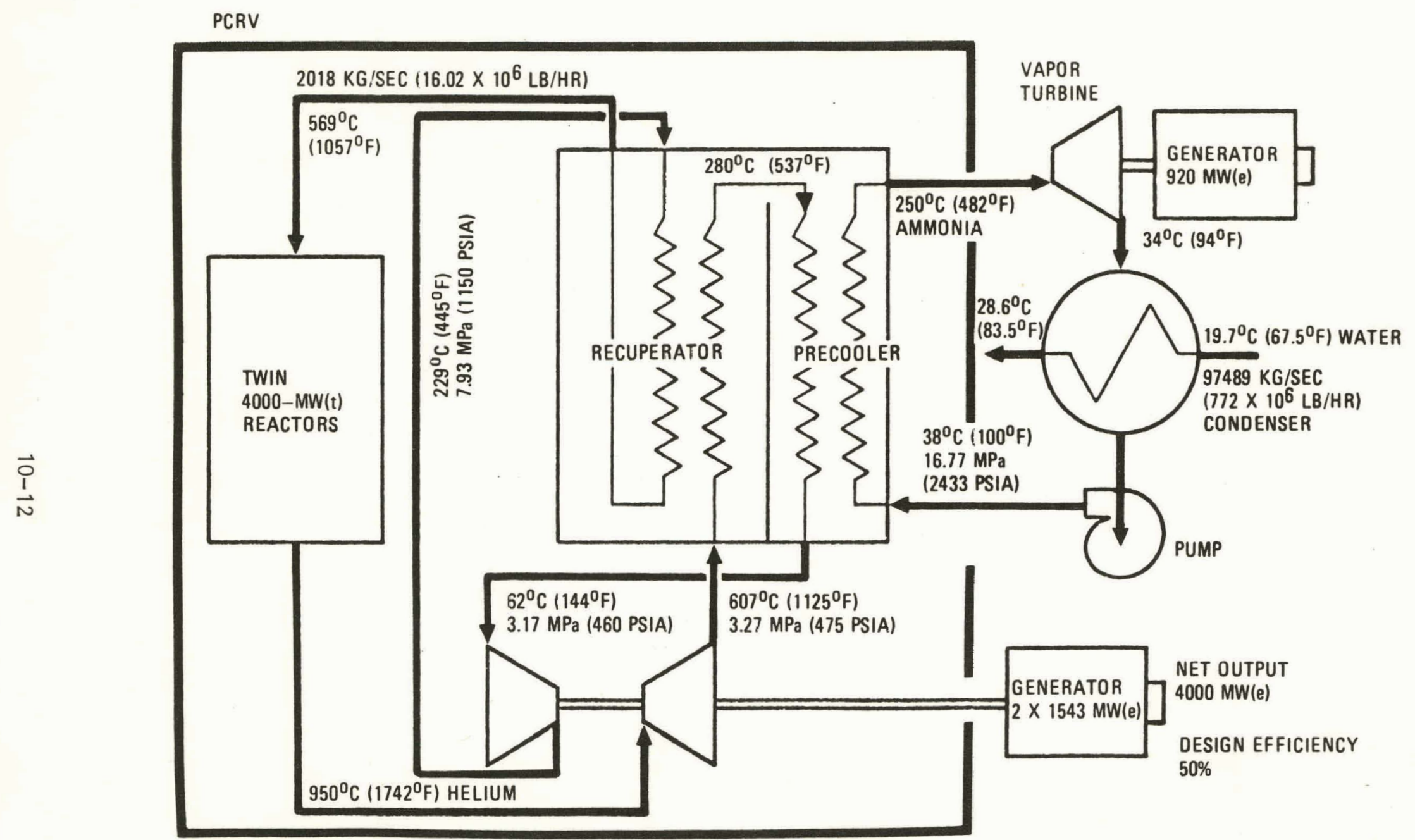

Fig. 10-8. Cycle diagram for nuclear closed-cycle gas turbine power plant with ammonia bottoming cycle 


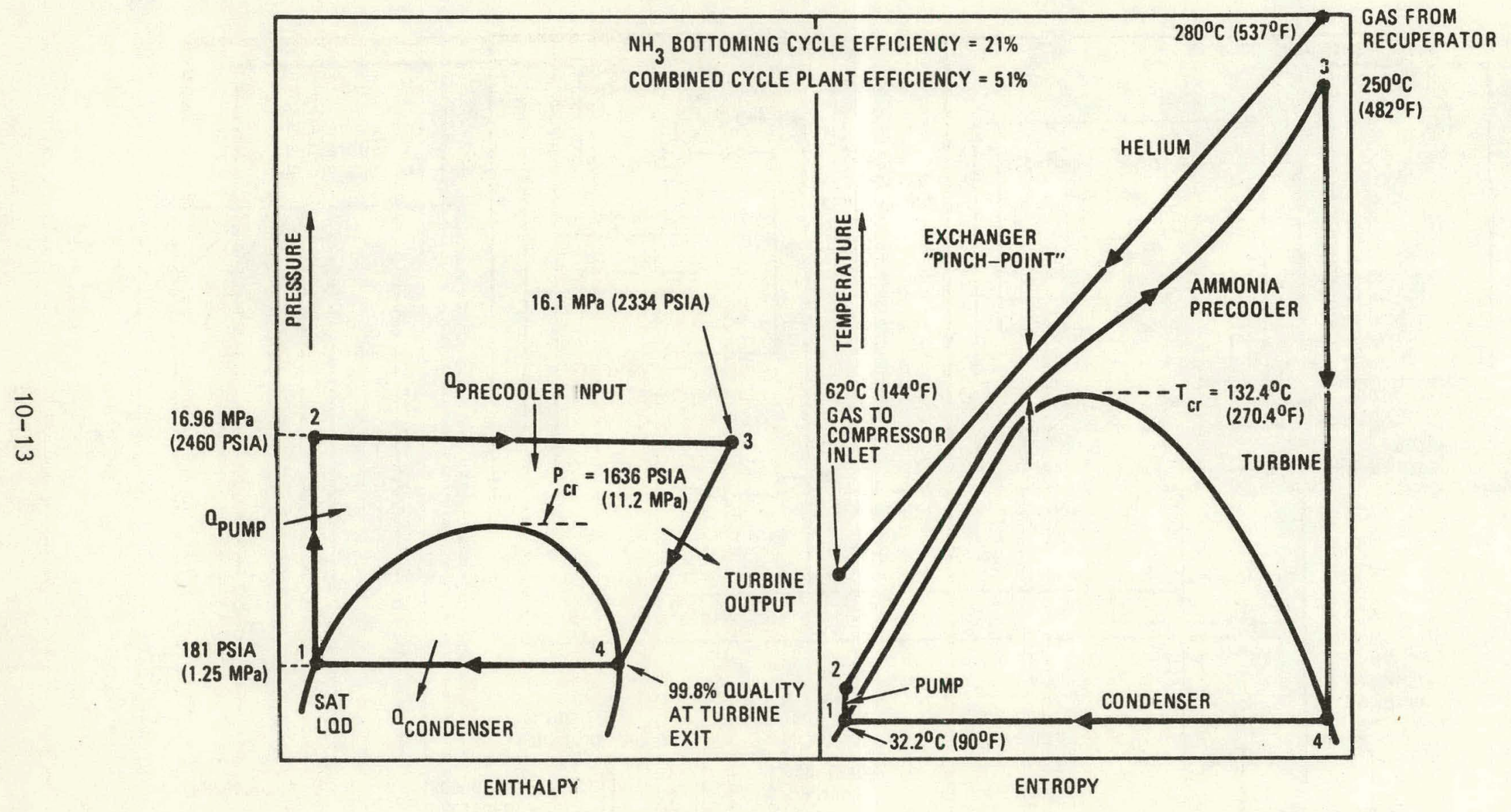

Fig. 10-9. Supercritical ammonia bottoming cycle diagram from GT-HTGR plant 


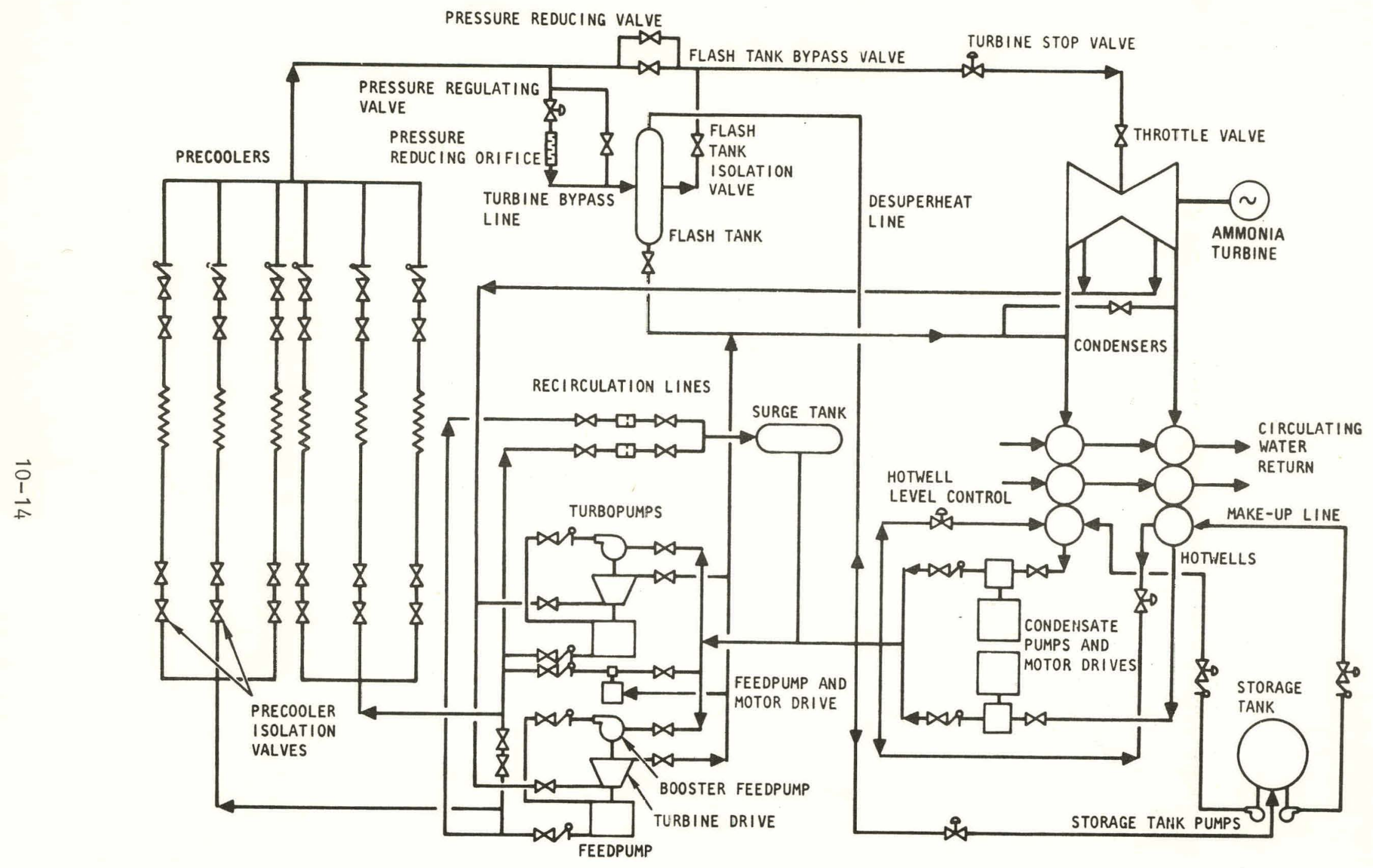

Fig. 10-10. Flow diagram for ammonia bottoming cycle 
reactor design was on the order of 50 percent, the power from the ammonia plant being 920 MWe.

Conceptual design work on the major components (Ref. 3) and ammonia turbine (Ref. 4) has been performed in sufficient detail to establish feasibility and cost. A conceptual arrangement of a 460 MWe ammonia turbine (two required per plant) is shown on Figure 10-11. In terms of power level, overall configuration, and size, there is considerable similarity between the ammonia turbine and modern intermediate pressure steam turbines.

Another cogeneration-related application, which has not been studied in detail to date, involves an ammonia refrigeration system to reduce the primary circuit compressor inlet temperature. This results in a substantial reduction in compressor pumping power with an attendant increase in plant efficiency. A study is required to compare the complexity and economics of compressor inlet temperature reduction versus the addition of a secondary power cycle.

\subsection{DISTRICT HEATING}

District heating has found application in Northern and Eastern Europe where the heating load is high and there has been an absence of high quality fossil fuels such as natural gas and oil. Since the 1973 oil crisis, district heating schemes have been studied with an increasing effort in a number of countries as one possible way of achieving lower heat costs, conserving the limited oil and natural gas resources, and reducing air pollution. The means for combined power and heat production from closed-cycle gas turbine plants has been thoroughly discussed in Reference 5. Possibilities for district heating using nuclear power plants have been reported (Ref. 6, 7), and in particular for a nuclear direct cycle plant (Ref. 8).

In the U.S. the availability and cost of natural gas and oil for heating may lead to renewed interest in centralized district heating (Ref.9). The particular merit of the HTGR-GT plant is again the availability of the higher temperature reject heat and the capability of effectively using this 


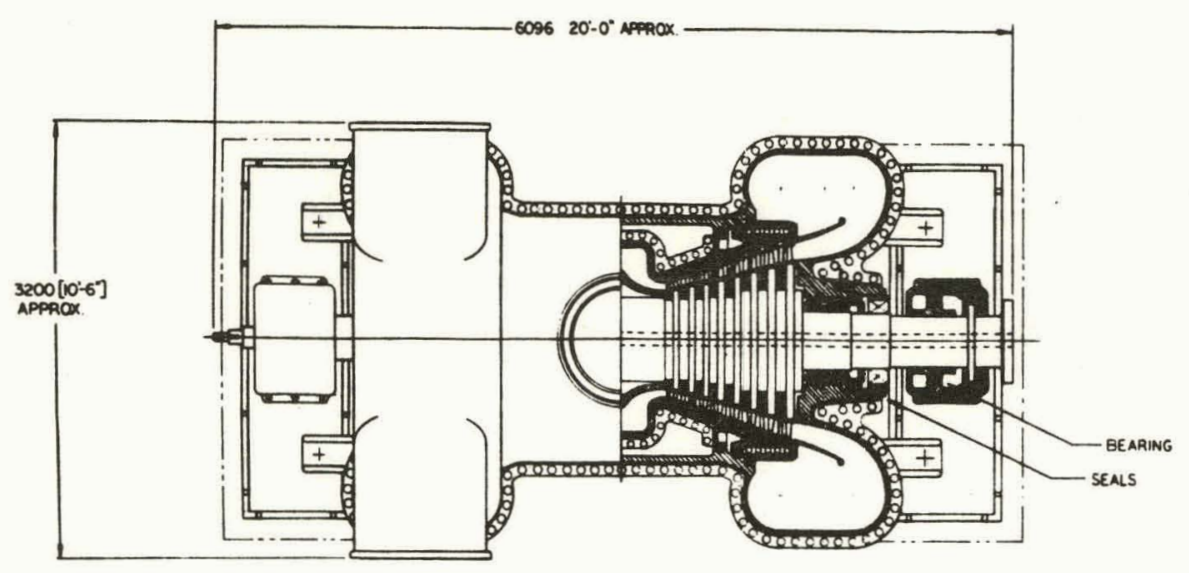

SIMPLFIED PLAN VIEW (PARTAL SECTION)

$\overrightarrow{\vec{i}}$
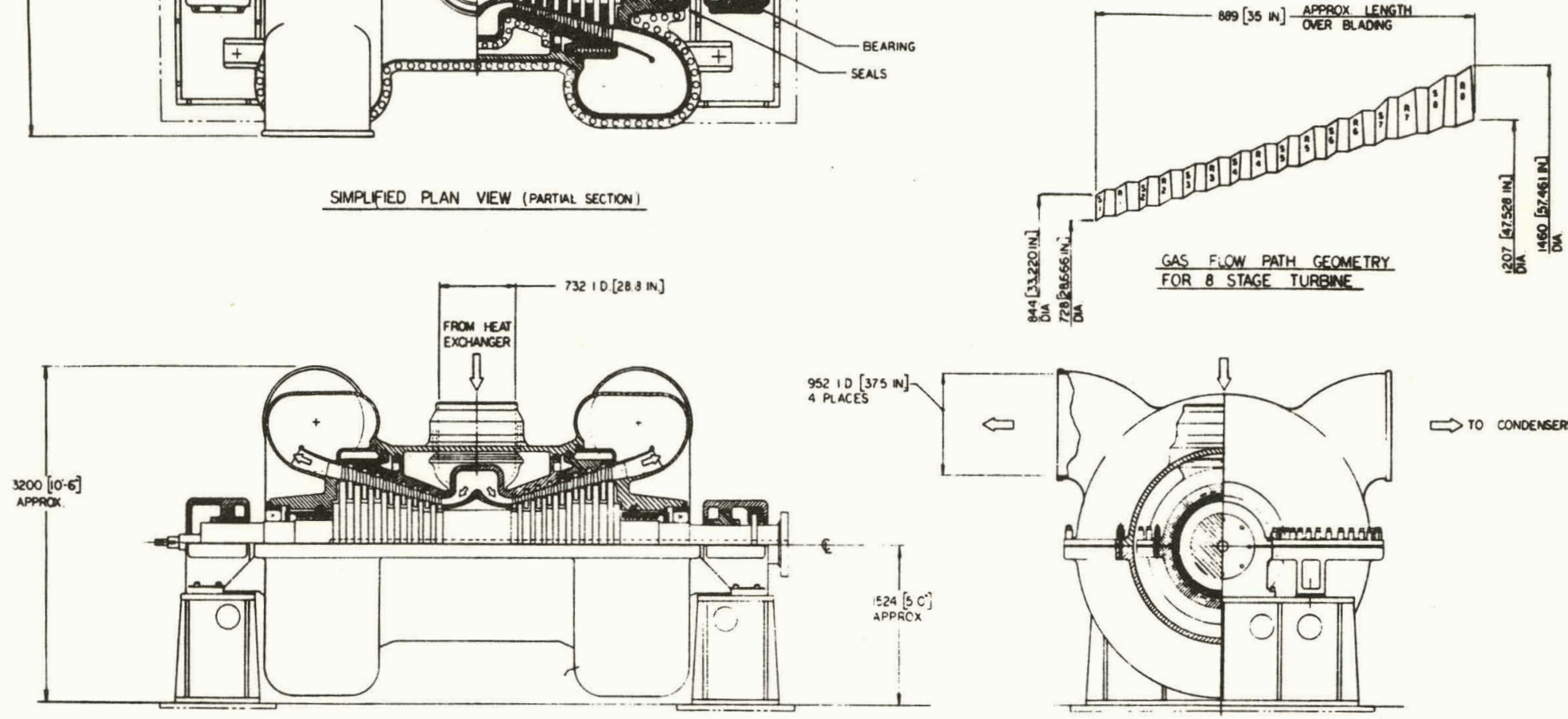

SIMPLIFIEd ELEVATION VIEW (PART AL SECTION)

SIMPLIFIED END VIEW (PARTILL SECTION)

Fig. 10-11. Conceptual design of 460-MW(e) double-flow ammonia turbine 
heat without compromising the electrical output of the plant. There are already many small installations supplying district heating in U.S. cities, but switching to large centralized facilities would require a major national program. The 50 MWe Oberhausen 2 helium turbine plant in Germany, with a reject thermal heat on the order of $54 \mathrm{MWt}$, is currently the largest closedcycle combined power and heating plant.

District heating, particularly of the magnitude with the $3000 \mathrm{MWt}$ HTGR-GT reference plant, requires a large transmission and distribution system. The reject heat is removed from the primary system and used in.the transfer heat exchangers as sensible rather than latent heat. European practice indicates that pressurized water, because of its efficient heat transfer properties and high specific heat, is probably the best transport fluid. An advantage of the HTGR-GT is that its high water reject temperature could allow air to be heated at the user and point, minimizing the expense of conversion for the end user, as a large number of the present residential and commercial installations now use air systems. Another advantage of the high water temperature is that it could be used for air conditioning, which would increase the annual utilization of the system.

The available reject heat from even a small HTGR-GT plant. (single loop, $400 \mathrm{MWe}$ ) is still sufficient for a population of approximately 50,000 living in a winter climate as severe as that of Chicago (Ref. 10). The availability of sites near such large population centres, and the economics of transmission and distribution, would need to be thoroughly investigated. The availability of essentially free energy from the already economical GT-HTGR electricity producer may be an incentive similar to those which led to natural gas transmission for heating purposes when natural gas was inexpensive and plentiful.

In view of the limitations of U.S. oil and gas resources and our increasing dependence on imports, it is necessary for the United States to take definite steps to reduce consumption, and the implementation of district heating wnuld constitute a sizable step in this direction. The point 
is clear that district heating can and must be seriously considered as an important element in the solutions of our problems of energy supply and demand.

\subsection{PROCESS STEAM SUPPLY}

of the total U.S. energy requirements, approximately $16 \%$ is used for the production of steam for industrial applications. In terms of European consumption, this would correspond approximately with total energy use of Germany and France combined. Even with conservation measures, this use is expected to increase at a rate of more than $2 \%$ per year over the next decades, with the steam consumption in some industries growing at a much higher rate.

Most industrial steam generating equipment is fired by natural gas or oil and is usually of a small capacity. In coming decades these two clean fossil fuels will be too valuable to burn for electricity and process steam production, and indeed will be needed for chemical feed stocks and transportation. It is of interest to note (from Rf. 11) that $45 \%$ of the energy used by American Industry goes into producing process steam, which is used at a typical temperature of around $350^{\circ} \mathrm{F}\left(177^{\circ} \mathrm{C}\right)$. This quality of steam can be generated from the heat leaving the precooler in the direct cycle HTGR plant. The electrical output from the plant would be unaffected by the process steam generation, and the efficiency and power costs would not be compromised.

\subsection{WATER DESALINATION}

Water shortage is becoming critical in several areas of the world; drought conditions in the western regions of the U.S. have become a significant problem in recent years. Although small-to-medium sized fossil-fired desalination plants are in operation in several countries, there has been very little extrapolation of available technology to the larger scale required for coupling to large plants. 
For the range of temperatures available from the reject heat side of a CCGT plant, and in particular the HTGR-GT, some modifications in the basic multistage flash evaporation (MSF) process arrangement typically used for desalination would be required. Preliminary studies for the HTGR-GT plant (Ref. 12) indicates that several progressively shorter parallel sections of the typical heat recovery modules should be used as shown in Figure 10-12. The condenser brine is successively fed from the largest train down to the shortest train, with produce water leaving each module. To use the multiple heat recovery principle, which is made possible by the high reject temperature of the CCGT, requires larger brine recycling pumps and results in approximately $3 \%$ higher capital costs for the desalination units as compared to a conventional set of units with a constant temperature heat input. This is more than offset by the approximately $80 \%$ increase in distilled water output for equivalent heat input.

In closing, it should be pointed out that with 40 years of operation the closed-cycle gas turbine is a proven cogeneration plant (Ref. 13). Emphasis in this section of the report has been placed on the utilization of the high grade reject heat for, 1) binary cycle, 2.) district heating, 3) process steam production, and 4) desalination. These uses deserve serious study since the heat rejection characteristics of the GT-HTGR are well suited to these areas of growing international importance as we enter a period of energy consciousness and eventual energy shortage.

\section{References}

1. Schuster, J. R., et. al., "Binary Plant Cycle Studies for the Gas Turb1ne HTGR," ASME Paper Nu. 76=GT-39.

2. Vrable, D. L., and J. R. Schuster, "A Secondary Power Plant for Gas Turbine HTGR Waste Heat Utilization," ASME Paper No: 75-WA/HT-45. 


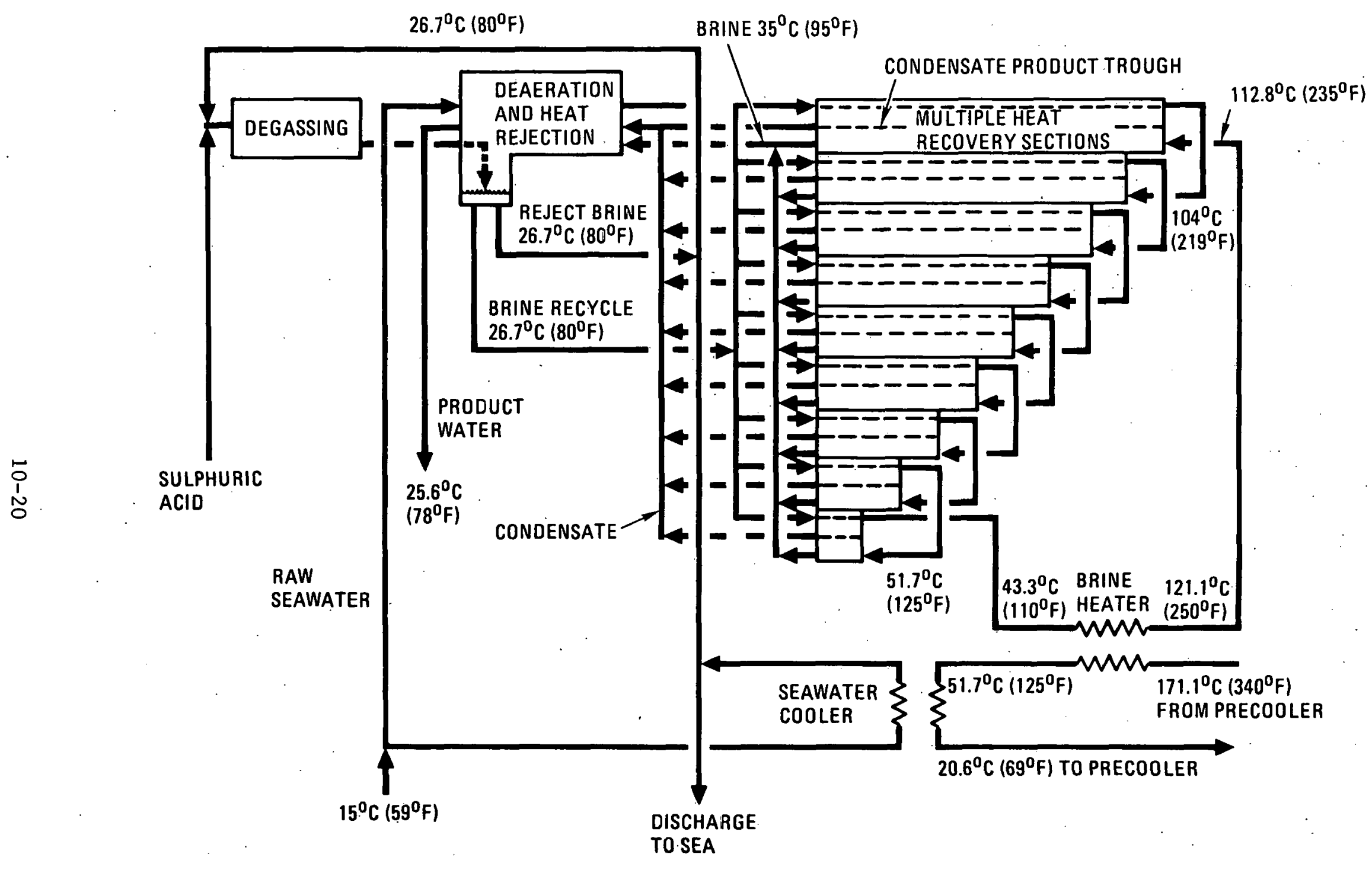

Fig. 10-12. Desalination module for coupling to GT-HTGR power plant 
3. McDonald, C. F., and D. L. Vrable, "Component Design Considerations for Gas Turbine HTGR Waste Heat Power Plant," Paper 769032 IECEC Meeting, Lake Tahoe, Nevada, September 12, 1976.

4. McDonald, C. F., and K. Vepa, "Ammonia Turbomachinery Design Considerations for the Direct Cycle Nuclear Gas Turbine Waste Heat Power Plant," ASME Paper No. 77-GT-75.

5. Frutschi, H. U., "The Relationship of Power and Heat Production with Closed-Cycle Gas Turbines," ASME Paper No. 79-GT-103.

6. Margen, P., "The Use of Nuclear Energy for District Heating," Progress in Nuclear Energy, Vo1. 2, pp 1-28, Pergamon Press 1978.

7. "Germany Looks Towards Nuclear District Heating," Energy International, August 1975.

8. Frutschi, H. U., and W. Muller, "High Temperature Reactor with Helium Turbine Special Operational Properties, Controlability, Waste Heat Recovery, and Dry Cooling Tower," Paper A3/10 presented at Nuclex 78, Basel, Switzerland, October 1978.

9. Karkheck, J., et. al., "Prospects for District Heating in the United States," Science 195, 1977.

10. Goodjohn, A. J., and S. H. Law, "GT-HTGR - A Total Energy Utilization Option," Paper presented at the AIAA/IEEE Conference on New Options in Fnergy Terhnology, San Francisco, Calif,, Aug. 2-4, 1977.

11. "Industry Can Save Energy Without Stunting Its Growth," Fortune, May 1977. 
12. Meyer, . .., and. J. W. Holland, "Gas Turbine HTGR As a Thermal Energy Source for Desalination and District Heating," A Paper presented at the International Energy Congress, Copenhagen, Denmark, October 4-8, 1976.

13. McDona1d, C. F., "The Closed-Cycle Gas Turbine - A Proven Cogeneration Plant Adaptable to Fossil, Nuclear, and Solar Heat Sources," Paper presented at a U.S. Department of Energy sponsored Conference on Energy Conservation and Solar Energy held in Milan, Italy, March 26-29, 1979. 


\section{IMPROVEMENT POTENTIAL}

The potential exists for the improvement of current HTGR-GT component and cycle design and adaption of new technologies to improve electric generating efficiency. The role of the HTGR-GT may well be extended into areas of industrial manufacturing and district heating by direct design application and optimization of waste heat usage which are described in details in Section 10 .

The following sections briefly describe other areas of potential improvement in the current HTGR-GT design. Several new technologies and cycle designs are discussed which impact the plant efficiency and extend the HTGR-GT beyond current limitation.

\subsection{HIGHER TURBINE INLET TEMPERATURE}

The singularly most important parameter affecting the performance of the gas turbine is the turbine inlet temperature. A value of $1562^{\circ} \mathrm{F}\left(850^{\circ} \mathrm{C}\right)$ was selected for the plant initial design so that a substantially unmodified HTGR core design could be used. At this temperature, the turbine could be designed with uncooled blades using existing nickel-base alloys.

The HTGR has the capability of providing a much higher core outlet ( $\sim$ turbine inlet) temperature than previously discussed. Temperatures in the order of $1742^{\circ} \mathrm{F}\left(950^{\circ} \mathrm{C}\right)$ are being used in current nuclear process heat studies. There are two acceptable approaches to increase the reactor outlet temperature: (a) the most readily predictable approach is by means of modifications of existing fuel block cooling arrangements, application of existing fuel particle types, and changing the fuel loading arrangement; and (b) using present fuel block cooling and loading arrangements, obtain 
increased core coolant outlet temperatures by modifying the fuel particle and particle coating chemistry to make fuel particles capable of withstanding higher fuel temperatures without unduly increasing fission product release.

With the foregoing modifications, it is postulated that the reactor outlet temperature could be increased to $1800^{\circ} \mathrm{F}\left(982^{\circ} \mathrm{C}\right)$ and, in fact, the reactor outlet temperature is not limited by the reactor but rather by the capabilities of the gas turbine loop. The nuclear gas turbine can be designed to accommodate a gas turbine inlet temperature of $1800^{\circ} \mathrm{F}\left(982^{\circ} \mathrm{C}\right)$ by the use of advanced refractory turbine blade materials, such as TZM, or the use of present-day materials designed with blade cooling. With a turbine inlet. temperature increase, the power rating from a given turbomachine frame size will be significantly higher than the current reference design. Performance improvement by temperature increase has been stressed because, by the projected introduction of the HTGR-GT in the 1990s, substantial gains will have been made in industrial gas turbine technology, permitting higher operating temperatures by advanced cooling techniques and metallurgical gains.

The heat exchangers in the closed-cycle gas turbine plant are key components from the standpoint of high plant efficiency and high reject heat temperature, making the HTGR-GT well suited for economic dry cooling and adaptable to district heating or a waste heating power plant.

Tubular types of construction were selected for both the recuperator and precooler. The main reason. for this selection was that it represents the only type of construction that has been proven to have structural integrity for long life electrical utility power service.

Straight tube axial counterflow heat exchanger configurations were selected for both the recuperator and precooler for the following reasons: (a) minimum surface area for high effectiveness, (b) low pressure loss, (c) minimal tube vibration effects, (d) minimal thermal stress effects, (e) simple headering, and (f) size compatibility with installation in the PCRV sidewall cavities. Because of the importance of heat exchangers on 
plant layout, performance, and cost, continuing efforts are underway to identify improved designs. These studies involve evaluation of flow configurations, plain or enhanced surfaces, and different types of construction, with emphasis being placed on maintenarce and in-service inspection. ". .

In addition to design improvememt of heat exchanger components, im:provements may be expected in primary coolant flow arrangement in an effort to reduce primary coolant pressure losses. These improvements which will follow the HTGR-GT design evolution can be expected to improve plant efficiency.

\subsection{INTERCOOLED HTGR-GT PLANT}

Limited studies have been performed by General Atomic to evaluate an intercooled HTGR-GT plant. The goal of the studies were to produce: (1) a conceptual design, (2) performance data and (3) cost data for a 2-loop intercooled plant.

The initial phase of the study involved the selection of the cycle parameters, and based on a series of component efficiency and loss assumptions, the computation of plant efficiency.

With the establishment of preliminary cycle conditions, conceptual sketches of plant configurations were started. This included conceptual sizing of the major components and resolution of the gas flow paths within the PCRV. Component design was limited to the heat exchanger and turbomachine. Table 11-1 is a condensed summary of the 2-loop intercooled plant performance parameters. Included for comparison is the $1200 \mathrm{MW}(\mathrm{e}) \mathrm{HTGR}-\mathrm{GT}$ Reterence Plant.

The intercooled HTGR-GT cycle is illustrated in Figure 11-1.

Table 11-2 compares the merits of the intercooled and non-intercooled cycles. The two most important factors in comparing the cycles are the 
TABLE 11-1

\begin{tabular}{|c|c|c|}
\hline \multicolumn{2}{|c|}{ GT-HTGR Power Plant Comparison } & \\
\hline Plant & $\begin{array}{c}\text { 3-Loop } \\
\text { Non-Intercooled }\end{array}$ & $\begin{array}{c}\text { 2-Loop } \\
\text { Intercooled }\end{array}$ \\
\hline Design status & $\begin{array}{l}\text { Reference Design } \\
\text { with Optimized } \\
\text { Cycle }\end{array}$ & $\begin{array}{l}\text { Initial Conceptual } \\
\text { Design }\end{array}$ \\
\hline Reactor Thermal Rating, MWt & 3000 & 3000 \\
\hline Number of Loops & 3 & 3 \\
\hline Cycle Type & Non-Intercooled & Intercooled \\
\hline Plant Type & Integrated & Integrated \\
\hline Heat Rejection & Dry-Cooled & Dry-Cooled \\
\hline Turbine Inlet Temp. ${ }^{\circ} \mathrm{F}\left({ }^{\circ} \mathrm{C}\right)$ & $1562(850)$ & $1562(860)$ \\
\hline Loop Rating, MWt & 1000 & 1500 \\
\hline Turbomachine Rating, MWe & 400 & 620 \\
\hline Turbomachine Orientation & Delta & Chordal. \\
\hline PCRV Diameter, ft (m) & $129(39.3)$ & $128(39)$ \\
\hline PCRV Helght, ft (m) & $116(35.4)$ & $125(38.1)$ \\
\hline $\begin{array}{l}\text { System Pressure Losses } \\
(\triangle \mathrm{P} / \mathrm{P}) \%\end{array}$ & 6.77 & 10.60 \\
\hline Plant Power, MWe & 1186 & 1237 \\
\hline Plant Efficiency, \% & 39.5 & 41.23 \\
\hline
\end{tabular}




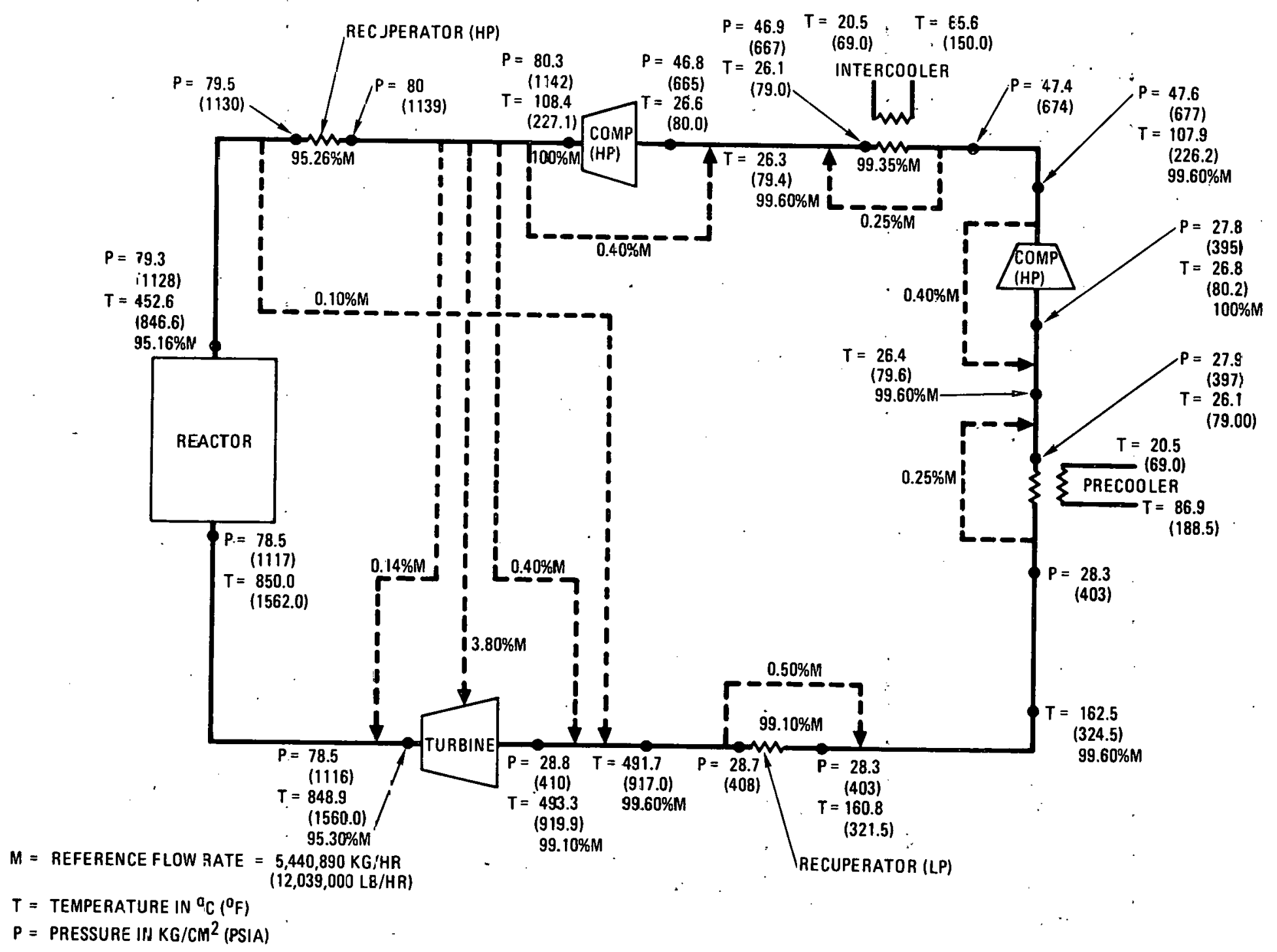

Fig. 11-1. 2-loop intercooled HTGR-GT 
TABLE 11-2

CYCLE SELECTION PARAMETERS

FOR INTEGRATED NUCLEAR GAS TURBINE POWER PLANT

\begin{tabular}{|c|c|c|}
\hline $\begin{array}{l}\text { CYCLE } \\
\text { CONFIGURATION } \\
\text { Parameter }\end{array}$ & Recuperator & $\begin{array}{l}\text { Recuperated } \& \\
\text { Intercooled }\end{array}$ \\
\hline $\begin{array}{l}\text { Performance } \\
\text { Dry Cooling } \\
\text { District Heating } \\
\text { Bottoming Cycle } \\
\text { Applicability of Fossil- } \\
\quad \text { Fired CCGT Technology } \\
\text { Primary System Layout } \\
\text { Turbomachine Arrangement } \\
\text { Component Sizes } \\
\text { Warm Liner Adaptability } \\
\text { Reliability } \\
\text { Maintainability } \\
\text { 1990-2000 Technology } \\
\text { Status }\end{array}$ & $\begin{array}{l}\text { G } \\
\text { G } \\
\text { G } \\
\text { A } \\
\text { A } \\
\text { G } \\
\text { A } \\
\text { P } \\
\ddot{G} \\
\text { A } \\
\text { A }\end{array}$ & $\begin{array}{r}\text { G } \\
\text { G } \\
\text { G } \\
\text { NF } \\
\text { G } \\
\text { P } \\
\text { A } \\
\text { G } \\
\text { G } \\
\text { A } \\
\text { A } \\
\text { G }\end{array}$ \\
\hline
\end{tabular}
G - Good
A - Acceptable
$\mathrm{P}$ - Poor
NE - Not Economic
$\mathrm{NF}$ - Not Feasible 
primary system complexity and the methods of utilizing the reject heat energy. With an integrated nuclear gas turbine plant, the addition of yet another heat exchanger (intercooled cycle) in the primary coolant flow path adds to the complexity of the primary circuit and the associated higher pressure losses tends to negate some of the efficiency advantage of the intercooled cycle. Studies have shown that an intercooled plant has an efficiency advantage of about two percentage points.

The water reject temperature from both cycles is suitable for both dry cooling and district heating. In the U.S., the basic framework for the distribution of reject heat for district heating does not yet exist and is viewed as a long-range goal.

As can be expected with a rather limited study of a new plant concept, all of the problem areas of the intercooled plant were not resolved in the first design iteration. While the intercooled plant efficiency is slightly better than that of the optimized 3-loop non-intercooled plant, it must be regarded as tentative. The first design iteration has not clearly established the best primary system arrangement and component designs. With a more comprehensive engineering effort to resolve some of the problems and identify more attractive solutions in the component design areas, it is projected that the efficiency of the 2-loop intercooled plant could be improved to 42.5 percent. Preliminary cost estimates $(\$ / \mathrm{KW})$ for the 2-loop intercooled plant compare favorabley to estimates for the non-interconler $1200 \mathrm{MW}(\mathrm{e})$ HTGR-Gl Reference Plant. 


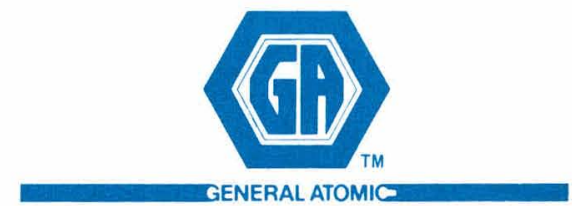

GENERAL ATOMIC COMPANY

P. O. BOX 81608

SAN DIEGO, CALIFORNIA 92138 